\title{
MHC-Klasse-I-Gene von Weißbüschelaffen (Callithrix jacchus) und deren Expression im Gehirn
}

\author{
Dissertation \\ zur Erlangung des Doktorgrades \\ der Mathematisch-Naturwissenschaftlichen Fakultäten \\ der Georg-August-Universität zu Göttingen
}

vorgelegt von

Ulrike Rölleke, geb. Geisler

aus Halberstadt

Göttingen 2007 
D7

Referent: Prof. Dr. F.-W. Schürmann

Korreferent: Prof. Dr. R. Hardeland

Tag der mündlichen Prüfung: 31.10.2007 
Diese Arbeit wurde in den Forschergruppen Primatengenetik und Klinische Neurobiologie am Deutschen Primatenzentrum Göttingen angefertigt.

Die Untersuchungen wurden durch Mittel des Graduiertenkollegs 289/3 unterstützt. 
ABKÜRZUNGSVERZEICHNIS 1

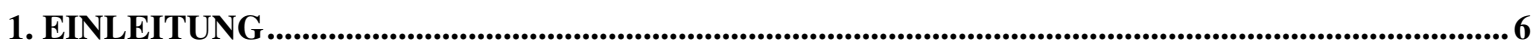

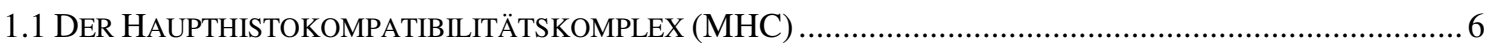



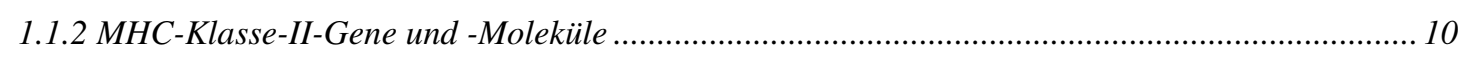

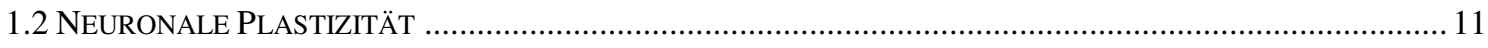

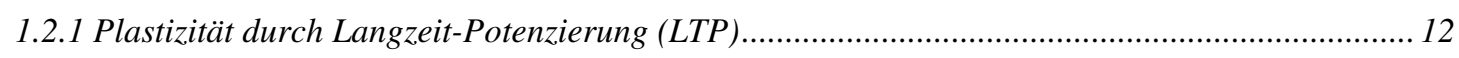

1.2.2 Plastizität durch strukturelle Änderungen ................................................................................ 13

1.2.3 Plastizität durch Genexpression .......................................................................................... 14

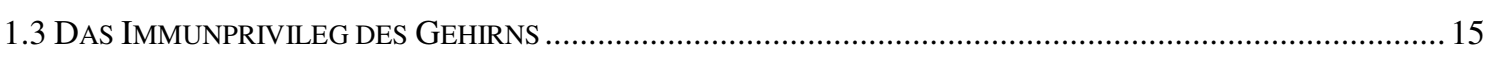







2. UNTERSUCHTE TIERE UND MATERIAL .............................................................................................22

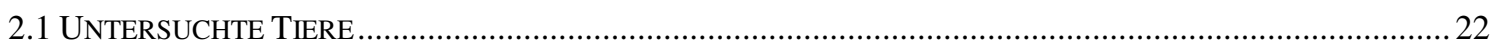

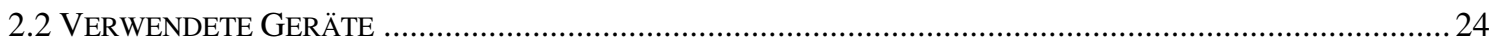

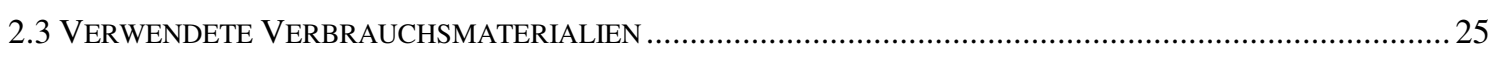

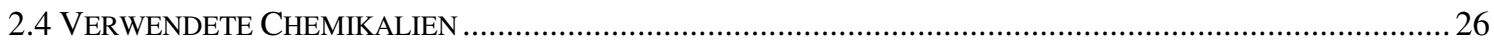

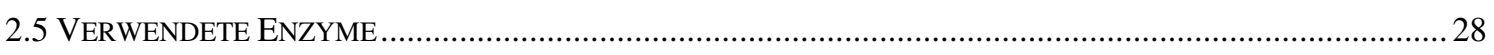



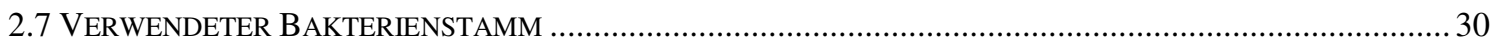

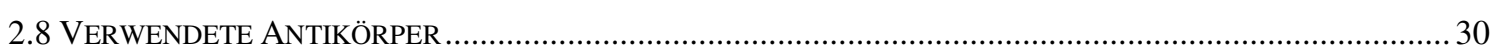

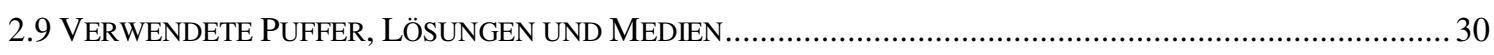



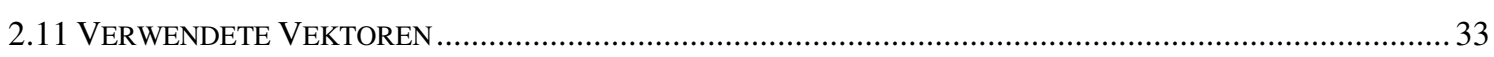

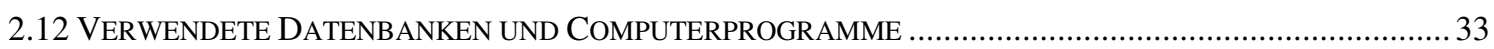

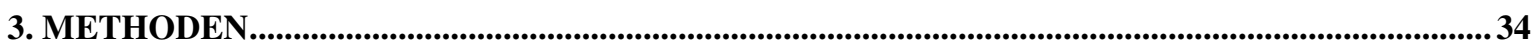

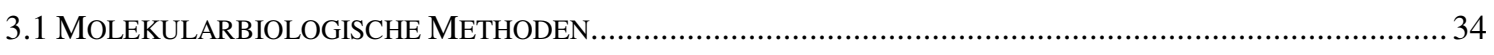

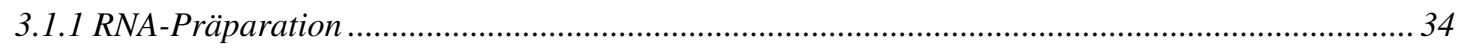









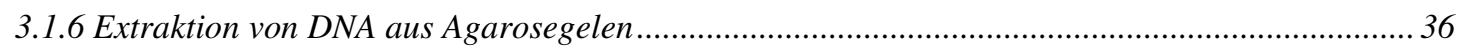

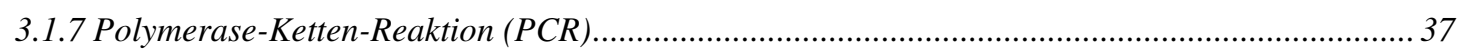

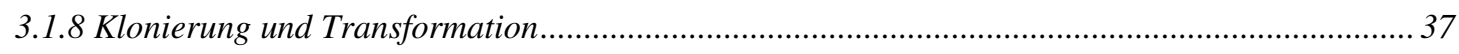

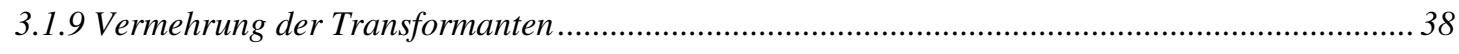

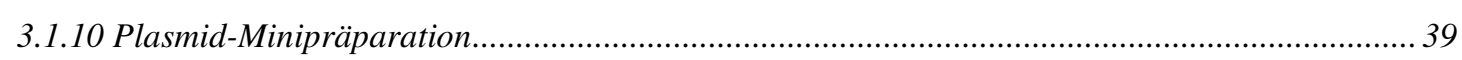

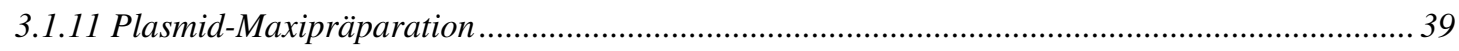




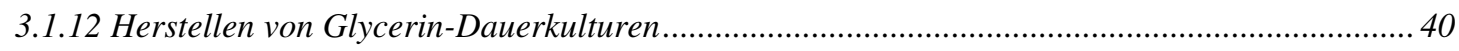

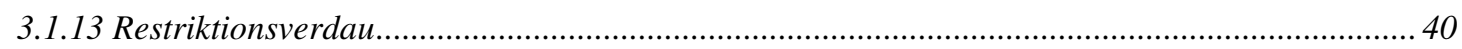

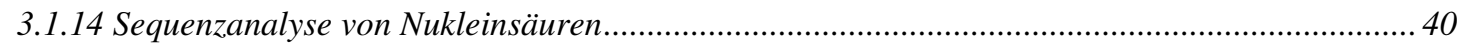

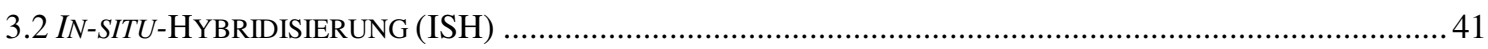

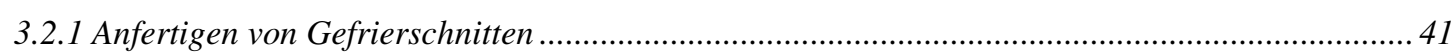

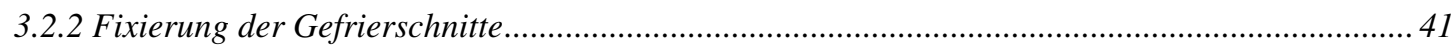

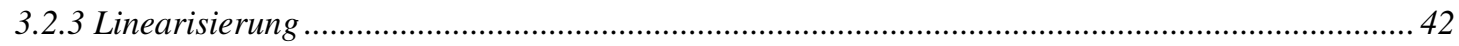

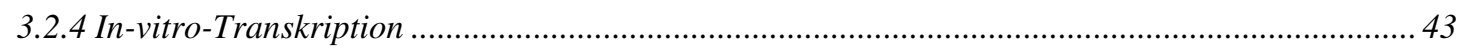

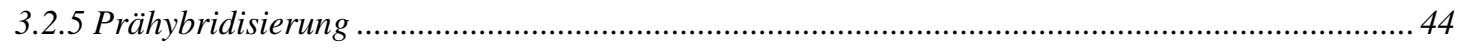

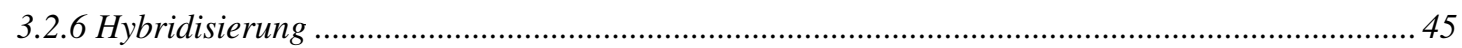

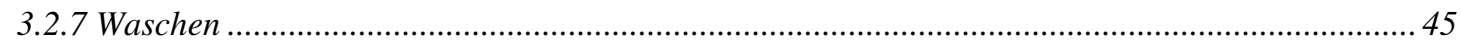

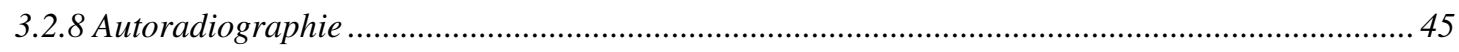

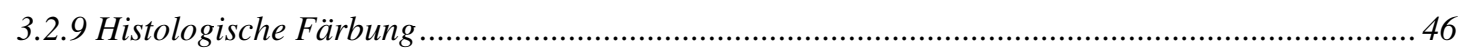

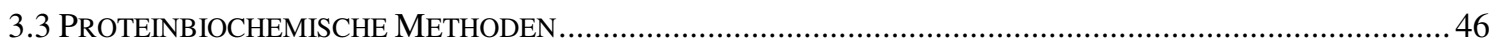



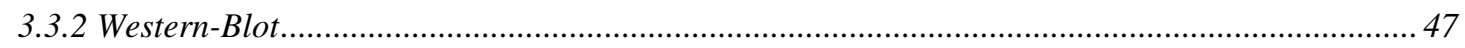

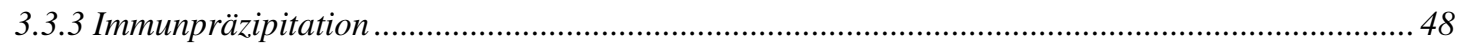

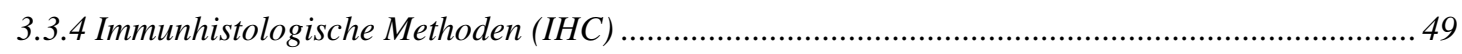

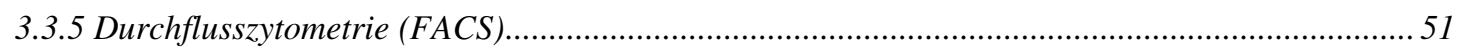

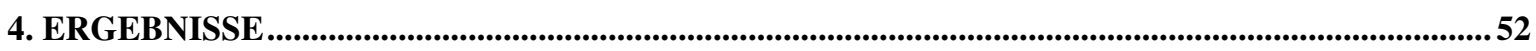

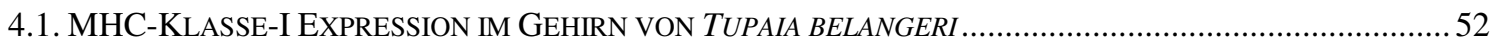

4.1.1 In-situ-Hybridisierungssonde für T. belangeri.................................................................. 52

4.1.2 In-situ-Hybridisierung mit Gehirnschnitten von T. belangeri MHC-Klasse-I-Sonde: Übersicht.. 53

4.1.3 In-situ-Hybridisierung mit Gehirnschnitten von T. belangeri mit MHC-Klasse-I-Sonde: Zellebene

.

4.1.4 Immunhistologie mit Gehirnschnitten von T. belangeri ............................................................. 60



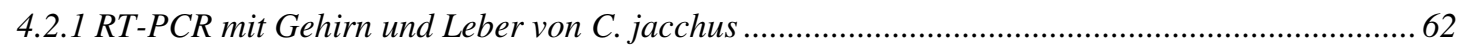

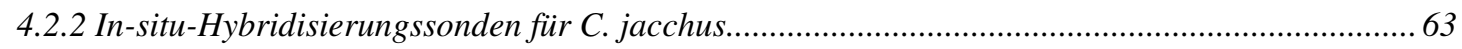

4.2.3 In-situ-Hybridisierung mit Gehirnschnitten von C. jacchus und Caja-G (Exon 2-4)-Sonde:

$\ddot{U}$ bersicht.

4.2.4 In-situ-Hybridisierung mit Gehirnschnitten von C. jacchus und Caja-G (Exon 2-4)-Sonde:

Zellebene

4.2.5 In-situ-Hybridisierung mit Gehirnschnitten von C. jacchus und Caja-G (Exon 2-3)- und Caja-E

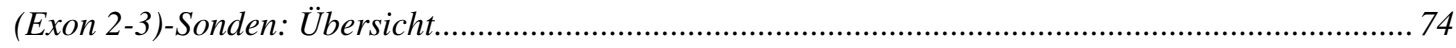

4.2.6 In-situ-Hybridisierung mit Gehirnschnitten von C. jacchus und B2M (Exon 2)-Sonde ................ 75

4.2.7 Immunhistologie von MHC-Klasse-I-Protein an Gehirnschnitten von C. jacchus........................ 76

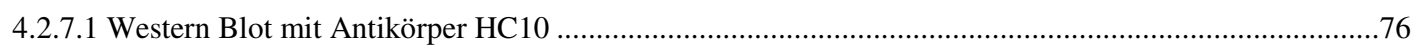

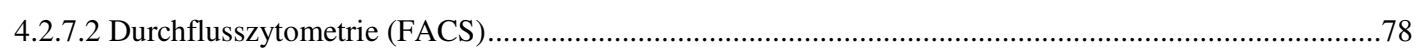

4.2.7.3 Immunhistologie mit Antikörper Ox-18 _..........................................................................................79 
4.2.7.4 Immunhistologie mit Antikörper HC-10 .82

4.2.7.5 Immunhistologie mit Antikörper HB115 .83

4.2.7.6 Doppelfärbung mit Antikörpern gegen Tyrosinhydroxylase und MHC-Klasse-I....................................85

4.2.8 Immunhistologie an immunsupprimierten C. jacchus ................................................................ 87

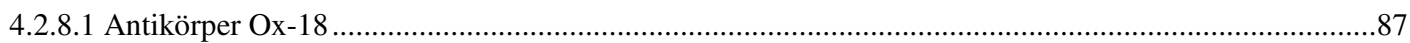

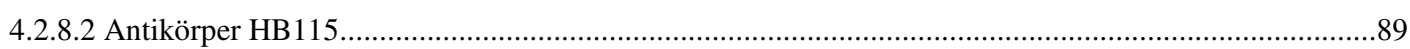

5. DISKUSSION

5.1 MHC-KLASSE-I-EXPRESSION IM GEHIRN VON TUPAIA BELANGERI UND CALLITHRIX JACCHUS ...............90



5.3 MHC-KLASSE-I-MOLEKÜLE UND DEREN MÖGLICHE FUNKTION IM GEHIRN ...................................99

5.3.1. Mögliche Rolle von MHC-Klasse-I bei der Neuroplastizität, bei der Entwicklung und im adulten



5.3.2. Pathologie - Einfluß von MHC-Klasse-I auf die Entstehung von Krankheiten ....................... 101

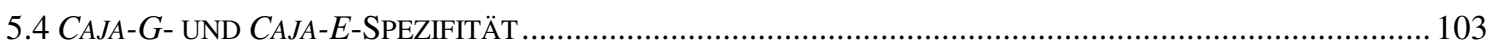



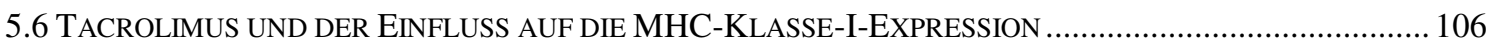

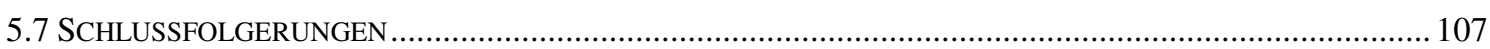

6. ZUSAMMENFASSUNG ................................................................................................................................. 109

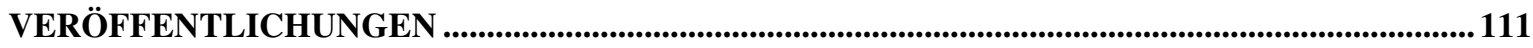








\section{Abkürzungsverzeichnis}

A

Abb.

$\mathrm{ABC}$

ALS

Amp

AMPA

AMPAR

APC

APS

AZGP1

B2M

bp

BSA

BT

bzw.

C

$\mathrm{C}$

CA

CA1

CA3

CD

CD94/NKG2

cDNA

CGL

CPL

CREB

DAB

ddNTP

DEPC

dg
Adenin

Abbildung

Avidin-Biotin-Complex-Kit

Amyotrophe Lateralsklerose

Ampicillin

a-Amino-3-Hydroxy-5-Methylisoxazole-4-Propionsäure

a-Amino-3-Hydroxy-5-Methylisoxazole-4-Propionsäure-

Rezeptor

antigenpräsentierende Zellen

Ammoniumpersulfat

Zn- $\alpha 2-G l y k o p r o t e i n$

Beta-2-Mikroglobulin

Basenpaar(e)

Bovine serum albumin (Rinderserumalbumin)

BSA-Triton-X

beziehungsweise

Cortex cerebri

Cytosin

Cornu Ammonis

Area CA1 hippocampi

Area CA3 hippocampi

Cluster of Differentiation

lectin-like receptor

komplementäre DNA

Corpus geniculatum laterale

Plexus choroideus

cAMP Responsive Element Binding Protein

3,3 Diaminobenzidin

Didesoxynukleotidtriphosphat

Diethylpyrocarbonat

Gyrus dentatus 


$\begin{array}{ll}\text { DNA } & \text { Desoxyribonukleinsäure } \\ \text { DNase } & \text { Desoxyribonuklease } \\ \text { dNTP } & \text { Desoxynukleosidtriphosphat } \\ \text { DPZ } & \text { Deutsches Primatenzentrum } \\ \text { DTT } & 1,4-\text { Dithiothreitol } \\ \text { E. coli } & \text { Escherichia coli } \\ \text { ECL } & \text { enhanced chemiluminescent } \\ \text { EDTA } & \text { Ethylendiamintetraacetat } \\ \text { ER } & \text { endoplasmatisches Retikulum } \\ \text { et al. } & \text { et alteri (und andere) }\end{array}$

FACS

Fluorescence activated cell sorting (Durchflusszytometrie)

FCGRT

Fc fragment of $\operatorname{IgG}$, receptor transporter, alpha

FG

Forschergruppe

FITC

Fluoreszeinisothiocyanat

for

forward

g

Gramm

G

Guanin

GABA

Gamma-aminobutyric acid

$\mathrm{h}$

Stunde

$\mathrm{H}$

Hilus

$\mathrm{H}_{2} \mathrm{O}$

Wasser

$\mathrm{HCl}$

Chlorwasserstoffsäure

HFE

Hemochromatosis

HLA

Human Leukocyte Antigen

IgG

Immunglobulin $\mathrm{G}$

IHC

Immunhistologie

II

2. Ventrikel

III

3. Ventrikel

IPGT

Isopropyl-B-D-thiogalactopyranosid

ISH

In-situ-Hybridisierung

KAc

Kaliumacetat

$\mathrm{KCl}$

Kaliumchlorid

$\mathrm{kDa}$

Kilodalton

$\mathrm{kg}$

Kilogramm 


\begin{tabular}{|c|c|}
\hline KIR & killer cell immunoglobulin-like receptor \\
\hline KMT & Kalium-Magnesium-Tris \\
\hline KöZ & Körnerzellen \\
\hline $\mathrm{kV}$ & Kilovolt \\
\hline LB & Luria-Bertani \\
\hline LILR/ILT & leukozyte immunoglobulin-like receptor \\
\hline LTD & Langzeit-Depression \\
\hline LTP & Langzeit-Potenzierung \\
\hline M & Molar \\
\hline $\mathrm{mA}$ & Milliampere \\
\hline $\max$ & Maximal \\
\hline $\mathrm{mg}$ & Milligramm \\
\hline $\mathrm{MgCl}_{2}$ & Magnesiumchlorid \\
\hline $\mathrm{MgSO}_{4}$ & Magnesiumsulfat \\
\hline $\mathrm{MHC}$ & Haupthistokompatibilitätskomplex \\
\hline MIC & MHC class I chain-related \\
\hline $\min$ & Minute \\
\hline $\mathrm{ml}$ & Milliliter \\
\hline $\mathrm{mM}$ & Millimolar \\
\hline $\mathrm{mm}$ & Millimeter \\
\hline MOPS & 3-(N-Morpholino)-propansulfonsäure \\
\hline mRNA & messenger-RNA (Boten-RNA) \\
\hline $\mathrm{NaAc}$ & Natriumacetat-Trihydrat \\
\hline $\mathrm{NaCl}$ & Natriumchlorid \\
\hline $\mathrm{NaOH}$ & Natriumhydroxid \\
\hline ng & Nanogramm \\
\hline NGS & normales Ziegenserum \\
\hline NK-Zellen & Natürliche Killerzellen \\
\hline $\mathrm{nm}$ & Nanometer \\
\hline NMDA & N-Methyl-D-Aspartat \\
\hline NMDAR & N-Methyl-D-Aspartat-Rezeptor \\
\hline NOD & Nucleus oculomotorius communis \\
\hline NR & Nucleus ruber \\
\hline NTE & Natriumchlorid-Tris-EDTA \\
\hline
\end{tabular}




\begin{tabular}{|c|c|}
\hline OD & optische Dichte \\
\hline PAGE & Polyacrylamidgelelektrophorese \\
\hline PBMC & Peripheral Blood Mononuclear Cell \\
\hline PBS & Phosphat-gepufferte Kochsalzlösung \\
\hline PCR & Polymerase-Ketten-Reaktion \\
\hline PFA & Paraformaldehyd \\
\hline \multirow[t]{2}{*}{$\mathrm{pH}$} & Negativer dekadischer Logarithmus der \\
\hline & Protonenkonzentration \\
\hline PirB & Paired-immunoglobulin-like receptor B \\
\hline pmol & Picomol \\
\hline PROCR & Protein $\mathrm{C}$ receptor, endothelial \\
\hline rev & reverse \\
\hline RNA & Ribonukleinsäure \\
\hline RNase & Ribonuklease \\
\hline $\mathrm{rpm}$ & Umdrehungen pro Minute \\
\hline RT & Raumtemperatur \\
\hline RT-PCR & Reverse Transkription-Polymerase-Ketten-Reaktion \\
\hline $\mathrm{s}$ & Sekunde \\
\hline SDS & Sodium dodecyl sulfate \\
\hline SN & Substantia nigra \\
\hline SOC-Medium & Glucose-haltiges Hefe-Trypton-Salz-Medium \\
\hline $\mathrm{SSC}$ & Standard sodium citrate \\
\hline $\mathrm{T}$ & Thymin \\
\hline Tab. & Tabelle \\
\hline TAP & transporter associated with antigen processing \\
\hline Taq & Thermus aquaticus \\
\hline TBE & Tris-Borsäure-EDTA \\
\hline TCR & T-Zell-Rezeptor \\
\hline TEMED & Tetramethylethylendiamin \\
\hline $\mathrm{TH}$ & Tyrosinhydroxylase \\
\hline Tris & Trishydroxymethylamoniomethan \\
\hline tRNA & transfer-RNA \\
\hline $\mathrm{U}$ & Unit (definierte Enzymeinheit) \\
\hline u. a. & unter anderem(n) \\
\hline
\end{tabular}




UV
V
Verd.
w/v
x g
X-Gal
z. B.
ZNS
$\left[\alpha{ }^{33} \mathrm{P}\right] \mathrm{dUTP}$
$\beta-\mathrm{ME}$
${ }^{\circ} \mathrm{C}$
$\mu \mathrm{Ci}$
$\mu \mathrm{l}$
$\mu \mathrm{m}$

Ultraviolett

Volt

Verdünnung

Masse pro Volumen

x Erdbeschleunigung $\left(9,81 \mathrm{~m} / \mathrm{s}^{2}\right)$

5-Brom-4-Chlor-3-Indolyl-ß-D-Galaktopyranosid zum Beispiel

Zentrales Nervensystem

alpha- ${ }^{33}$ Phosphor markiertes Uracil-Tri-Phosphat

B-Mercaptoethanol

Grad Celsius

Mikrocurie

Mikroliter

Mikrometer 


\section{Einleitung}

\subsection{Der Haupthistokompatibilitätskomplex (MHC)}

Der Haupthistokompatibilitätskomplex oder Major Histocompatibility Complex (MHC) bezeichnet eine Genregion im Genom aller kieferhaltigen Wirbeltiere (Gnathostomata). Der Hauptteil der darin zu findenen Gene codieren Proteine, die an der Immunfunktion beteiligt sind (Janeway et al., 2001). Im Menschen ist dieser Genkomplex auf dem Chromosom 6 lokalisiert (Abb. 1.1). Charakteristisch für den MHC sind die hochpolymorphen MHC-Klasse-I- und MHC-Klasse-II-Gene, deren Produkte bei Transplantationsexperimenten beobachteten Abstoßungsreaktionen vermitteln (Gorer, 1936; Snell, 1948).

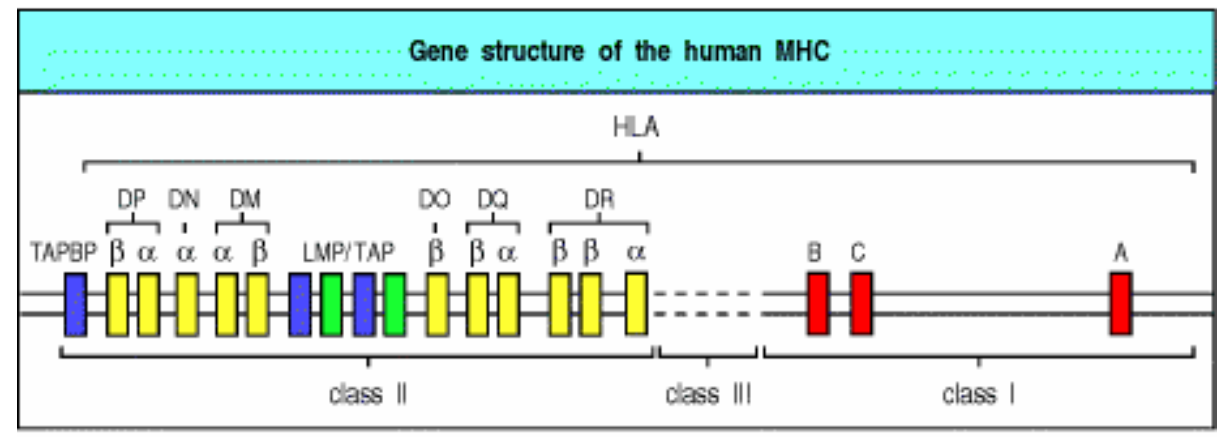

Abb. 1.1: Genstruktur des humanen Haupthistokompatibilitätskomplexes (MHC). Es können separate Genkomplexe unterschieden werden, die als Klasse-I- (rot markiert) und Klasse-II-Gene (gelb markiert) bezeichnet werden. In der Klasse-I gibt es drei Hauptgene: HLA-A, HLA-B und HLAC. In der Klasse-II sind die Gene für die $\alpha$ - und $\beta$-Kette des antigenpräsentierenden MHC-KlasseII-Moleküls (HLA-DR, HLA-DP, HLA-DQ) lokalisiert. Zusätzlich sind im MHC-Klasse-II Gene für den TAP1:TAP2-Peptidtransporter; LMP-Gene, die die Untereinheiten des Proteasoms codieren; Gene, die die DM $\alpha$ - und DMß-Kette codieren; Gene, die die $\alpha$ - und $\beta$-Ketten des DOMoleküls (DN $\alpha$ und DOß) codieren und Gene für Tapasin (TAPBP) lokalisiert. Die so genannten MHC-Klasse-III-Gene codieren verschiedene andere Proteine mit Immunfunktionen (Abbildungen und Text aus: Janeway et al., 2001).

Die folgenden Abschnitte über MHC orientientieren sich als Quelle unter anderem am Lehrbuch „Immunobiology“ (Janeway et al., 2001).

Die Aufgabe der Klasse-I- bzw. Klasse-II-Moleküle besteht in der Präsentation kurzer Peptide an zytotoxische T-Zellen bzw. an T-Helferzellen. Im Mensch wird der MHC auch als HLA-System (Human Leukocyte Antigen) bezeichnet. MHC-Klasse-I- und -Klasse-IIMoleküle bilden eine Grube, in der die Peptide gebunden werden. Aufgrund der unterschiedlichen Herkunft der präsentierten Peptide gibt es zwei verschiedene Klassen 
von MHC-Molekülen. Während Klasse-I-Moleküle Peptide von Pathogenen binden, die sich im Zytosol der Zelle befinden, werden von Klasse-II-Molekülen Peptide gebunden, die von extrazellulären Pathogenen stammen. Die Ausstattung mehrerer Gene in der jeweiligen Klasse (Polygenie) macht es weiterhin möglich, viele verschiedene Peptide von Pathogenen binden zu können. Im Menschen gibt es somit drei Klasse-I-(alpha ( $\alpha$ )-Kette) Gene (HLA-A, -B, -C). Bei manchen Spezies wie z. B. in Nagetieren (Maus, Ratte) und gewissen Primaten (Rhesusaffe, Pavian) ist die Polygenie der MHC-Klasse-I-Gene besonders stark ausgeprägt.

Ein bedeutendes Charakteristikum des HLA-Komplexes ist der ausgeprägte Polymorphismus. Dies bedeutet, dass innerhalb der Population einer Spezies eine Vielzahl allelischer Varianten eines Gens vorkommt. Zur Zeit sind z. B. von dem MHC-Klasse-IGen HLA-B 894 Allele und vom MHC-Klasse-II-Gen HLA-DRB1 577 Allele in der humanen Population bekannt (IMGT/HLA Database, Stand Mai 2007).

Da die MHC-Allele ko-dominant exprimiert werden, wird die Diversität von MHCMolekülen innerhalb eines Individuums deutlich erhöht. Diese hohe adaptive Fähigkeit ermöglicht einer Population, über einen langen Zeitraum auf neue Pathogene zu reagieren. Allerdings trägt dieser Polymorphismus auch zu höheren Anfälligkeiten oder Resistenzen bei Krankheiten bei, insbesondere $\mathrm{zu}$ chronischen Entzündungsreaktionen und Autoimmunkrankheiten (Parham, 2005).

\subsubsection{MHC-Klasse-I-Gene und -Moleküle}

MHC-Klasse-I-Moleküle werden auf nahezu allen kernhaltigen Zellen exprimiert. Diese Notwendigkeit rührt daher, dass Viren zur Replikation den Zellkern des Wirtes nutzen. Klasse-I-Moleküle bestehen aus zwei Polypeptidketten: einer polymorphen schweren Kette $(\alpha-K e t t e, ~ \sim 45 \mathrm{kDa})$, die nicht-kovalent an eine nicht-polymorphe leichte Kette (Beta-2Mikroglobulin, B2M, $12 \mathrm{kDa}$ ) gebunden ist (Abb. 1.2 b, d). Die $\alpha$-Kette wird im MHC codiert und das B2M außerhalb des MHC. Die Klasse-I-Moleküle sind über die $\alpha$-Kette in der Membran befestigt. Weiterhin bildet die $\alpha$-Kette drei Domänen ( $\alpha 1-3)$, wobei die $\alpha 1$ und $\alpha 2$-Domäne in ihrer dreidimensionalen Struktur eine Grube auf der Oberfläche des Moleküls bilden (Abb. 1.2 c). MHC-Klasse-I-Moleküle binden in ihrer Grube Peptide einer Länge von 8-10 Aminosäureresten (Falk et al., 1990, 1991). Dies ist eine notwendige Vorraussetzung für die Stabilität und die korrekte Faltung der MHC-Klasse-I-Moleküle. Die stabile Bindung der Peptide wird durch 2-3 Kontakte des MHC-Klasse-I-Moleküls mit den freien Amino- und Carboxygruppen des Peptids an beiden Enden der Grube erreicht. 
Da die Grube in der $\alpha 1$-und $\alpha 2$-Kette codiert ist und diese in diesem Aminosäureabschnitt einen starken Polymorphismus aufweisen, können verschiedene MHC-Klasse-I-Moleküle verschiedene Spektren von Peptiden binden. Allerdings können auch verschiedene Peptide mit ähnlichen Sequenzmotiven an gleiche MHC-Klasse-I-Moleküle binden (Falk et al., 1990, 1991).

Abb. 1.2: Struktur der MHC-KlasseI-Moleküle. (a) zeigt eine Computergrafik, die das MHC-Klasse-I-Molekül darstellt. Die farblichen Zuordnungen entsprechen den Domänen in b-d.

(b) und (c) zeigen ein Banddiagramm eines MHC-Klasse-I-Moleküls (b) und die durch spezifische Faltung der $\alpha 1$ und $\alpha 2$-Domäne erzeugte Grube (c). Die schematische Darstellung eines MHC-Klasse-IMoleküls ist in (d) dargestellt (Abbildungen und Text aus Janeway et al., 2001).


Die gebundenen Aminosäurereste oder Antigene werden durch Antigenprozessierung aus zelleigenen Proteinen oder aus Pathogenen (meist Viren) im Zytosol auf die MHC-KlasseI-Moleküle geladen. Dadurch können diese Antigene dem Immunsystem präsentiert werden und im Fall der Erkennung eines Fremdantigens wird die Zelle durch zytotoxische CD8 ${ }^{+}-\mathrm{T}-Z$ Zellen eliminiert und weitere Pathogenvermehrung dadurch verhindert.

Die Beladung der MHC-Klasse-I-Moleküle mit dem Peptid erfolgt im Lumen des endoplasmatischen Retikulums (ER). Dabei werden die Peptide aus dem Zytosol durch einen ATP-abhängigen Transportprozess in das Lumen des ER geleitet. Der Transport wird durch zwei ABC- (ATP-binding cassette) Transporter (Higgins, 1992) vermittelt, die als TAP1 und TAP2 (transporter associated with antigen processing) bezeichnet werden. Die Bildung des ladefähigen Peptids erfolgt im Zytosol der Zelle. Virusproteine oder zelleigene Proteine werden zum größten Teil im Proteasom (Vinitsky et al., 1997; Rock und Goldberg, 1999; Mo et al., 1999; York et al., 1999; Van Kaer, 2002) degradiert. Die 
entstehenden Peptide werden durch TAP transportiert und an MHC-Klasse-I-Moleküle gebunden (Williams et al., 2002).

Die Peptidbindung an das MHC-Klasse-I-Molekül dient der Erkennung von Pathogenen befallenen Zellen. Die Unterscheidung des Peptids als fremd oder eigen erfolgt über Rezeptoren (T-Zell-Rezeptor, TCR) auf zytotoxischen CD8 ${ }^{+}$-T-Lymphozyten (T-Zellen) (Davis und Bjorkman, 1988). T-Zellen erkennen die Antigene nur über die an MHCKlasse-I-Moleküle gebundene Form und nicht wie B-Zellen, die freie Antigene über Immunglobuline binden können.

Der TCR bildet Kontakte sowohl mit dem Peptid als auch mit dem MHC-Klasse-I-Molekül auf der Zielzelle. Damit ergibt sich eine Spezifität des TCR nicht nur gegenüber dem gebundenen Peptid sondern auch gegenüber dem MHC-Klasse-I-Molekül (T-ZellRestriktion) (Zinkernagel, Doherty, 1974a, b). Rolf Zinkernagel und Peter Doherty wurden für diese Entdeckung 1996 mit dem Nobelpreis geehrt.

Erkennt der TCR das Peptid als fremd, so führt dies durch das Ausschütten zytotoxischer Proteine zum programmierten Zelltod (Apoptose) der Zielzelle. Neben der Erkennung durch TCR gibt es noch weitere Rezeptoren für MHC-Klasse-I-Moleküle.

MHC-Klasse-I-Moleküle spielen auch eine wichtige Rolle als Liganden für Rezeptoren der Natürlichen Killerzellen (NK-Zellen) (Trowsdale, 2001). Sie kontrollieren dadurch den funktionellen Status dieser Lymphozyten (Moretta und Moretta, 2004a, b; Lanier, 2005; Parham, 2005). NK-Zellen spielen eine wichtige Rolle bei der Abwehr von Infektionen und Tumorwachstum, vor allem vor der Mobilisierung zytotoxischer T-Zellen. Durch „,inhibitorische“ und „,aktivierende“ Rezeptoren ist es den NK-Zellen möglich, Änderungen der Anzahl der MHC-Klasse-I-Moleküle auf der Oberfläche, die durch Pathogene oder Mutationen hervorgerufen wurde, festzustellen und gegebenenfalls Apoptose der Zielzelle auszulösen. Zu diesen Rezeptoren gehören im Menschen die so genannten „killer cell immunoglobulin-like receptors“ (KIR) (Parham, 2005), „leukozyte immunoglobulin-like receptors“ (LILR oder ILT) (Brown et al., 2004), sowie „lectin-like receptors“ (CD94/NKG2).

In diesem Zusammenhang sind die ,nicht-klassischen“ MHC-Klasse-I-Gene (MHCKlasse-Ib) (im Menschen HLA-E, HLA-F, HLA-G, MICA, MICB, CDIA-CDIE, HFE, FCGRT, AZGP1, PROCR) zu nennen. Die Unterteilung basiert auf deren Polymorphismus, Expressionsmuster und Funktion. Diese nicht-klassischen MHC-Klasse-I-Gene sind im Allgemeinen weniger polymorph und zeigen häufig eine eingeschränkte Expressionsverteilung (Shawar et al., 1994). MHC-Klasse-Ib-Moleküle spielen eine Rolle 
bei der angeborenen Immunität z. B. über die Aktivierung oder Inhibition von NK-Zellen, aber auch bei der adaptiven Immunität in Antwort auf Tumoren und Pathogene (Sullivan et al., 2006; Fishman et al., 2004). Das MHC-Klasse-Ib-Molekül HLA-E, das als Ligand für die NK-Zell-Rezeptoren CD94/NKG2A und CD94/NKG2C funktioniert, sendet Signale zur Vermeidung der Zelllyse durch NK-Zellen (Braud et al., 1998; Lee et al., 1998; Leibson, 1998). HLA-E kann auch zur Peptidpräsentation zytotoxischen T-Zellen dienen (Garcia et al., 2002; Michaelsson et al., 2002; Heinzel et al., 2002), andere sind am Eisenstoffwechsel (Feder et al., 1996; Cardoso und de Sousa, 2003), bei der Aufnahme mütterlicher Immunglobuline aus der Milch (Simister und Mostov, 1989) oder an der Blutgerinnung beteiligt (Fukudome und Esmon, 1994).

Eine weitere Gengruppe sind die MIC-(MHC class I chain-related) Gene. Im Unterschied zu den klassischen MHC-Molekülen binden z. B. MICA- und MICB-Moleküle weder B2M (Groh et al., 1996; Zwirner et al., 1998) noch Peptide (Groh et al., 1996, 1998). Die Expression der MIC-Gene wird durch Stress induziert, und MIC-Proteine werden durch NKG2D-Rezeptoren auf NK-Zellen detektiert (Gleimer und Parham, 2003). Das Fehlen der B2M-Kette ist ebenfalls charakteristisch für das MHC-Klasse-I-ähnliche Protein Zna2-Glykoprotein (AZGP1) (Araki et al., 1988), das als lösliches Protein im Serum und anderen Körperflüssigkeiten vorliegt und am Fettstoffwechsel beteiligt ist (Sanchez et al., 1999).

\subsubsection{MHC-Klasse-II-Gene und -Moleküle}

Im Gegensatz zu MHC-Klasse-I-Genen werden MHC-Klasse-II-Gene (HLA-DR, -DP, -DQ, -DM, -DO im Menschen) weitaus begrenzter exprimiert. MHC-Klasse-II-Moleküle präsentieren Peptide, die von intravesikulären und extrazellulären Pathogenen stammen. Sie werden auf B-Lymphozyten, dendritischen Zellen, Makrophagen und antigenpräsentierenden Zellen (APC) exprimiert. Bei Fremdantigenerkennung stimulieren $\mathrm{CD}^{+}$-T-Zellen wiederum andere Immunzellen zur Antikörperproduktion oder Pathogenabtötung. Wie bei MHC-Klasse-I-Genen findet sich auch bei MHC-Klasse-IIGenen ein starker Polymorphismus. Da in dieser Arbeit die MHC-Klasse-I-Gene im Vordergrund stehen, soll an dieser Stelle nicht weiter auf die MHC-Klasse-II-Gene eingegangen werden. 


\subsection{Neuronale Plastizität}

Unter „,neuronaler Plastizität“ versteht man die Fähigkeit des Gehirns durch Modulation neuronaler Verbindungen auf Veränderungen der Umwelt $\mathrm{zu}$ reagieren, sowie Lernprozesse und Erinnerungsvermögen zu fördern. Die Mechanismen dazu sind vielfältig und ermöglichen im Zusammenspiel unterschiedliche Intensitäten der Plastizität. Das sich entwickelnde Nervensystem ist durch eine hohe adaptive Fähigkeit ausgezeichnet, auf Veränderungen der Umwelt $\mathrm{zu}$ reagieren. Dabei sind Perioden besonders starker Flexibilität vorhanden, die als sensible oder kritische Phasen in der Entwicklung bezeichnet werden. Die zugrunde liegenden Mechanismen reichen von der de novo Aussprossung dendritischer und axonaler Nerventerminalen, lokaler Proliferation der neuronalen Dendriten oder terminaler Axonverzweigungen, Zunahme der Anzahl und Größe dendritischer Dornen (,spines“) oder synaptischer Endigungen bis zur Anpassung der synaptischen Effizienz durch Änderung der Anzahl der Synapsen oder der Position auf dem Zielneuron. Während der Ontogenese/Synaptogenese unterliegen der Zielerkennung und der Synapsenformation wahrscheinlich aktivitätsunabhängige Ereignisse, dagegen ist die Bildung effektiver Synapsen durch Stabilisierung oder Eliminierung von synaptischen Verbindungen im sich entwickelnden Nervensystem abhängig von elektrischer Aktivität (Goodman und Shatz, 1993). So sind visuelle Aktivitäten während der kritischen Periode ausschlaggebend bei der Formation der okularen Dominanzsäulen im primären visuellen Cortex (Hubel und Wiesel, 1970; Hubel et al., 1977; Levay et al., 1978; 1980).

Für die Umbildung unreifer neuronaler Schaltkreise in organisierte neuronale Verbindungen, die adulten Gehirnfunktionen unterliegen, ist neuronale Aktivität generell erforderlich. So sind früh in der Entwicklung entstehende spontane Aktivitäten an der Formation neuronaler Schaltkreise beteiligt. Mit zunehmender Entwicklung der sensorischen Organe bedarf das Gehirn weniger dieser spontanen Aktivitäten und zunehmender sensorischer Erfahrungen (Katz und Shatz, 1996).

Im Gegensatz dazu ist im ausgereiften, adulten Gehirn weniger Potential zur Plastizität gegeben, aber es bestehen immer noch Mechanismen, im begrenzten Ausmaß auf Veränderungen zu reagieren sowie Lern- und Gedächtnisfunktionen $\mathrm{zu}$ ermöglichen (Purves et al., 2001).

Im Rahmen der neuronalen Plastizität ist die synaptische Plastizität auf Synapsen beschränkt und bestimmt die Änderung der Effizienz der synaptischen Übertragung. Dabei können präsynaptische und postsynaptische Mechanismen unterschieden werden. Bei 
präsynaptischen Mechanismen kann das ankommende Aktionspotential zu einer vermehrten Transmitterausschüttung und dadurch zu einer verstärkten Aktivierung der postsynaptischen Zelle führen. Bei postsynaptischen Mechanismen können in die Postsynapse mehr Transmitterrezeptoren eingebaut und darüber eine verstärkte Aktivierung erreicht werden. So können bei der im folgenden Kapitel beschriebenen Langzeit-Potenzierung prä- und postsynaptische Elemente zum Tragen kommen und die „Stärkung“ der Synapse ermöglichen (Pike et al., 1999).

\subsubsection{Plastizität durch Langzeit-Potenzierung (LTP)}

Im Zusammenhang mit den zuvor beschriebenen Änderungen der Effizienz der synaptischen Übertragung ist die experimentelle Entdeckung von Bliss und Lømo (1973) bedeutend. Sie fanden heraus, dass im Hippocampus kurze, hochfrequente Stimuli eine Verstärkung des synaptischen Potentials in postsynaptischen Neuronen produzieren und diese für Stunden, Tage oder Wochen anhalten können. Dadurch werden stabile und lang anhaltende Veränderungen der synaptischen Stärke ermöglicht. Dieses Phänomen wird als LTP (Long-Term Potentation, Langzeit-Potenzierung) bezeichnet. LTD (Long-Term Depression, Langzeit-Depression) ist das gegenteilige Phänomen (Linden, 1994). Es wird angenommen, dass LTP als Form der synaptischen Plastizität in die Prozesse des Lernens und Gedächtnisses involviert ist (Malenka und Nicoll, 1999). Castellani et al. (2005) zeigten anhand eines biophysikalischen Modells eine mögliche Korrelation zwischen der Phosphorylierung des postsynaptischen Glutamatrezeptors $\alpha$-Amino-3-Hydroxy-5Methylisoxazole-4-Propionsäure-Rezeptor (AMPAR) und LTP. Die Regulation der synaptischen Stärke durch Mechanismen wie Phosphorylierung und Dephosphorylierung wurde zuvor schon beschrieben (Walaas und Greengard, 1991; Malinow und Malenka, 2002). Es konnte ebenfalls gezeigt werden, dass LTP mit dem Einfügen von AMPAR (Shi et al., 1999; Hayashi et al., 2000) und LTD mit dem Entfernen von AMPAR von dendritischen Dornen (Carroll et al., 1999) korreliert. Ein anderer synaptischer Rezeptor (Untergruppe der Glutamatrezeptoren) ist der N-Methyl-D-Aspartat-Rezeptor (NMDAR), der die Calciumkanäle reguliert und durch Magnesium blockiert wird. Um aktiviert zu werden, müssen zwei unterschiedliche Bedingungen vorliegen: Bindung von Glutamat und Depolarisation an der Postsynapse. Dadurch wird Magnesium entfernt, Calcium kann durch die Kanäle gelangen und LTP induzieren. Genetische Manipulationen zeigten, dass NMDA-Rezeptoren Einfluss auf die synaptische Plastizität im Hippocampus haben (Sakimura et al., 1995; Kew et al., 2000) und eine kritische Rolle beim Lernen spielen 
(Nakazawa et al., 2002). Das Blockieren der Rezeptoren führt zu einem verzögerten Hippocampus-abhängigem Lernen. Die Aktivierung von NMDAR trägt zur synaptischen Plastizität im Hippocampus bei und ist daher für Hippocampus-abhängiges Lernen notwendig (Shapiro, 2001).

\subsubsection{Plastizität durch strukturelle Änderungen}

Die korrekte Funktionalität des Nervensystems beruht auf präzisen synaptischen Verschaltungen. Synaptische Mechanismen, bei denen durch Aktivität langfristige strukturelle Änderungen hervorgerufen werden, sind wahrscheinlich ähnlich der LTP im Hippocampus. In rezeptiven Feldern im adulten Cortex liegen Mechanismen vor, die denen von LTP ähneln und damit zeigen, dass synaptische Plastizität auch bei Gedächtnisfunktionen eine Rolle spielt (Martin und Morris, 2002). Wahrscheinlich herrschen bekannte Prinzipien erfahrungsabhängiger synaptischer Plastizität sowohl im Hippocampus als auch im Neocortex (Intrator et al., 1993). Änderungen der synaptischen Effizienz, die möglicherweise zur Bildung dauerhafter Erinnerungen notwendig sind, werden wahrscheinlich durch Änderungen der synaptischen Struktur vermittelt (Thompson, 2000).

Im Zusammenhang mit LTP und synaptischer Plastizität zeigten Engert und Bonhoeffer (1999) die Ausbildung von dendritischen Dornen aufgrund von LTP. Durch niedrigere Reizfrequenz (LTD) konnte das Verschwinden der Dornen beobachtet werden (Nägerl et al., 2004). Trachtenberg et al. (2002) zeigten im adulten Cortex, dass die Dornen an Dendriten häufig erscheinen und verschwinden, wohingegen das Wachsen oder Rückziehen von Dendriten oder Axonen nicht beobachtet werden konnte. Die Aussprossung von Dornen ist mit der Formation von Synapsen assoziiert und der Rückzug von Dornen mit der Eliminierung von Synapsen. Die Rate der synaptischen Formation/Eliminierung steigt in Reaktion auf neue sensorische Erfahrungen (erfahrungsabhängige Plastizität). Die Synaptogenese ist damit nicht auf Entwicklungsperioden beschränkt, sondern auch im adulten Gehirn zu finden. Die Autoren zeigten, dass die bekannte gleich bleibende synaptische Dichte im adulten Neocortex eher als eine Balance in Synapsenbildung und -eliminierung zu sehen ist. Damit, vermuten die Autoren, werden im adulten Neocortex adaptive Änderungen im Bindungsmuster durch Aussprossen und Rückzug dendritischer Dornen ermöglicht, ohne dass große Umorganisationen neuronaler Fasern wie das Wachsen oder Eliminieren von Axonen oder dendritischer Bäume stattfinden. Dadurch befindet sich das Ausmaß der adulten cortikalen 
Adaptation in deutlichem Kontrast $\mathrm{zu}$ kritischen Perioden in der Entwicklung des Nervensystems (Trachtenberg et al., 2002). Da LTP auch im sich entwickelnden visuellen Cortex eine Rolle spielt (Kirkwood et al., 1993; Kirkwood und Bear, 1995), könnte dies ebenfalls ein Mechanismus sein, der zur synaptischen Plastizität beiträgt (Katz und Shatz, 1996). Schmidt-Hieber et al. (2004) zeigten, dass neugeborene Neuronen im adulten Hippocampus plastischere neuronale Eigenschaften zeigen als reife Neuronen. Die neugeborenen Neuronen waren stärker erregbar und konnten leichter ihre synaptischen Verbindungen mit anderen Neuronen stärken oder schwächen.

\subsubsection{Plastizität durch Genexpression}

Die elektrische Aktivität von Neuronen hat Einfluss auf die Genexpression und ermöglicht dadurch aktivitätsabhängige Plastizität während der Entwicklung und daraus die Formation neuronaler Netze im Gehirn (Corriveau, 1999). Bei der Stabilisierung von Synapsen durch Aktivität spielen Zelladhäsionsmoleküle und unter anderem der Transkriptionsfaktor cAMP Responsive Element Binding Protein (CREB) eine wichtige Rolle in aktivitätsabhängiger synaptischer Umstrukturierung (Dash et al., 1990) sowie beim Aufrufen von Erinnerungen (Kida et al., 2002). Lang anhaltende Formen der synaptischen Plastizität erfordern somit die Expression von Genen (Martin und Kandel, 1996).

Der Begriff Plastizität bezieht sich auf Änderungen der synaptischen Stärke, dessen Ausmaß sehr variieren kann. Es reicht von Änderungen der synaptischen Transmission bis zu Extremen während der Entwicklung wie bei Formation und Eliminierung ganzer Synapsen (Corriveau, 1999). Kurzfristige Plastizität ist abhängig von posttranslationalen Modifikationen existierender Proteine. Dagegen ist langfristige Plastizität abhängig von Genexpression und de novo Proteinsynthese (Abraham und Tate, 1997).

Im adulten Gehirn können sowohl synaptische „Festigungen“ als auch „Schwächungen“ gezeigt werden (Malenka und Nicoll, 1993). Transkription und Translation sind für das Langzeitgedächtnis vonnöten (Davis und Squire, 1984). Der Hippocampus ist für die Verfestigung (Konsolidierung) von Erinnerungen erforderlich, allerdings spielt diese Gehirnstruktur eine zeitlich begrenzte Rolle beim Langzeitgedächtnis (Altgedächtnis), das vermutlich in neocorticalen Bereichen gespeichert wird (Squire et al., 2001). In beiden Bereichen spielt allerdings die synaptische Plastizität entweder zeitlich begrenzt (Hippocampus) oder permanent (Neocortex) eine entscheidende Rolle (Squire et al., 2001). 


\subsection{Das Immunprivileg des Gehirns}

Das Gehirn der Säugetiere ist in einem nicht-elastischen Schädel eingebettet, der keine exzessive Zellanreicherung und Anschwellen zulässt. Durch Inflammation im ZNS kann es zum Zelltod kommen und zum Verschwinden wichtiger Neuronen. Damit können wichtige neuronale Verbindungen unterbrochen und neuronale Beeinträchtigungen hervorgerufen werden (Carson et al., 2006).

Im Zusammenhang dazu führte Medawar (1948) den Begriff „Immunprivileg“ ein. Er transplantierte Hautgewebe in das Auge und das Gehirn und entdeckte, dass diese für unerwartet lange Zeit nicht abgestoßen wurden. Seinerzeit wurde davon ausgegangen, dass durch fehlende Lymphbahnen, wie im Gehirn und Auge, keine Interaktionen zwischen Antigenen und aktiven Immunzellen besteht und dadurch diese ,immunprivilegierten“ Organe vom Immunsystem nicht erkannt werden (Barker und Billingham, 1977; Streilein, 1993). Als weitere Säule des „Immunprivilegs“ galt die Blut-Gehirn-Schranke, die mit ihren Endothelzellen (,tight junctions“) (Dermietzel, 1975; Risau und Wolburg, 1990) den Durchtritt von T-Lymphozyten einschränkt (Aarli, 1983). Allerdings wurden diese Annahmen durch neuere Forschungen korrigiert, die ergaben, dass das Immunsystem sehr wohl an aktiven Regulationen in ,immunprivilegierten“ Organen teilnimmt (Ferguson und Griffith, 1997; Streilein und Stein-Streilein, 2000; Boulanger und Shatz, 2004) und TLymphozyten auch über den Liquor cerebrospinalis (Gehirn-Rückenmarks-Flüssigkeit) und durch die Plexus choroidei in das ZNS gelangen (Ransohoff et al., 2003). Doch auch in Gegenwart von zytotoxischen T-Lymphozyten zeigen Neuronen nach viraler Infektion Resistenzen gegen Zelllyse (Rall et al., 1995). Daher bedeutet „Immunprivileg“ nicht Immunisolation, sondern eher Immunspezialisierung mit einer Reihe von ZNS-vermittelten Mechanismen, die aktiv T-Zellantworten im ZNS regulieren (Carson et al., 2006).

In diesem Zusammenhang ist die Expression von MHC-Klasse-I-Genen in Neuronen von großer Bedeutung, was im folgenden Kapitel beschrieben wird.

\subsection{MHC-Klasse-I-Moleküle und neuronale Plastizität}

Das Gehirn wurde lange als ,immunprivilegiertes“ Organ bezeichnet. Es wurde angenommen, dass Neuronen keine MHC-Klasse-I-Moleküle exprimieren. (Lampson und Hickey, 1986; Vass und Lassmann, 1990; Joly et al., 1991; Mucke und Oldstone, 1992; Rall et al.,1995). Zahlreiche Studien verfehlten den Nachweis von MHC-Klasse-I-Protein 
in unbehandelten Gehirnschnitten (Lampson et al., 1988), in Kultur gehaltenen Neuronen (Fujimaki et al., 1996) oder Neuron-ähnlichen immortalisierten Zelllinien (Lampson et al., 1984; Joly et al., 1991,1992; Drew et al., 1993; White et al., 1994; Lampson, 1995) (Übersichtsartikel Boulanger und Shatz, 2004).

Im Gegensatz dazu exprimieren Neuronen große Mengen an MHC-Klasse-I-Protein nach verschiedenen Behandlungen, wie Axotomie (Olsson et al., 1989; Maehlen et al., 1988), Durchtrennung der Ventralhornwurzel (Lidman et al., 1999), pharmakologischer Manipulation der elektrischen Aktivität (Fujimaki et al., 1996; Linda et al., 1998; Corriveau et al., 1998) oder akuter und chronischer Entzündung (Olsson et al., 1987; Kimura und Griffin, 2000; Foster et al., 2002) (Übersichtsartikel Boulanger und Shatz, 2004). Weiterhin kann die MHC-Klasse-I-Expression in neuronalen Zelllinien (Drew et al., 1993; Joly et al., 1992) und Neuronen in Kultur (Wong et al., 1984, 1985; Neumann et al., 1995, 1997) durch Interferon-gamma-Behandlung induziert werden. Außerdem exprimieren auch Gliazellen MHC-Klasse-I-Gene in Antwort auf Zytokine (Finsen et al., 1993; Lampson, 1995; Peng et al., 1998).

Allerdings konnte kürzlich in in-vivo-Untersuchungen im sich entwickelnden Gehirn von Maus und Katze eine funktionelle und geordnete MHC-Klasse-I-Expression nachgewiesen werden (Corriveau et al., 1998; Huh et al., 2000; Oliveira et al., 2004). Durch In-situHybridisierung mit Maus-MHC-Klasse-I-Genen zeigte sich ein deutlich spezifisches Muster der MHC-Klasse-I-Gene in Bezug auf die zeitliche Expression und die Spezifität der Genloci im Gehirn (Huh et al., 2000). MHC-Klasse-I-mRNA und/oder -Protein wurden in verschiedenen Neuronenpopulationen nachgewiesen: motorische Kerne, Substantia nigra (Lidman et al., 1999; Huh et al., 2000), Spinalganglienneuronen (Neumann et al., 1997), sich entwickelnde und adulte Pyramidenneuronen des Hippocampus (Neumann et al., 1995; Corriveau et al., 1998) und Pyramidenneuronen des Cortex (Corriveau et al., 1998; Huh et al., 2000) (Übersichtsartikel Boulanger und Shatz, 2004). Einige dieser Studien zeigen, dass MHC-Klasse-I-Expression in Neuronen nach Axotomie, Cytokingabe (Linda et al., 1998) und Änderung der elektrischen Aktivität (Corriveau et al., 1998; Huh et al., 2000) weiter erhöht werden kann (Übersichtsartikel Boulanger und Shatz, 2004). Außerdem wurde gezeigt, dass bestimmte nagerspezifische MHC-Klasse-Ib-Moleküle, Mitglieder der M1- und M10-Genfamilien, essentiell für die Pheromonrezeption durch Bindung an spezifische Rezeptoren im Vomeronasalorgan sind (Loconto et al., 2003; Ishii et al., 2003). Ebenfalls scheint der Polymorphismus der Klasse-Ia-Gene mit unterschiedlichem Verhalten der Regenbogenforellen zu korrelieren (Azuma et al., 2005). 
Diese Ergebnisse indizieren eine neurobiologische Funktion für MHC-Klasse-I-Moleküle und die Beteiligung an Prozessen der Gehirnentwicklung und neuronaler Plastizität (Corriveau et al., 1998; Huh et al., 2000; Oliveira et al., 2004).

Wie im Abschnitt „,neuronale Plastizität“ beschrieben, ist die neuronale Vernetzung und Entwicklung präziser synaptischer Verbindungen im ZNS ein komplexer Prozess, der nicht nur den Aufbau synaptischer Verbindungen, sondern auch den Abbau (Eliminierung) nicht mehr benötigter Synapsen während der Entwicklung verbindet. Dabei ist dieser Prozess unter anderem abhängig von der Aktivität der Neuronen. Die Aktivität oder Nicht-Aktivität einzelner Neuronen spielt dabei eine Schlüsselrolle in der Stabilisierung notwendiger Verbindungen oder der Eliminierung nicht mehr benötigter Verbindungen. Allerdings sind die diesen Prozessen zugrunde liegenden Mechanismen noch nicht vollständig geklärt. In diesem Kontext wurde nunmehr gezeigt, dass die MHC-Klasse-I-Expression in Neuronen der Katze durch spontane und reizgetriebene neuronale Aktivität reguliert wird (Corriveau et al., 1998). Die neuronale MHC-Klasse-I-Expression korrespondiert dabei mit gut charakterisierten Zeiten und Regionen aktivitätsabhängiger Entwicklung und synaptischer Plastizität im ZNS der Katze (Corriveau et al., 1998). Aus diesem Grund scheint es wahrscheinlich, dass MHC-Klasse-I-Moleküle, die primär an der Antigenpräsentation im Immunsystem beteiligt sind, eine Rolle in struktureller und synaptischer Umgestaltung im sich entwickelnden und reifen Gehirn spielen (Huh et al., 2000). Zusätzliche Hinweise für eine Beteiligung von MHC-Klasse-I-Molekülen an synaptischer Plastizität kommen von Arbeiten an genetisch modifizierten Mäusen. Es zeigte sich, dass Mäuse ohne TAP1 oder B2M, also essentielle Komponenten einer funktionellen MHC-Klasse-I-Expression, deutliche Unterschiede in der synaptischen Plastizität verglichen zum Wildtyp erkennen ließen (Huh et al., 2000). Darüber hinaus wurde festgestellt, dass MHC-Klasse-Ia- und -IbGene von distinkten Neuronengruppen der Maus unterschiedlich exprimiert werden (Huh et al., 2000). Lidman et al. (1999) zeigten in verschiedenen Neuronenpopulationen der Ratte eine starke Expression von nicht-klassischen MHC-Klasse-I-Genen (RT1-U), dagegen aber keine oder wenig Expression von klassischen MHC-Klasse-I-Genen (RT1-A). Weiterhin wurde gezeigt, dass die Regulation dieser Gene sich in Neuronen und Gliazellen nach Verletzung des Nerves unterscheidet. Damit wird wahrscheinlich, dass MHC-KlasseIb-Moleküle eine andere Rolle im ZNS spielen als MHC-Klasse-Ia-Moleküle. Aus den Ergebnissen der Studie vermuten Lidman et al. (1999) für MHC-Klasse-Ib-Moleküle eine wichtige Rolle in der Interaktion zwischen Neuronen und Immunzellen und damit auch für die Immunüberwachung im ZNS. In diesem Zusammenhang sind die weiter oben 
beschriebenen Funktionen von MHC-Klasse-Ib-Molekülen interessant, die unter anderem als Liganden zur Aktivierung oder Inhibition von NK-Zellen aber auch von T-Zellen eine Rolle spielen. In diesem Kontext ist die Regulation der Zelllyse in Neuronen durch MHCKlasse-Ib-Moleküle möglich. Damit scheint die aus dem Immunsystem bekannte funktionelle Heterogenität der Klasse-Ia- und Ib-Genen auch im ZNS eine Rolle zu spielen (Huh et al., 2000).

Aufgrund zahlreicher Studien ist nunmehr eine Beteiligung von MHC-Klasse-I-Molekülen an der synaptischen Plastizität und im engeren Sinn an der „Festigung“ oder „Lockerung“ synaptischer Verbindungen sehr wahrscheinlich. Aus diesem Grund ist die Suche nach möglichen Interaktionspartnern im ZNS und damit der Klärung der Signaltransduktion von großer Bedeutung. Aus dem Immunsystem sind die im Kapitel 1.1.1 beschriebenen Rezeptoren wie TCR, KIR, LILR, CD94/NKG2 und NKG2D bekannt. Untersuchungen im ZNS wurden zu TCR (Syken und Shatz, 2003), KIR (Bryceson et al., 2005) und LILR (Syken et al., 2006) durchgeführt.

Im Hinblick auf den TCR fanden Syken und Shatz (2003), dass der TCRß-Lokus in verschiedenen Neuronengruppen der Maus exprimiert ist und dabei während der Entwicklung dynamisch reguliert wird. Allerdings konnten die Autoren keine weiteren Anhaltspunkte dafür finden, dass es sich bei TCRß um den neuronalen Rezeptor für MHCKlasse-I-Moleküle im ZNS handelt. Ein der MHC-Klasse-I-Expression ähnliches KIRähnliches Genexpressionsmuster fanden Bryceson et al. (2005) im Gehirn der Maus. Die Autoren vermuten daher auch für KIR-ähnliche Moleküle eine neue Funktion im ZNS. Allerdings fehlen noch Untersuchungen, die eine funktionelle Rolle KIR-ähnlicher Moleküle der Maus in der synaptischen Plastizität zeigen. Ein weiterer möglicher Rezeptor wurde von Syken et al. (2006) untersucht. Sie zeigten, dass PirB (Paired-immunoglobulinlike receptor $\mathrm{B}$, ortholog $\mathrm{zu}$ humanen LILR) im gesamten Gehirn der Maus aller Altersstufen exprimiert ist. Aufgrund von Mutationsstudien vermuten die Autoren, dass in allen Altersstadien, auch in kritischen Perioden während der Entwicklung, wenn neuronale Schaltkreise ein hohes Potenzial zu Veränderungen zeigen, ein molekularer Mechanismus aktiv ist, der die synaptische Plastizität limitiert. Dadurch könnte eine kontrollierte Bildung/Etablierung synaptischer Verbindungen ermöglicht werden. Innerhalb dieser Prozesse sehen Syken et al. (2006) eine Rolle für PirB, das damit als möglicher Rezeptor im Gehirn für MHC-Klasse-I-Moleküle in Betracht kommt.

Eine aktuelle Studie (Goddard et al., 2007) liefert neue Einblicke in die subzelluläre Lokalisation der MHC-Klasse-I-Moleküle in Kultur gehaltener Hippocampusneuronen der 
Maus. Es konnte gezeigt werden, dass MHC-Klasse-I-Moleküle sich postsynaptisch an erregenden (exzitatorischen) Synapsen befinden. Die Autoren vermuten, dass MHCKlasse-I-Moleküle vielleicht Teil des retrograden Signalsystems sind. Allerdings ist nicht bekannt, ob der retrograde Effekt direkt erfolgt über einen präsynaptischen Rezeptor wie PirB (Syken et al., 2006), oder über postsynaptische Bestandteile wie Glutamatrezeptoren (Goddard et al., 2007).

Da sowohl MHC-Klasse-I-mRNA als auch postsynaptisch lokalisiertes MHC-Klasse-IProtein durch neuronale Aktivität reguliert werden, vermuten die Autoren, dass MHCKlasse-I-Moleküle präsynaptische Funktionen mit postsynaptischer Aktivität verbinden und damit die Kommunikation zwischen beiden Seiten der Synapse koordinieren könnten (Goddard et al., 2007).

Zusammenfassend zeigt sich auf Grund der Ergebnisse der bisherigen Studien, dass für MHC-Klasse-I-Moleküle eine Rolle in aktivitätsabhängiger synaptischer Plastizität sehr wahrscheinlich ist und damit neben der immunologischen Funktion von MHC-Klasse-IMolekülen eine weitere Funktion im zentralen Nervensystem vorliegt.

\subsubsection{MHC-Klasse-I-Moleküle und neurodegenerative Krankheiten}

Die Degeneration von Neuronen unter pathologischen Bedingungen ist ein Charakteristikum einer Vielzahl neurologischer Erkrankungen. Beispiele neurodegenerativer Krankheiten sind Amyotrophe Lateralsklerose (ALS), Morbus Parkinson und Morbus Alzheimer, aber auch Multiple Sklerose (Olsson et al., 2005).

Es wird vermutet, dass genetische Heterogenität und Polymorphismus verschiedener Gene die Anfälligkeit oder den Verlauf neurologischer Erkrankungen im ZNS beeinflusst (Olsson et al., 2005).

In diesem Zusammenhang sind bestimmte Kombinationen von klassischen MHC-Klasse-IGenen mit inhibitorischen oder aktivierenden hochpolymorphen KIR-Genen und der Anfälligkeit verschiedener Krankheiten (Infektionen, Tumore, Autoimmunkrankheiten) im Menschen bekannt (Rajagopalan und Long, 2005; Parham, 2005). Die Assoziation von MHC-Klasse-I-Genen mit autoimmunen Bedingungen oder Resistenzen gegenüber Infektionen ist aus dem Immunsystem bekannt (Kelley et al., 2005a).

Neben der Beteiligung von MHC-Klasse-I-Molekülen an der synaptischen Plastizität sind auch erhöhte Anfälligkeiten für neurodegenerative Krankheiten aufgrund eines bestimmten MHC-Klasse-I-Genotyps nicht auszuschließen. So vermuten Linda et al. (1998), dass die MHC-Klasse-I-Moleküle auf Motorneuronen Peptidantigene zytotoxischen T-Zellen 
präsentieren und dadurch für die resultierende Schädigung der Neuronen bei neurodegenerativen Krankheiten wie ALS verantwortlich sein könnten. In diesem Zusammenhang wird ein Einfluss der allelischen Diversität der MHC-Klasse-I-Moleküle nicht ausgeschlossen (Linda et al., 1998).

\subsection{Zielsetzung der Arbeit}

Eine Beteiligung von MHC-Klasse-I-Molekülen an der synaptischen Plastizität wurde anhand von Untersuchungen an der Ratte, Maus und Katze gezeigt (Corriveau et al., 1998; Huh et al., 2000; Oliveira et al., 2004; Goddard et al., 2007). Dabei wurden distinkte Neuronengruppe gefunden, die MHC-Klasse-I-mRNA und -Moleküle exprimieren. Anhand von genetisch modifizierten Mäusen und Blockaden von Aktionspotentialen konnte eine Beteiligung von MHC-Klasse-I-Molekülen an aktivitäts-abhängigen Prozessen nachgewiesen werden und damit eine weitere Rolle für die aus der Antigenpräsentation im Immunsystem bekannten Moleküle gezeigt werden.

Der Weißbüschelaffe (Callithrix jacchus) als Vertreter der Neuwelt- oder Breitnasenaffen (Platyrrhini) gehört der Familie der Krallenaffen (Callitrichidae) an. Im Gegensatz zu Menschen, Menschenaffen und Altweltaffen, sind die MHC-Klasse-I-Gene der Neuweltaffen wenig charakterisiert. Im Weißbüschelaffen sind bisher nur drei Typen von MHC-Klasse-I-Genen identifiziert, Caja-G-, Caja-E- und Caja-F-Gene (Cadavid et al., 1997). Während Caja-E und Caja-F jeweils eindeutig orthologe Gene der menschlichen $H L A-E$ bzw. HLA-F-Gene sind, ist eine orthologe Beziehung zwischen Caja-G und HLA-G zweifelhaft (Adams und Parham, 2001). Entsprechend zu mRNA- und Proteinexpressionsdaten gelten die $M H C-G$-Gene der Neuweltaffen als MHC-Klasse-IaGene, wohingegen $M H C-E$ und $M H C-F$ den MHC-Klasse-Ib-Gene zugeordnet werden (Watkins, 1990a, b; Watkins, 1995).

Aufgrund der dem Menschen ähnlichen Physiologie werden C. jacchus häufig für vorklinische Studien (Hibino et al., 1999) und als nicht-humanes Primatenmodel für Studien über Infektionen und autoimmune Krankheiten, aber auch in der neurobiologischen Forschung eingesetzt (Genain und Hauser, 2001; 't Hart et al., 2004; Abbott et al., 2003).

Des Weiteren wurden Untersuchungen am Spitzhörnchen T. belangeri durchgeführt. Tupaia gehören zur Ordnung der Scandentia (Spitzhörnchen) und sind geeignete Tiermodelle in der Neurobiologie, z. B. der Stressforschung (Fuchs und Flügge, 2001; 
Fuchs et al., 2001). Aufgrund der langjährigen Verwendung von Tupaia in der Forschung sind die Gehirnstrukturen sehr gut bekannt. Auch stehen Daten zur MHC-Klasse-IExpression im Gehirn von Tupaia zur Verfügung (Flügge et al., 2002).

Da die Anzahl der MHC-Gene zwischen verschiedenen Spezies aufgrund einer sehr dynamischen Evolution stark variieren kann (Kelley et al., 2005b), erscheinen Zusammenhänge zwischen der MHC-Klasse-I-Expression und beispielsweise neurodegenerativen Krankheiten möglich. Da sich Primaten in ihren Immungenen (MHCKlasse-I, KIR, LILR) zum Teil recht deutlich von anderen Spezies unterscheiden, können die Expressionsdaten aus der Maus, Ratte und Katze (Corriveau et al., 1998; Huh et al., 2000; Oliveira et al., 2004; Goddard et al., 2007) nicht ohne weiteres auf Primaten übertragen werden. Daher ergaben sich für die vorliegende Arbeit folgende Zielsetzungen.

i. Zunächst sollten Untersuchungen zur MHC-Klasse-I-Expression an Gehirnschnitten des Spitzhörnchen T. belangeri durchgeführt werden. Da zuvor die MHC-Klasse-I-Expression mittels Northern-Blot-Analyse in verschiedenen Gehirnarealen nicht gestresster T. belangeri beschrieben wurde (Flügge et al., 2002), sollte auf diesen Daten aufgebaut werden und ein detailliertes Expressionsprofil erstellt werden. Dabei standen die Lokalisation der MHC-KlasseI-Expression und die Zelltypbestimmung im Fokus. Abschließend sollte die MHCKlasse-I-Expression im Gehirn von T. belangeri und C. jacchus auf eventuelle Parallelen bzw. Muster hin verglichen werden.

ii. Da es sich bei den bisherigen Studien (Corriveau et al., 1998; Huh et al., 2000; Oliveira et al., 2004; Goddard et al., 2007) um Untersuchungen an Nagetieren handelt, war die Hauptfrage der vorliegenden Arbeit, ob die geschilderten neuronalen MHC-Klasse-I-Expressionsmuster auch im Gehirn eines nicht-humanen Primaten (C. jacchus) wiederzufinden sind. Dazu sollten an Gehirnschnitten des $C$. jacchus Untersuchungen zur MHC-Klasse-I-mRNA- und -Proteinexpression durchgeführt werden.

iii. Es sollten grundlegende Erkenntnisse zur MHC-Klasse-I-Expression im Gehirn von C. jacchus ermittelt werden; diese sind notwendige Vorraussetzung für zukünftige Untersuchungen an diesen Tieren.

iv. Nachdem an unbehandelten C. jacchus eine MHC-Klasse-I-Expression auf verschiedenen Neuronengruppen festgestellt werden konnte, sollte untersucht werden, ob es im Gehirn durch immunsupprimierende Behandlung zur Beeinflussung der MHC-Klasse-I-Expression kommt. 


\section{Untersuchte Tiere und Material}

\subsection{Untersuchte Tiere}

Für die Experimente in dieser Arbeit wurden Callithrix jacchus (Weißbüschelaffe) und Tupaia belangeri (Spitzhörnchen) verwendet. Der Weißbüschelaffe als Vertreter der Neuwelt- oder Breitnasenaffen (Platyrrhini) gehört der Familie der Krallenaffen (Callitrichidae) an. Die Spitzhörnchen gehören der Ordnung der Scandentia an. Alle Tierversuche wurden entsprechend dem Tierschutzgesetz durchgeführt und waren von der Bezirksregierung Braunschweig genehmigt.

\section{Experimente mit Tupaia belangeri}

Zunächst wurde in dieser Arbeit die Expression von MHC-Klasse-I-Genen im Gehirn von T. belangeri untersucht. Dies sollte einerseits der Etablierung von Methoden dienen, andererseits die Möglichkeit bieten, eventuelle Unterschiede in der Expression von MHCKlasse-I-Genen zwischen den Arten zu finden. Für Untersuchungen an T. belangeri wurde Material aus früheren Experimenten von der FG Klinische Neurobiologie, DPZ, bereitgestellt. Zur Verfügung standen Gefrierschnitte von unperfundierten Tieren (männlich, adult) für die In-situ-Hybridisierung, ebenso wie schwimmende Schnitte eines PFA-perfundierten Tieres für immunhistologische Untersuchungen.

\section{Experimente mit Callithrix jacchus}

Die Untersuchungen zur Expression von MHC-Klasse-I-Genen im Gehirn von C. jacchus wurden zunächst an experimentell unbehandelten Tieren durchgeführt (Tab. 2.1). Die dabei erzielten Ergebnisse dienten der allgemeinen Beschreibung und um einen Überblick über die MHC-Klasse-I-Expression zu erhalten. Außerdem wurden diese Daten für Vergleichszwecke herangezogen. Im weiteren Verlauf der Arbeit wurden Untersuchungen auch an experimentell behandelten Tieren durchgeführt. Dabei wurde von der FG Klinische Neurobiologie, DPZ, Material von zwei Tieren zur Verfügung gestellt, die mit FK506 (Tacrolimus) immunsupprimiert wurden (Tab. 2.1). 
Tab. 2.1: Untersuchte $C$. jacchus.

(IS: Immunsupprimiert; ISH: In-situ-Hybridisierung; IHC: Immunhistologie)

\begin{tabular}{|c|c|c|c|c|}
\hline Bezeichnung & Behandlung & Verwendung & $\begin{array}{l}\text { Alter } \\
\text { (Monate) }\end{array}$ & Geschlecht \\
\hline $\mathbf{A}$ & - & ISH & 22 & $\hat{0}$ \\
\hline $\mathbf{B}$ & - & ISH & 32 & $\hat{0}$ \\
\hline $\mathbf{C}$ & - & ISH & 33 & $\hat{0}$ \\
\hline D & - & Extraktion RNA/Protein & 22 & $\hat{0}$ \\
\hline $\mathbf{E}$ & - & IHC & 129 & o \\
\hline $\mathbf{F}$ & - & IHC & 26 & $\hat{0}$ \\
\hline $\mathbf{G}$ & IS & IHC & 75 & $\hat{0}$ \\
\hline $\mathbf{H}$ & IS & IHC & 72 & $\hat{0}$ \\
\hline
\end{tabular}

C. jacchus - unbehandelte Tiere

Für molekulargenetische Untersuchungen und In-situ-Hybridisierungen (ISH) wurden unbehandelte $C$. jacchus mit einer Überdosis Ketamin $(50 \mathrm{mg} / \mathrm{ml})$, Xylazin $(10 \mathrm{mg} / \mathrm{ml})$ und Atropin $(0.1 \mathrm{mg} / \mathrm{ml})$ eingeschläfert. Nach Eintritt des Todes wurden die Organe entnommen und in flüssigem Stickstoff tiefgefroren. Organe, die später am Kryostaten geschnitten werden sollten, wurden dagegen sofort mit der Schnittfläche auf Einbettmedium gebettet, um später das Aufblocken zu erleichtern.

Für immunhistologische Untersuchungen wurde Material von der FG Klinische Neurobiologie, DPZ, von unbehandelten Kontrolltieren bereitgestellt. Die Tiere wurden ebenfalls mit einer Überdosis Ketamin $(50 \mathrm{mg} / \mathrm{ml})$, Xylazin $(10 \mathrm{mg} / \mathrm{ml})$ und Atropin $(0,1$ $\mathrm{mg} / \mathrm{ml}$ ) eingeschläfert. Anschließend wurden die Tiere mit $0.9 \%$ Kochsalzlösung, gefolgt von $200 \mathrm{ml}$ Fixierlösung für 15 min perfundiert. Die entnommenen Organe wurden über Nacht in der Fixierlösung fixiert und danach in 0,1 M PBS (pH 7,2), 30 \% Saccharose und $10 \%$ Glycerol bei $-80{ }^{\circ} \mathrm{C}$ gelagert.

C. jacchus - immunsupprimierte Tiere

Durch Überlassung von Probenmaterial von der FG Klinische Neurobiologie, DPZ (Dr. B. Czéh) konnten Untersuchungen an immunsupprimierten $C$. jacchus durchgeführt werden. In dieser Arbeit konnte auf in PBS schwimmende Schnitte für immunhistologische Untersuchungen zurückgegriffen werden. Die nachfolgend beschriebene Immunsuppression und FK506-Messungen wurden von Dr. C. Schlumbohm am DPZ und Prof. Dr. V.W. Armstrong am Universitätsklinikum Göttingen durchgeführt. Die Präparation der Tiere wurde von Dr. B. Czéh am DPZ durchgeführt.

Zwei Tiere wurden mit dem Immunsuppressivum FK506 behandelt. FK506 wird in der Leber vom Cytochrome-P450-System umgesetzt. Da C. jacchus eine hohe Verstoffwechselung dieser Substanz zeigt, wurde zuvor die FK506-Blutkonzentration 
bestimmt, die einen stabilen immmunsupprimierenden Effekt darstellt. In einem Pilotprojekt wurden ansteigende FK506-Konzentrationen $(0,2 ; 0,4 ; 2,0 ; 4,0$ und 5,0 $\mathrm{mg} / \mathrm{kg} / \mathrm{Tag}$ ) oral verabreicht und FK506-Konzentrationen im Blut durch hochspezifische Massenspektrometrie (Streit et al., 2002) quantifiziert. Die Dosis von $5 \mathrm{mg} / \mathrm{kg} / \mathrm{Tag}$ wurde für ausreichend immunsupprimierend befunden (Blutkonzentration zwischen 10 und 15 $\mu 1 / 1)$. Diese Konzentration entspricht der therapeutischen Konzentration zu Beginn der Post-Transplantationsphase zur Prophylaxe gegen akute Abstoßungsreaktionen bei Nierenund Lebertransplantationen (Armstrong und Oellerich, 2001). Den Tieren wurde die Dosis 39 Tage in zwei Rationen (morgens und abends) oral verabreicht. Anschließend wurden die Tiere wie oben beschrieben perfundiert.

\subsection{Verwendete Geräte}

Tab. 2.2: Verwendete Geräte

\begin{tabular}{|c|c|c|}
\hline Geräte & Modell & Hersteller/Bezugsquelle \\
\hline Autoklav & Varioklav® 400E & $\mathrm{H}+\mathrm{P}$ Labortechnik \\
\hline Backofen & & Heraeus \\
\hline Blotter, Semi-Dry & V20-SDB & Roth \\
\hline Brutschrank Platten & & Heraeus \\
\hline Brutschrank Schüttler & 3033 & GFL \\
\hline Drehrad & Testtube Rotator & GLW \\
\hline Durchflusszytometer & FACScan & Becton Dickinson \\
\hline Eisschrank $-80^{\circ} \mathrm{C}$ & $\mathrm{U} 725$ & NB Scientific \\
\hline Eisschrank $-20^{\circ} \mathrm{C}$ & Premium & Liebherr \\
\hline Elektrogerät & Standard Power Pack P25 & Biometra \\
\hline Elektrophoresekammer (DNA) & Horizon 58 & GibcoBRL \\
\hline Elektrophoresekammer (Protein) & & PeqLab \\
\hline Elektroporationsgerät & Gene Pulser II & BioRad \\
\hline Entwicklermaschine & M 35 X-OMAT Processor & Kodak \\
\hline Feinwaage & BP $310 \mathrm{~S}$ & Sartorius \\
\hline Filmkassetten & Cronex-Kassette & DuPont de Nemours \\
\hline Folienschweißgerät & Vakuumpack & Krupps \\
\hline Gel-Dokumentation & Gel Jet Imager 2000 & Intas \\
\hline Handmessgerät & LB122 & Barthold \\
\hline Heizblock & Thermomixer comfort & Eppendorf \\
\hline Heizblock Liebisch & M32 & GLW \\
\hline Hybridisierungsofen & 430 & Bachofer \\
\hline Konfokales Mikroskop & LSM 5 Pascal & Zeiss \\
\hline
\end{tabular}




\begin{tabular}{|c|c|c|}
\hline Kryostat & CM3050 & Leica \\
\hline Kühlschrank $4^{\circ} \mathrm{C}$ & Profi Line & Liebherr \\
\hline Lichtmikroskop & Axiophot II microscope & Zeiss \\
\hline Magnetrührer & MR $3001 \mathrm{~K}$ & Heidolph \\
\hline Mikrowelle & Micromat & AEG \\
\hline PCR-Zykler & GeneAmp PCR System 2700 & Applied Biosystems \\
\hline pH-Meter & pH 535 Multi Cal@ & WTW \\
\hline Photometer & Gene Quant II & Pharmacia Biotech \\
\hline Pipetten & $\begin{array}{l}\text { Reference } 10 \mu \mathrm{l} \\
\text { Reference } 100 \mu \mathrm{l} \\
\text { Reference } 1000 \mu \mathrm{l}\end{array}$ & Eppendorf \\
\hline Schüttler & Titramax 1000 & Heidolph \\
\hline Sequenzierer & ABI 3100-Avant & Applied Biosystems \\
\hline Sterilbank & Kojair & Bio-Flow Technik \\
\hline Szintillationsmessgerät & $\begin{array}{l}\text { Liquid-Szintillation Counter } \\
1414\end{array}$ & Wallac \\
\hline Vakuumtrockner & Speedvac & Helmut Saur, Laborbedarf \\
\hline Vortexer & L46 & GLW \\
\hline Wasserbad & 1083 & GFL \\
\hline Zentrifugen & $\begin{array}{l}\text { Centrifuge } 5810 \mathrm{R} \\
\text { Centrifuge } 5414 \mathrm{R} \\
\text { Multifuge } 1 \mathrm{~S}-\mathrm{W}\end{array}$ & $\begin{array}{l}\text { Eppendorf } \\
\text { Heraeus }\end{array}$ \\
\hline Zentrifugenrotoren & $\begin{array}{l}\text { F } 45-24-11 \\
\text { A-4-62 } \\
75002000\end{array}$ & $\begin{array}{l}\text { Eppendorf } \\
\text { Heraeus }\end{array}$ \\
\hline
\end{tabular}

\subsection{Verwendete Verbrauchsmaterialien}

Tab. 2.3: Verwendete Verbrauchsmaterialien

\begin{tabular}{l|l} 
Produkt & Hersteller/Bezugsquelle \\
\hline DakoCytomation Pen & DakoCytomation \\
\hline Deckgläschen & Menzel-Gläser \\
\hline Elektroporationsküvette & Biozym \\
\hline Falcon-Röhrchen $15 \mathrm{ml}, 50 \mathrm{ml}$ & CELLSTAR® \\
\hline Filter & Satorius \\
\hline GelBond ${ }^{\circledR}$ Film & Bio Whittaker Molecular Applications \\
\hline Hybond-N+ Nylon Transfer Membrane & Amersham \\
\hline Hyperfilm ECL & Amersham \\
\hline Hyperfilm & AM \\
High performance autoradiography film & Amersham \\
\hline
\end{tabular}




\begin{tabular}{l|l} 
Kimwipes Präzisionswischtücher & Kimberlay-Clark \\
\hline Objektträger & Marienfeld, Laboratory Glassware \\
\hline Petrischalen & Greiner \\
\hline Pipettenspitzen $100 \mu \mathrm{l}, 1000 \mu \mathrm{l}$ & Sarstedt \\
\hline Pipettenspitzen $2,5 \mu \mathrm{l}, 20 \mu \mathrm{l}$ & Biozym \\
\hline Plastik-Röhrchen, $12 \mathrm{ml}$ & Greiner \\
\hline Quarz-Küvette & Hellma \\
\hline Reaktionsgefäße, 0,5 ml, 1,5 ml, $2 \mathrm{ml}$ & Sarstedt \\
\hline Röntgenfilm, BIO-MAX MR film & Amersham \\
\hline Whatmanpapier GB 002, GB 005 & Schleicher \& Schuell \\
\hline
\end{tabular}

\subsection{Verwendete Chemikalien \\ 2.4 Verwendete Chemikalien}

Tab. 2.4: Verwendete Chemikalien

Chemikalien

\begin{tabular}{|c|c|}
\hline$\left[{ }^{33} \mathrm{P}\right] \mathrm{dUTP}$ & MP Biomedicals \\
\hline Aceton & Roth \\
\hline Agar & Roth \\
\hline Agarose & Cambrex (Biozym) \\
\hline Ammoniumacetat & Merck \\
\hline Ammoniumchlorid & Merck \\
\hline Ammoniumpersulfat & Sigma \\
\hline Ampicillin, & Sigma \\
\hline Borsäure & Roth \\
\hline Bromphenolblau & Sigma \\
\hline BSA & Sigma \\
\hline Chloroform & J. T. Baker \\
\hline Chloroform:Isoamylalkohol (49:1) & Sigma \\
\hline D19 Entwickler & Kodak \\
\hline DEPC & Roth \\
\hline Desoxycholat & Sigma \\
\hline Dextransulfat & Pharmacia \\
\hline Dimethylformamid & Roth \\
\hline Dinatriumhydrogenphosphat & Roth \\
\hline di-Natriumtetraborat & Merck \\
\hline DTT & Sigma \\
\hline EDTA & Sigma \\
\hline Eisessig & Roth \\
\hline Entwickler & Kodak \\
\hline
\end{tabular}

\section{Hersteller/Bezugsquelle}

MP Biomedicals

Cambrex (Biozym)

Sigma

Sigma 


\begin{tabular}{|c|c|}
\hline Essigsäureanhydrid & Merck \\
\hline Ethanol, rein & Roth \\
\hline Ethanol, vergällt & Roth \\
\hline Ethidiumbromid & Roth \\
\hline Eukitt & Fluka \\
\hline Ficoll 400 & Sigma \\
\hline Fixierer Polymax & Kodak \\
\hline Formaldehyd & Roth \\
\hline Formamid & Roth \\
\hline Glukose & Sigma \\
\hline Glycerin & J.T. Baker \\
\hline Guanidinthiocyanat & Roth \\
\hline Hefeextrakt & Roth \\
\hline Hepes & Roth \\
\hline HiDi $^{\mathrm{TM}}$ Formamid & Applied Biosystems \\
\hline IGEPAL CA-630 & Sigma \\
\hline IPGT & Roth \\
\hline Isoamylalkohol & Merck \\
\hline Isopropanol & Roth \\
\hline Kaliumacetat & Roth \\
\hline Kaliumchlorid & Merck \\
\hline Kaliumhydrogencarbonat & Merck \\
\hline Kaliumhydrogenphosphat & Merck \\
\hline Lauroylsarcosin & Sigma \\
\hline Levamisol & Fluka \\
\hline Lithiumchlorid & Roth \\
\hline Luminol & Fluka \\
\hline Magnesiumchlorid & Merck \\
\hline Magnesiumsulfat & Merck \\
\hline Methanol & Merck \\
\hline Milchpulver & DE-VAU-GE Gesundkostwerk \\
\hline MOPS (3-(N-Morpholino)-propansulfonsäure) & Roth \\
\hline Mounting medium & DAKO \\
\hline N, N-Dimethylformamid & Sigma \\
\hline Natriumacetat & Roth \\
\hline Natriumazid & Serva \\
\hline Natriumchlorid & Roth \\
\hline Natriumcitrat & Roth \\
\hline Natrium-Desoxycholat & Sigma \\
\hline Natriumdodecylsulfat & Roth \\
\hline
\end{tabular}




\begin{tabular}{|c|c|}
\hline Natriumhydroxid & Roth \\
\hline Natriumjodid & Roth \\
\hline NP40 & Sigma \\
\hline Paraformaldehyd & Merck \\
\hline p-Cumarsäure & Sigma \\
\hline Phenol & Roth \\
\hline Polyacrylamidstammlösung 33\% & Roth \\
\hline Polyvinylpyrrolidon & Sigma \\
\hline Ponceau-S & Sigma \\
\hline Saccharose & Merck \\
\hline Salzsäure & Roth \\
\hline Silica & Sigma \\
\hline B-Mercaptoethanol & Sigma \\
\hline Stickstoff, flüssig & Vesper \\
\hline TEMED & Fluka \\
\hline Toluidinblau-O & Sigma \\
\hline Triethanolamin & Merck \\
\hline Tris & Roth \\
\hline Triton-X-100 & Sigma \\
\hline Trypanblau & PAA \\
\hline Trypton / Pepton & Roth \\
\hline Tween 20 & Sigma \\
\hline Unifix Fixierer Emulsion & Kodak \\
\hline Wasser (HPLC-Qualität) & Merck \\
\hline Wasserstoffperoxid, $30 \%$ & Roth \\
\hline $\mathrm{X}-\mathrm{Gal}$ & Roth \\
\hline Xylol & Roth \\
\hline
\end{tabular}

\subsection{Verwendete Enzyme}

Tab. 2.5: Verwendete Enzyme

\begin{tabular}{l|l} 
Produkt & Hersteller/Bezugsquelle \\
\hline BamHI & New England Biolabs \\
\hline DNaseI & Promega \\
\hline EcoRI & New England Biolabs \\
\hline HindIII & New England Biolabs \\
\hline Reverse Transkriptase & Promega \\
\hline Rnase A & Roche \\
\hline RNasin & Promega \\
\hline SP6-RNA-Polymerase & Promega \\
\hline
\end{tabular}




\begin{tabular}{l|l} 
T4-DNA-Ligase & New England Biolabs \\
\hline T7-RNA-Polymerase & Promega \\
\hline Taq-DNA-Polymerase & Genecraft \\
\hline
\end{tabular}

\subsection{Verwendete Kits und sonstige Substanzen}

Tab. 2.6: Verwendete Kits und sonstige Substanzen

\begin{tabular}{|c|c|}
\hline 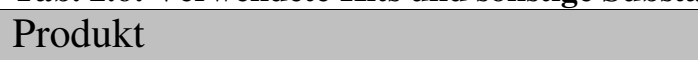 & Hersteller/Bezugsquelle \\
\hline BigDye ${ }^{\circledR}$ Terminator v 1.1 Cycle Sequencing Kit & Applied Biosystems \\
\hline Bio-Rad DC Protein Assay & Bio-Rad Laboratories \\
\hline dNTPs & Invitrogen \\
\hline Einbettmedium Tissue tek $^{\circledR}$ & Sakura Finetek \\
\hline Eindeckmedium (mounting medium) & DAKO \\
\hline FK506 (Prograf) & Fujisawa \\
\hline Heringssperma-DNA & Invitrogen \\
\hline Micro Spin Columns S-400HR & Amersham \\
\hline NBT2 Autoradiographieemulsion & Kodak \\
\hline Normales Schafserum & Vector Laboratories \\
\hline Normales Ziegenserum & Vector Laboratories \\
\hline Nucleo Spin Extract Kit & Machery-Nagel \\
\hline Nukleotide removal Kit & Amersham \\
\hline Oligo $(\mathrm{dT})_{12-18}$ Primer & Invitrogen \\
\hline pDrive Cloning kit & Qiagen \\
\hline Peroxidase Substrate Kit DAB SK-4100 & Vector Laboratories \\
\hline Protein-G Sepharose 4 Fast flow & Amersham \\
\hline Protein-G-Sepharose 4 Fast flow & Amersham \\
\hline QIAquick $^{\circledR}$ Gel Extraction Kit & Qiagen \\
\hline QIAquick ${ }^{\circledR}$ Plasmid Midi Kit & Qiagen \\
\hline Riboprobe In Vitro Transcription System & Promega \\
\hline Szintillationslösung (HiSafe 3) & PerkinElmer \\
\hline tRNA & Promega \\
\hline Vectastain ${ }^{\circledR}$ Elite ABC-Kit & Vector Laboratories \\
\hline
\end{tabular}




\subsection{Verwendeter Bakterienstamm}

Tab. 2.7: Verwendeter Bakterienstamm

\begin{tabular}{l|l} 
Produkt & Hersteller/Bezugsquelle \\
\hline Escherichia coli $\mathrm{TOP} 10$ & Invitrogen \\
$\left(\mathrm{F}^{-}\right.$mcrA $\Delta($ mrr-hsdRMS-mcrBC) $\quad$ 80/acZ $\Delta \mathrm{M} 15 \quad \Delta / a c X 74 \quad$ recA1 & \\
araD139 $\Delta($ araleu $) 7697$ gaN galK rpsL $\left(\mathrm{Str}^{\mathrm{R}}\right)$ endA1 nupG) &
\end{tabular}

\subsection{Verwendete Antikörper}

Tab. 2.8: Verwendete Antikörper

\begin{tabular}{l|l} 
Produkt & Hersteller/Bezugsquelle \\
\hline $\begin{array}{l}\text { Esel-anti-Maus-IgG-Sekundärantikörper } \\
\text { (Alexa Fluor }{ }^{\circledR} \text { 594) }\end{array}$ & Invitrogen \\
\hline $\begin{array}{l}\text { HB115 (monoklonal Maus-anti-Human-MHC-Klasse I, } \\
\text { Hybridomüberstand) }\end{array}$ & $\begin{array}{l}\text { Prof. Dr. Johnson, Institut für Immunologie, } \\
\text { München }\end{array}$ \\
\hline $\begin{array}{l}\text { HC-10 (monoklonal anti-human-MHC-Klasse-I; } \\
\text { Hybridomüberstand }\end{array}$ & Prof. Dr. Ziegler, Charité, Berlin \\
\hline $\begin{array}{l}\text { Meerrettich-Peroxidase-gekoppelter Ziege-Anti-Maus } \\
\text { Sekundärantikörper }\end{array}$ & Santa Cruz Biotechnology \\
\hline $\begin{array}{l}\text { Ox-18 ( monoklonal Maus-anti-Ratte-MHC-Klasse I) } \\
\text { TH (polyklonal Kaninchen-anti-Human, Ratten- und } \\
\text { Maus-Tyrosinhydroxylase) }\end{array}$ & Serotec \\
\hline $\begin{array}{l}\text { Tü149 (monoklonaler anti-human-MHC-Klasse-I; } \\
\text { Hybridomüberstand }\end{array}$ & Prof. Dr. Ziegler, Charité, Berlin \\
\hline $\begin{array}{l}\text { Ziege-anti-Kaninchen-IgG- Sekundärantikörper } \\
\text { (Alexa Fluor }{ }^{\circledR} \text { 488) }\end{array}$ & Invitrogen \\
\hline $\begin{array}{l}\text { Ziege-anti-Maus-IgG-Antikörper, FITC-gebunden } \\
\text { Ziege-anti-Maus-Ig-Sekundärantikörper, biotinyliert }\end{array}$ & Vector Laboratories \\
\hline
\end{tabular}

\subsection{Verwendete Puffer, Lösungen und Medien}

Tab. 2.9: Verwendete Puffer, Lösung und Medien

\begin{tabular}{l|l} 
Bezeichnung & Zusammensetzung \\
\hline $1 \mathrm{x}$ TBS & $\begin{array}{l}8,5 \mathrm{~g} \mathrm{NaCl}, 20 \mathrm{ml} \mathrm{1} \mathrm{M} \mathrm{Tris/HCL}(\mathrm{pH} 7,2) \\
\mathrm{ad} 1000 \mathrm{ml} \mathrm{H}_{2} \mathrm{O}\end{array}$ \\
\hline $4 \%$ PFA & $10 \mathrm{~g}$ Paraformaldehyd \\
\hline
\end{tabular}




\begin{tabular}{|c|c|}
\hline & $\begin{array}{l}\text { ad } 250 \mathrm{ml} 1 \mathrm{x} \text { PBS } \\
\mathrm{pH} 7,0 \text { einstellen, filtrieren }\end{array}$ \\
\hline $4 \mathrm{x}$ Tris/SDS $(\mathrm{pH} 6,8)$ & $\begin{array}{l}\text { 6,05 g Tris, } 4 \mathrm{~g} \text { SDS } \\
\text { ad } 100 \mathrm{ml} \mathrm{H}_{2} \mathrm{O}, \mathrm{pH} 6,8 \text { einstellen }\end{array}$ \\
\hline $4 \mathrm{x}$ Tris/SDS $(\mathrm{pH} 8,8)$ & $\begin{array}{l}\text { 45,5 g Tris, } 1 \mathrm{~g} \text { SDS } \\
\text { ad } 250 \mathrm{ml} \mathrm{H}_{2} \mathrm{O}, \mathrm{pH} 8,8 \text { einstellen }\end{array}$ \\
\hline Acetylierungslösung & $\begin{array}{l}\text { 3,35 ml Triethanolamin-HCl, } 625 \mu \text { l Essigsäureanhydrid } \\
\text { ad } 250 \mathrm{ml} \text { DEPC- } \mathrm{H}_{2} \mathrm{O}, \mathrm{pH} 8,0\end{array}$ \\
\hline ACG-Mix & $\begin{array}{l}10 \mu 1 \text { ATP }(10 \mathrm{mM}) \\
10 \mu 1 \text { CTP }(10 \mathrm{mM}) \\
10 \mu 1 \text { GTP }(10 \mathrm{mM}) \\
10 \mu 1 \text { steriles } \mathrm{H}_{2} \mathrm{O}\end{array}$ \\
\hline Blocklösung (Westernblot) & $\begin{array}{l}5 \%(\mathrm{w} / \mathrm{v}) \text { Magermilchpulver, } 0,05 \% \text { Tween } 20 \text {, in } 1 \mathrm{x} \text { TBS } \\
\text { filtrieren }\end{array}$ \\
\hline Blockpuffer (Immunhistochemie) & $\begin{array}{l}3 \% \text { Normales Ziegenserum, } 0,25 \% \text { Triton } \mathrm{X}-100 \\
\text { in 1x PBS }\end{array}$ \\
\hline BT-Puffer & $\begin{array}{l}10 \%(\mathrm{w} / \mathrm{v}) \mathrm{BSA}, 7 \%(\mathrm{w} / \mathrm{v}) \text { Triton X-100 } \\
\text { steril filtriert }\end{array}$ \\
\hline Denhardt's-Lösung $(50 \mathrm{x})$ & $\begin{array}{l}5 \text { g Ficoll 400, } 5 \text { g Polyvinylpyrrolidon, } 5 \text { g BSA } \\
\text { ad } 500 \mathrm{ml} \mathrm{H}_{2} \mathrm{O}\end{array}$ \\
\hline DEPC-H2O & $\begin{array}{l}0,1 \% \text { DEPC-Lösung }(97 \%) \\
\text { autoklaviert }\end{array}$ \\
\hline ECL-Lösung I &  \\
\hline ECL-Lösung II & $6 \mu \mathrm{l} \mathrm{H}_{2} \mathrm{O}_{2}(30 \%), 1 \mathrm{ml} 1 \mathrm{M}$ Tris/HCL (pH 8,5), $9 \mathrm{ml} \mathrm{ddH_{2 } \mathrm { O }}$ \\
\hline $\begin{array}{l}\text { Elektrophoresepuffer }(5 \mathrm{x}) \\
\text { (Proteingel) }\end{array}$ & $\begin{array}{l}\text { 15,1 g Tris, } 94 \mathrm{~g} \text { Glycine, 5\% (v/v) SDS (10\%), } \\
\text { ad } 1000 \mathrm{ml} \mathrm{H}_{2} \mathrm{O}\end{array}$ \\
\hline Elutionspuffer & $1 \%$ SDS, $100 \mathrm{mM}$ DTT, $50 \mathrm{mM}$ Tris/HCL $(\mathrm{pH} 7,5)$ \\
\hline Fixierlösung & 4\% Paraformaldehyd in 0,1 M Natrium-Phosphatpuffer $(\mathrm{pH} 7,2)$ \\
\hline Hybridisierungspuffer & $\begin{array}{l}20 \mu \mathrm{l} 0,5 \mathrm{M} \text { EDTA } \\
100 \mu \mathrm{l} 1 \mathrm{M} \text { Tris pH } 8,0 \\
600 \mu \mathrm{l} 5 \mathrm{M} \mathrm{NaCl} \\
200 \mu 150 \times \text { Denhardt's } \\
2000 \mu 150 \% \text { Dextransulfat } \\
500 \mu 110 \mu \mathrm{g} / \mu 1 \text { tRNA } \\
1000 \mu \mathrm{l} \text { DTT } \\
5000 \mu \mathrm{l} \text { Formamid } \\
580 \mu \mathrm{l} \text { H2O }\end{array}$ \\
\hline KMT-Puffer & $\begin{array}{l}1 \% 1 \mathrm{M} \mathrm{MgCl}_{2}, 10 \% 2,5 \mathrm{M} \mathrm{KCl}, 1,72 \% 1 \mathrm{M} \mathrm{HCl} \text {, } \\
4,4 \% 1 \mathrm{M} \text { Tris, steril filtriert }\end{array}$ \\
\hline Ladepuffer (DNA) & $66 \%(w / v)$ Saccharose, $0,004 \%$ (w/v) Bromphenolblau \\
\hline
\end{tabular}




\begin{tabular}{|c|c|c|c|}
\hline Laemmli-Puffer $(2 \mathrm{x})$ & \multicolumn{3}{|c|}{$\begin{array}{l}\text { 1,51 g Tris, } 4 \mathrm{~g} \text { SDS, } 5 \mathrm{~g} \text { Saccharose } \\
\text { ad } 80 \mathrm{ml} \mathrm{H} 2 \mathrm{O}, \mathrm{pH} 6,8 \text { einstellen } \\
30 \mathrm{mg} \text { Bromphenolblau } \\
\text { ad } 100 \mathrm{ml} \mathrm{H} 2 \mathrm{O} \text {, filtrieren }\end{array}$} \\
\hline $\begin{array}{l}\text { LB/Amp/IPTG/X-Gal- } \\
\text { Agarplatten }\end{array}$ & \multicolumn{3}{|c|}{$\begin{array}{l}\text { LB/Amp-Selektionsmedium, 1,5\% Agar-Agar, 0,1\% IPTG, } \\
0,2 \% \mathrm{X}-\mathrm{Gal}\end{array}$} \\
\hline LB/Amp-Agarplatten & \multicolumn{3}{|c|}{ LB/Amp-Selektionsmedium mit 1,5\% Agar-Agar } \\
\hline LB/Amp-Selektionsmedium & \multicolumn{3}{|c|}{ LB-Medium mit 0,1\% Ampicillin $(50 \mathrm{mg} / \mathrm{ml})$} \\
\hline LB-Medium & \multicolumn{3}{|c|}{$\begin{array}{l}1 \% \text { Trypton, } 0,5 \% \text { Hefeextrakt, } 1 \% \mathrm{NaCl} \\
\text { in } \mathrm{H}_{2} \mathrm{O} \text {, autoklaviert }\end{array}$} \\
\hline Lösung D & \multicolumn{3}{|c|}{$\begin{array}{l}\text { 94,5 g Guanidinthiocyanat, 2,5\% } 1 \mathrm{M} \text { Na-Citrat } \\
\text { ad } 200 \mathrm{ml} \text { DEPC- } \mathrm{H}_{2} \mathrm{O} \text {, vor Gebrauch Zugabe von } 360 \mu \mathrm{l} \\
\beta-\mathrm{ME} / 50 \mathrm{ml} \text { Lösung D }\end{array}$} \\
\hline Lysepuffer P2 & \multicolumn{3}{|c|}{$400 \mathrm{mM} \mathrm{NaOH}[1: 1] 2 \%$ SDS } \\
\hline MOPS-Puffer $(5 \mathrm{x})$ & \multicolumn{3}{|c|}{$\begin{array}{l}0,65 \%(\mathrm{w} / \mathrm{v}) \mathrm{NaAc}, 2 \%(\mathrm{w} / \mathrm{v}) \mathrm{MOPS} \text { in } \mathrm{H}_{2} \mathrm{O} \\
\mathrm{pH} 7,0 \text { einstellen } \\
10 \%(\mathrm{v} / \mathrm{v}) 0,5 \mathrm{M} \text { EDTA }(\mathrm{pH} 8,0)\end{array}$} \\
\hline Neutralisationspuffer P3 & \multicolumn{3}{|l|}{$3 \mathrm{M} \mathrm{KAc}(\mathrm{pH} 4,8)$} \\
\hline NTE-Puffer & \multicolumn{3}{|c|}{$\begin{array}{l}10 \% 5 \mathrm{M} \mathrm{NaCl}, 1 \% 1 \mathrm{M} \text { Tris/ } \mathrm{HCl}(\mathrm{pH} 8,0) \\
1 \% 0,5 \mathrm{M} \text { EDTA }(\mathrm{pH} 8,0)\end{array}$} \\
\hline PBS $(10 x)$ & \multicolumn{3}{|c|}{$\begin{array}{l}80 \mathrm{~g} \mathrm{NaCl}, 2 \mathrm{~g} \mathrm{KCl}, 15,4 \mathrm{~g} \mathrm{Na} 2 \mathrm{HPO} 4 \cdot 12 \mathrm{H} 2 \mathrm{O}, 2 \mathrm{~g} \mathrm{KH} 2 \mathrm{PO} 4 \\
\text { ad } 1000 \mathrm{ml} \mathrm{H} 2 \mathrm{O}\end{array}$} \\
\hline Resuspensionspuffer P1 & \multicolumn{3}{|c|}{$\begin{array}{l}2 \% \text { RNase A }(10 \mathrm{mg} / \mathrm{ml}), 50 \mathrm{mM} \text { Tris, } \\
1 \mathrm{mM} \text { EDTA }(\mathrm{pH} 8,0)\end{array}$} \\
\hline RIPA-Puffer & \multicolumn{3}{|c|}{$\begin{array}{l}1 \% \text { IGEPAL CA-630 }{ }^{\circledR}, 0,5 \% \text { Na-Deoxycholat, } 0,1 \% \text { SDS, } 1 \times \\
\text { PBS, Protease Inhibitor Cocktail Tablets (Roche }\end{array}$} \\
\hline Lagerungslösung für Gehirn & \multicolumn{3}{|c|}{$\begin{array}{l}\text { 0,1 M PBS; pH 7.2, } 30 \% \text { Saccharose und } 10 \% \text { Glycerol), } \\
\text { DEPC- }\end{array}$} \\
\hline SDS-Sammelgel (4\%) & \multicolumn{3}{|c|}{$\begin{array}{l}\text { 0,54 ml 30\% Polyacrylamid, } 1 \mathrm{ml} \mathrm{4x} \mathrm{Tris/SDS} \mathrm{(pH} \mathrm{6,8),} \\
2,46 \mathrm{ml} \mathrm{H}_{2} \mathrm{O}, 50 \mu 1 \text { 10\% APS, } 20 \mu 1 \text { TEMED }\end{array}$} \\
\hline SDS-Trenngel & $\begin{array}{l}30 \% \text { Polyacrylamid } \\
4 x \text { Tris/SDS }(\mathrm{pH} 8,8) \\
\mathrm{H}_{2} \mathrm{O} \\
10 \% \text { APS } \\
\text { TEMED }\end{array}$ & $\begin{array}{l}\underline{10 \%} \\
3,33 \mathrm{ml} \\
2,5 \mathrm{ml} \\
4,16 \mathrm{ml} \\
50 \mu \mathrm{l} \\
15 \mu \mathrm{l}\end{array}$ & $\begin{array}{l}\underline{12,5 \%} \\
4,17 \mathrm{ml} \\
2,5 \mathrm{ml} \\
3,33 \mathrm{ml} \\
50 \mu \mathrm{l} \\
15 \mu \mathrm{l}\end{array}$ \\
\hline TBST & $1 \times \mathrm{TBS}+0,05 \%$ Twe & & \\
\hline Transfer-Puffer & $\begin{array}{l}3 \mathrm{~g} \text { Tris, } 11,3 \mathrm{~g} \text { Glycir } \\
\text { ad } 1000 \mathrm{ml} \mathrm{H}_{2} \mathrm{O}\end{array}$ & Methanol & \\
\hline SSC $(20 x)$ & $\begin{array}{l}175,3 \mathrm{~g} \mathrm{NaCl}, 88,2 \mathrm{~g} \mathrm{I} \\
\text { ad } 1000 \mathrm{ml} \mathrm{H} \mathrm{O}_{2} \mathrm{pH} 7\end{array}$ & & \\
\hline
\end{tabular}




\begin{tabular}{l|l}
\hline TBE-Puffer $(10 \mathrm{x})$ & 1 M Tris, 0,8 M Borsäure, $10 \mathrm{mM}$ EDTA (pH 8,0)] \\
\hline TE-Puffer & $\begin{array}{l}10 \mathrm{mM} \text { Tris/HCL }(\mathrm{pH} 7,4), 1 \mathrm{mM} \text { EDTA }(\mathrm{pH} 8,0) \\
\text { in DEPC- } \mathrm{H}_{2} \mathrm{O}\end{array}$ \\
\hline
\end{tabular}

\subsection{Verwendete Marker}

Tab. 2.10: Verwendete Marker

\begin{tabular}{l|l} 
Produkt & Hersteller/Bezugsquelle
\end{tabular}

\begin{tabular}{l|l}
\hline GeneRuler 100bp DNA Ladder Plus & Fermentas \\
\hline Prestained Protein Ladder $\sim 10-160 \mathrm{kDa}$ & Fermentas \\
\hline
\end{tabular}

\subsection{Verwendete Vektoren}

Tab. 2.11: Verwendete Vektoren

\begin{tabular}{l|l} 
Produkt & Hersteller/Bezugsquelle \\
\hline pDrive Cloning & Qiagen \\
\hline pUC19 DNA & Fermentas \\
\hline
\end{tabular}

\subsection{Verwendete Datenbanken und Computerprogramme}

\section{Datenbanken:}

NCBI: http://www.ncbi.nlm.nih.gov/

IMGT/HLA Database: http://www.ebi.ac.uk/imgt/hla/stats.html

\section{Online-Programme:}

ClustalW: http://bioweb.pasteur.fr/seqanal/interfaces/clustalw-simple.html (Thompson et al., 1994)

Expasy Translate Tool: http://au.expasy.org/tools/dna.html

Reverse Complement: http://bioinformatics.org/sms/rev_comp.html

\section{Programme:}

AIS software (Imaging Systems)

Sequencing Analysis (Applied Biosystems) 


\section{Methoden}

\subsection{Molekularbiologische Methoden}

\subsubsection{RNA-Präparation}

Bei allen Arbeiten mit RNA wurde darauf geachtet, dass keine RNase-Kontaminationen auftraten. Alle Lösungen wurden daher mit sterilem oder DEPC-behandeltem Wasser angesetzt und anschließend autoklaviert. Glaswaren wurden bei $180{ }^{\circ} \mathrm{C}$ für $8 \mathrm{~h}$ gebacken. Plastikwaren, wie Spitzen und Reaktionsgefäße, die RNase-frei ausgeliefert wurden, konnten ohne Autoklavieren verwendet werden. Für die RNA-Extraktion aus Organen (Leber, Cerebellum, Hippocampus) wurden bis zu $400 \mathrm{mg}$ Gewebe unter Zufuhr von flüssigem Stickstoff zerkleinert, danach in 50-ml-Reaktionsgefäße überführt und $4 \mathrm{ml}$ Lösung D zugegeben. Daraufhin wurden sukzessiv zugegeben und geschüttelt: $400 \mu 12 \mathrm{M}$ Natriumacetat ( $\mathrm{pH} 4,0), 800 \mu$ l Chloroform:Isoamylalkohol (49:1) und $4 \mathrm{ml}$ Phenol. Die Mischung wurde $10 \mathrm{~s}$ auf dem Vortexer geschüttelt, danach 15 min auf Eis inkubiert und anschließend zentrifugiert (20 min, 1500 x g, $4{ }^{\circ} \mathrm{C}$ ). Aus dem entstandenen ZweiphasenGemisch wurde die obere Phase mit der darin enthaltenen RNA abgenommen und auf 1,5ml-Reaktionsgefäße verteilt. Zur Fällung der RNA wurde in jedes Reaktionsgefäß 1 Volumen Isopropanol gegeben und für $1 \mathrm{~h}$ bei $-20{ }^{\circ} \mathrm{C}$ eingefroren. Anschließend wurde die Lösung zentrifugiert (20 $\mathrm{min}, 18800 \mathrm{x} \mathrm{g}, 4{ }^{\circ} \mathrm{C}$ ). Das daraus resultierende RNA-Pellet wurde mit $500 \mu 175 \%$ Ethanol gewaschen, 5 min erneut zentrifugiert (5 min, $18800 \mathrm{x} \mathrm{g,} 4$ ${ }^{\circ} \mathrm{C}$ ) und in einem Vakuumtrockner getrocknet. Durch Zugabe von 30-50 $\mu 1 \mathrm{H}_{2} \mathrm{O}$ wurde das RNA-Pellet resuspendiert und bei $-80{ }^{\circ} \mathrm{C}$ bis zur weiteren Nutzung aufbewahrt.

\subsubsection{DNA/RNA-Konzentrationsbestimmungen}

Um DNA- und RNA-Konzentrationen zu ermitteln, wurden diese photometrisch gemessen. Dazu wurde ein Aliquot der Probe zu einem bestimmten Volumen $\mathrm{H}_{2} \mathrm{O}$ in eine Quarzküvette (Schichtdicke $10 \mathrm{~mm}$ ) gegeben. Die photometrische Bestimmung der Absorption erfolgte im Photometer bei einer Wellenlänge von $260 \mathrm{~nm}$. Durch folgende Formeln wurden die Konzentrationen berechnet:

\section{$[\mathrm{DNA}]=\underline{\mathrm{OD}}_{260}$ (optische Dichte bei $\left.260 \mathrm{~nm}\right) \times 50 \mu \mathrm{g} / \mathrm{ml} \times$ Verdünnung Volumen DNA-Aliquot}




\section{$[\mathrm{RNA}]=\underline{\mathrm{OD}}_{260} \underline{\text { (optische Dichte bei } 260 \mathrm{~nm}) \times 40 \mu \mathrm{g} / \mathrm{ml} \times \text { Verdünnung }}$ Volumen RNA-Aliquot \\ (für reine RNA-Lösung gilt ein Wert von $1 \mathrm{OD}_{260}=40 \mu \mathrm{g} / \mathrm{ml}$ )}

Neben der photometrischen Konzentrationsbestimmung wurden DNA-Konzentrationen auch im Agarosegel abgeschätzt. Dazu wurde ein Aliquot DNA neben einer Vektor-DNA definierter Konzentration auf ein Gel geladen und durch Vergleich der Bandenstärke die Menge abgeschätzt. Für die Konzentrationsbestimmung von Plasmidpräparationen, die in Ligationen eingesetzt werden sollten, war diese Messmethode ausreichend.

\subsection{3 cDNA-Synthese - Reverse Transkription (RT)}

Die cDNA-Synthese wurde von dem Enzym Reverse Transkriptase M-MuLV (Moloney Murine Leukemia Virus) vermittelt. Als Primer für die reverse Transkription wurde ein Oligo-dT-Adapter eingesetzt, der an die Poly-A-Anhänge von mRNA binden kann. Für einen RT-Reaktionsansatz von $25 \mu \mathrm{l}$ wurden $2,5 \mu \mathrm{g}$ Gesamt-RNA und $1 \mu \mathrm{l}(0,5 \mu \mathrm{g} / \mu \mathrm{l})$ Oligo(dT) $)_{12-18}$ eingesetzt, das Gemisch auf $11 \mu \mathrm{l}$ mit $\mathrm{H}_{2} \mathrm{O}$ aufgefüllt und für 10 min bei 70 ${ }^{\circ} \mathrm{C}$ denaturiert. Anschließend wurde der Ansatz sofort auf Eis gestellt und die weiteren Komponenten (5 $\mu 1$ 5x Reaktionspuffer (250 mM Tris- $\mathrm{HCl}$; 0,375 $\mathrm{M} \mathrm{KCl}_{2}, 15 \mathrm{mM} \mathrm{MgCl}$, $50 \mathrm{mM}$ DTT), 1,25 $\mu 1$ dNTP-Mix (je 10mM), 25 U RNasin, 200 U M-MuLV RT) zugegeben und mit $\mathrm{H}_{2} \mathrm{O}$ auf $25 \mu \mathrm{l}$ aufgefüllt. Der Ansatz wurde gemischt und für $1 \mathrm{~h}$ bei $42{ }^{\circ} \mathrm{C}$ inkubiert. Nach Abschluss der cDNA-Synthese wurde der Ansatz bei $95{ }^{\circ} \mathrm{C}$ für 5 min denaturiert. Die cDNA wurde danach sofort auf Eis gekühlt, aliquotiert und bei $-20{ }^{\circ} \mathrm{C}$ aufbewahrt.

\subsubsection{Primer für die PCR}

Im Anschluss an die cDNA-Synthese folgte die Amplifikation spezifischer C. jacchus cDNA-Fragmente mittels PCR. Dazu mussten zuvor spezifische Primer mit Hilfe von Gendatenbanken (NCBI) gefunden werden (Tab. 3.1). Die daraus resultierenden cDNAProdukte wurden später als Sonden in der In-situ-Hybridisierung (ISH) an Gehirnschnitten eingesetzt. Für die Detektion einer möglichst großen Breite an exprimierten MHC-KlasseI-Genen in der ISH wurde das Primerpaar P1 (erhalten von PD Dr. L. Walter, DPZ) eingesetzt. Der Vorwärts-Primer setzte am Exon 2; der Rückwärts-Primer im konservierten Exon 4 einer MHC-Klasse-I-cDNA an (Flügge et al., 2002). Zur Generierung zweier 
spezifischer Sonden wurden zwei Primerpaare (P2, P3) gewählt, die innerhalb der polymorphen Exone 2 und 3 liegen und damit das konservierte Exon 4 ausschließen. Das Primerpaar $\mathbf{P 2}$ ist spezifisch für Caja-G Exon 2-3; P3 für Caja-E Exon 2-3. Zur Amplifikation des Beta-2-Mikroglobulin-Gens (B2M) wurde das Primerpaar P4 konstruiert, das innerhalb des Exon 2 liegt.

Die Sonde für die ISH an T. belangeri Gehirnschnitten wurde durch eine Umklonierung generiert. Dafür wurde an einem zur Verfügung gestellten Vektor (Flügge et al., 2002), der als Insert das MHC-Klasse-I-Exon2-4-Fragment Tube-W02 enthielt, ebenfalls eine PCR mit dem Primerpaar P1 durchgeführt. Das PCR-Produkt wurde anschließend in den Transkriptionsvektor pDrive einkloniert.

Die Primerpaare P2, P3 und P4 wurden bei Invitrogen bestellt und nach Lösung der lyophylisierten Primer bei $-20{ }^{\circ} \mathrm{C}$ gelagert.

Tab. 3.1: Sequenzen und Annealing-Temperaturen (T) der Primerpaare P1-P4 und M13.

\begin{tabular}{|l|c|c|l|}
\hline \multicolumn{1}{|c|}{ Bezeichnung } & Forward 5'-3' & Reverse 5'-3' & \multicolumn{1}{c|}{$\mathbf{T}^{\prime}$} \\
\hline P1: MHC-Klasse-I Exon2-4 & GCTCCCACTCCATGAGGTATT & CGCCCACTTCTGGAAGGTTC & $61^{\circ} \mathrm{C}$ \\
\hline P2: Caja-G MHC I Exon2-3 & CTCCCACTCCATGAGGTA & TAGGCTCTCCTCCTCTCA & $53^{\circ} \mathrm{C}$ \\
\hline P3: Caja-E MHC I Exon2-3 & CTCCCACTCCATGAGGTA & CACGTGTCCTCCAGGTA & $53{ }^{\circ} \mathrm{C}$ \\
\hline P4: B2M Exon 2 & CGTCATCCGGCAGAGAATGG & ACATGGCTCACACGGCAGGCA & $56^{\circ} \mathrm{C}$ \\
\hline M13: Sequenzierung & GTAAAACGACGGCCAGT & AACAGCTATGACCATG & $50{ }^{\circ} \mathrm{C}$ \\
\hline
\end{tabular}

\subsubsection{Agarosegelelektrophorese}

Zur Herstellung von $1 \%(\mathrm{w} / \mathrm{v})$ Agarosegelen wurde Agarose in 1x TBE-Puffer aufgekocht, auf $55^{\circ} \mathrm{C}$ abgekühlt, mit $5 \mu$ l Ethidiumbromid versetzt $(10 \mathrm{mg} / \mathrm{ml})$, in ein Gelbett gegossen und ein Kamm eingesetzt. Anschließend wurde das ausgehärtete Gel mit 1x TBE-Puffer überschichtet und die mit 5x Ladepuffer versetzten Proben in die Taschen pipettiert ( $2 \mu$ l Probe für ein qualitatives Gel bis $50 \mu$ lür ein präparatives Gel). Als Längenstandard wurde der GeneRuler 100bp DNA Ladder Plus aufgetragen. Das Ergebnis der elektrophoretischen Auftrennung wurde anschließend mit UV-Licht sichtbar gemacht und mit dem Gel Jet Imager 2000 dokumentiert.

\subsubsection{Extraktion von DNA aus Agarosegelen}

Die Extraktion erfolgte mit dem „QIAquick ${ }^{\circledR}$ Gel Extraction“ Kit nach Angaben des Herstellers. Dazu wurden nach Ablauf der elektrophoretischen Auftrennung die gewünschten Banden mit einem Skalpell aus dem Gel ausgeschnitten. Die Gelstücke inklusive der darin gebundenen DNA wurden auf 1,5-ml-Reaktionsgefäße (max. $400 \mathrm{mg}$ 
Gel) aufgeteilt, 3 Volumenteile QG-Puffer zugegeben und bei $50{ }^{\circ} \mathrm{C}$ bis zur Auflösung des Gelstückes inkubiert. Anschließend wurde das Gemisch auf eine QIAquick Säule aufgetragen und in ein 2-ml-Auffanggefäß gesetzt. Nach der Zentrifugation (1 min, 16200 x g, RT) und Bindung der DNA an die Membran wurde der Durchfluss verworfen, die Säule erneut in das Auffanggefäß gestellt und $750 \mu$ PE-Puffer auf die Säule gegeben. Nach erneuter Zentrifugation wurde der Durchfluss verworfen, die Säule in das Auffanggefäß gestellt und noch einmal zentrifugiert, um restlichen Puffer zu entfernen. Für die Elution der DNA wurde die Säule in ein neues 1,5-ml-Reaktionsgefäß gesetzt, 20-50 $\mu 1$ $\mathrm{H}_{2} \mathrm{O}$ in die Mitte des Säulenbettes gegeben und für 1 min bei RT inkubiert. Die von der Membran nun in Lösung gegangene DNA wurde durch Zentrifugieren (1 min, 16200 x g, RT) vom Reaktionsgefäß aufgefangen. Durch Auftragen eines Aliquots auf ein Gel konnte die Qualität und Quantität beurteilt werden.

\subsubsection{Polymerase-Ketten-Reaktion (PCR)}

Die PCRs wurden als „Hot-Start“-PCRs durchgeführt, um unspezifische Hybridisierungen von Primern an der DNA zu vermeiden. Dabei werden die Primer bis zum ersten Denaturierungsschritt durch eine Wachsschicht von der Taq-DNA-Polymerase und der Ausgangs-DNA getrennt. Ein typischer PCR-Ansatz enthielt bei $30 \mu \mathrm{l}$ Gesamtvolumen 6 $\mu 1$ KMT-Puffer, $4 \mu \mathrm{l}$ BT-Buffer, $1 \mathrm{U}$ Taq-DNA-Polymerase, 0,13 mM dNTP und je 10 pmol Primer. Alle PCR-Programme starteten mit einem Vordenaturierungsschritt von 3 min bei $95{ }^{\circ} \mathrm{C}$, gefolgt von 35 Zyklen, die sich wie folgt zusammensetzen: Denaturierung bei $95{ }^{\circ} \mathrm{C}$ für $30 \mathrm{~s}$, Annealing bei variierenden Temperaturen für $30 \mathrm{~s}$ und Elongationsphase bei $72{ }^{\circ} \mathrm{C}$ für $60 \mathrm{~s}$. Abschließend wurde ein finaler Elongationsschritt von $7 \mathrm{~min}$ bei $72^{\circ} \mathrm{C}$ angefügt.

\subsubsection{Klonierung und Transformation}

In den Klonierungsvektor pDrive können PCR-Produkte direkt über einen T/A-Überhang an den Enden des linearisierten Vektors eingebaut werden. Klonierungen in pDrive wurden durchgeführt, um cDNA-Fragmente zu konservieren und zu sequenzieren. Darüber hinaus wurde der Vektor für die In-vitro-Transkription von radioaktiv-markierten Ribo-Sonden eingesetzt.

Das Ergebnis der RT-PCR wurde durch Agarosegelelektrophorese überprüft. Bei Auftreten von mehreren entweder unerwünschten Banden oder eventuellen Spleißvarianten der cDNA wurde eine Gelextraktion durchgeführt. Ergab die PCR eindeutige Banden, wurde 
das PCR-Produkt direkt aus dem PCR-Ansatz in die Ligation eingesetzt. PCR-Produkte mit folgenden Primerpaaren wurden in pDrive kloniert: P1, P2, P3, P4 (Tab.3.1). Pro Ligationsansatz wurden $1 \mu \mathrm{l}$ pDrive Cloning Vector (50 ng/ $\mu \mathrm{l}), 5 \mu 12 \mathrm{x}$ Ligations Master Mix, 1-4 $\mu \mathrm{l}$ PCR-Produkt eingesetzt und mit $\mathrm{H}_{2} \mathrm{O}$ auf $10 \quad \mu l$ aufgefüllt. Die Ligationsreaktion erfolgte über Nacht bei $16{ }^{\circ} \mathrm{C}$ in einem Heizblock. Am folgenden Tag wurde der Ansatz durch Zugabe von $3 \mu 13$ M Natriumacetat (pH 5,0), $70 \mu 1100 \%$ Ethanol und $17 \mu \mathrm{l} \mathrm{H}_{2} \mathrm{O}$ bei $-20{ }^{\circ} \mathrm{C}$ für $1 \mathrm{~h}$ gefällt. Anschließend wurde der Ansatz zentrifugiert (20 min, $16200 \mathrm{x} \mathrm{g}, 4{ }^{\circ} \mathrm{C}$ ), das Pellet mit $500 \mu 170 \%$ Ethanol gewaschen, erneut zentrifugiert, ausreichend getrocknet und in $10 \mu 1 \mathrm{H}_{2} \mathrm{O}$ resuspendiert.

Der Ligationsansatz wurde anschließend in kompetente E. coli Zellen (TOP10) transformiert. Dazu wurden $50 \mu \mathrm{l}$ kompetente Zellen auf Eis aufgetaut, $1 \mu \mathrm{l}$ Ligationsansatz zugegeben, kurz gemischt und dieser Bakterien-Ligations-Mix in eine gekühlte Elektroporationsküvette pipettiert. Die Transformation erfolgte in einem GenePulser für 2,5 s bei 1,6 kV. Anschließend wurden $500 \mu \mathrm{l}$ SOC-Medium zugegeben, das Bakteriengemisch in ein $10 \mathrm{ml}$-Reaktionsgefäß überführt und für $1 \mathrm{~h}$ bei $37^{\circ} \mathrm{C}$ und 160 rpm inkubiert. Von diesem Ansatz wurden anschließend 50-450 $\mu$ l auf LB-Platten (X-galIPGT-Ampicillin) ausgestrichen und über Nacht bei $37^{\circ} \mathrm{C}$ inkubiert.

\subsubsection{Vermehrung der Transformanten}

Nach etwa 16 h Inkubationszeit wurde das Ergebnis der Klonierung überprüft. Im Fall des pDrive-Vektors erfolgte neben der Selektion über die auf dem Vektor befindliche Ampicillin-Resistenz auch eine Blau-Weiß-Selektion. Auf dem Vektor befindet sich ein lacZ $\alpha$-Gen, das für das N-terminale $\alpha$-Fragment der $\beta$-Galactosidase codiert. Wird es in einen E. coli-Stamm transformiert, der das C-terminale $\omega$-Fragment besitzt, erlangt das Proteinprodukt die vollständige $\beta$-Galactosidase-Aktivität durch $\alpha$-Komplementation.

IPTG, das den Platten zugegeben wurde, induziert die Expression des lacZa-Gens. Die aktive $\beta$-Galactosidase spaltet von dem Substrat X-Gal den Galactosyl-Rest ab. Der IndolAnteil wird dadurch blau und unlöslich. Durch Insertion eines DNA-Fragments, also durch eine erfolgreiche Klonierung, wird das lacZ $\alpha$-Gen unterbrochen und es entsteht keine aktive $\beta$-Galactosidase. Die Kolonien erscheinen im Agar weiß. Dementsprechend kann durch Selektion weißer Kolonien von blauen Kolonien zwischen Rekombinanten (Bakterien, die den Vektor mit eingebauten Insert aufgenommen haben) und NichtRekombinanten (Bakterien, die den Vektor ohne Insert aufgenommen haben) unterschieden werden. Dementsprechend positive Kolonien wurden mit einem Zahnstocher 
von den Agar-Platten gepickt und in $3 \mathrm{ml}$ LB-Medium und dem entsprechenden selektiven Antibiotikum über Nacht bei $37^{\circ} \mathrm{C}$ und $260 \mathrm{rpm}$ vermehrt.

\subsubsection{Plasmid-Minipräparation}

Um die gepickten Klone zu analysieren, wurden die entsprechenden Plasmide extrahiert. Mit der hier gewählten Plasmid-Minipräparation können bis zu $20 \mu \mathrm{g}$ DNA erhalten werden, die anschließend durch Restriktionsverdau oder PCR auf das Vorhandensein des richtigen Vektors inklusive Insert analysiert werden können. Dazu wurden $2 \mathrm{ml}$ Bakterienkultur in 2-ml-Reaktionsgefäße überführt und bei $16200 \mathrm{x} g$ für $20 \mathrm{~s}$ zentrifugiert. Der Überstand wurde verworfen und das Bakterienpellet in $150 \mu 1$ Resuspendierungspuffer P1 resuspendiert. Durch Zugabe von $150 \mu$ l Lysepuffer P2 wurden die Zellen lysiert. Dabei wurden die Reaktionsgefäße mehrmals geschwenkt bis die Lösungen klar und viskos wurden. Nach 5 min Inkubation bei RT wurden $150 \mu \mathrm{l}$ Neutralisierungspuffer P3 zugegeben und erneut geschwenkt. Der ausgefallene ProteinSalz-Komplex wurde durch Zentrifugation (16200 x g, $10 \mathrm{~min}$ ) pelletiert. Anschließend wurde der Überstand in ein neues Reaktionsgefäß überführt und die Plasmid-DNA durch Zugabe des gleichen Volumens Isopropanol gefällt. Durch Zentrifugation (16200 x g, 15 min) wurde die DNA pelletiert. Die Pellets wurden mit $500 \mu 170 \%$ Ethanol gewaschen, anschließend ausreichend getrocknet und in $20 \mu \mathrm{H}_{2} \mathrm{O}$ resuspendiert.

\subsubsection{Plasmid-Maxipräparation}

Die Maxi-Präparation liefert Plasmid-DNA in größerem Maßstab (bis zu $500 \mu \mathrm{g}$ DNA). Diese Präparation wurde nur für positive Klone angewandt, von denen größere Mengen an DNA isoliert werden sollte. Die Präparation erfolgte mit dem „Qiagen Plasmid Maxi“ Kit nach Herstellerangaben.

Zunächst wurde vom entsprechenden Klon eine Vorkultur angesetzt. Dazu wurden $2 \mathrm{ml}$ LB-Medium mit entsprechendem Antibiotikum angeimpft und über Nacht bei $37{ }^{\circ} \mathrm{C}$ und $260 \mathrm{rpm}$ inkubiert. Von dieser Vorkultur wurde $1 \mathrm{ml}$ abgenommen, in $500 \mathrm{ml}$ LB-Medium mit entsprechendem Antibiotikum gegeben und über Nacht bei $37{ }^{\circ} \mathrm{C}$ und $260 \mathrm{rpm}$ vermehrt. Die $500 \mathrm{ml}$ Bakteriensuspension wurde gleichmäßig auf 12 50-mlReaktionsgefäße verteilt, zentrifugiert (20 min, $1500 \mathrm{x} \mathrm{g}, 4{ }^{\circ} \mathrm{C}$ ) und das Bakterienpellet mit $880 \mu 1$ Puffer P1 resuspendiert. Anschließend wurden $880 \mu$ l Puffer P2 zugegeben, das Gemisch mehrmals geschwenkt und 5 min bei RT inkubiert. Auf die lysierten Bakterien wurden $800 \mu 1$ des gekühlten Puffers P3 gegeben, ebenfalls mehrmals geschwenkt und auf 
Eis für 20 min inkubiert. Währenddessen wurde auf ein 50-ml-Reaktionsgefäß ein Membranfilter gesetzt und anschließend das Lysat in den Filter gegossen. Der Durchfluss wurde auf eine Qiagen-tip 500 Säule gegeben, die zuvor mit $10 \mathrm{ml}$ QBT-Puffer equilibriert wurde. Der Durchfluss wurde verworfen und die nun an die Säule gebundene DNA mit 2 x $30 \mathrm{ml}$ Puffer QC gewaschen. Zur Elution der DNA wurden $15 \mathrm{ml}$ Puffer QF auf die Säule gegeben und der Durchfluss aufgefangen. Das DNA-enthaltene Eluat wurde auf 1,5-mlReaktionsgefäße verteilt, mit 0,7 Volumenteilen Isopropanol versetzt und zentrifugiert (16200 x g, $20 \mathrm{~min}, 4^{\circ} \mathrm{C}$ ). Der Überstand wurde vorsichtig vom DNA-Pellet entfernt und verworfen. Das Pellet wurde mit $500 \mu 170 \%$ Ethanol gewaschen, erneut zentrifugiert (16200 x g, $10 \mathrm{~min}, 4{ }^{\circ} \mathrm{C}$ ), getrocknet und in $50 \mu 1 \mathrm{H}_{2} \mathrm{O}$ resuspendiert.

\subsubsection{Herstellen von Glycerin-Dauerkulturen}

Von positiven Klonen, die durch Restriktionsanalyse und Sequenzierung analysiert wurden, wurden Dauerkulturen angelegt. Damit waren die Klone dauerhaft konserviert und konnten jederzeit durch neues Animpfen angezogen werden. Dazu wurden von dem jeweiligen Klon 0,5 ml Bakteriensuspension 1:1 mit $40 \%$ Glycerol gemischt in flüssigem Stickstoff tiefgefroren. Anschließend wurde die Dauerkultur bei $-80^{\circ} \mathrm{C}$ aufbewahrt.

\subsubsection{Restriktionsverdau}

Klonierungen in den pDrive-Vektor wurden durch Restriktionsverdau von Plasmid-DNA überprüft. Dazu wurde das Restriktionsenzym EcoRI verwendet, da dieses das einzige ist, welches auf beiden Seiten der Multiple Cloning Site schneidet. Um dieses Enzym jedoch verwenden $\mathrm{zu}$ können, musste sichergestellt werden, dass das Insert keine interne Schnittstelle für EcoRI besitzt. Der Restriktionsverdau mit einem Gesamtvolumen von 20 $\mu \mathrm{l}$ setzte sich aus $1 \mu \mathrm{g}$ Plasmid-DNA, $5 \mathrm{U}$ EcoRI, $2 \mu \mathrm{l}$ 10x Restriktionspuffer und $\mathrm{H}_{2} \mathrm{O}$ zusammen. Der Ansatz wurde für $1,5 \mathrm{~h}$ bei $37^{\circ} \mathrm{C}$ inkubiert und anschließend das Ergebnis durch Agarosegelelektrophorese überprüft.

\subsubsection{Sequenzanalyse von Nukleinsäuren}

Die Sequenzanalysen in dieser Arbeit wurden nach dem Kettenabbruch-Verfahren (Sanger et al., 1977) durchgeführt, wobei in der PCR neben dNTPs auch ddNTPs enthalten sind. Wird ein ddNTP eingebaut, können keine weiteren Nukleotide angefügt werden, sodass es zum Kettenabbruch kommt. Da die ddNTPs mit unterschiedlichen Fluoreszenzfarbstoffen markiert sind, können diese von einem Laser detektiert werden. 
In die Sequenzreaktion mit einem Gesamtvolumen von $10 \mu 1$ wurden 200-300 ng PlasmidDNA bzw. 20-30 ng PCR-Produkt, $1 \mu$ l Sequenzier-Primer M13 rev/for (3,3 pmol, Sequenz aus pDrive-Handbuch), $1 \mu 1$ BigDye $^{\circledR}, 1,5 \mu 15 x$ Sequenzier-Verdünnungspuffer und $\mathrm{H}_{2} \mathrm{O}$ eingesetzt. Das PCR-Programm umfasste 25 Zyklen, die sich wie folgt zusammensetzten: $30 \mathrm{~s}$ bei $96^{\circ} \mathrm{C}, 15 \mathrm{~s}$ bei $50^{\circ} \mathrm{C}$ und 4 min bei $60^{\circ} \mathrm{C}$.

Im Anschluss wurde die Sequenzreaktion gefällt. Dazu wurden zu $10 \mu$ l Reaktionsansatz $250 \mu 1100 \%$ Ethanol, $10 \mu \mathrm{l} 3 \mathrm{M} \mathrm{Na}$-Acetat $(\mathrm{pH} 5,0), 90 \mu \mathrm{H}_{2} \mathrm{O}$ zugegeben und zentrifugiert (15 min, $16200 \mathrm{x} \mathrm{g}$, RT). Anschließend wurde der Überstand verworfen und das Pellet mit $250 \mu 170 \%$ Ethanol gewaschen, 5 min zentrifugiert und für 5 min getrocknet. Zur Sequenzierung wurde das Pellet in $10 \mu 1$ Formamid $\left(\mathrm{HiDi}^{\mathrm{TM}}\right)$ gelöst und in einem Kapillar-Sequenziergerät analysiert. Die Sequenzanalysen wurden mit dem Programm Sequencing Analysis durchgeführt. Für weitere Auswertungen wurden mehrere Möglichkeiten der NCBI-Datenbank (http://www.ncbi.nlm.nih.gov) genutzt.

\subsection{In-situ-Hybridisierung (ISH)}

Mit Hilfe der In-situ-Hybridisierung sollten bestimmte mRNA-Sequenzen im Gehirn lokalisiert werden. Dazu wurde eine Antisense-Sonde radioaktiv markiert und auf einem Gewebeschnitt hybridisiert. Enthielt dieser Schnitt die komplementäre Sequenz, konnte die Antisense-Sonde daran binden und die Markierung der Sonde sichtbar gemacht werden. In dieser Arbeit wurden die Nukleinsäuren mit radioaktivem Uracil-Tri-Phosphat $\left(\left[\alpha^{33} \mathrm{P}\right] \mathrm{dUTP}\right)$ markiert, welches über Autoradiographie auf einen Röntgenfilm und mit Fotoemulsion sichtbar gemacht wurde.

\subsubsection{Anfertigen von Gefrierschnitten}

Die in Einbettmedium befestigten Gehirne wurden am Kryostaten bei $-17{ }^{\circ} \mathrm{C}$ geschnitten. Die bei $-80^{\circ} \mathrm{C}$ gelagerten Gehirne wurden zunächst für 30 min zur Temperaturanpassung in den Kryostaten gelegt. Anschließend wurden $10 \mu \mathrm{m}$ dicke coronale Schnitte angefertigt. Dabei wurde ein Zusammenrollen der Schnitte durch das parallel angelegte Streckplättchen vermieden. Die Schnitte wurden dann auf Objektträger aufgezogen.

\subsubsection{Fixierung der Gefrierschnitte}

Nach Beendigung des Schneidens wurden die Schnitte für 20 min bei RT getrocknet und anschließend in 4 \% Paraformaldehyd-Lösung bei RT fixiert. Dadurch wurden die Ziel- 
RNAs im Gewebe immobilisiert und endogene RNasen inaktiviert. Danach wurden die Schnitte jeweils 5 min in 3 x PBS und zweimal in 1 x PBS gewaschen, um dann in einer aufsteigenden Ethanolreihe (je $2 \min 30 \%, 50 \%, 70 \%, 80 \%, 90 \%, 100 \%$ ) dehydriert zu werden. Die Schnitte wurden für 1 h bei RT getrocknet und in Objektträger-Kästen bei - 80 ${ }^{\circ} \mathrm{C}$ gelagert.

\subsubsection{Linearisierung}

In der In-vitro-Transkription wurden die Sonden radioaktiv markiert. Um AntisenseSonden, die zur Ziel-mRNA komlementär waren und Sense-Sonden, die als Kontrolle dienten, herzustellen, wurde der pDrive-Vektor an verschiedenen Stellen linearisiert. Die Richtung des Inserts im Vektor bestimmte dabei, welches Enzym (BamHI oder HindIII) für die Linearisierung der Antisense- oder Sense-Sonde eingesetzt wurde (Abb. 3.1). Für die Linearisierung wurden $10 \mu \mathrm{g}$ Plasmid-DNA, $2 \mu \mathrm{l}$ Enzym, die entsprechende Menge Puffer eingesetzt und für $2 \mathrm{~h}$ bei $37^{\circ} \mathrm{C}$ inkubiert. Anschließend wurde die Vollständigkeit der Linearisierung auf einem Agarosegel kontrolliert. Um in der In-vitro-Transkription optimale Ergebnisse $\mathrm{zu}$ erhalten, wurde die linearisierte DNA aufgereinigt. Die Aufreinigung erfolgte mit dem „Nucleo Spin Extract“ Kit nach Herstellerangaben. Dazu wurde der Ansatz mit $\mathrm{H}_{2} \mathrm{O}$ auf $100 \mu \mathrm{l}$ aufgefüllt, mit $400 \mu \mathrm{l}$ Puffer NT2 gemischt und auf eine Mini-Säule pipettiert. Zum Binden der DNA wurde die Säule zentrifugiert (16200 x g, $1 \mathrm{~min}$ ), anschließend 2x mit jeweils $700 \mu$ l Puffer NT3 gewaschen und zentrifugiert. Um restlichen Puffer zu entfernen, wurde die Säule erneut zentrifugiert. Zur Eluation der DNA wurden $30 \mu \mathrm{H} \mathrm{H}_{2} \mathrm{O}$ in die Mitte des Säulenbettes pipettiert, 5 min bei RT inkubiert und für 1 min zentrifugiert (16200 x g). Anschließend wurde die Konzentration der DNA photometrisch bestimmt. 


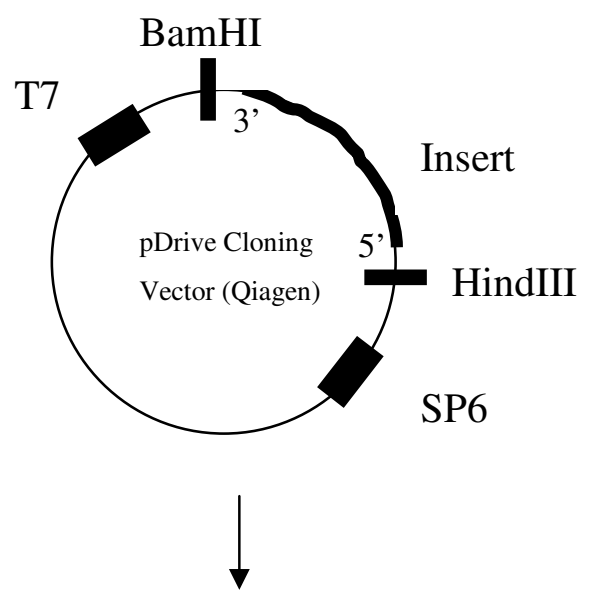

HindIII-Verdau

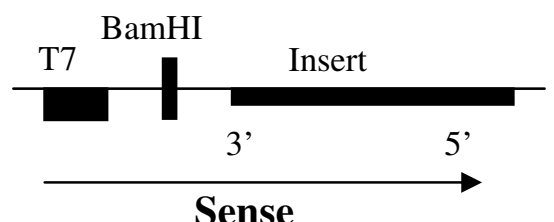

BamHI-Verdau

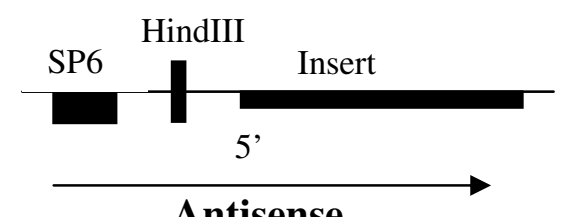

Antisense

Abb. 3.1: Unterschiedliche Linearisierung der Vektor-DNA inklusive Insert durch Restriktionsverdau mit HindIII oder BamHI. Durch HindIII-Verdau und anschließender In-vitro-Transkription mit der T7-RNA-Polymerase entsteht die Sense-Sonde, die identisch zum mRNA-Transkript im Gewebe ist und deshalb nicht bindet. Durch BamHI-Verdau und anschließender In-vitro-Transkription mit der SP6-RNA-Polymerase entsteht die Antisense-Sonde, die komplementär zum mRNATranskript im Gewebe ist und deshalb bindet.

\subsubsection{In-vitro-Transkription}

Die In-vitro-Transkription wurde mit dem „Riboprobe In Vitro Transcription System“ durchgeführt. Dabei wurde die linearisierte Plasmid-DNA in RNA umgeschrieben und dabei gleichzeitig mit radioaktivem $\left[\alpha^{33} \mathrm{P}\right] \mathrm{dUTP}(500 \mu \mathrm{Ci})$ markiert. War das Insert wie in Abb. 3.1 eingebaut, erzeugte die Transkription mit der SP6-RNA-Polymerase im BamHIVerdau die Antisense-Sonde, die T7-RNA-Polymerase im HindIII-Verdau die SenseSonde. War das Insert in der anderen Richtung eingebaut, erzeugte die SP6-RNAPolymerase die Sense-Sonde, die T7-RNA-Polymerase die Antisense-Sonde. Der Einbau des Inserts wurde zuvor durch die Sequenzierung geklärt.

Für den Ansatz wurde zunächst das $\left[\alpha^{33} \mathrm{P}\right] \mathrm{dUTP}$ für die Sense- und Antisense-Sonde in zwei 1,5-ml-Reaktionsgefäße verteilt. Die jeweils $25 \mu 1\left[\alpha^{33} \mathrm{P}\right] \mathrm{dUTP}$ wurden für $45 \mathrm{~min}$ in einer Vakuumtrockenmaschine eingedampft. Auf die eingedampfte Radioaktivität wurde anschließend der Transkriptionsansatz pipettiert. Dazu wurden $4 \quad \mu l \quad 5 \quad x$ Transkriptionspuffer, $2 \mu 1100$ mM DTT, $1 \mu$ RNasin, $4 \mu \mathrm{l}$ ACG-Mix (je 10 mM), $1 \mu \mathrm{g}$ 
gereinigte, linearisierte Plasmid-DNA, $1 \mu$ SP6- oder T7-RNA-Polymerase, mit $\mathrm{H}_{2} \mathrm{O}$ auf $20 \mu \mathrm{l}$ aufgefüllt, gemischt und $1 \mathrm{~h}$ bei $37^{\circ} \mathrm{C}$ inkubiert. Anschließend wurde die DNA durch Zugabe von $1 \mu$ l DNase und 15 min Inkubation bei $37{ }^{\circ} \mathrm{C}$ abgebaut. Der Ansatz wurde mit $\mathrm{H}_{2} \mathrm{O}$ auf $50 \mu \mathrm{l}$ aufgefüllt und die eingebaute Aktivität vor und nach der anschließenden Aufreinigung gemessen. Dazu wurden zunächst jeweils $1 \mu$ l Antisenseoder Sense-Sonde entnommen und in $2 \mathrm{ml}$ Szintillationslösung gegeben. Die restliche Probe wurde über die „Micro Spin Columns S-400HR“ aufgereinigt und damit von nicht eingebauter Radioaktivität und vom Enzym gereinigt. Das Säulenmaterial musste zunächst auf dem Vortexer aufgeschüttelt und der Äquilibrierungspuffer abzentrifugiert (1 min, 900 x g) werden. Anschließend wurden die Proben auf das Säulenbett gegeben, zentrifugiert (2 min, $900 \mathrm{x} \mathrm{g}$ ) und der Durchfluss mit den markierten aufgereinigten Sonden aufgefangen. Von diesen Proben wurde wieder $1 \mu$ l entnommen und in $2 \mathrm{ml}$ Szintillationslösung gegeben. An einem Szintillationsmessgerät wurden die Proben auf ihren Radioaktivitätsgehalt hin gemessen. Die Proben, die nach der Aufreinigung abgenommen wurden, gaben die tatsächlich eingebaute Radioaktivität wieder und wurden zur Berechnung der eingesetzten Menge für die Hybridisierung herangezogen.

\subsubsection{Prähybridisierung}

Die in der Prähybridisierung und Hybridisierung eingesetzten Geräte, Lösungen und Reagenzien mussten steril und RNase-frei sein. Dazu wurden sie entweder gebacken ( $8 \mathrm{~h}$, $180{ }^{\circ} \mathrm{C}$ ) oder autoklaviert $\left(20 \mathrm{~min}, 121^{\circ} \mathrm{C}\right)$. Das in dieser Arbeit verwendete Protokoll entspricht weitgehend dem beschriebenen Protokoll von Meyer et al. (2000) mit zwei Veränderungen:

(1) Hybridisierungen wurden bei $60{ }^{\circ} \mathrm{C}$ (Caja-G/Caja-E und Tube-W02) oder $45^{\circ} \mathrm{C}$ (Caja$B 2 M$ ) für $18 \mathrm{~h}$ ausgeführt und (2) dem RNase-Waschschritt folgte ein stringenter Waschschritt (0,2 x SSC, 60 min, Hybridisierungstemperatur $\left.+5^{\circ} \mathrm{C}\right)$.

Für die Prähybridisierung wurden die gefrorenen Schnitte für $1 \mathrm{~h}$ bei RT getrocknet, anschließend in einer absteigenden Ethanolreihe (100\%, $90 \%, 80 \%, 70 \%, 50 \%, 30 \%)$ rehydriert, 5 min in 1 x PBS gewaschen, 10 min in $0,9 \% \mathrm{NaCl}$ inkubiert und in $4 \%$ Paraformaldehyd-Lösung für 20 min fixiert. Nach erneutem Waschen, wurden die Schnitte für $10 \mathrm{~min}$ in $0,25 \%$ Essigsäureanhydrid (in $0,1 \mathrm{M}$ Triethanolamine- $\mathrm{HCl}, \mathrm{pH} \mathrm{8,0)}$ acetyliert, um damit unspezifische Bindungsstellen zu blockieren. Anschließend wurden die Schnitte gewaschen und erneut in $0,9 \% \mathrm{NaCl}$ für 10 min inkubiert. Zum Schluss 
wurden die Schnitte in einer aufsteigenden Ethanolreihe $(30 \%, 50 \%, 70 \%, 80 \%, 90 \%$, $100 \%$ ) dehydriert und für $1 \mathrm{~h}$ bei RT getrocknet.

\subsubsection{Hybridisierung}

Die radioaktivmarkierten Sonden wurden in Hybridisierungspuffer zu einer Radioaktivität von $50000 \mathrm{cpm} / \mu 1$ verdünnt. Die Schnitte wurden während der Hybridisierung in einer Feuchtkammer aufbewahrt, die mit zwei Lagen in $50 \%$ Formamid (in 1 x SSC) getränktem 3MM Whatman-Papier ausgelegt wurde. Um mögliche Sekundärstrukturen in den einzelsträngigen Sonden zu vermeiden, wurden die Sonden für $15 \mathrm{~min}$ auf $70{ }^{\circ} \mathrm{C}$ im Thermoblock erhitzt und anschließend jeweils $90 \mu 1$ Probe auf einen Schnitt pipettiert. Auf die Schnitte wurden dann GelBond ${ }^{\circledR}$-Deckgläschen gelegt, wobei vermieden wurde, dass Luftblasen entstanden. Die Feuchtkammer mit Schnitten wurde dann über Nacht (12-18 h) im Wärmeschrank inkubiert. Aus Vorversuchen wurde dabei für die Caja-G, Caja-E und Tube-W02 Sonde eine optimale Temperatur von $60{ }^{\circ} \mathrm{C}$ ermittelt, für die Caja-B2M-Sonde von $45{ }^{\circ} \mathrm{C}$.

\subsubsection{Waschen}

Nach der Hybridisierung wurden unspezifisch gebundene und restliche Sonden durch eine Reihe von Waschschritten entfernt. Dabei wurden die Lösungen aufsteigend stringenter. Ein RNase-Verdau sorgte dafür, dass nicht gebundene Sonden degradiert wurden. Der Waschschritt mit der höchsten Stringenz wurde mit 0,2 x SSC bei $5{ }^{\circ} \mathrm{C}$ über der Hybridisierungstemperatur durchgeführt. Folgende Waschschritte wurden durchgeführt: 4 x SSC (10 min, $\left.37^{\circ} \mathrm{C}\right)$; NTE (15 min, $\left.37^{\circ} \mathrm{C}\right)$; NTE + RNase A $(20 \mu \mathrm{g} / \mathrm{ml})\left(30 \mathrm{~min}, 37^{\circ} \mathrm{C}\right)$; $\operatorname{NTE}\left(15 \mathrm{~min}, 37^{\circ} \mathrm{C}\right) ; 2 \times \operatorname{SSC}\left(10 \mathrm{~min}, 37^{\circ} \mathrm{C}\right) ; 0,5 \times \operatorname{SSC}\left(10 \mathrm{~min}, 37^{\circ} \mathrm{C}\right) ; 0,2 \times \operatorname{SSC}(1 \mathrm{~h}$, Hybridisierungstemperatur $\left.+5{ }^{\circ} \mathrm{C}\right) ; 0,1 \times \operatorname{SSC}\left(10 \mathrm{~min}, 37^{\circ} \mathrm{C}\right) ; 0,1 \times \mathrm{SSC}(10 \mathrm{~min}, \mathrm{RT})$. Zur Dehydrierung der Schnitte schloss sich eine aufsteigende Ethanolreihe (je 2 min in 30 $\%, 50 \%, 70 \%, 80 \%, 90 \%, 100 \%, 100 \%$, RT) an, wobei (mit Ausnahme der $100 \%$ Ethanol-Lösung) den Lösungen zusätzlich 8,3 ml 7,5 M NH${ }_{4} \mathrm{OAc}$ zugegeben wurde. Anschließend wurden die Schnitte bei RT für 1 h getrocknet.

\subsubsection{Autoradiographie}

Die getrockneten Schnitte wurden in eine Filmkassette gelegt. Bei Rotlicht wurde ein Röntgenfilm auf die Schnitte gelegt, die Kassette lichtdicht verschlossen und für 4 Tage im Kühlschrank gelagert. Anschließend wurde der Film entnommen und in der 
Dunkelkammer $5 \mathrm{~min}$ entwickelt, in Wasser gespült und $5 \mathrm{~min}$ fixiert. Die Bilddokumentation erfolgte mit der AIS Software. Histologische Lokalisationen wurden anhand des stereotaxischen Atlas des C. jacchus (Stephan et al., 1980) und des Tupaia glis (Tigges und Shantha, 1969) durchgeführt.

Um die Hybridisierung auf zellulärer Ebene zu visualisieren, wurden die Schnitte mit einer Filmemulsion (NTB2) bei Rotlicht gleichmäßig und dünn überschichtet. Durch die Emulsion werden an den Stellen, wo sich die radioaktive Sonde befindet, schwarze Silberkörner akkumuliert. Durch die Akkumulation über bestimmten Zellen, können diese als Ort der gesuchten mRNA-Expression erkannt werden.

Die beschichteten Schnitte wurden $1 \mathrm{~h}$ in der Dunkelkammer getrocknet und anschließend in einer lichtdichten, trockenen Kiste bei $4{ }^{\circ} \mathrm{C}$ für 7 Wochen gelagert. Anschließend wurden die Objektträger 5 min entwickelt, in Wasser gespült und 5 min fixiert.

\subsubsection{Histologische Färbung}

Um die Zellen histologisch darzustellen, wurde eine Nissl-Färbung mit Toluidinblau durchgeführt. Dazu wurden die Schnitte direkt nach der Fixierung der Silberkörner kurz in Wasser gespült und anschließend für 30-60 s (je nach Stärke der Färbung) in 0,05 \% Toluidinblau (in 0,1\% di-Natriumtetraborat) gefärbt und erneut kurz in Wasser gespült. Danach wurde die Färbung in einer ansteigenden Ethanolreihe $(30 \%, 50 \%, 70 \%, 80 \%$, $90 \%, 100 \%$ ) differenziert. Nach dem $100 \%$ Ethanolbad wurden die Schnitte 3x für mindestens 1 min in Xylol inkubiert und anschließend mit Eukitt eingedeckt. Nach dem Aushärten der Eukittschicht wurden die Objektträger unter dem Lichtmikroskop untersucht und mit Digitalkamera und der AIS Software analysiert.

\subsection{Proteinbiochemische Methoden}

\subsubsection{Proteinpräparation}

Zur Isolation von Gesamtprotein wurden Leber- und Gehirngewebe von C. jacchus verwendet. Um endogene Protease-Aktivitäten $\mathrm{zu}$ verhindern, wurden die Extraktionsschritte im Kühlraum bei $4{ }^{\circ} \mathrm{C}$ ausgeführt. Eiskalter RIPA-Puffer wurde auf das Gewebe gegeben ( $3 \mathrm{ml}$ pro $1 \mathrm{~g}$ ) und mit einem Glashomogenisator homogenisiert. Das Homogenisat wurde anschließend für 30 min auf Eis inkubiert, dann auf 1,5-mlReaktionsgefäße verteilt und zentrifugiert (10 min, $\left.16200 \mathrm{x} \mathrm{g}, 4{ }^{\circ} \mathrm{C}\right)$. Der Überstand wurde abgenommen und erneut zentrifugiert. Der Schritt wurde wiederholt, bis der Überstand frei 
von Verunreinigungen war. Die Proteinkonzentration wurde mit dem „Bio-Rad DC Protein Assay“ nach Angaben des Herstellers photometrisch bestimmt.

\subsubsection{Western-Blot}

SDS-Polyacrylamidgelelektrophorese (SDS-PAGE)

Zur Auftrennung der MHC-Klasse-I-Proteine wurden $10 \%$ Trenngele, die mit $6 \%$ Sammelgelen überschichtet wurden, verwendet. Die Proteinproben wurden vor dem Auftragen mit RIPA-Puffer verdünnt und anschließend mit 2 x Lämmlipuffer versetzt. Die Ansätze wurden für $10 \mathrm{~min}$ bei $70{ }^{\circ} \mathrm{C}$ denaturiert und anschließend 5-100 $\mu$ g pro Tasche eines Minigels aufgetragen. Zusätzlich wurden $5 \mu$ l eines gefärbten Größenstandards aufgetragen. Die Elektrophorese wurde für ca. 2 h bei $20 \mathrm{~mA}$ durchgeführt.

\section{Halbtrockener Blot}

Die Übertragung der Proteine aus dem Gel auf Nitrozellulose wurde mit einem halbtrockenen Blot bei $112 \mathrm{~mA}$ für $2 \mathrm{~h}$ durchgeführt. Dazu wurden sechs Lagen $3 \mathrm{~mm}$ dickes Whatman-Papier (Filterpapier) mit Transfer-Puffer getränkt, die Membran ebenfalls in den Puffer gelegt und anschließend der Blot luftblasenfrei aufgebaut. Dabei wurden in die Blotkammer drei Lagen Whatman-Papier gelegt, darauf die Membran und anschließend das Gel. Abschließend wurden noch einmal drei Lagen Whatman-Papier aufgelegt (Abb. 3.2).



Abb. 3.2: Aufbau des halbtrockenen Blot.

Proteindetektion im Blot

Nach Beendigung des Proteintransfers wurde der Blot abgebaut. Um die Qualität des Transfers zu überprüfen, wurde die Membran vorsichtig mit einer Pinzette für $1 \mathrm{~min}$ in eine Schale mit Ponceau-S gelegt, anschließend mit $\mathrm{H}_{2} \mathrm{O}$ gespült und die dadurch sichtbar 
gewordenen Banden wurden kontrolliert. Außerdem wurden die Taschen mit einem Bleistift markiert. Durch längeres Wässern wurde die Farbe wieder entfernt und die Membran für $1 \mathrm{~h}$ in Blockpuffer bei RT geblockt. Dabei wurden unspezifische Bindungsmöglichkeiten abgesättigt. Nach dem Blocken wurde die Membran über Nacht bei $4{ }^{\circ} \mathrm{C}$ mit dem 1. Antikörper HC-10 (monoklonaler anti-human-MHC-Klasse-I HLA-B, C; Hybridomüberstand, Verdünnung 1:5) in Blockpuffer inkubiert. Anschließend 6x für 5 min mit TBST gewaschen und für $1 \mathrm{~h}$ bei RT mit dem 2. Antikörper MeerrettichPeroxidase-gekoppelter Ziege-anti-Maus (Verdünnung 1:3000) in Blockpuffer inkubiert. Danach wurde die Membran erneut 6x für 5 min mit TBST und 1x in TBS gewaschen, bevor durch Chemilumineszenz das Bindungssignal nachgewiesen wurde. Dazu wurden ECL-Lösung I und ECL-Lösung II lichtgeschützt angesetzt und in einer Dunkelkammer zusammengegeben. In dieses Gemisch wurde nun die Membran für 1 min gelegt, anschließend mit Filterpapier abgetupft und in eine Filmkassette mit einem Film gelegt. Je nach gewünschter Stärke des Signals wurde für $10 \mathrm{~s}$ bis $30 \mathrm{~min}$ belichtet. Anschließend wurde der Film in einem automatischen Entwickler entwickelt. Mit Hilfe des gefärbten Größenstandard auf der Membran, konnten die Signale bestimmten Größen zugeordnet werden.

\subsubsection{Immunpräzipitation}

Durch die Immunpräzipitation konnten einzelne Proteine aus Proteingemischen isoliert werden. Dazu wurde das Proteingemisch mit einem spezifischen ersten Antikörper inkubiert, so dass sich ein Antikörper-Antigen-Komplex bildet. Dieser Komplex wurde dann durch Zugabe von Protein-G-Sepharose an diese gekoppelt und somit immobilisiert. Das restliche Proteingemisch konnte damit entfernt werden. Um Proteaseaktivität zu verhindern, wurden alle Schritte auf Eis oder bei $4{ }^{\circ} \mathrm{C}$ durchgeführt.

Pro Präzipitation wurden $100 \mu \mathrm{l}$ aufgeschüttelte Protein-G-Sepharose zum Waschen in ein 1,5-ml-Reaktionsgefäß gegeben und mit $900 \mu$ l RIPA-Puffer aufgefüllt. Der Ansatz wurde kurz geschwenkt und anschließend zentrifugiert $\left(20 \mathrm{~s}, 16200 \mathrm{x} \mathrm{g}, 4{ }^{\circ} \mathrm{C}\right)$. Der Überstand wurde vorsichtig über dem Sepharosebett abgenommen und verworfen. Dieser Waschschritt wurde zweimal wiederholt. Auf das letzte Sepharosebett wurden $100 \mu 1$ RIPA-Buffer gegeben. 
Immunpräzipitation - Vorreinigung

Zunächst wurde das Proteingemisch vorgereinigt, um eventuell unspezifische Bindungen zu vermeiden. Dazu wurden $40 \mu \mathrm{l}$ der Sepharose zu $1000 \mu \mathrm{l}$ Proteingemisch $(7 \mu \mathrm{g} / \mu \mathrm{l})$ gegeben und für $1 \mathrm{~h}$ bei $4{ }^{\circ} \mathrm{C}$ geschwenkt. Der Ansatz wurde danach zentrifugiert $(20 \mathrm{~s}$, $16200 \mathrm{x} \mathrm{g}, 4{ }^{\circ} \mathrm{C}$ ) und anschließend der Proteinüberstand abgenommen und in ein Reaktionsgefäß überführt. Die Sepharose wurde 3x mit RIPA-Puffer gewaschen und für weitere Analysen aufbewahrt.

\section{Präzipitation}

Zur Bildung des Antikörper-Antigen-Komplex wurden zu $1000 \mu$ l Proteinüberstand $100 \mu \mathrm{l}$ des 1. Antikörpers Tü149 (monoklonaler anti-human-MHC-Klasse-I HLA-B, C, einige HLA-A; Hybridomüberstand, Verd. 1:11) gegeben. Die Inkubation erfolgte für $3 \mathrm{~h}$ bei 4 ${ }^{\circ} \mathrm{C}$ unter sanftem Schwenken. Anschließend wurde der Antikörper-Antigen-Komplex aus dem Proteingemisch durch Zugabe der restlichen $60 \mu$ Sepharose präzipitiert. Die Präzipitation erfolgte für $1 \mathrm{~h}$ bei $4{ }^{\circ} \mathrm{C}$ durch leichtes Schwenken. Anschließend wurde die Sepharose mit dem gebundenen Antikörper-Antigen-Komplex abzentrifugiert (1 min, $16200 \mathrm{x} \mathrm{g}, 4{ }^{\circ} \mathrm{C}$ ), 3x mit RIPA-Puffer gewaschen und in $30 \mu$ l Elutionspuffer-Puffer resuspendiert.

Elution des Proteins von der Sepharose

Um den Antikörper-Antigen-Komplex von der Sepharose wieder zu eluieren, wurde der Ansatz in Elutionspuffer für 3 min bei $95^{\circ} \mathrm{C}$ erhitzt. Nach der Zentrifugation wurde der Überstand mit dem eluierten Antikörper-Antigen-Komplex abgenommen und mit Hilfe von SDS-PAGE und Western-Blot analysiert.

\subsubsection{Immunhistologische Methoden (IHC)}

Anfertigen von schwimmenden Schnitten

Für immunhistologische Markierungen wurden $40 \mu \mathrm{m}$ dicke schwimmende Schnitte eingesetzt. Bis auf ein Tier lagen die Gehirne bereits geschnitten vor (aus dem Projekt von Dr. B. Czéh, DPZ). Für die Herstellung der Schnitte wurde das in Lagerungslösung eingefrorene Gehirn coronal angeschnitten und mit der Schnittebene auf einen Schneideblock aufgeblockt. Nach Ausrichten der Ebene wurden jeweils $40 \mu \mathrm{m}$ dicke coronale Schnitte am Kryostat angefertigt, die in einer 12-Loch-Platte, gefüllt mit 1 x PBS, 
aufgefangen wurden. Zum längeren Lagern bei $4{ }^{\circ} \mathrm{C}$ wurden den Schnitten noch $20 \mu 1100$ $\mathrm{mM}$ Natriumazid pro $2 \mathrm{ml} 1 \mathrm{x}$ PBS hinzugefügt.

Immunhistologische Markierung mit DAB

Zunächst wurden die schwimmenden Schnitte 3x für $10 \mathrm{~min}$ in $10 \mathrm{ml} 1 \mathrm{x}$ PBS auf einem Schüttler gewaschen. Anschließend wurde die endogene Peroxidase-Aktivität durch 20 min Inkubation in $1 \% \mathrm{H}_{2} \mathrm{O}_{2}$ (in $1 x$ PBS) blockiert, danach erneut $3 x$ gewaschen, bevor zur Blockierung unspezifischer Bindungsstellen die Schnitte in $3 \%$ normalem Ziegenserum (NGS) $1 \mathrm{~h}$ bei $4{ }^{\circ} \mathrm{C}$ inkubiert wurden. Anschließend wurden die Schnitte mit primären Maus monoklonalen Antikörpern gegen humanes MHC-Klasse-I (HC-10, Hybridomüberstand, Verd. 1:10 , Stam et al., 1986; oder HB115, Verd. 1:5, Hybridomüberstand) oder mit einem Maus monoklonalen Antikörper gegen MHC-Klasse-I der Ratte (Ox-18, Verd. 1:2000, Fukumoto et al., 1982) in 1 x PBS, 0,5 \% NGS und 0,5\% Triton X-100 gegeben und über Nacht bei $4{ }^{\circ} \mathrm{C}$ inkubiert. Negativkontrollen wurden jeweils ohne Primärantikörper durchgeführt. Danach wurden die Schnitte $3 \mathrm{x}$ in $1 \mathrm{x}$ PBS mit $2 \%$ Milchpulver gewaschen und mit einem biotinylierten Anti-Maus Ig Sekundärantikörper (Verd. 1:100) für $2 \mathrm{~h}$ bei $4{ }^{\circ} \mathrm{C}$ oder $1 \mathrm{~h}$ bei RT inkubiert. Anschließend wurden die Schnitte in 1 x PBS mit $2 \%$ Milchpulver gewaschen, dann $1 \mathrm{~h}$ bei $4{ }^{\circ} \mathrm{C}$ in $2 \mathrm{ml}$ ABC-Kit-Lösung (Verd. 1:200) in 0,5\% Triton X-100 inkubiert und erneut in 1 x PBS ohne Milchpulver gewaschen. Die Markierung der Schnitte erfolgte in $10 \mathrm{ml} 1 \mathrm{x}$ PBS mit 2 Tropfen $\mathrm{H}_{2} \mathrm{O}_{2}$ und 4 Tropfen 3,3 Diaminobenzidin (DAB) für bis $\mathrm{zu} 5$ Minuten. Anschließend wurden die Schnitte erneut in 1 x PBS gründlich gewaschen, um restliche DAB-Lösung zu entfernen. Die Schnitte wurden danach in eine Petrischale mit Glycerinlöung $(0,01 \%)$ überführt und von dort auf Objektträger mit einem Pinsel aufgezogen, ausgerichtet und über Nacht bei $37^{\circ} \mathrm{C}$ getrocknet. Die auf dem Objektträger getrockneten Schnitte wurden am nächsten Tag in Xylol für mindestens 10 min inkubiert und anschließend mit Eukitt und Deckgläschen luftblasenfrei eingedeckt. Die Analyse der Färbung erfolgte am Lichtmikroskop.

Immunhistologische Fluoreszenzmarkierung

Zur Analyse der Co-Expression zweier Proteine besteht die Möglichkeit einer Doppelmarkierung. Dazu werden Sekundärantikörper eingesetzt, die mit einem fluoreszierenden Farbstoff konjugiert sind. Da verschiedene Sekundärantikörper mit 
unterschiedlichen Fluoreszenzfarbstoffen erhältlich sind, können in einer Inkubation mehr als ein primärer Antikörper eingesetzt werden.

In dieser Arbeit wurden Doppelmarkierungen gegen MHC-Klasse-I (Ox-18) und gegen Tyrosinhydroxylase (TH) durchgeführt. TH ist ein Markerenzym für dopaminerge Neuronen. Die Schnitte wurden zunächst über Nacht mit Ox-18 (Verd. 1:1000) bei $4{ }^{\circ} \mathrm{C}$ in $1 \mathrm{x}$ PBS, $1 \%$ NGS und $5 \%$ Triton X-100 inkubiert und anschließend mit einem fluoreszierenden Sekundärantikörper Anti-Maus IgG (Verd. 1:200) für $2 \mathrm{~h}$ bei $4{ }^{\circ} \mathrm{C}$ inkubiert. Anschließend wurden die Schnitte 3x in 1 x PBS mit $2 \%$ Milchpulver gewaschen. Daran schloss sich eine Inkubation über Nacht mit dem polyklonalen Kaninchenantikörper gegen humane, Ratten- und Maus-Tyrosinhydroxylase TH (Verd. 1:1000) bei $4{ }^{\circ} \mathrm{C}$ in 1 x PBS, $1 \%$ NGS, $5 \%$ Triton X-100 an. Anschließend an das Waschen in 1 x PBS mit $2 \%$ Milchpulver, wurden die Schnitte mit dem fluoreszierenden Sekundärantikörper Anti-Kaninchen IgG (Verd. 1:200) für $2 \mathrm{~h}$ bei $4{ }^{\circ} \mathrm{C}$ inkubiert, danach in 1 x PBS gewaschen, auf Objektträger aufgezogen, über Nacht im Kühlschrank in einer lichtgeschützten Kiste getrocknet und mit 1-5 Tropfen Eindeckmedium und Deckgläschen eingedeckt. Anschließend wurden die Ränder mit farblosem Nagellack umrandet, um ein Austrocknen zu verhindern. Die Auswertung der Markierung erfolgte mittels konfokaler Laser-scanning-Mikroskopie.

\subsubsection{Durchflusszytometrie (FACS)}

Um Kreuzreaktionen des monoklonalen Antikörper Maus-anti-Ratte MHC-Klasse-I (Ox18) und des Antikörpers Maus-anti-HLA-B7/-B40 (HB115) mit Klasse-I-Molekülen von C. jacchus $\mathrm{zu}$ testen, wurden durchflusszytometrische Analysen durchgeführt. Die Analysen wurden von PD Dr. R. Dressel (Institut für Immunologie, Universität Göttingen) vorgenommen.

Nach Lysierung der Erythrozyten wurden periphere Blutleukozyten für 45 Minuten mit 2 $\mu \mathrm{g} / \mathrm{ml}$ Ox-18 oder $20 \mu \mathrm{l}$ HB115 Hybridomüberstand in $200 \mu 11$ x PBS mit 5\% normalem Ziegenserum bei $4{ }^{\circ} \mathrm{C}$ inkubiert. Anschließend wurden die Zellen mit PBS gewaschen und danach mit einem 1:200 verdünnten polyklonalen FITC-gebundenen Ziege-anti-Maus IgG Antikörper markiert. Die Zellen wurden erneut mit PBS gewaschen und in $500 \mu 1$ PBS mit $27 \mu \mathrm{g} / \mathrm{ml}$ Propidiumjodid resuspendiert um abgestorbene Zellen von der Analyse auszuschließen. Die Analyse wurde an einem FACScan Durchflusszytometer durchgeführt. 


\section{Ergebnisse}

\subsection{MHC-Klasse-I Expression im Gehirn von Tupaia belangeri}

\subsubsection{In-situ-Hybridisierungssonde für T. belangeri}

Zur Herstellung einer Sonde für die In-situ-Hybridisierung mit $T$. belangeri Gewebeschnitten wurde ein Klon mit einem MHC-Klasse-I-Gen von Tupaia zur Verfügung gestellt (Flügge et al., 2002). Der Klon enthielt den Vektor pcDNA3.1/V5 mit einem 1,4 kb MHC-Klasse-I-cDNA-Fragment (Tube-W02). Die Vektor-DNA wurde als Template in einer PCR mit dem Primerpaar P1 (MHC-Klasse-I Exon2-4) eingesetzt. Das erhaltene PCR-Produkt (731 bp) wurde anschließend in den Klonierungsvektor pDrive kloniert und sequenziert. Der Vergleich der Sequenz mit Sequenzen aus der Datenbank ergab eine 100 \%ige Übereinstimmung mit der MHC-Klasse-I-cDNA Tube-W02 (GenBank accession AJ313091) (Abb. 4.1). Durch die Sequenzierung konnte gleichzeitig die Richtung des eingebauten Inserts in den Vektor ermittelt und somit festgestellt werden, welches linearisierte Plasmid als Antisense- und welches als Sense-Sonde diente. Die Hybridisierungssonde umfasst die vollständigen Exons 2 und 3, von Exon 4 waren 188 der 276 bp vorhanden.

>gc tcc cac tcc atg agg tat ttc ttc acc tcc gtg tcc cgg ccg gga
ggg gac ccc cgc ttc atc ttg gtc ggc tac gtg gac gac acg cag ttc gtg
cgg ttc gac agc gac tcg gcg agt cag agg gtg gag ccg cgg gcg ccc tgg
atg gac cag atg gac ggg gag tac tgg gag gag cag acg cgg agg gcc aag
ggc tgg gca cag att gaa cga ggg agc ttg cgg acc ctg cgc ggc tac tac
aac cag agc gag gcc ggc tct cac act tac cag agg atg tac ggc tgc gac
gtg ggg ccg ggc ggg cgc ctc ctc cgc ggg tac tat cag gac gcc tac gac
ggc cgg gac tac atc gcc ctg aac gag gac ctg cgc tcc tgg acc gcg gcc
gac atg gcg gcc cag atc acc cag cgc aag tgg gag gcg gct gat gtg gct
gag caa gac agg gcc tac ctg gag ggg gag tgc gtg cag tgg ctg ggc acc
tac ctg gag aac ggg aag gag acg ctg cag cgc gca gac ccc cca aag gcg
cac gtg acc cac cac ccc act tct gac cgt gag gcc acc ctg agg tgc tgg
gcc ctg ggc ttc tac cct gcg gag atc tcc ctg acc tgg cag cgg gat ggg
gag gac cag acc cag gac atg gag ctg gtg gag acc agg cct gca ggg gac
gga acc ttc cag aag tgg gcg

Abb. 4.1: Sequenz der In-situ-Hybridisierungssonde für T. belangeri Tube-W02 (GenBank accession AJ313091) (731 bp). rot: Exon 2 (polymorph); blau: Exon 3 (polymorph); grün: Exon 4 (konserviert). Kursiv: Primerpaar P1 


\subsubsection{In-situ-Hybridisierung mit Gehirnschnitten von T. belangeri MHC- Klasse-I-Sonde: Übersicht}

Die In-situ-Hybridisierung mit Gehirnschnitten von $T$. belangeri wurde mit der radioaktiven Tube-W02-Antisense-Sonde durchgeführt. Als Negativkontrolle wurde die Sense-Sonde eingesetzt. In Abbildung 4.2 sind Autoradiogramme mit den coronalen Gehirnschnitten von T. belangeri nach der In-situ-Hybridisierung gezeigt. Anhand der schwarzen Signale können die Bereiche ausfindig gemacht werden, die MHC-Klasse-I exprimieren. Folgende Regionen zeigen leichte bis starke MHC-Klasse-I-Expression: Cortex cerebri, Substantia nigra, Corpus geniculatum laterale, Hippocampus, Nucleus nervi oculomotorii, Plexus choroideus (Abb. 4.2 a, b). Mit der Sense-Sonde konnten keine Signale gefunden werden (Abb. 4.2 c), was darauf schließen ließ, dass keine unspezifischen Bindungen in der Hybridisierung auftraten. 

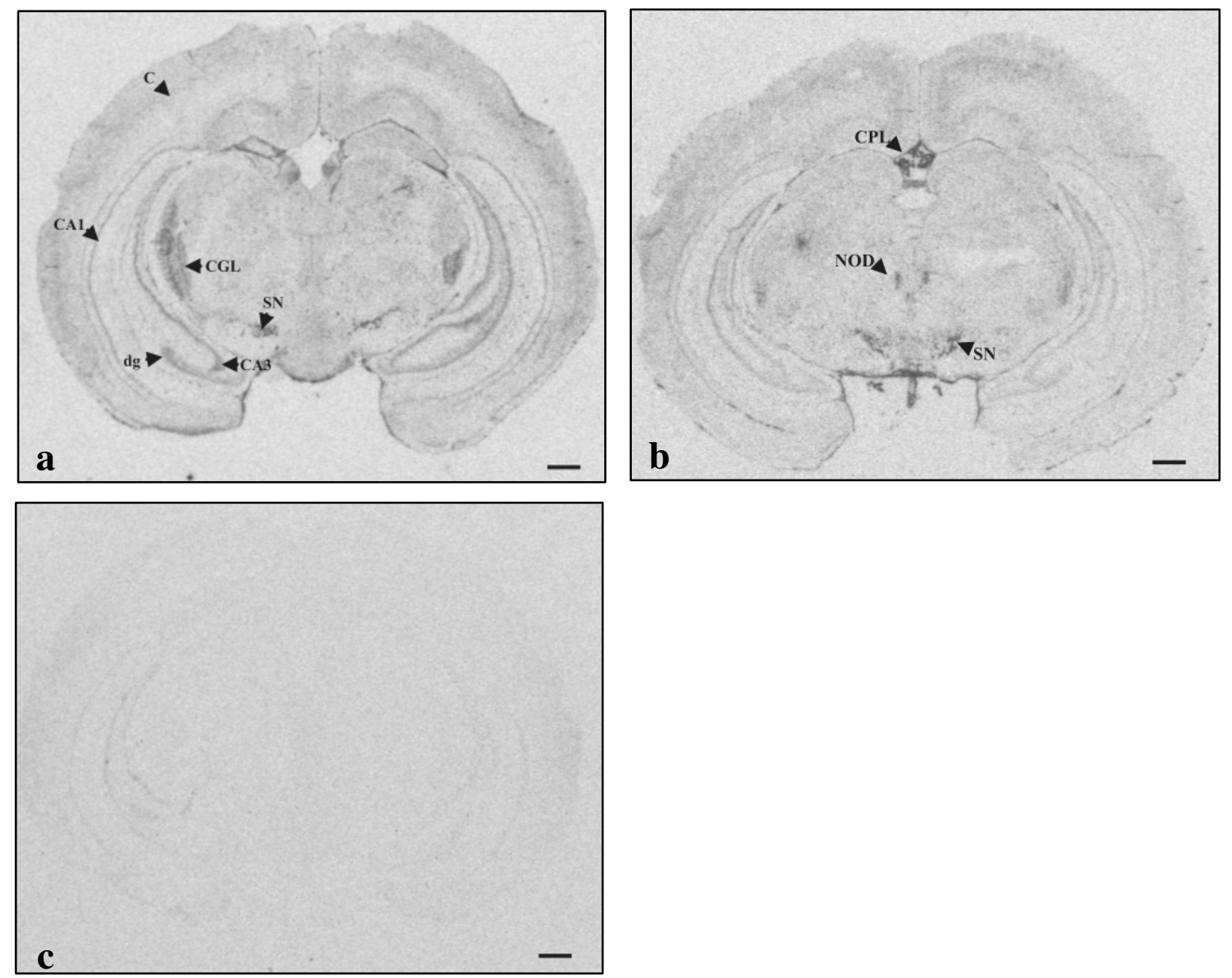

Abb. 4.2: Autoradiogramm der MHC-Klasse-I-Expression in der In-situ-Hybridisierung von ${ }^{33} \mathrm{P}$-dUTP markierter Tube-W02 Antisense-Sonde mit coronalen T. belangeri Gehirnschnitten (a, b). Positive MHC-Klasse-I-Expression (dunkel markierte Bereiche) findet sich in folgenden Hirnregionen: Hippocampus-Formation (CA1: Area CA1 hippocampi; CA3: Area CA3 hippocampi; dg: Gyrus dentatus); Corpus geniculatum laterale (CGL); Substantia nigra (SN); Cortex cerebri (C); Nucleus oculomotorius communis (NOD); Plexus choroideus (CPL). In der In-situ-Hybridisierung mit ${ }^{33} \mathrm{P}$-dUTP markierter Sense-Sonde von Tube-W02 sind auf dem Autoradiogramm keine spezifischen Signale erkennbar (c). Skala: $1 \mathrm{~mm}$.

\subsubsection{In-situ-Hybridisierung mit Gehirnschnitten von T. belangeri mit MHC-}

\section{Klasse-I-Sonde: Zellebene}

Anhand der MHC-Klasse-I-Expressionsverteilung auf den Autoradiogrammen (Abb. 4.2 a, b) wurden Hirnregionen ausgewählt, deren MHC-Klasse-I-Expression auf Zellebene untersucht wurde. Eine positive Expression wurde mikroskopisch mittels Fotoemulsion durch Akkumulation schwarzer Silberkörner nachgewiesen. Die Unterscheidung von Neuron- und Gliazellen erfolgte aufgrund der unterschiedlichen Anfärbung mit Toluidinblau. Gliazellen erscheinen klein und zeigen nur die dunkelblaue Färbung ihrer Zellkerne, während Neuronen größer und schwächer gefärbt sind. Folgende Hirnareale wurden dabei genauer betrachtet: Cortex cerebri, Substantia nigra, Hippocampus- 
Formation (CA1, CA3, dg), Plexus choroideus, Corpus geniculatum laterale, Nucleus oculomotorius communis, Blutgefäß/Hirnhaut.

In jeder In-situ-Hybridisierung wurde eine Sense-Sonde als Negativkontrolle mitgeführt. So wie auf dem Autoradiogramm (Abb. 4.2 c) keine Signale detektiert wurden, konnten auch keine spezifischen Silberkörneranreichungen, beobachtet werden (Abb. 4.5 d; 4.6 c). Ein geringfügiger unspezifischer Background an Silberkörnern war in jeder SenseHybridisierung vorhanden.

\section{Cortex cerebri}

Im Cortex cerebri konnten anhand des Autoradiogramms (Abb. 4.2 a) schwache Signale positiver MHC-Klasse-I-Expression beobachtet werden. Auf zellulärer Ebene (Abb. 4.3) konnten mikroskopisch vereinzelte Pyramidenneuronen mit einer Akkumulation von Silberkörnern gefunden werden. Diese Pyramidenneuronen exprimieren MHC-Klasse-ImRNA.
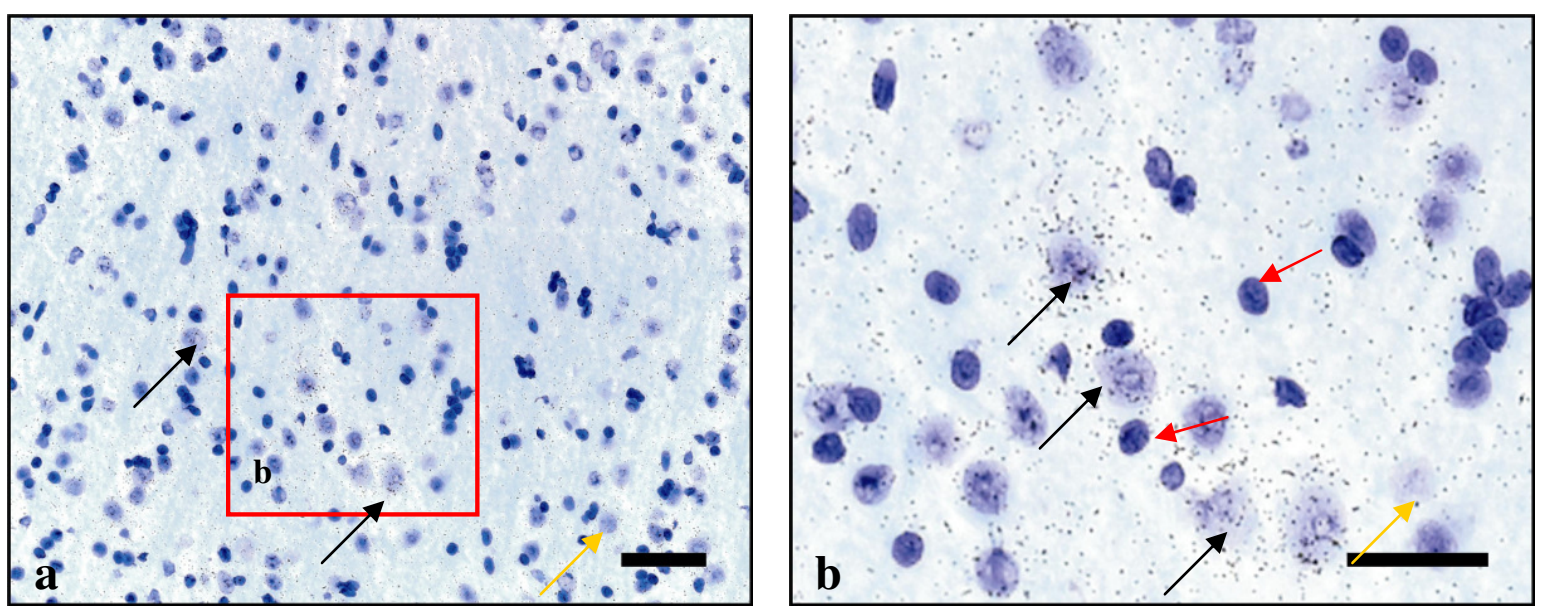

Abb. 4.3: Cortex cerebri mit Akkumulation von Silberkörnern über einzelnen Zellen nach In-situHybridisierung mit ${ }^{33} \mathrm{P}$-dUTP markierter Antisense-Sonde Tube-W02. MHC-Klasse-I-positive Neuronen (schwarze Pfeile, hellblau gefärbt) akkumulieren Silberkörner. MHC-Klasse-I-negative Neuronen akkumulieren keine Silberkörner (orange Pfeile). Keine Silberkörneranreicherung um dunkel gefärbte Gliazellen (rote Pfeile). Coronale Gehirnschnitte von T. belangeri. Gegenfärbung mit Toluidinblau. (b) Ausschnitt von (a) (roter Kasten). Skala: (a) $50 \mu \mathrm{m}$ (b) $30 \mu \mathrm{m}$.

Wie in Abb. 4.3 zu erkennen ist, exprimieren nicht alle Neuronen MHC-Klasse-I-mRNA. Die dunkel gefärbten Gliazellen zeigen keine Akkumulation von Silberkörnern. Die MHCKlasse-I-negativen Gliazellen sind entweder in enger Nachbarschaft zu Neuronen oder isoliert und ohne direktem Kontakt zu anderen Zellen. 


\section{Substantia nigra}

Zunächst konnten anhand der Autoradiogramme (Abb. 4.2) im Bereich der Substantia nigra starke Hybridisierungssignale nachgewiesen werden. Eine sehr starke MHC-KlasseI-mRNA-Expression konnte daraufhin auch auf zellulärer Ebene festgestellt werden (Abb. 4.4). Dass es sich hierbei vorwiegend um neuronale Expression (große Zellen, schwach gefärbt) handelt, ist deutlich in Abb. 4.4 zu erkennen. Eine leichte Anreicherung von Silberkörnern und somit MHC-Klasse-I-mRNA findet sich auch über glialen Zellen.
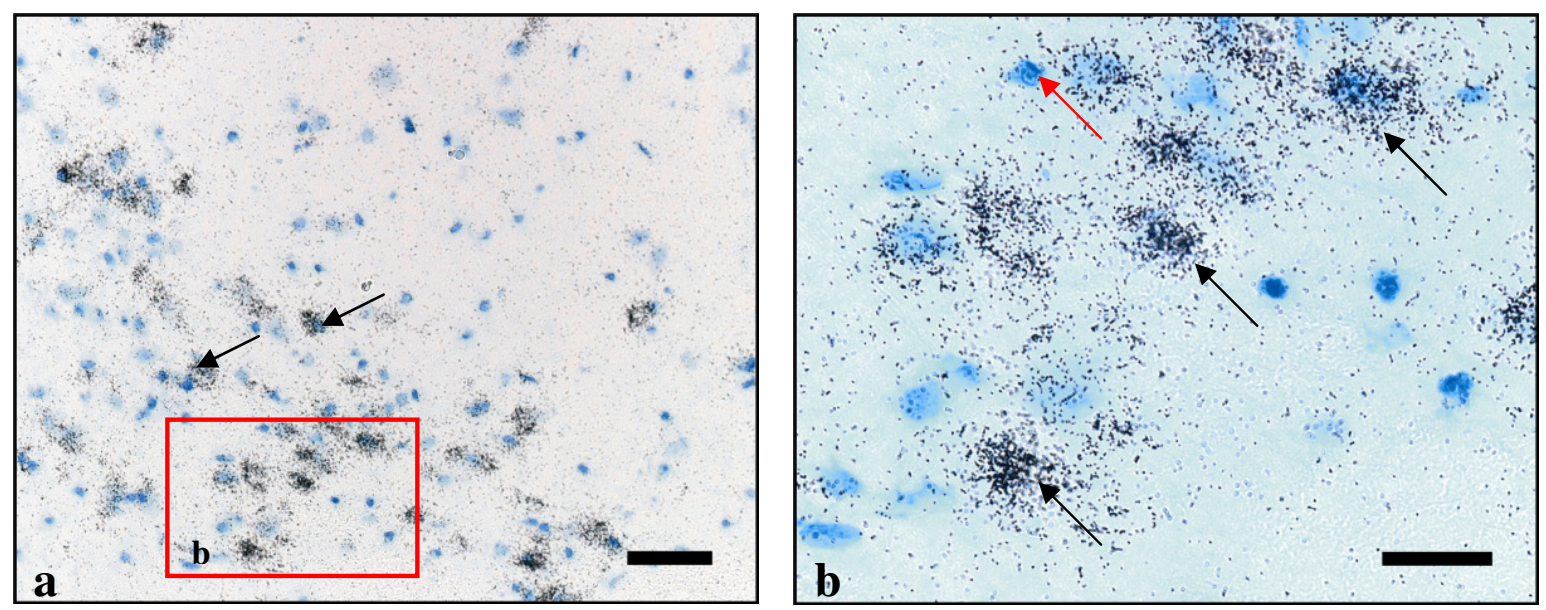

Abb. 4.4: Substantia nigra pars compacta (unten links in (a)) mit starker Silberkörneranreicherung nach In-situ-Hybridisierung mit ${ }^{33} \mathrm{P}$-dUTP markierter Antisense-Sonde Tube-W02. Positive MHCKlasse-I-Expression über schwach blau gefärbten, großen Zellen (Neuronen, schwarze Pfeile). Starke Reduzierung der Expression in der Substantia nigra pars diffusa (oben rechts in (a)). MHC-Klasse-I-positive Neuronen (schwarze Pfeile) finden sich neben vereinzelten positiven Gliazellen (rote Pfeile). Coronale Gehirnschnitte von $T$. belangeri. Gegenfärbung mit Toluidinblau. (b) Ausschnitt von (a) (roter Kasten). Skala (a) $50 \mu \mathrm{m}$, (b) $20 \mu \mathrm{m}$.

\section{Hippocampus-Formation}

Die Hippocampus-Formation umfasst den Hippocampus proper (CA-Regionen) und den Gyrus dentatus. In der Hippocampus-Formation konnten auf dem Autoradiographiefilm (Abb. 4.2) in der Region CA1 (Area CA1 hippocampi), CA3 (Area CA3 hippocampi), CA4 (Area CA4 hippocampi) und im Gyrus dentatus (dg) Signale positiver MHC-KlasseI-Expression festgestellt werden. Auf zellulärer Ebene zeigten sich sowohl in CA1 (Abb. 4.5 a), CA3 (Abb. 4.5 b) als auch im Gyrus dentatus (dg) (Abb. 4.5 c) Neuronen mit Silberkörnerakkumulation, das heißt MHC-Klasse-I-positive Zellen. In allen drei Bereichen sind allerdings nicht alle Neuronen positiv. 



Abb. 4.5: Hippocampus-Formation mit Ausschnitt aus der CA1-Region (a), CA3-Region (b) und Gyrus dentatus mit Körnerzellen (KöZ) sowie CA4-Region (CA4) (c) mit Silberkörneranreicherung nach In-situ-Hybridisierung mit ${ }^{33} \mathrm{P}$-dUTP markierter Antisense-Sonde Tube-W02. MHC-KlasseI-positive Neuronen (schwarze Pfeile). Hintergrund von Silberkörnern nach In-situHybridisierung mit ${ }^{33} \mathrm{P}$-dUTP markierter Sense-Sonde Tube-W02 im Gyrus dentatus (d). Wenige Silberkörner ergeben das unspezifische Hintergrundrauschen. Coronale Gehirnschnitte von $T$. belangeri. Gegenfärbung mit Toluidinblau. Skala:(a) $20 \mu \mathrm{m}$, (b) $10 \mu \mathrm{m}$, (c, d) $50 \mu \mathrm{m}$.

\section{Plexus choroideus}

Wie auf dem Autoradiogramm (Abb. 4.2) zu erkennen ist, wies der Bereich des Plexus choroideus eine sehr starke MHC-Klasse-I-Expression auf. Auf mikroskopischer Ebene (Abb: 4.6) konnte eine starke Ansammlung von Silberkörnern über den Zellen des Plexus choroideus beobachtet werden. Nahezu alle Zellen zeigten diese Anhäufung, so dass wahrscheinlich alle Zellen des Plexus choroideus MHC-Klasse-I-positiv sind. 

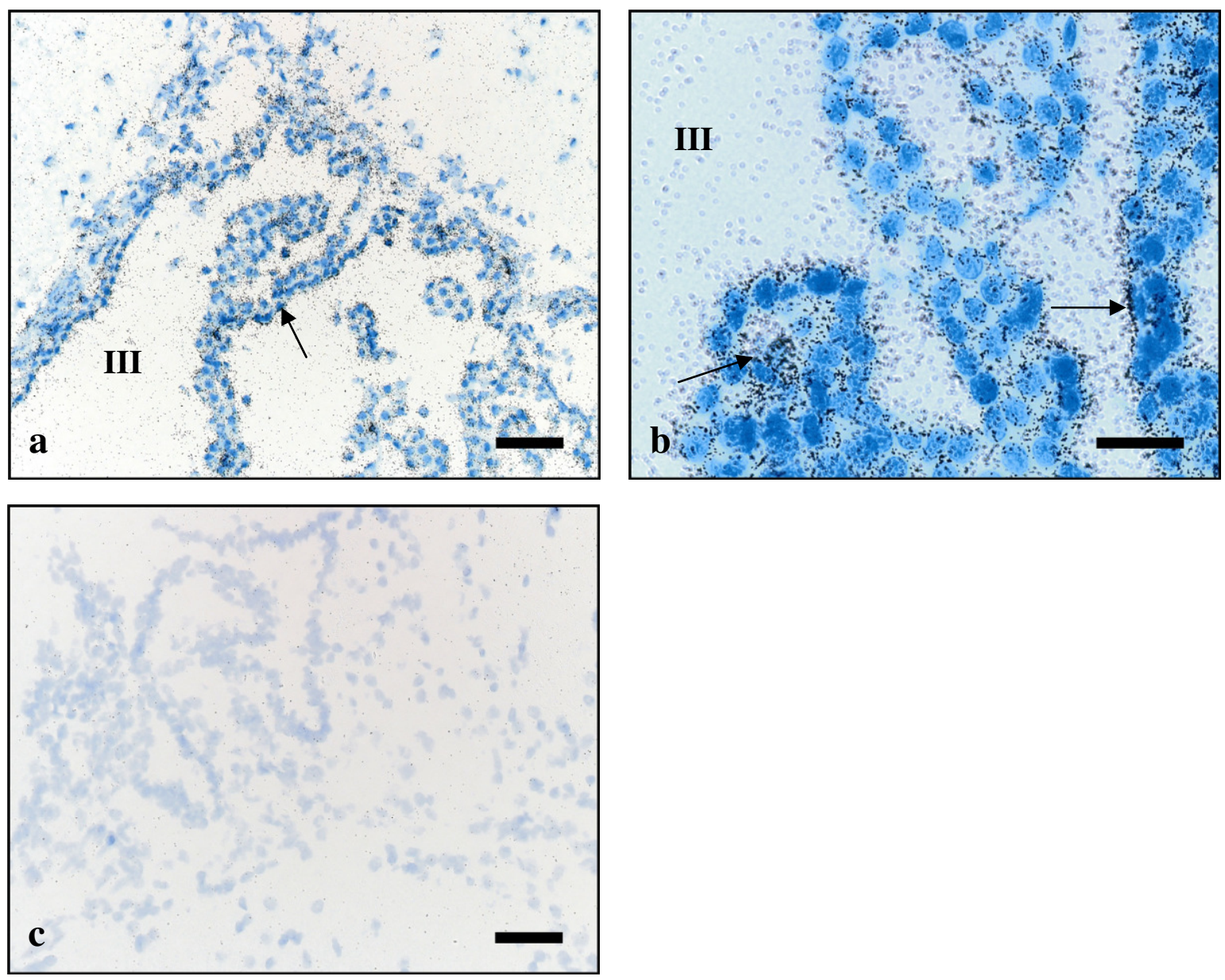

Abb. 4.6: Plexus choroideus mit starker Silberkörneranreicherung nach In-situ-Hybridisierung mit ${ }^{33} \mathrm{P}$ dUTP markierter Antisense-Sonde Tube-W02 (a, b). MHC-Klasse-I-positive Zellen (schwarze Pfeile). Im Bereich des 3. Ventrikels (III) unspezifisches Hintergrundrauschen von Silberkörnern. Hintergrund von Silberkörner nach In-situ-Hybridisierung mit ${ }^{33} \mathrm{P}$-dUTP markierter Sense-Sonde Tube-W02 (c). Wenige Silberkörner ergeben das unspezifische Hintergrundrauschen. Coronale Gehirnschnitte von T. belangeri. Gegenfärbung mit Toluidinblau. Skala: (a, c) $50 \mu \mathrm{m}$, (b) $20 \mu \mathrm{m}$.

\section{Corpus geniculatum laterale}

Im Bereich des Corpus geniculatum laterale konnten auf dem Autoradiogramm Signale einer positiven MHC-Klasse-I-Expression gefunden werden (Abb. 4.2). Auf mikroskopischer Ebene konnten die Zellen aufgrund der Silberkörnerakkumulation als Neuronen identifiziert werden (Abb. 4.7). Aber nicht alle Neuronen sind MHC-Klasse-Ipositiv.

In Abb. 4.7 b ist ein Neuron in direkter Nähe zu einer Gliazelle lokalsiert. Die Silberkörnerakkumulation ist allerdings auf das Neuron beschränkt; dies deutet daraufhin, dass MHC-Klasse-I nur in dem Neuron exprimiert ist. 



Abb. 4.7: Ausschnitt aus dem Corpus geniculatum laterale mit starker Silberkörneranreicherung nach Insitu-Hybridisierung mit ${ }^{33} \mathrm{P}$-dUTP markierter Antisense-Sonde Tube-W02. MHC-Klasse-Ipositive Neuronen (schwarze Pfeile) mit eng benachbarter MHC-Klasse-I-negativer Gliazelle (roter Pfeil). Einige Neuronen sind MHC-Klasse-I-negativ (orangefarbener Pfeil) Coronale Gehirnschnitte von T. belangeri. Gegenfärbung mit Toluidinblau. Skala: (a) $20 \mu \mathrm{m}$, (b) $10 \mu \mathrm{m}$.

\section{Nucleus oculomotorius communis}

Im Bereich des Nucleus oculomotorius communis (NOD) zeigten sich auf dem Autoradiogramm (Abb. 4.2) Signale positiver MHC-Klasse-I-Expression. In Abb. 4.8 ist ein stark begrenzter Bereich positiver MHC-Klasse-I-Expression anhand von Silberkörnerakkumulation $\mathrm{zu}$ erkennen. In der Vergrößerung des Bereiches ist $\mathrm{zu}$ erkennen, dass es sich dabei um neuronale MHC-Klasse-I-Expression handelt. Gliale Zellen erscheinen MHC-Klasse-I-negativ, da sie keine Akkumulation von Silberkörner aufweisen.
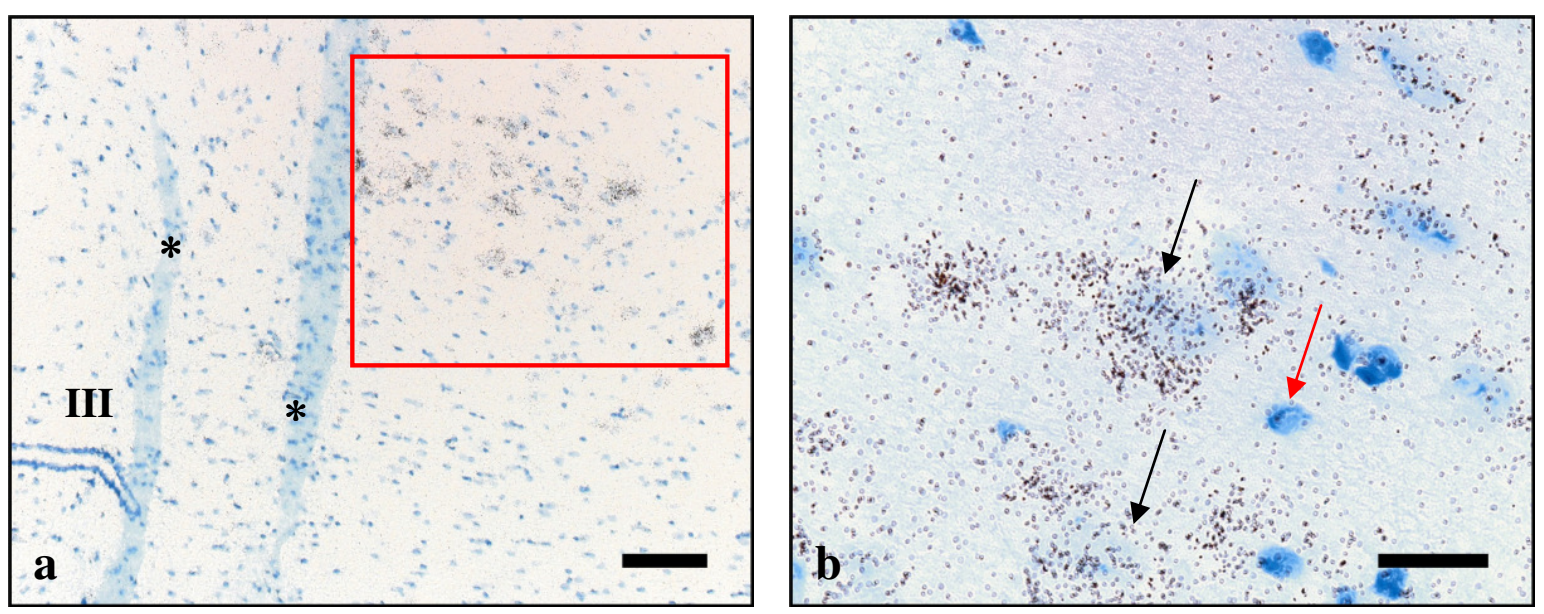

Abb. 4.8: Silberkörneranreicherung im Nucleus oculomotorius communis, pars dorsalis nach In-situHybridisierung mit ${ }^{33} \mathrm{P}$-dUTP markierter Antisense-Sonde Tube-W02. MHC-Klasse-I-positive Zellen in einem begrenzten Bereich (roter Kasten in (a)) entlang des 3. Ventrikels (III). MHCKlasse-I-positive Neuronen (schwarze Pfeile) und MHC-Klasse-I-negative Gliazellen (roter Pfeil) in (b). Coronale Gehirnschnitte von T. belangeri. Gegenfärbung mit Toluidinblau. Artefakte (*):

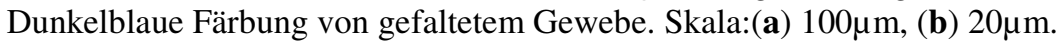




\section{Blutgefäß/Hirnhaut}

Anhand der Anreicherung von Silberkörnern um Blutgefäße (Abb. 4.9 a) und im Hirnhautgewebe (Abb. 4.9 b) konnte auch in diesen Bereichen eine Expression von MHCKlasse-I festgestellt werden. Wie in Abb. 4.9 a zu sehen, sind nahezu alle Endothelzellen, die das Blutgefäß auskleiden und damit Teil der Blut-Gehirn-Schranke bilden, MHCKlasse-I-positiv.

Die Hirnhaut stellt wie der Plexus choroideus einen Teil der Blut-Liquor-Schranke dar. In Abb. 4.9 b ist anhand der starken Akkumulation an Silberkörnern eine starke MHCKlasse-I-Expression in den Zellen der Hirnhaut zu beobachten.
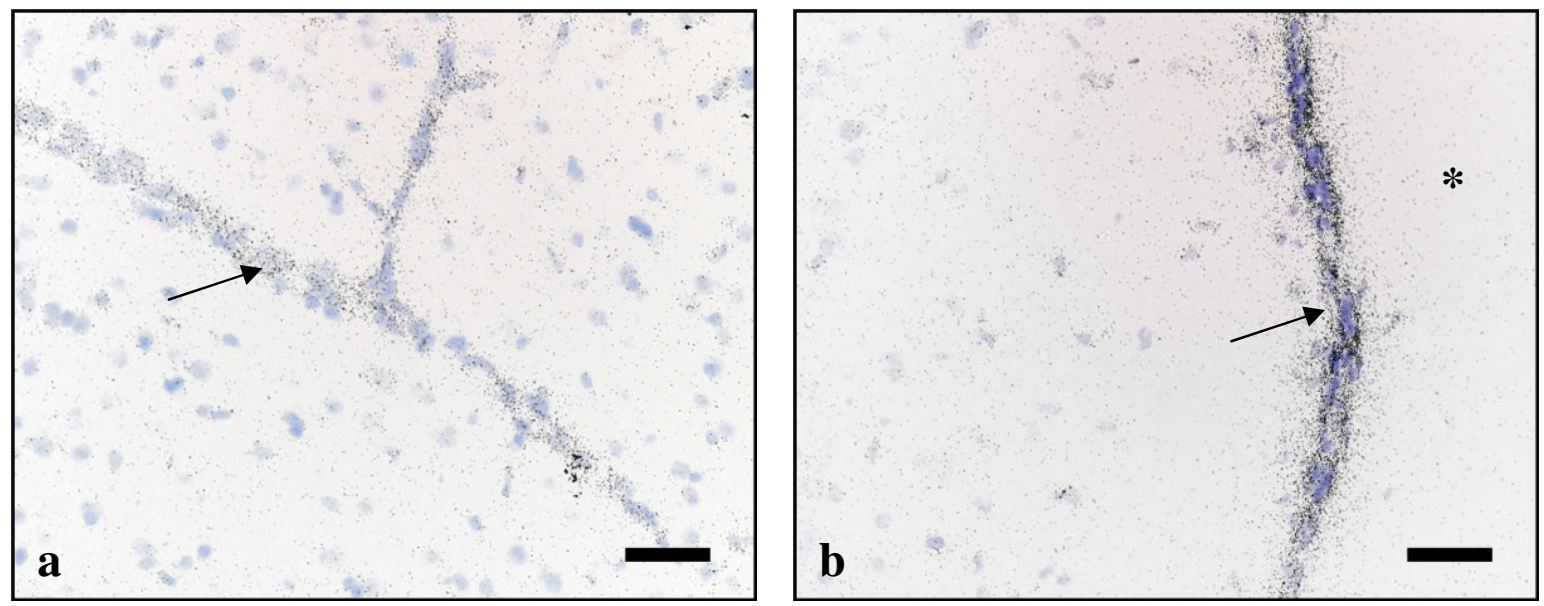

Abb. 4.9: Blutgefäß (a) und Bereich der Hirnhaut (b) mit starker Silberkörneranreicherung nach In-situHybridisierung mit ${ }^{33} \mathrm{P}$-dUTP markierter Antisense-Sonde Tube-W02. MHC-Klasse-I-positive Endothelzellen der Blutgefäße und MHC-Klasse-I-positive Zellen der Hirnhaut (schwarze Pfeile). Außerhalb des Schnitts (*). Coronale Gehirnschnitte von T. belangeri. Gegenfärbung mit Toluidinblau. Skala: (a, b) $50 \mu \mathrm{m}$.

\subsubsection{Immunhistologie mit Gehirnschnitten von T. belangeri}

Außer der Expression von MHC-Klasse-I-mRNA wurde auch die Proteinexpression untersucht. Da keine kommerziell erhältlichen Antikörper speziell gegen MHC-Klasse-I von T. belangeri verfügbar waren, wurden monoklonale Antikörper gegen humane MHCKlasse-I-Moleküle (HC10) und gegen MHC-Klasse-I-Moleküle der Ratte (Ox-18) verwendet. Der Antikörper Ox-18, der ursprünglich spezifisch für Ratten MHC-Klasse-IMoleküle ist, zeigte in der Immunhistologie mit Tupaia-Gehirnschnitten starke Signale in den Neuronen der Substantia nigra, Hippocampus und Cortex (Abb. 4.10 a-c). In diesen Bereichen stimmt die MHC-Klasse-I-Proteinexpression mit der oben beschriebenen MHCKlasse-I-mRNA Expression überein. Dies bedeutet, dass der Ox-18-Antikörper mit MHC- 
Klasse-I-Molekülen von T. belangeri kreuzreagiert und zum Nachweis dieser Moleküle im Tupaia geeignet erscheint.


Abb. 4.10: Immunhistologie mit den monoklonalen Antikörpern Ox-18 (a, b, c) und HC10 (d, e). MHCKlasse-I-Proteinexpression in Neuronen des Cortex (a), der Hippocampus-Formation (CA4: Area CA4 hippocampi, Hilus (H), Körnerzellschicht (KöZ)) (b) und der Substantia nigra (c) durch blaue Pfeile gekennzeichnet. Keine Proteinanfärbung durch den Antikörper HC10 im Cortex (d) und der Hippocampus-Formation (CA4: Area CA4 hippocampi, Hilus (H), Körnerzellschicht (KöZ)) (e). Coronale Gehirnschnitt von T. belangeri. Skala:(a, b, c, d, e) $100 \mu \mathrm{m}$. 
Mit dem Antikörper $\mathrm{HC10}$, der ursprünglich spezifisch für humane MHC-Klasse-IMoleküle ist, konnten keine spezifischen Signale in den untersuchten Regionen beobachtet werden. Beispielhaft dazu sind die Bereiche Cortex und Hippocampus gezeigt (Abb. 4.10 d, e). Kontrollschnitte, die ohne 1. Antikörper inkubiert wurden und damit unspezifische Bindungen des 2. Antikörpers zeigen sollten, waren alle negativ (Daten nicht gezeigt).

\subsection{MHC-Klasse-I-Expression im Gehirn von Callithrix jacchus}

\subsubsection{RT-PCR mit Gehirn und Leber von C. jacchus}

Zunächst wurde aus einem Tier (D) Hippocampus- und Cerebellum-RNA und aus einem anderen Tier (A) Leber-RNA gewonnen und diese anschließend durch RT-PCR in cDNA umgeschrieben. Das dabei eingesetzte Primerpaar (P1) war spezifisch für den Bereich Exon 2 bis Exon 4 von MHC-Klasse-I-Genen. Da das Exon 4 hochkonserviert ist, war davon auszugehen, dass mit dem Primerpaar (P1) möglichst viele verschiedene MHCKlasse-I-mRNA-Fragmente erfasst würden, die in diesen Geweben exprimiert sind. Die cDNA wurde anschließend in einen Vektor (pDrive) kloniert und die verschiedenen Klone mit Sequenzierprimern aus dem Vektor heraus sequenziert. Ein anschließender Vergleich mit Sequenzdatenbanken (NCBI) ergab die in Tabelle 4.1 aufgeführten Ergebnisse.

Tab. 4.1: Vergleich der Klone mit Sequenzdatenbank (NCBI). Exon (Ex)

\begin{tabular}{|c|c|c|}
\hline $\begin{array}{l}\text { Organ } \\
\text { (Tier) }\end{array}$ & $\begin{array}{c}\text { Caja-E-Allele } \\
\text { Allel (GenBank accession) } \\
\text { Homologie }(\%), \text { Vergleich bp, Exon }\end{array}$ & $\begin{array}{c}\text { Caja-G-Allele } \\
\text { Allel (GenBank accession) } \\
\text { Homologie }(\%) \text {, Vergleich bp, Exon }\end{array}$ \\
\hline $\begin{array}{l}\text { Leber } \\
\text { (A) }\end{array}$ & $\begin{array}{l}\text { Caja-E, Genotyp A/G } \\
(\text { EF014284/ EF014285) } \\
(100 \%, 319 \text { bp, Ex. } 2-3)\end{array}$ & $\begin{array}{l}\text { Caja-G-04 (U59640) } \\
(100 \%, 734 \text { bp, Ex. 2-4) } \\
\text { Caja-G-05 (U59641) } \\
(99,81 \%, 534 / 535 \text { bp, Ex. 2-3 und Ex. 4) }\end{array}$ \\
\hline $\begin{array}{l}\text { Hippocampus } \\
\text { (D) }\end{array}$ & $\begin{array}{l}\text { Caja-E, Genotyp A/G } \\
(\text { EF014284/ EF014285) } \\
(99,24 \%, 391 / 394 \text { bp, Ex. 2-3) }\end{array}$ & $\begin{array}{l}\text { Caja-G-05 (U59641) } \\
(88,15 \%, 439 / 498 \text { bp, Ex. } 2 \text { und Ex. 4) }\end{array}$ \\
\hline $\begin{array}{l}\text { Cerebellum } \\
\text { (D) }\end{array}$ & $\begin{array}{l}\text { Caja-E, Genotyp A/G } \\
(\text { EF014284/ EF014285) } \\
(99,47 \%, 375 / 377 \text { bp, Ex. } 3-4)\end{array}$ & $\begin{array}{l}\text { Caja-G-05 (U59641) } \\
(98,82 \%, 336 / 340 \text { bp, Ex. 3-4) } \\
\text { Caja-G-04 (U59640) } \\
(99,44 \%, 359 / 361 \text { bp, Ex. 3-4) }\end{array}$ \\
\hline
\end{tabular}


In der Leber von Tier A konnte eine Caja-G-Expression nachgewiesen werden, die zu 100 \% übereinstimmt mit den bekannten Allelen Caja-G-04 (GenBank accession U59640) (Anhang Abb. A.4) und zu 99,8 \% mit Caja-G-05 (GenBank accession U59641) (Anhang Abb. A.5). Eine Expression von Caja-E in der Leber konnte ebenfalls nachgewiesen werden. Der sequenzierte Abschnitt stimmte dabei mit den bisher bekannten Caja-E Allelen (GenBank accession EF014284 und EF014285) $100 \%$ überein (Anhang Abb. A.1). MHC-Klasse-I-Expression aus dem Gehirn von Tier A konnte nicht über Sequenzierung nachgewiesen werden, da das gesamte Gehirn für Dünnschnitte in der Insitu-Hybridisierung verwendet wurde.

Die MHC-Klasse-I-Expression von Tier D wurde im Hippocampus und Cerebellum auf Sequenzebene untersucht. Leber war von diesem Tier nicht vorhanden. Im Hippocampus konnten nur wenige Klone gefunden werden. Ein Klon zeigte eine 88 \%ige Ähnlichkeit mit Caja-G-05 (GenBank accession U59641) (Anhang Abb. A.6). Weiterhin konnten im Cerebellum Klone identifiziert werden, die eine 98,8 \%ige Ähnlichkeit ebenfalls mit dem Allel Caja-G-05 (GenBank accession U59641) (Anhang Abb. A.7) bzw. 99,4 \%ige Ähnlichkeit mit Caja-G-04 (GenBank accession U59640) (Anhang Abb. A.8) aufwiesen. cDNA-Klone aus dem Hippocampus (Anhang Abb. A.2) und dem Cerebellum (Anhang Abb. A.3) zeigten annähernd identische DNA-Sequenzen mit dem Caja-E-Gen (Tab. 4.1). Die Herstellung der cDNA-Klone diente vor allem der Generierung von MHC-Klasse-ISonden für die In-situ-Hybridisierung.

\subsubsection{In-situ-Hybridisierungssonden für C. jacchus}

Nach der Sequenzierung der cDNA-Klone wurden Caja-G- und Caja-E-Klone aus Leber für die Herstellung von Sonden für die In-situ-Hybridisierung ausgewählt. In Abb. 4.11 ist die vollständige Sequenz der Hybridisierungssonde Caja-G (Exon 2-4) dargestellt. Die Sequenz ist zu $100 \%$ identisch mit Caja-G-04 (GenBank accession U59640). Die Sonde wurde in der Hybridisierung eingesetzt, um möglichst alle MHC-Klasse-I-Transkripte zu detektieren, darunter neben Caja-G auch Caja-E und eventuell noch weitere nicht bekannte MHC-Klasse-I-Transkripte. Die Kreuzreaktion dieser Sonde sollte durch den Exon-4Bereich, der in allen MHC-Klasse-I-Genen hochkonserviert ist, erreicht werden. 


\begin{tabular}{|c|c|c|c|c|c|c|c|c|c|c|c|c|c|c|c|c|}
\hline & & & & & & & & & & & & & & & & \\
\hline & & F & TTC & f & & & GCC & GCG & AGT & & & & & & & \\
\hline G & GG & GTG & GAG & CAG & GAG & GGG & CCG & GAG & & & & & & & & \\
\hline &  & $c$ & CTC & $\mathrm{CA}$ & & & & & & & & & & & & \\
\hline & & Ac & $\mathrm{CAG}$ & $\mathrm{CC}$ & & & Ge & & & & & & & & & \\
\hline & & & GG & CG & & & & & c & & & & & & & \\
\hline & & & $A G$ & GAC & & & & & & & & & & & & \\
\hline & & & GTG & CG & & & & & & & & & & & & \\
\hline & & $A G$ & AGG & AGG & AGA & & $1 \mathrm{~A}$ & $\mathrm{CT}$ & $\mathrm{AG}$ & GG & & & & & & -1 \\
\hline 3) & AGA & C & $\mathrm{CTG}$ & GAG & $\mathrm{AAC}$ & $\mathrm{GC}$ & AAG & GAG & ACG & $\mathrm{CTG}$ & $c$ & CGC & G & ( & & $C C$ \\
\hline & & & & & & & & & T & & & & & & & \\
\hline & & & C & & & & & & ( & & & & & & & $C G$ \\
\hline$A T$ & $G G G$ & $G A G$ & $G A C$ & $C A G$ & $A C C$ & $C A G$ & GAC & $A T G$ & $G A G$ & CTC & GTA & $G A G$ & $A C C$ & $A G G$ & $C C A$ & $G C A$ \\
\hline$G G$ & $A T$ & & 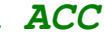 & & & & & TGG & sec & & & & & & & \\
\hline
\end{tabular}

Abb. 4.11: Sequenz der In-situ-Hybridisierungssonde Callithrix jacchus MHC-Klasse-I Caja-G (Exon 24) (734bp) (Klon 15 aus Leber (A)). rot: Exon 2 (polymorph); blau: Exon 3 (polymorph); grün: Exon 4 (konserviert) Kursiv: Primerpaar P1.

Neben der In-situ-Hybridisierung mit der CajaG (Exon 2-4)-Sonde wurden auch zwei genspezifische Sonden hergestellt. Dazu wurde aus der cDNA aus Leber (A) mit Hilfe eines spezifischen Primerpaars (P2) für Caja-G ein PCR-Produkt erzeugt, das nur mit Exon 2-3 überlappte. Der gleiche Ansatz wurde für eine Caja-E-spezifische Sonde mit einem anderen spezifischen Primerpaar (P3) verwendet. Beide PCR-Produkte wurden kloniert, sequenziert und in der In-situ-Hybridisierung eingesetzt. Mit diesen beiden Sonden Caja-G (Exon 2-3) (Abb. 4.12) und Caja-E (Exon 2-3) (Abb. 4.13) sollten nur die spezifischen Caja-G- bzw. Caja-E-Transkripte detektiert werden. Der Sequenzvergleich der beiden Sonden untereinander wies eine Übereinstimmung von $85 \%$ auf (Abb. 4.14).



Abb. 4.12: Sequenz der In-situ-Hybridisierungssonde Callithrix jacchus MHC-Klasse-I Caja-G (Exon 2-3) (474bp) aus Leber cDNA (A). rot: Exon 2; blau: Exon 3 nur 206 bp von 276bp. Kursiv: Primerpaar P2. 


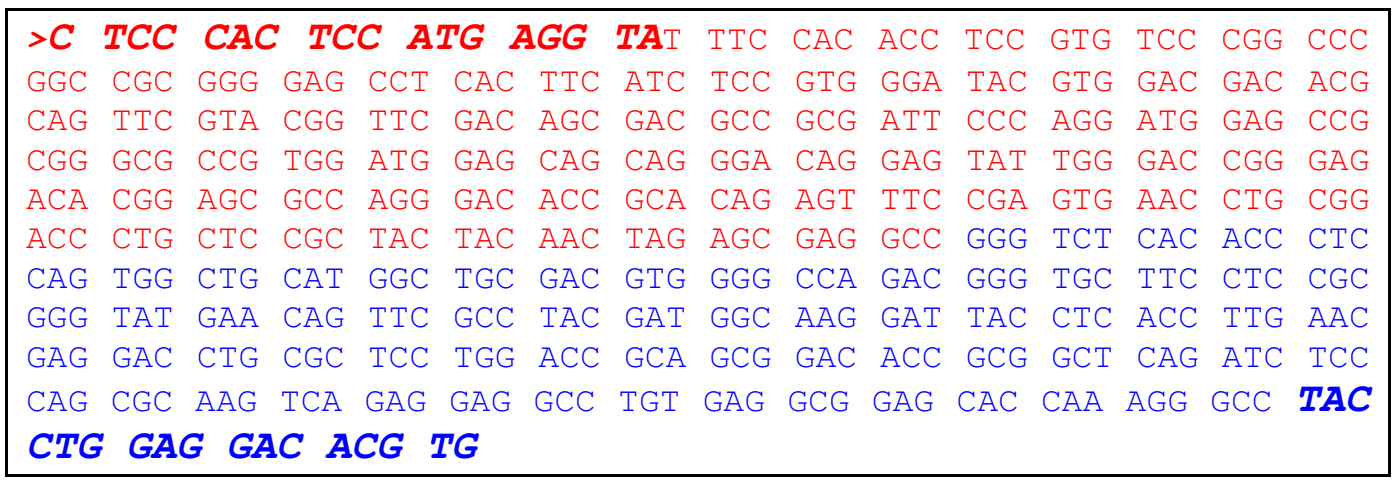

Abb. 4.13: Sequenz der In-situ-Hybridisierungssonde Callithrix jacchus MHC-Klasse-I Caja-E (Exon 2-3) (489bp) aus Leber cDNA (A). rot: Exon 2; blau: Exon 3 nur 221 bp von 276bp. Kursiv: Primerpaar P3.

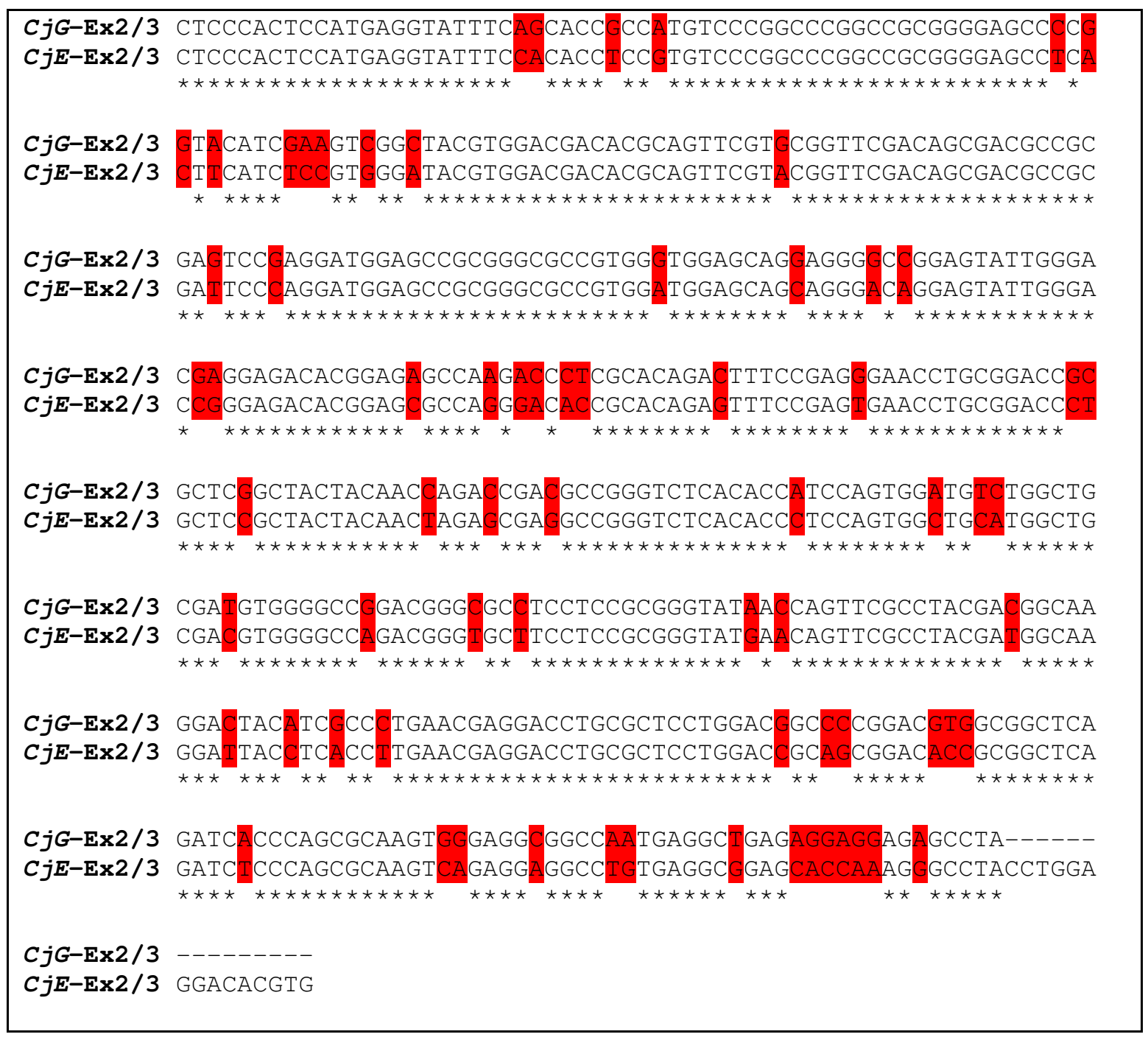

Abb. 4.14: Sequenzvergleich zwischen den Hybridisierungssonden Caja-G (Exon 2-3) (CjG-Ex2/3) und Caja-E (Exon2-3) (CjE-Ex2/3). 70 bp von 474 bp sind nicht identisch (rot markiert). Die Sequenzen stimmen zu $85 \%$ überein. 


\subsubsection{In-situ-Hybridisierung mit Gehirnschnitten von C. jacchus und Caja-G (Exon 2-4)-Sonde: Übersicht}

Zunächst wurde in der In-situ-Hybridisierung die radioaktive Sonde Caja-G (Exon 2-4) für

Gehirnschnitte von C. jacchus eingesetzt. Mit dieser Sonde sollten möglichst viele MHC-

Klasse-I-Transkripte nachgewiesen werden.
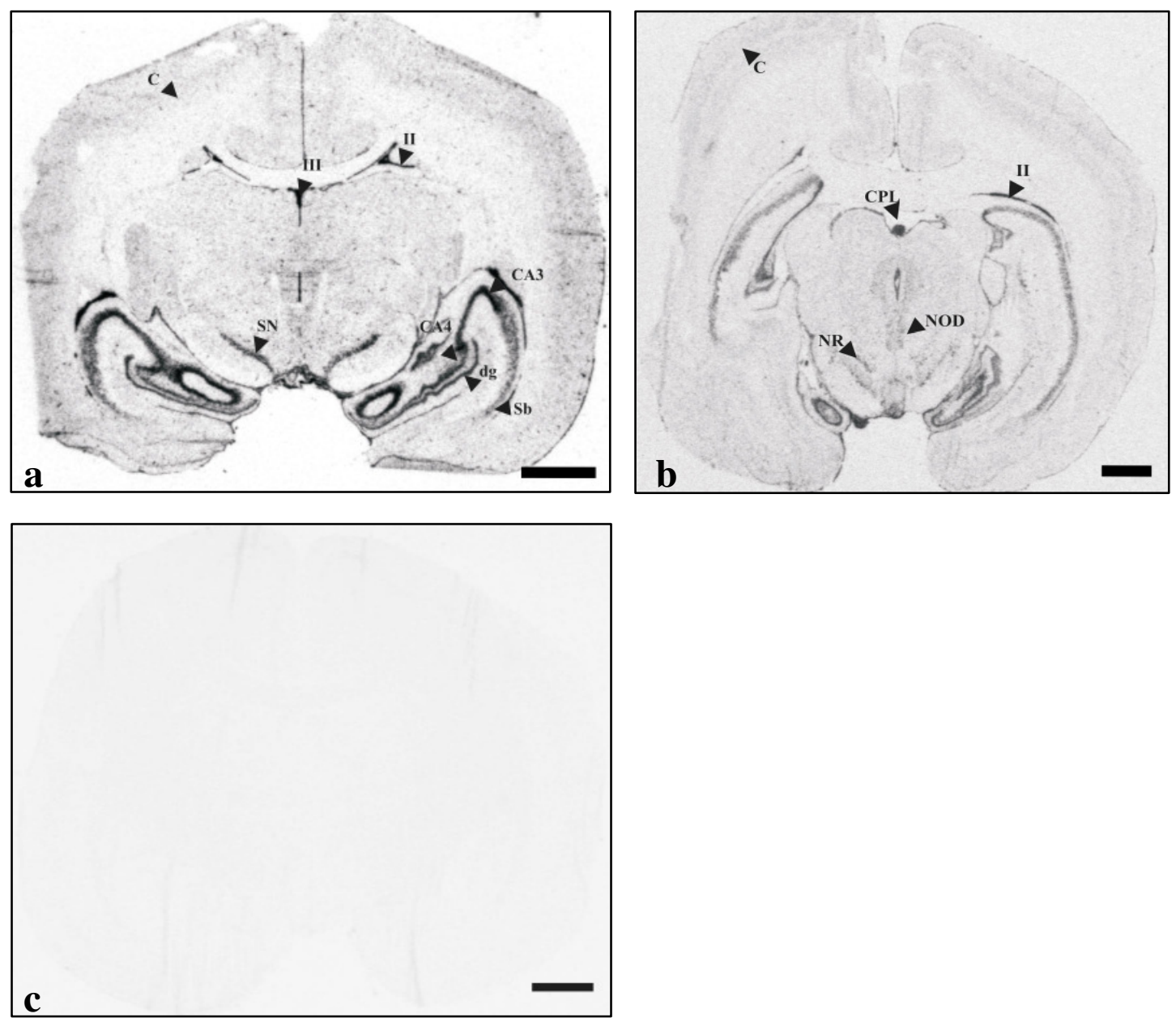

Abb. 4.15: MHC-Klasse-I-Expression nach In-situ-Hybridisierung von ${ }^{33} \mathrm{P}-\mathrm{dUTP}$ markierter Caja-G (Exon 2-4)-Antisense-Sonde mit coronalen C. jacchus Gehirnschnitten (a: Tier B; b: Tier A). Positive MHC-Klasse-I-Expression (dunkel markierte Bereiche) findet sich in folgenden Hirnregionen: Hippocampus-Formation (CA3: Area CA3 hippocampi; CA4: Area CA4 hippocampi; Gyrus dentatus (dg); Subiculum (Sb)); Substantia nigra (SN); Cortex cerebri (C); Nucleus ruber (NR); Nucleus oculomotorius communis (NOD); Plexus choroideus (CPL). 3. Ventrikel (III); 2. Ventrikel (II). In-situ-Hybridisierung mit der ${ }^{33} \mathrm{P}$ dUTP markierten Caja-G (Exon 2-4)-Sense-Sonde mit coronalen $C$. jacchus Gehirnschnitten ergab keine spezifischen Signale (c). Skala: $3 \mathrm{~mm}$.

Abb. 4.15 a, b zeigt Autoradiogramme zweier Gehirnschnitte, die mit der Antisense Caja$G$ (Exon 2-4)-Sonde hybridisiert wurden. Deutliche Signale positiver MHC-Klasse-IExpression sind in der Hippocampus-Formation (CA3, CA4, Gyrus dentatus, Subiculum), 
Substantia nigra, Cortex cerebri, Nucleus ruber, Nucleus oculomotorius communis, Plexus choroideus und in den Ventrikeln zu erkennen. Abb. 4.15 c zeigt die Hybridisierung mit der Caja-G (Exon 2-4)-Sense-Sonde. Es sind keine Signale zu erkennen und damit können eventuelle unspezifische Bindungen der Antisense Caja-G (Exon 2-4)-Sonde ausgeschlossen werden.

\subsubsection{In-situ-Hybridisierung mit Gehirnschnitten von C. jacchus und Caja-G (Exon 2-4)-Sonde: Zellebene}

Die in den Autoradiogrammen als MHC-Klasse-I-positiv nachgewiesenen Regionen wurden auf Zellebene unter dem Mikroskop untersucht. Die MHC-Klasse-Iexprimierenden Zellen wurden anhand der Anhäufung von Silberkörnern identifiziert. Durch Gegenfärbung der Zellen mit Toluidinblau wurden Neuronen (hellblau gefärbt) von Gliazellen (dunkelblau) unterschieden. In folgenden Regionen beziehungsweise Strukturen wurde auf Zellebene die Expression untersucht: Hippocampus-Formation, Substantia nigra, Cortex cerebri, Nucleus ruber, Nucleus oculomotorius communis, Plexus choroideus und Ventrikelwände.

Die Hybridisierung mit der Caja-G (Exon 2-4)-Sense-Sonde ergab auf den Autoradiogrammen (Abb. 4.15 c) keine positiven Signale. Auch auf Zellebene können in Bereichen, in denen mit der Caja-G (Exon 2-4)-Antisense-Sonde starke MHC-Klasse-ISignale nachgewiesen wurden, keine spezifischen Signale in Form von Silberkörnerakkumulationen mit der Sense-Sonde beobachtet werden (Abb. 4.16 h, 4.21 c). Wie in beiden Abbildungen $\mathrm{zu}$ erkennen ist, sind immer geringe Mengen an Silberkörnern zu finden, die als Hintergrund bezeichnet werden. Auf Zellebene können damit auch unspezifische Bindungen der Antisensesonde ausgeschlossen werden.

\section{Hippocampus-Formation}

In der Hippocampus-Formation wurden MHC-Klasse-I-positive Neuronen im Subiculum (Abb. 4.16 a, b), in der CA3-Region (Abb. $4.16 \mathrm{c}, \mathbf{d}$ ), in der CA4-Region (Abb. 4.16 e, f) und in den Körnerzellen des Gyrus dentatus (Abb. 4.16 g) nachgewiesen.

Im Subiculum waren allerdings nicht alle Pyramidenneuronen MHC-Klasse-I-positiv. Zudem waren die meisten Gliazellen negativ. 

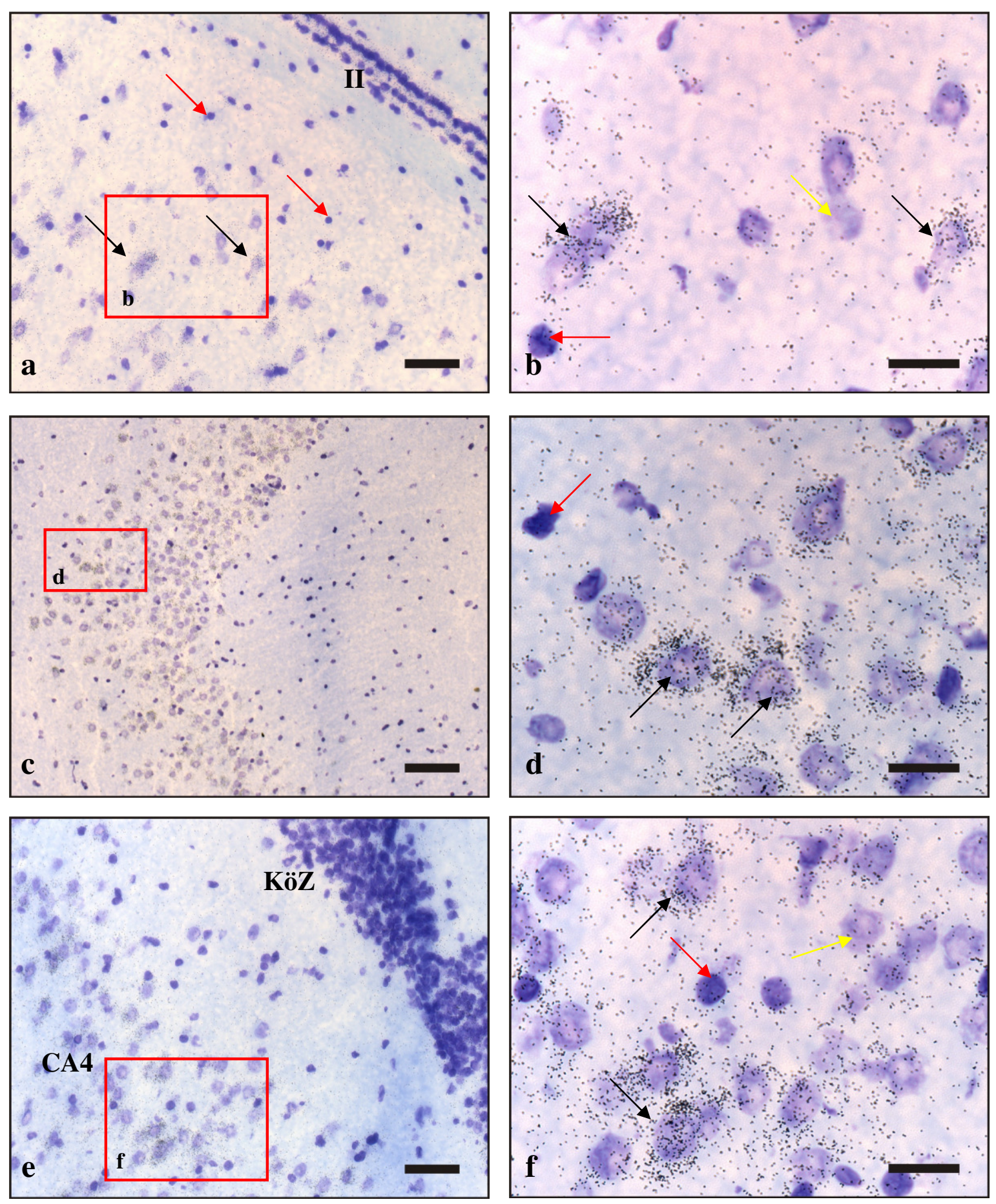

Bildunterschrift auf folgendender Seite $\longrightarrow$ 

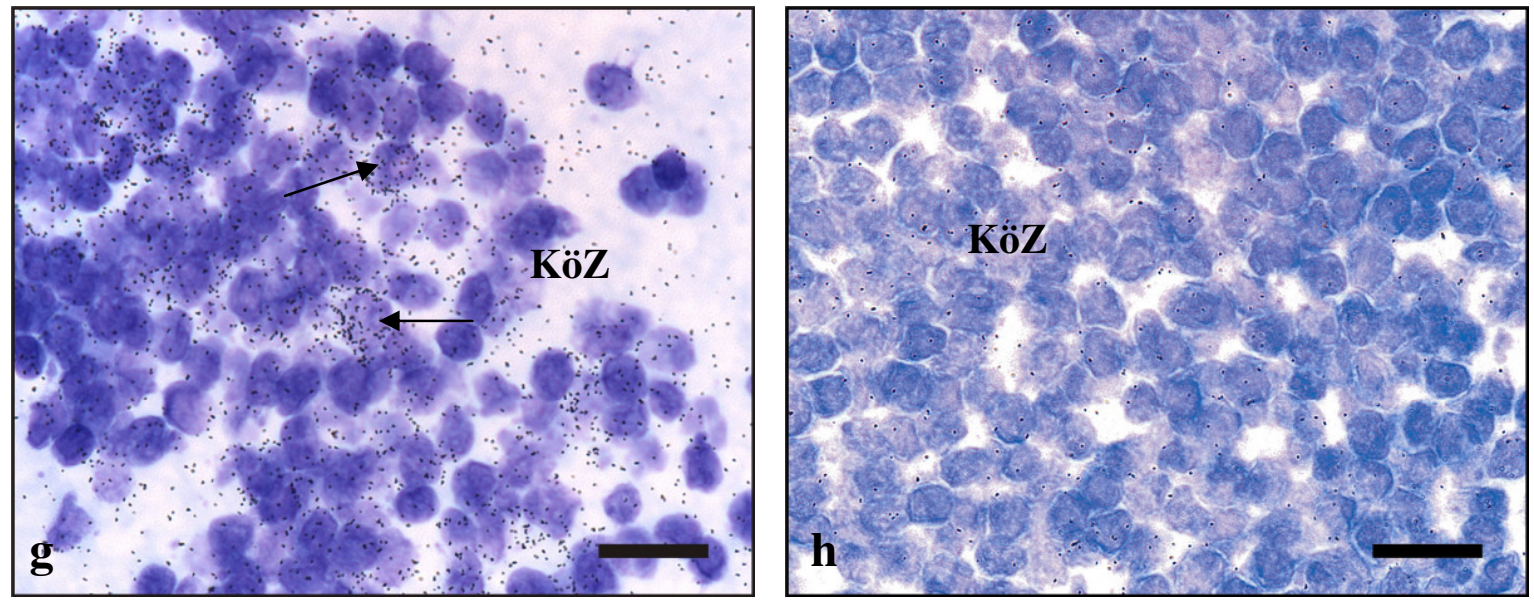

Abb. 4.16: Hippocampus-Formation mit Silberkörneranreicherung nach In-situ-Hybridisierung mit ${ }^{33} \mathrm{P}$ dUTP markierter Antisense-Sonde Caja-G (Exon 2-4) (a, b, c, d, e, f, g). MHC-Klasse-I-positive Neuronen (schwarze Pfeile) akkumulieren Silberkörner im Subiculum (a, b); CA3 (c, d); CA4 (e, f) und Gyrus dentatus (Körnerzellschicht: KöZ)) (g). MHC-Klasse-I-negative Neuronen (gelbe Pfeile, keine Silberkörner) (b, f). Gliazellen (rote Pfeile, keine bis wenig Silberkörner) (a, b, d, f). Nach In-situ-Hybridisierung mit ${ }^{33}$ P-dUTP markierter Sense-Sonde Caja-G (Exon 2-4) sind nur wenige Silberkörner ohne spezifische Anhäufungen zu sehen (h). Rote Kästen markieren Ausschnitte. II: 2. Ventrikel. Coronale Gehirnschnitte von C. jacchus (A). Gegenfärbung mit Toluidinblau. Skala:(a, e) $50 \mu \mathrm{m} ;(\mathbf{b}, \mathbf{d}, \mathbf{f}, \mathbf{g}, \mathbf{h}) 20 \mu \mathrm{m}$; (c) $100 \mu \mathrm{m}$.

Die Mehrzahl der Neuronen in der CA3-Region waren MHC-Klasse-I-positiv. Gliazellen, auch in enger Nachbarschaft zu Neuronen, waren vorwiegend MHC-Klasse-I-negativ.

Im Bereich CA4 der Hippocampus-Formation wurden ebenfalls viele Neuronen als MHCKlasse-I-exprimierend nachgewiesen. Zum Teil zeigte sich eine starke Akkumulation von Silberkörner, was auf eine starke Expression hinweist. Wie in Abb. 4.16 f ebenfalls zu erkennen ist, sind nicht alle Neuronen in der CA4-Region MHC-Klasse-I-positiv. Außerdem konnte nachgewiesen werden, dass die meisten Gliazellen keine Silberkörner akkumulierten und damit MHC-Klasse-I-negativ sind. Im Bereich des Gyrus dentatus wurden einzelne wenige Körnerzellen als MHC-Klasse-I-positiv nachgewiesen.

\section{Substantia nigra}

In der Substantia nigra wurden vor allem in der Substantia nigra pars compacta sehr viele Neuronen als MHC-Klasse-I-positiv nachgewiesen (Abb. 4.17). Teilweise sehr starke Silberkörnerakkumulation über dem Zytoplasma zeigt eine längliche Form des Neurons (Abb. 4.17 b). Gliazellen akkumulierten nur in wenigen Fällen Silberkörner. Die meisten Gliazellen, auch in der Nähe positiver Neuronen, waren MHC-Klasse-I-negativ. 

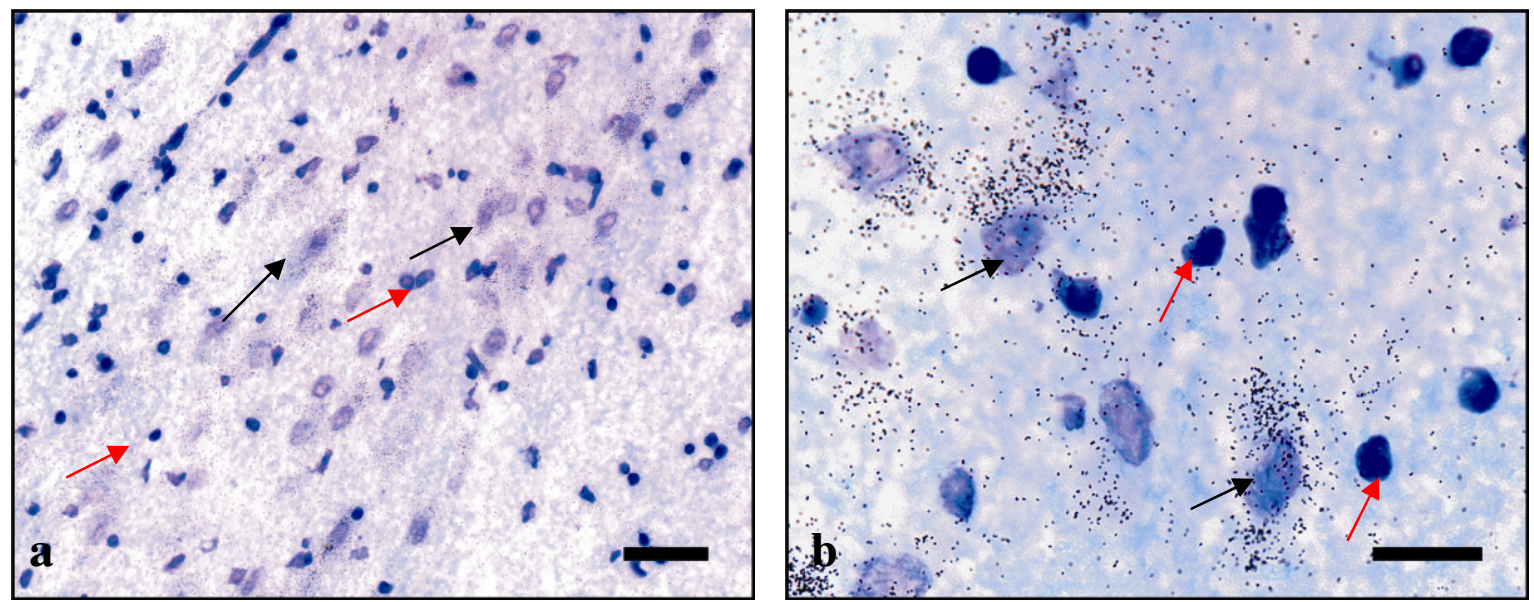

Abb. 4.17: Substantia nigra pars compacta mit Silberkörneranreicherung nach $\mathrm{In}$-situ-Hybridisierung mit ${ }^{33}$ P-dUTP markierter Antisense-Sonde Caja-G (Exon 2-4). MHC-Klasse-I-positive Neuronen (schwarze Pfeile) akkumulieren Silberkörner. Gliazellen (rote Pfeile) zeigen keine Silberkörnerakkumulation. Coronale Gehirnschnitte von C. jacchus (A). Gegenfärbung mit Toluidinblau. Skala: (a) $50 \mu \mathrm{m}$; (b) $20 \mu \mathrm{m}$.

\section{Cortex cerebri}

Auf den Autoradiogrammen (Abb. 4.15 a, b) konnten im Cortex cerebri nur sehr schwache Signale nachgewiesen werden. Auf zellulärer Ebene konnten anschließend einzelne Pyramidenneuronen vorwiegend in der Cortexschicht 5 als Silberkörner akkumulierend und damit MHC-Klasse-I-positiv nachgewiesen werden (Abb. 4.18). In der daran angrenzenden Schicht sind kaum MHC-Klasse-I-positive Neuronen zu finden. Die Expression von MHC-Klasse-I ist vorwiegend in Pyramidenneuronen nachzuweisen. Gliazellen sind von keinen oder nur wenigen Silberkörnern umgeben und damit MHC-

Klasse-I-negativ.
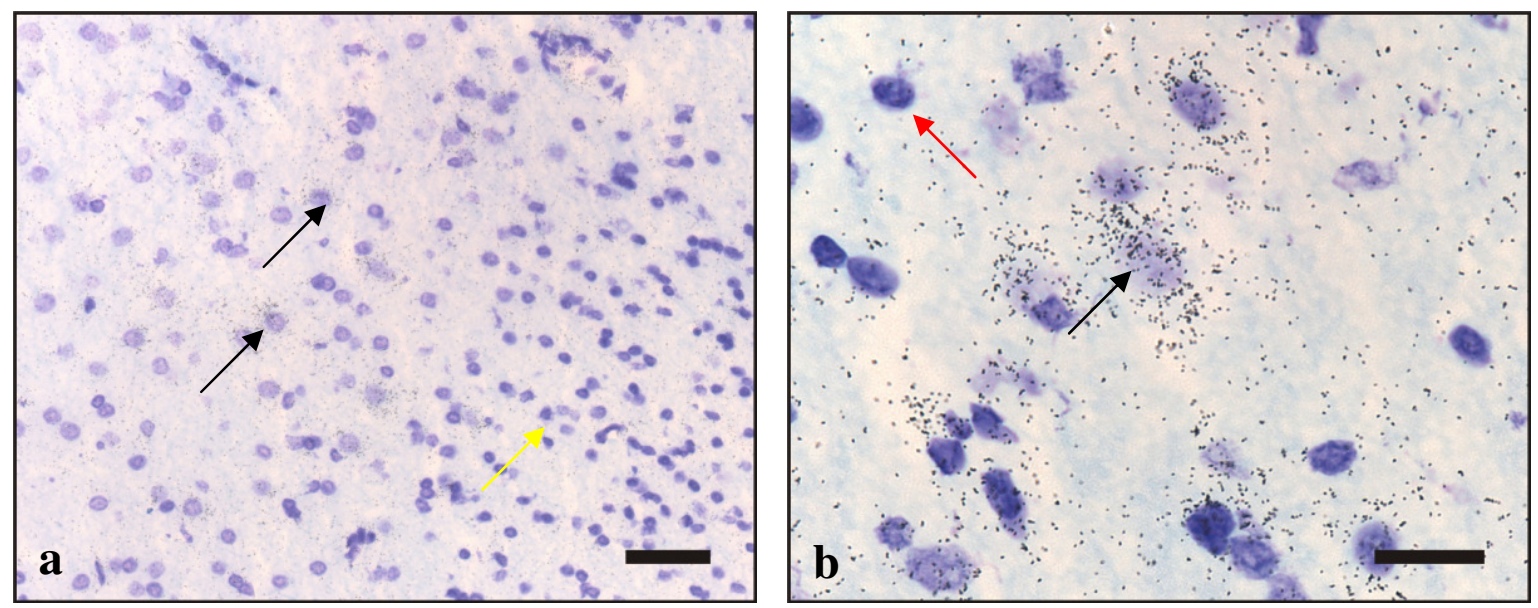

Abb. 4.18: Cortex cerebri (Schicht 5) mit vereinzelter Silberkörneranreicherung nach In-situHybridisierung mit ${ }^{33} \mathrm{P}$-dUTP markierter Antisense-Sonde Caja-G (Exon 2-4). MHC-Klasse-Ipositive Pyramidenneuronen (schwarze Pfeile) akkumulieren Silberkörner. Gliazellen (rote Pfeile) zeigen wenig Silberkörnerakkumulation. Die angrenzende Schicht weist kaum MHCKlasse-I-positive Neuronen auf (gelber Pfeil). Coronaler Gehirnschnitt von C. jacchus (A). Gegenfärbung mit Toluidinblau. Skala: (a) $50 \mu \mathrm{m}$, (b) $20 \mu \mathrm{m}$. 


\section{Nucleus ruber}

Im Nucleus ruber (pars magnocellularis) umgeben viele Silberkörner auffallend große Zellkerne (Abb. 4.19). An den Gliazellen sind keine Silberkörnerakkumulationen und damit keine MHC-Klasse-I-Expression zu erkennen. In Abb. 4.19 b ist sehr deutlich der Größenunterschied der Zellkerne zwischen den Neuronen und den Gliazellen zu sehen.
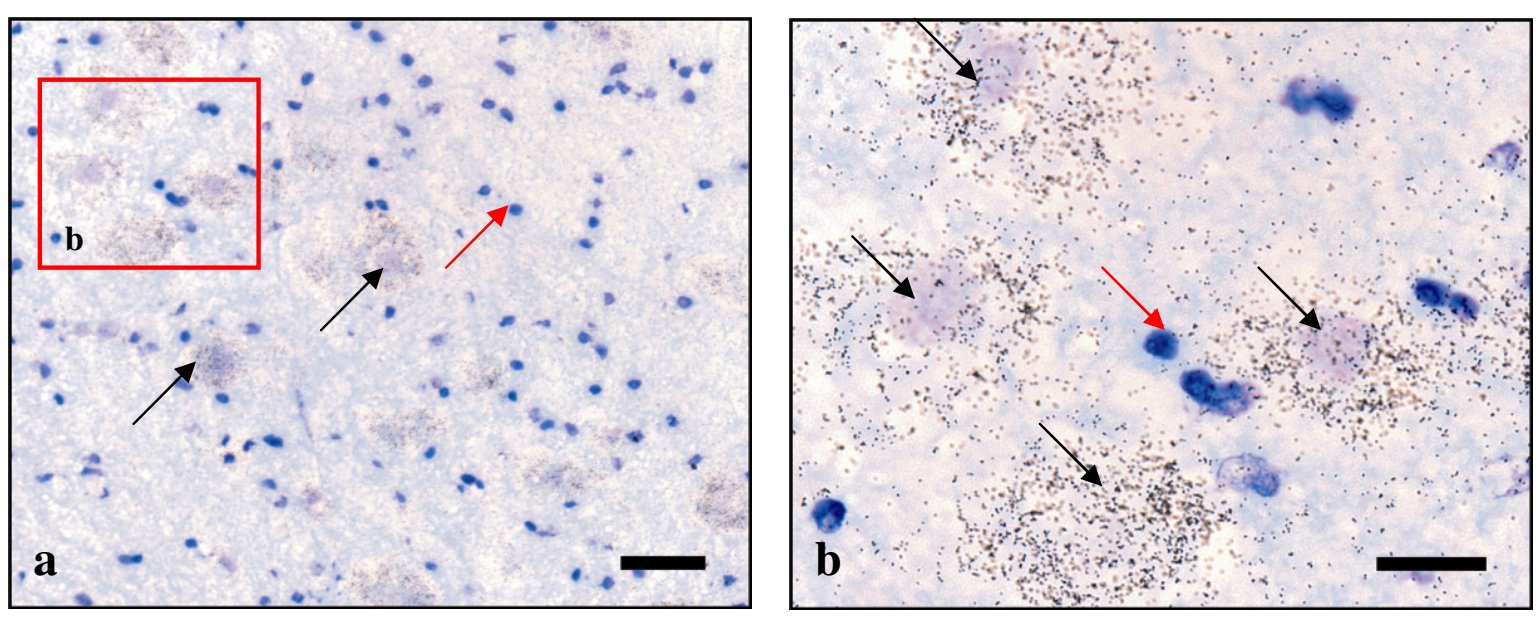

Abb. 4.19: Nucleus ruber pars magnocellularis mit starker Silberkörneranreicherung nach In-situHybridisierung mit ${ }^{33} \mathrm{P}$-dUTP markierter Antisense-Sonde Caja-G (Exon 2-4). MHC-Klasse-Ipositive Neuronen (schwarze Pfeile) akkumulieren Silberkörner. Gliazellen (rote Pfeile) zeigen wenig Silberkörnerakkumulation. Coronale Gehirnschnitte von C. jacchus (A). Gegenfärbung mit Toluidinblau. Skala: (a) $50 \mu \mathrm{m}$, (b) $20 \mu \mathrm{m}$. 


\section{Nucleus oculomotorius communis}

Wie im Autoradiogramm Abb. 4.15 b zu erkennen ist, weist der Bereich um den dritten Ventrikel herum positive Signale auf. Dabei handelt es sich um den Nucleus oculomotorius communis. Auf Zellebene konnten in diesem Kern Neuronen als Quelle der positiven MHC-Klasse-I-Expression nachgewiesen werden (Abb. 4.20). Wie in Abb. 4.20 a zu erkennen, finden sich die positiven Neuronen im Nucleus oculomotorius communis in direkter Nähe zum dritten Ventrikel. Neuronen mit kleinerem Zellkern und sichtbaren Neuriten im Nucleus oculomotorius communis sind nicht von Silberkörnern umgeben und deshalb MHC-Klasse-I-negativ.
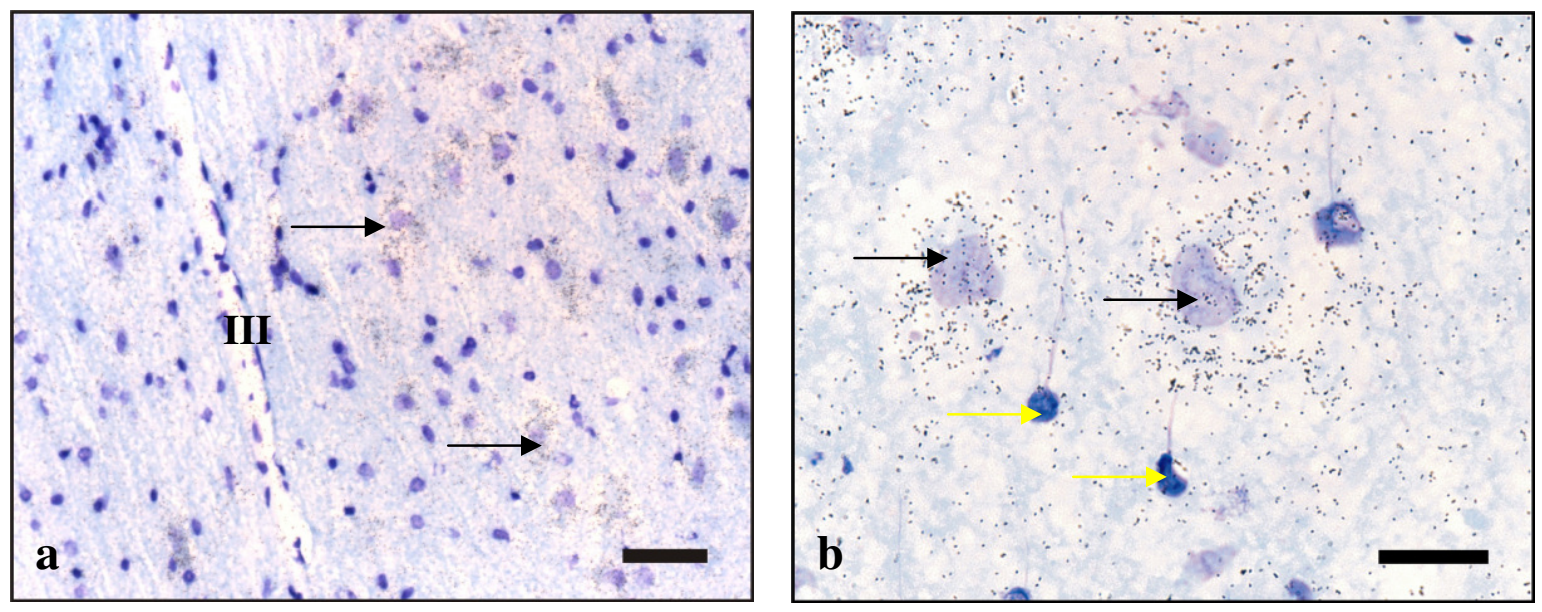

Abb. 4.20: Nucleus oculomotorius communis (a, b) mit starker Silberkörneranreicherung nach In-situHybridisierung mit ${ }^{33} \mathrm{P}$-dUTP markierter Antisense-Sonde Caja-G (Exon 2-4). MHC-Klasse-Ipositive Neuronen (schwarze Pfeile) akkumulieren Silberkörner. MHC-Klasse-I-negative Neuronen (gelbe Pfeile) sind nicht von Silberkörnern umgeben. III: Dritter Ventrikel. Coronale Gehirnschnitte von $C$. jacchus (A). Gegenfärbung mit Toluidinblau. Skala: (a) $50 \mu \mathrm{m}$, (b) $20 \mu \mathrm{m}$. 


\section{Plexus choroideus}

Im Plexus choroideus finden sich sehr starke Ansammlungen von Silberkörnern. Die Zellen des Plexus choroideus ragen in den Ventrikelraum herein (Abb. 4.21 a) und nahezu alle Zellen zeigen eine Akkumulation von Silberkörnern und damit eine positive MHCKlasse-I-Expression (Abb. 4.21 b).
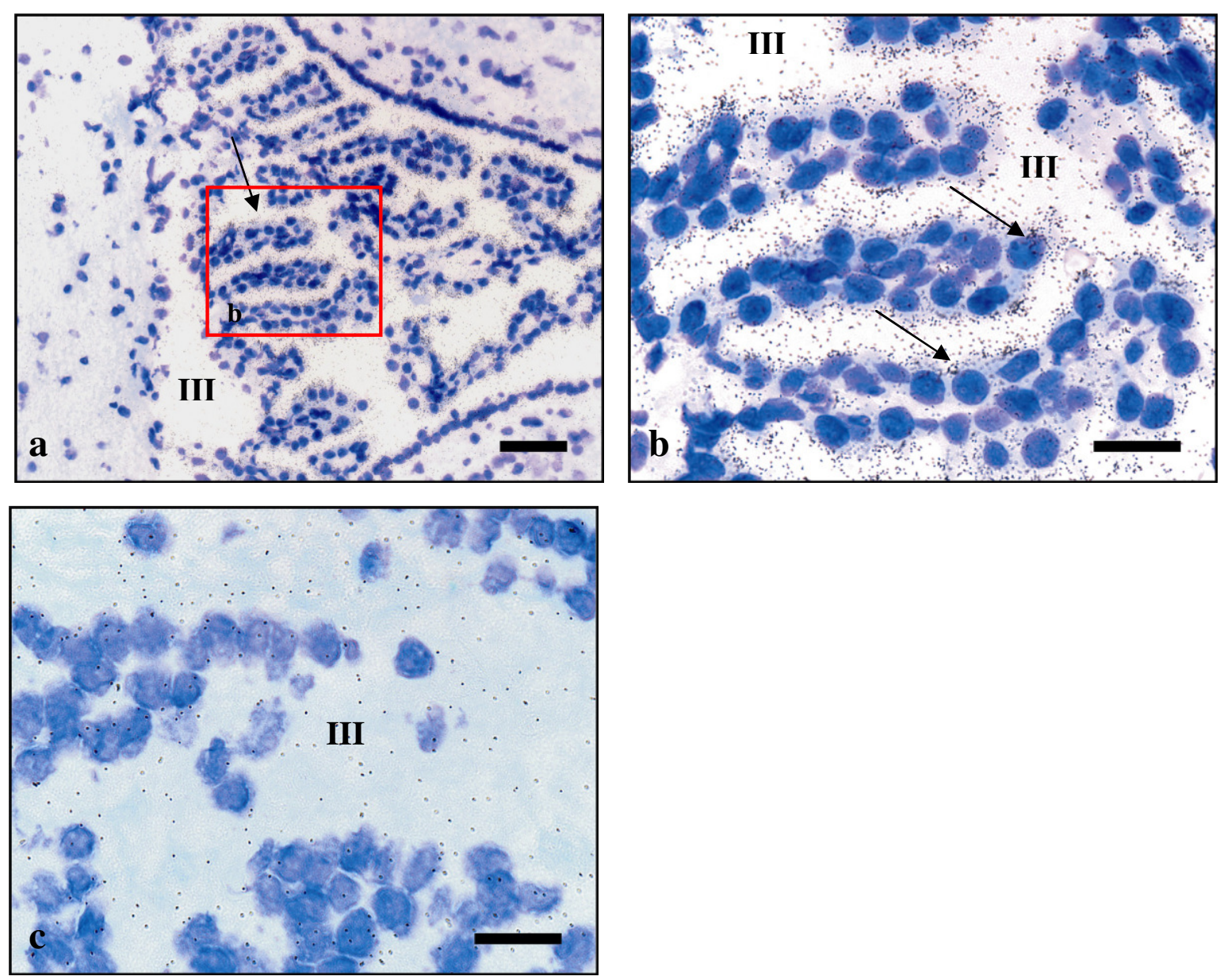

Abb. 4.21: Plexus choroideus mit starker Silberkörneranreicherung nach In-situ-Hybridisierung mit ${ }^{33} \mathrm{P}-$ dUTP markierter Antisense-Sonde Caja-G (Exon 2-4) (a, b). MHC-Klasse-I-positive Zellen (schwarze Pfeile) akkumulieren Silberkörner und ragen in den Ventrikelraum (III) hinein. In-situHybridisierung mit ${ }^{33} \mathrm{P}$-dUTP markierter Sense-Sonde Caja-G (Exon 2-4) führt zu wenigen Silberkörnern ohne spezifische Anhäufungen (c). Roter Kasten zeigt Ausschnitt. Coronaler Gehirnschnitt von C. jacchus (A389). Gegenfärbung mit Toluidinblau. Skala: (a) $50 \mu \mathrm{m}$, (b, c) 20 $\mu \mathrm{m}$.

\section{Ventrikelwände}

Wie in den Autoradiogrammen (Abb. 4.15 a, b) zu sehen ist, zeigen sich an den Ventrikelwänden ebenfalls positive Signale. Auf Zellebene können in diesen Bereichen Ependymzellen, die den Ventrikelraum auskleiden, mit Silberkörneransammlungen und damit positiver MHC-Klasse-I-Expression nachgewiesen werden (Abb. 4.22). 




Abb. 4.22: Zweiter Ventrikel mit Silberkörneranreicherung nach In-situ-Hybridisierung mit ${ }^{33} \mathrm{P}-\mathrm{dUTP}$ markierter Antisense-Sonde Caja-G (Exon 2-4). MHC-Klasse-I-positive Ependymzellen (schwarze Pfeile) akkumulieren Silberkörner. II: Ventrikelraum. Coronaler Gehirnschnitt von $C$.

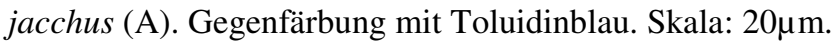

\subsubsection{In-situ-Hybridisierung mit Gehirnschnitten von C. jacchus und Caja-G (Exon 2-3)- und Caja-E (Exon 2-3)-Sonden: Übersicht}

Neben der In-situ-Hybridisierung mit der Caja-G (Exon 2-4)-Sonde wurden C. jacchus (A) Gehirnschnitte auch mit der Caja-G (Exon 2-3)- und Caja-E (Exon 2-3)-Sonde hybridisiert. Diese beiden Sonden waren um das konservierte Exon 4 der Caja-G (Exon 24) Sonde kürzer und enthielten nur noch die polymorphen Exons 2 und 3. Mit den kürzeren Sonden sollten in der Hybridisierung nur noch die jeweils für Caja-G bzw. Caja-E spezifischen Transkripte detektiert werden. In Abb. 4.23 sind Autoradiogramme aus der Hybridisierung mit der Caja-G (Exon 2-3)- (a) und Caja-E (Exon 2-3)-Sonde (b) zu sehen. Mit beiden Sonden konnten gleiche Expressionsmuster nachgewiesen werden. Allerdings waren die Signale mit der Caja-E (Exon 2-3)-Sonde deutlich schwächer als mit der Caja-G (Exon 2-3)-Sonde. Die Hybridisierung mit beiden Sonden wurde mit Gehirnschnitten von einem weiteren Tier $C$. jacchus (C) wiederholt und ebenfalls eine unterschiedliche Signalstärke nachgewiesen (Daten nicht gezeigt). Auf zellulärer Ebene konnten Silberkörnerakkumulationen in den Bereichen positiver Signale um Neuronen herum nachgewiesen werden. Dabei wurden Unterschiede in der Anzahl der Silberkörner beobachtet. Mit der Caja-G (Exon 2-3)-Sonde wurden mehr Silberkörner beobachtet als mit der Caja-E (Exon 2-3)-Sonde. 

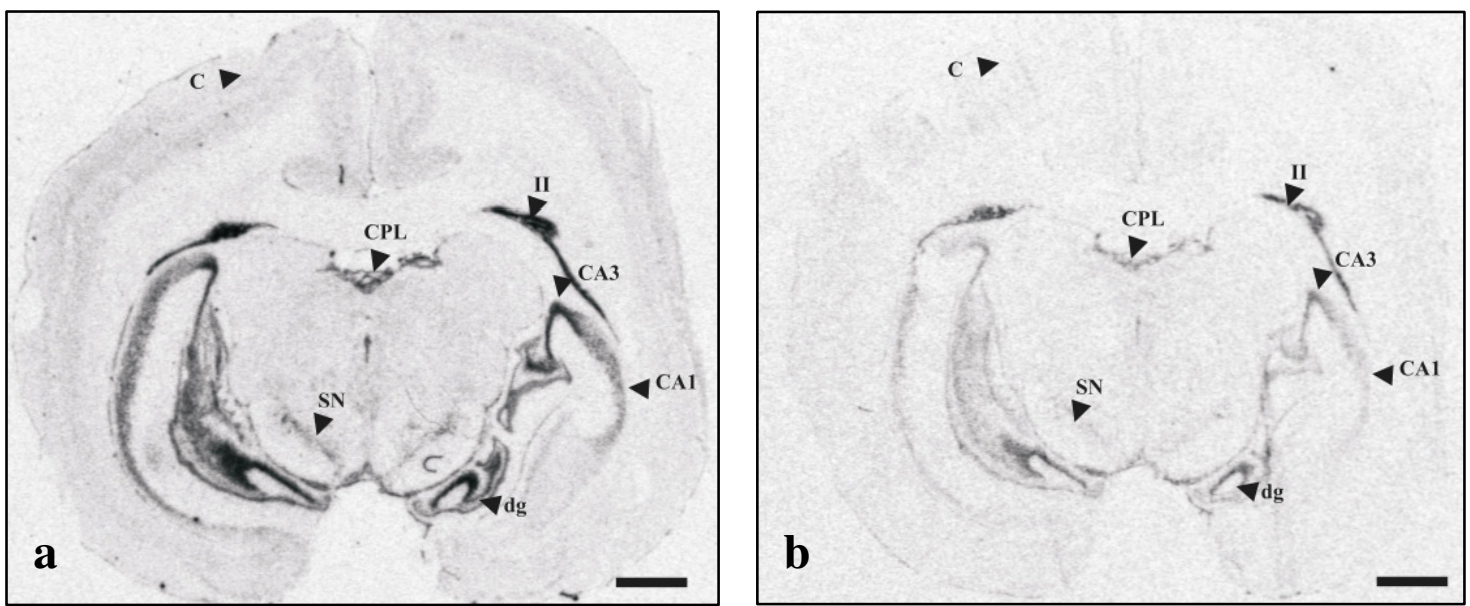

Abb. 4.23: MHC-Klasse-I-Expression nach In-situ-Hybridisierung von ${ }^{33} \mathrm{P}$-dUTP markierter (a) Caja-G (Exon 2-3)- und (b) Caja-E (Exon 2-3)-Antisense-Sonden mit aneinander grenzenden coronalen $C$. jacchus Gehirnschnitten (A). Positive MHC-Klasse-I-Expression (schwarze Pfeilspitzen) findet sich in verschiedenen Hirnregionen. Die Caja-G (Exon 2-3)-AntisenseSonde liefert deutlich stärkere Signale als die Caja-E (Exon 2-3)-Antisense-Sonde. Hippocampus-Formation (CA1: Area CA1 hippocampi; CA3: Area CA3 hippocampi; Gyrus dentatus (dg); Substantia nigra (SN); Cortex cerebri (C); Plexus choroideus (CPL); 2. Ventrikel (II). Skala: $3 \mathrm{~mm}$

\subsubsection{In-situ-Hybridisierung mit Gehirnschnitten von C. jacchus und B2M (Exon 2)-Sonde}

Neben der MHC-Klasse-I-Expression im Gehirn von $C$ jacchus wurde auch die Expression des Genes Beta-2-Mikroglobulin (B2M) untersucht. Dazu wurde aus Leber-cDNA die Hybridisierungssonde B2M mit Hilfe spezifischer Primer (P4) in der RT-PCR hergestellt. Die Sonde umfasste den Exon-2-Bereich des Gens. (Abb. 4.24).



Abb. 4.24: Sequenz der In-situ-Hybridisierungssonde C. jacchus Beta-2-Mikroglobulin B2M (221bp des Exon 2) aus Leber cDNA (A389). Kursiv: Primerpaar P4.

Nach der Hybridisierung mit der B2M-Sonde konnten auf dem Autoradiogramm (Abb. 4.25 a) positive Signale nachgewiesen werden, die mit denen der MHC-Klasse-IExpression übereinstimmten (Hippocampus, Substantia nigra, Cortex und Ventrikel). Auf zellulärer Ebene konnte in einer späteren nicht-radioaktiven Hybridisierung (siehe 
Diplomarbeit Stephanie Plehm) mit der B2M-Sonde die Expression Beta-2-Mikroglobulins in Neuronen der auf den Autoradiogrammen positiven Bereiche nachgewiesen werden.
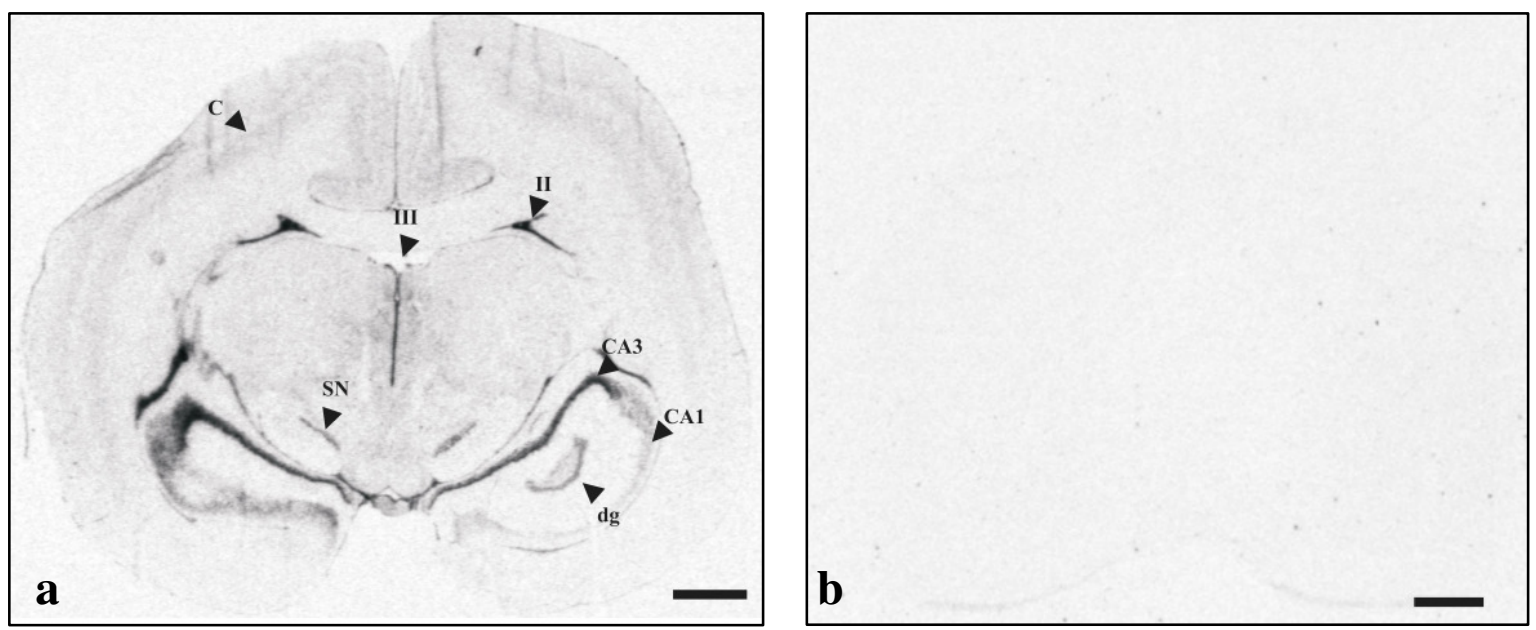

Abb. 4.25: Beta-2-Mikroglobulin-Expression in der In-situ-Hybridisierung von ${ }^{33} \mathrm{P}$-dUTP markierter $B 2 M$ (Exon 2)-Antisensesonde mit coronalen $C$. jacchus Gehirnschnitten (A) (a). B2M-mRNA (schwarze Pfeilspitzen) findet sich in verschiedenen Hirnregionen: Hippocampus (CA1: Area CA1 hippocampi; CA3: Area CA3 hippocampi); Gyrus dentatus (dg); Substantia nigra (SN); Cortex (C); 2. Ventrikel (II), 3. Ventrikel (III). In-situ-Hybridisierung mit der ${ }^{33} \mathrm{P}-\mathrm{dUTP}$ markierten B2M (Exon 2)-Sense-Sonde ergab keine spezifischen Signale (b). Skala: $3 \mathrm{~mm}$.

\subsubsection{Immunhistologie von MHC-Klasse-I-Protein an Gehirnschnitten von $C$. jacchus}

Nachdem mit Hilfe der In-situ-Hybridisierung in Neuronen verschiedener Hirnbereiche von C. jacchus MHC-Klasse-I-mRNA-Expression nachgewiesen werden konnte, wurde durch Immunhistologie auch die MHC-Klasse-I-Proteinexpression untersucht. Dazu wurden die monoklonalen Antikörper Ox-18, HC10 und HB115 eingesetzt.

Die Kreuzreaktivität des Antikörpers HC10 konnte durch Westernblot (Abb. 4.26 a-d) und Immunpräzipitation (Abb. 4.26 e) gezeigt werden; von Ox-18 und HB115 durch FACSAnalyse (Abb. 4.27).

Der Nachweis der Antikörper-Antigen Bindung in der Immunhistologie erfolgte mit einem biotinylierten Sekundärantikörper und DAB-Reaktion.

\subsubsection{Western Blot mit Antikörper HC10}

Um die Kreuzreaktivität des Antikörpers HC10 mit C. jacchus-Protein zu untersuchen, wurde der Antikörper HC10 zunächst auf seine Reaktivität im Western Blot mit Gehirnund Leberprotein von $C$. jacchus getestet. Im Bereich des Molekulargewichts um 48 kDa 
konnte in beiden Proteingemischen eine starke Bande nachgewiesen werden (Abb. 4.26 ad), die der Größe von MHC-Klasse-I-Proteinen entspricht.


Abb. 4.26: Kreuzreaktivität des monoklonalen Antikörpers HC10 mit Protein aus Gehirn und Leber von $C$. jacchus im Western Blot (a-d). Jeweils $50 \mu \mathrm{g}$ und $100 \mu \mathrm{g}$ Gehirn- und Leberhomogenat (Leberprotein: a: $50 \mu \mathrm{g}$ b: $100 \mu \mathrm{g}$. Gehirnprotein: c: $50 \mu \mathrm{g}$, d: $100 \mu \mathrm{g}$ ) von $C$. jacchus wurden in einem $10 \%$ SDS-Page aufgetrennt und anschließend auf Nitrocellulose transferiert. Der Western Blot wurde mit dem monoklonalen Antikörper HC-10 (Verdünnung 1:5) inkubiert. Bei ca. $48 \mathrm{kDa}$ (MHC-Klasse-I, dicker roter Pfeil) kann eine starke Bande nachgewiesen werden. Gehirnprotein von C. jacchus wurde mit dem Antikörper Tü149 immunpräzipitiert und anschließend im Western Blot (10 \% SDS-Page) auf Reaktivität mit HC10 (Verdünnung 1:5) getestet (e). Bei ca. $48 \mathrm{kDa}$ kann eine Bande nachgewiesen werden (MHC-Klasse-I, dicker roter Pfeil). Die schwere (54 kDa, dünner roter Pfeil) und leichte ( $25 \mathrm{kDa}$, dünner blauer Pfeil) Kette des primären Antikörpers Tü149 sind ebenfalls zu erkennen. Sekundärantikörper: HRP-Ziegeanti-Maus (Verdünnung 1:3000). Die Detektion erfolgte durch Chemilumineszenz. Größenstandard: Protein Ladder 10-160 kDa.

Weiterhin wurde eine Immunpräzipitation zum Testen der Kreuzreaktivität des Antikörpers HC10 durchgeführt. Dazu wurde Gehirnprotein von C. jacchus mit dem monoklonalen Antikörper Tü149 (anti-human MHC-Klasse-I) inkubiert. Anschließend wurde das daraus resultierende Präzipitat im Proteingel aufgetrennt und geblottet. Der Western Blot wurde daraufhin mit dem Antikörper HC10 (anti-human MHC Klasse I) getestet. Es konnte eine Bande von ca. 48 kDa nachgewiesen werden (Abb. 4.26 e), die der Größe der schweren Ketten von MHC-Klasse-I-Proteinen entspricht. Zusätzlich sind schwache Banden (54 kDa, $25 \mathrm{kDa}$ ) zu erkennen, die von der schweren und leichten Kette des primären Antikörpers (Tü149) stammen. 
4.2.7.2 Durchflusszytometrie (FACS)

Leukozyten aus Blut von C. jacchus wurden auf Reaktivität mit den Antikörpern Ox-18 und HB115 mit Hilfe der Durchflusszytometrie analysiert. Die Untersuchung und Auswertung wurde von PD Dr. R. Dressel (Immunologie, Universität Göttingen) durchgeführt und die Daten zur Verfügung gestellt. Sowohl Ox-18 als auch HB115 zeigten Kreuzreaktionen mit MHC-Klasse-I-Molekülen von C. jacchus. HB115 reagierte sehr stark mit MHC-Klasse-I-Molekülen auf Leukozyten des Marmoset. Im Vergleich dazu reagierte Ox-18 schwächer, aber dennoch spezifisch (Abb. 4.27).

HB115

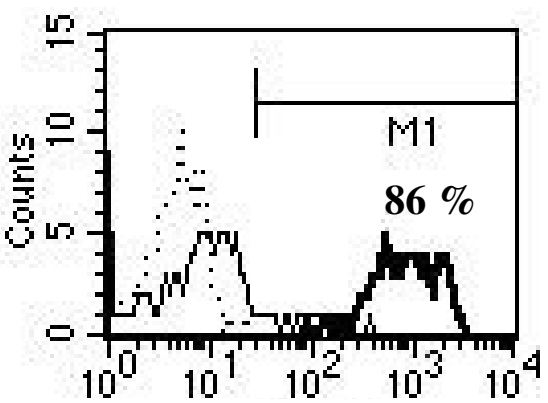

Granulozyten

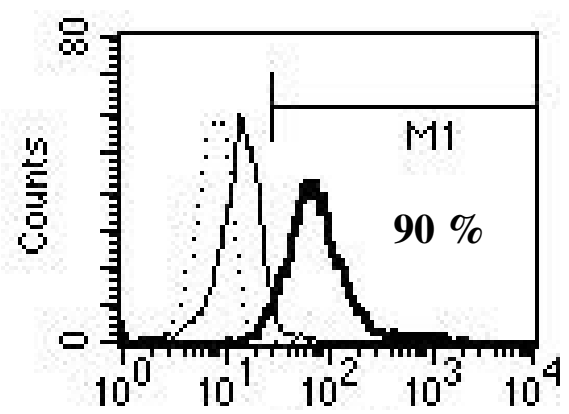

Ox-18
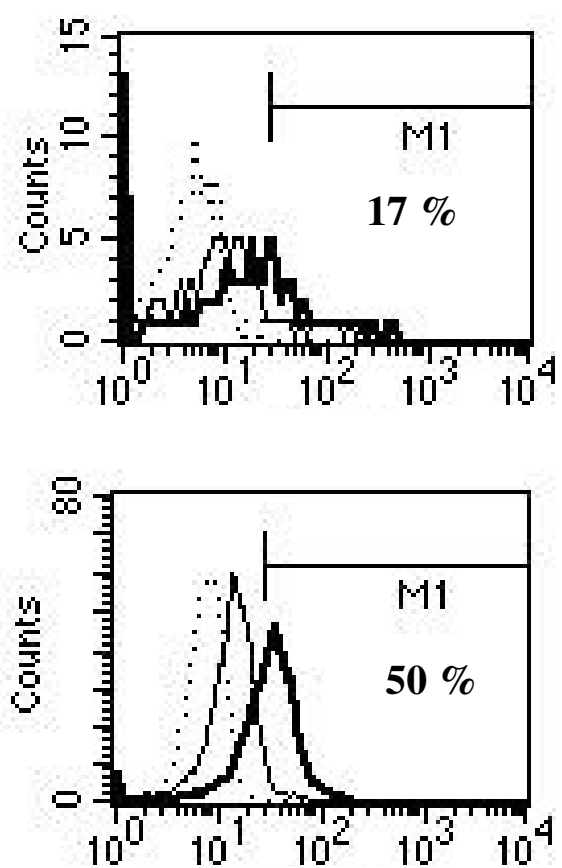

Abb. 4.27: Durchflusszytometrie mit Blutleukozyten eines C. jacchus Individuums und den Antikörpern HB115 und Ox-18. Das Histogramm zeigt die Autofluoreszenz (gestrichelte Linie), die Färbung mit dem sekundären Antikörper (dünne Linie) und die spezifische Färbung mit dem primären und sekundären Antikörper (fette Linie). Die Prozente von spezifisch gefärbten Zellen sind in den Figuren angegeben. Für die Berechnung der positiven Zellen wurde der Marker M1 herangezogen. PBMC: Peripheral Blood Mononuclear Cell.

Aus diesen Ergebnissen ergibt sich damit, dass Ox-18, HB115 und HC10 als geeignete Antikörper für die Detektion von MHC-Klasse-I-Molekülen von C. jacchus eingesetzt werden können. 


\subsubsection{Immunhistologie mit Antikörper Ox-18}

Mit Hilfe des Ox-18-Antikörpers konnte eine MHC-Klasse-I-Proteinexpression im Cortex cerebri, Hippocampus, Nucleus ruber, Substantia nigra und Nucleus oculomotorius communis nachgewiesen werden (Abb. 4.28-4.32).

\section{Cortex cerebri}

Im Cortex cerebri konnte deutlich MHC-Klasse-I-Proteinexpression an Pyramidenneuronen (lang gestreckte Morphologie) anhand starker Braunfärbung festgestellt werden (Abb. 4.28 a, b). Deutlich war ebenfalls die Färbung der apikalen Dendriten zu erkennen. Weiterhin war zu beobachten, dass die kleineren Zellen, vermutlich Interneuronen, leichte bis keine Braunfärbung aufwiesen (Abb. 4.28 b).
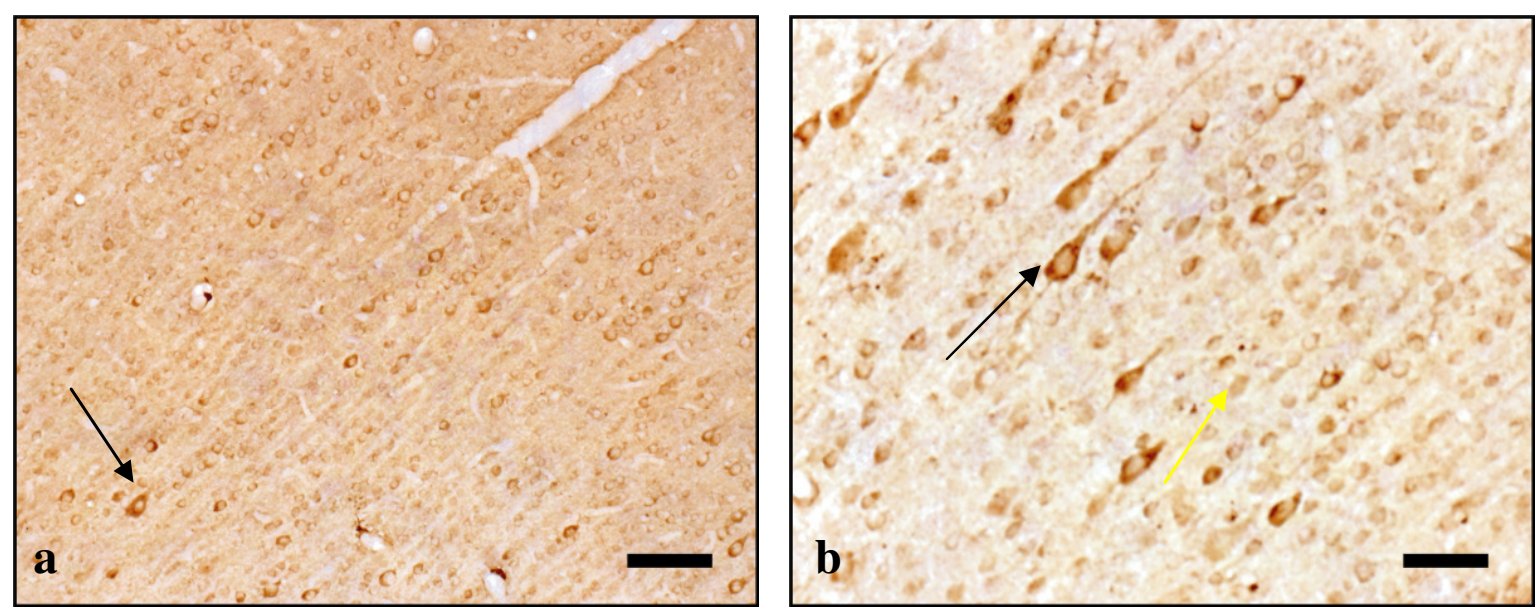

Abb. 4.28: Cortex cerebri mit Braunfärbung (DAB) in Pyramidenneuronen (schwarze Pfeile) nach Immunhistologie mit Antikörper Ox-18. Interneuronen schwächer gefärbt (gelber Pfeil). Coronale Schnitte des Gehirns von C. jacchus (E). Skala: (a) $100 \mu \mathrm{m}$, (b) $50 \mu \mathrm{m}$.

\section{Hippocampus-Formation}

Im Hippocampus konnte eine starke MHC-Klasse-I-Proteinexpression in Pyramidenneuronen im Bereich CA1 (Abb. 4.29 a, b) und CA4 (Abb. 4.29 c, d) nachgewiesen werden. Braunfärbungen an den dendritischen Fortsätzen waren ebenfalls festzustellen. Im Gyrus dentatus (Abb. 4.29 c, d) waren nur wenige Körnerzellen braun gefärbt. 

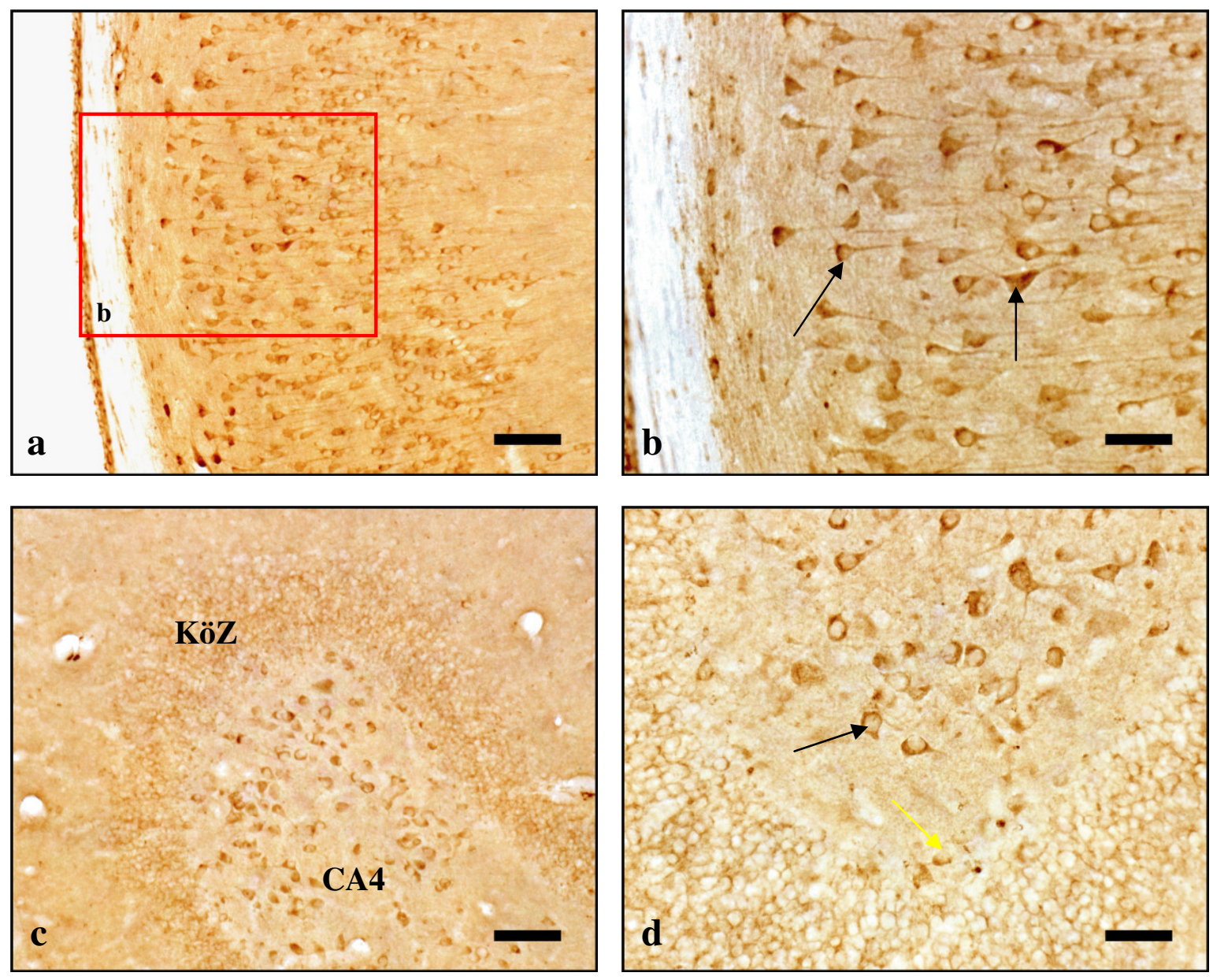

Abb. 4.29: Hippocampus-Formation im Bereich CA1 (a, b); CA4 (c, d) und Gyrus dentatus (c, d) mit Braunfärbung (DAB) nach Immunhistologie mit Antikörper Ox-18. Pyramidenzellen im CA1 und CA4 sind stark braun gefärbt (schwarze Pfeile). Im Gyrus dentatus sind nur wenige Körnerzellen (KöZ) braun gefärbt (gelbe Pfeile). Coronale Schnitte des Gehirns von C. jacchus (E). Roter Kasten: Ausschnitt. Skala: (a, c) $100 \mu \mathrm{m},(\mathbf{b}, \mathbf{d}) 50 \mu \mathrm{m}$. 


\section{Nucleus ruber}

Im Nucleus ruber (pars magnocellularis) konnte eine starke Braunfärbung und damit MHC-Klasse-I-Expression in den großen Neuronen des Kerns nachgewiesen werden (Abb.

4.30 a, b). Gliazellen waren nicht gefärbt.
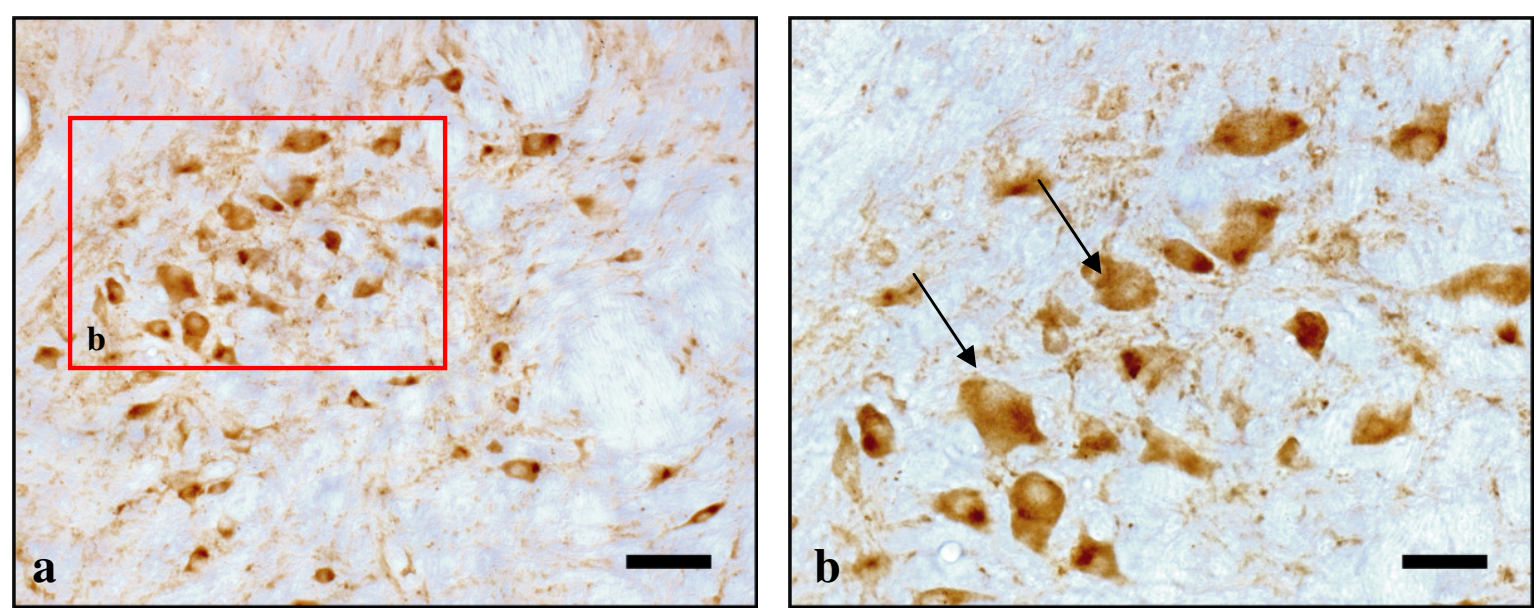

Abb. 4.30: Nucleus ruber mit Braunfärbung (DAB) in Neuronen (schwarze Pfeile) nach Immunhistologie mit Antikörper Ox-18. Coronale Schnitte des Gehirns von C. jacchus (E). Roter Kasten: Ausschnitt. Skala: (a) $100 \mu \mathrm{m}$, (b) $50 \mu \mathrm{m}$.

\section{Substantia nigra}

In der Substantia nigra konnte vor allem in der Substantia nigra pars compacta MHCKlasse-I-Proteinexpression durch Braunfärbung in den Neuronen nachgewiesen werden (Abb. $4.31 \mathrm{a}, \mathrm{b})$.
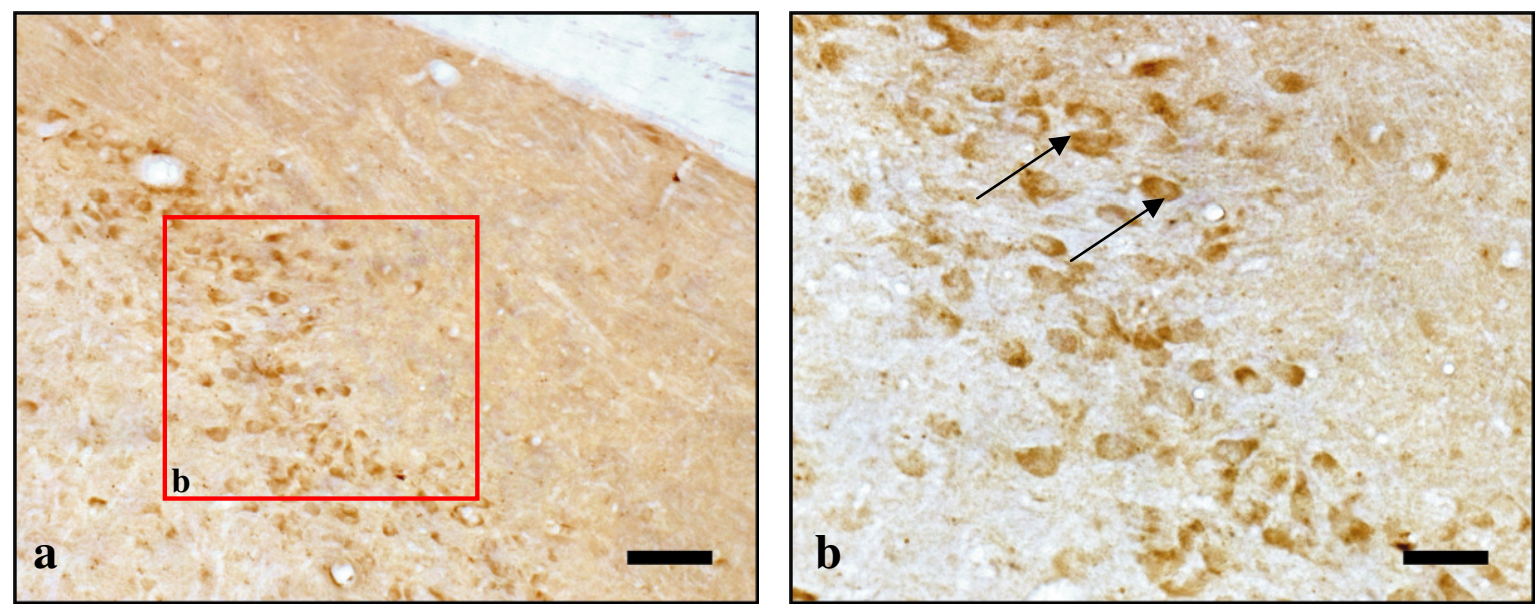

Abb. 4.31: Substantia nigra (pars compacta) mit Braunfärbung (DAB) in Neuronen (schwarze Pfeile) nach Immunhistologie mit Antikörper Ox-18. Coronale Schnitte des Gehirns von C. jacchus (E). Roter Kasten: Ausschnitt. Skala: (a) $100 \mu \mathrm{m}$, (b) $50 \mu \mathrm{m}$. 


\section{Nucleus oculomotorius communis}

Im Nucleus oculomotorius communis konnte in vielen Neuronen eine starke Braunfärbung beobachtet werden (Abb. 4.32 a, b). In einem sehr begrenzten Bereich entlang des dritten Ventrikels konnten Neuronen mit MHC-Klasse-I-Expression nachgewiesen werden.


Abb. 4.32: Nucleus oculomotorius communis mit Braunfärbung (DAB) in Neuronen (schwarze Pfeile) nach Immunhistologie mit Antikörper Ox-18. Coronale Schnitte des Gehirns von C. jacchus (E). III: dritter Ventrikel. Skala: (a) $100 \mu \mathrm{m}$, (b) $50 \mu \mathrm{m}$.

\subsubsection{Immunhistologie mit Antikörper HC-10}

Nachdem die Kreuzreaktivität des monoklonalen Antikörpers HC10 gegen MHC-Klasse-IMoleküle von C. jacchus durch Western Blot (Abb. 4.26 a-d) und Immunpräzipitation (Abb. 4.26 e) nachgewiesen wurde, wurde der Antikörper auch in der Immunhistologie mit C. jacchus Gehirnschnitten eingesetzt. Dabei konnte eine positive Bindung des Antikörpers in den gleichen Bereichen, die auch mit dem Antikörper Ox-18 beschrieben wurden, nachgewiesen werden: Cortex (Abb. 4.33 a), Hippocampus (Abb. 4.33 b), Nucleus ruber (Abb. 4.33 c), Substantia nigra (Abb. 4.33 d), Nucleus oculomotorius communis (Abb. 4.33 e). Allerdings sind die Färbungen der Neuronen insgesamt schwächer als die mit Ox18. 



Abb. 4.33: Cortex (a), Hippocampus (CA4) (b), Nucleus ruber (c), Substantia nigra (d) und Nucleus oculomotorius communis (e) mit Braunfärbung (DAB) in Neuronen (schwarze Pfeile) nach Immunhistologie mit Antikörper HC10. Coronale Schnitte des Gehirns von C. jacchus (E). Skala: (a, b, d) $20 \mu \mathrm{m}$, (c, e) $50 \mu \mathrm{m}$.

\subsubsection{Immunhistologie mit Antikörper HB115}

Der monoklonale Antikörper HB115 zeigte in der FACS-Analyse Kreuzreaktionen mit Leukozyten aus C. jacchus. Daraufhin wurde der Antikörper ebenfalls für immunhistologische Untersuchungen an C. jacchus eingesetzt. Anders als die Antikörper 
Ox-18 und HC10 konnten mit HB115 keine Braunfärbungen und damit keine MHCKlasse-I-Moleküle in Neuronen nachgewiesen werden. Im Gegensatz dazu erkannte HB115 aber MHC-Klasse-I-Moleküle in den Kapillaren des Gehirns, die wiederum nicht mit Ox-18 und HC10 detektiert wurden. Die markierten Blutgefäße konnten in allen Regionen festgestellt werden. In Abb. 4.34 sind Ausschnitte aus Cortex (Abb. 4.34 a, b), Hippocampus (Abb. 4.34 c) und Corpus Callosum (Abb. 4.34 d) mit entsprechend gefärbten Kapillaren zu sehen.
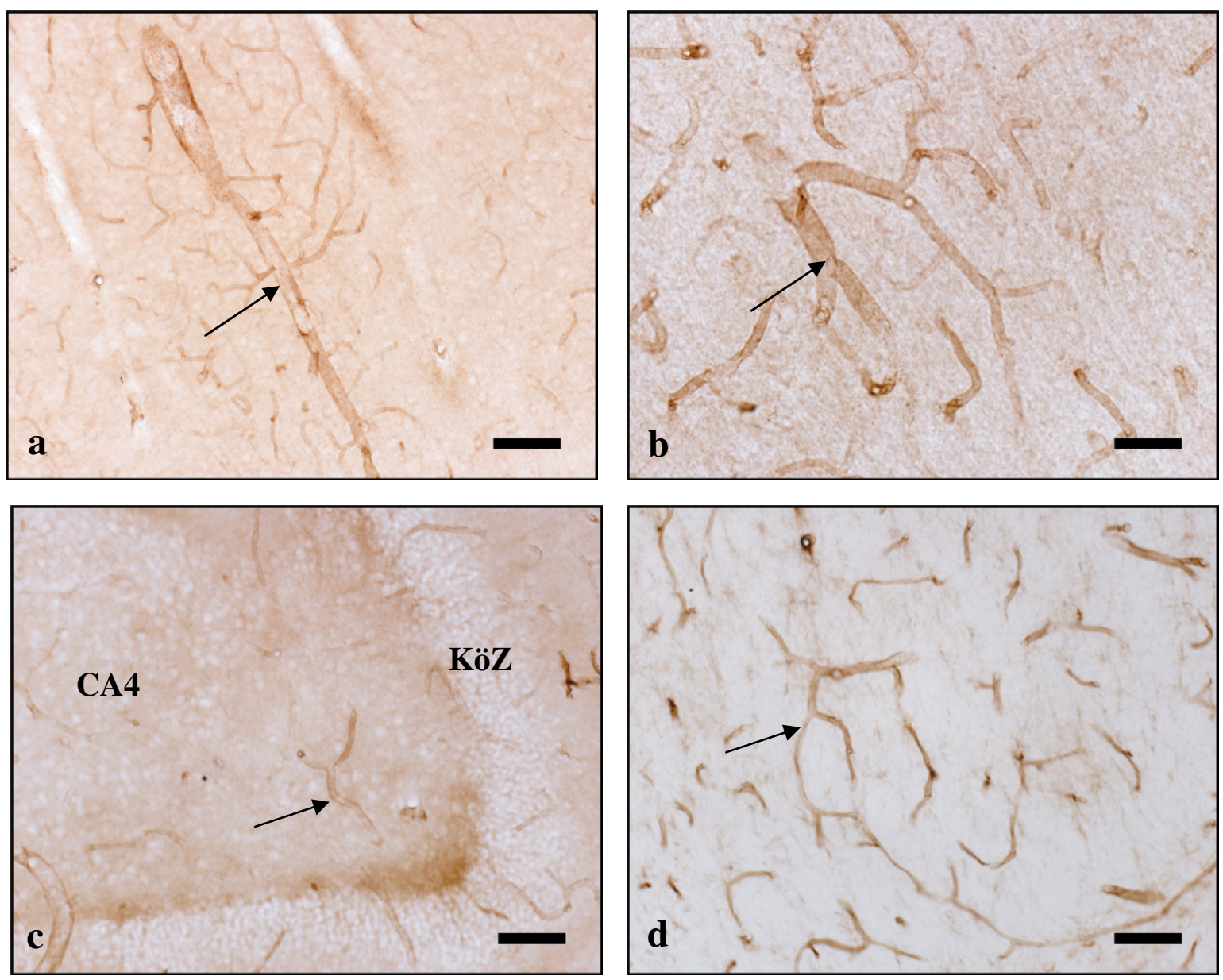

Abb. 4.34: Cortex (a, b), Hippocampus-Formation (CA4 und Gyrus dentatus mit Körnerzellen (KöZ)) (c) und Corpus callosum (d) mit Braunfärbung (DAB) des Kapillarsystems (schwarze Pfeile) nach Immunhistologie mit Antikörper HB115. Neuronen sind nicht gefärbt. Coronale Schnitte des Gehirns von C. jacchus (F). Skala: (a, c, d) $100 \mu \mathrm{m}$, (b) $50 \mu \mathrm{m}$.

Daraus kann geschlossen werden, dass Ox-18 und HB115 offensichtlich verschiedene MHC-Klasse-I-Moleküle erkennen. Es zeigt sich, dass die auf den Leukozyten/Endothelzellen vorkommenen MHC-Klasse-I-Moleküle nicht auf Neuronen exprimiert werden. Anders herum scheinen die auf Neuronen vorkommenen MHC-Klasse- 
I-Moleküle nicht auf Leukozyten/Endothelzellen der Blutgefäße exprimiert zu werden. Um welche es sich dabei im Einzelnen handelt, ist noch unbekannt.

\subsubsection{Doppelfärbung mit Antikörpern gegen Tyrosinhydroxylase und MHC-Klasse-I}

Mittels der In-situ-Hybridisierung wurde in Neuronen der Substantia nigra MHC-Klasse-ImRNA-Expression nachgewiesen. Des Weiteren wurden positive MHC-Klasse-I-Proteine mit Hilfe der Immunhistologie (Ox-18) in Neuronen der Substantia nigra festgestellt. Sowohl mRNA- als auch Proteinexpression wurden vor allem in der Substantia nigra pars compacta, die zahlreiche dopaminerge Neuronen enthält, nachgewiesen. Um eine Coexpression von MHC-Klasse-I und Tyrosinhydroxylase (TH), ein Markerenzym für dopaminerge Neuronen, zu untersuchen, wurde eine Doppelmarkierung mit Ox-18 und einem TH-Antikörper und fluoreszierenden Sekundärantikörpern als Markierung durchgeführt. Dabei wurde in Neuronen der Substantia nigra die gleichzeitige Expression von MHC-Klasse-I und TH beobachtet (Abb. 4.35 a1-a3. b, c) und damit die Expression von MHC-Klasse-I-Molekülen in dopaminproduzierenden Neuronen (TH-positiv) nachgewiesen. 

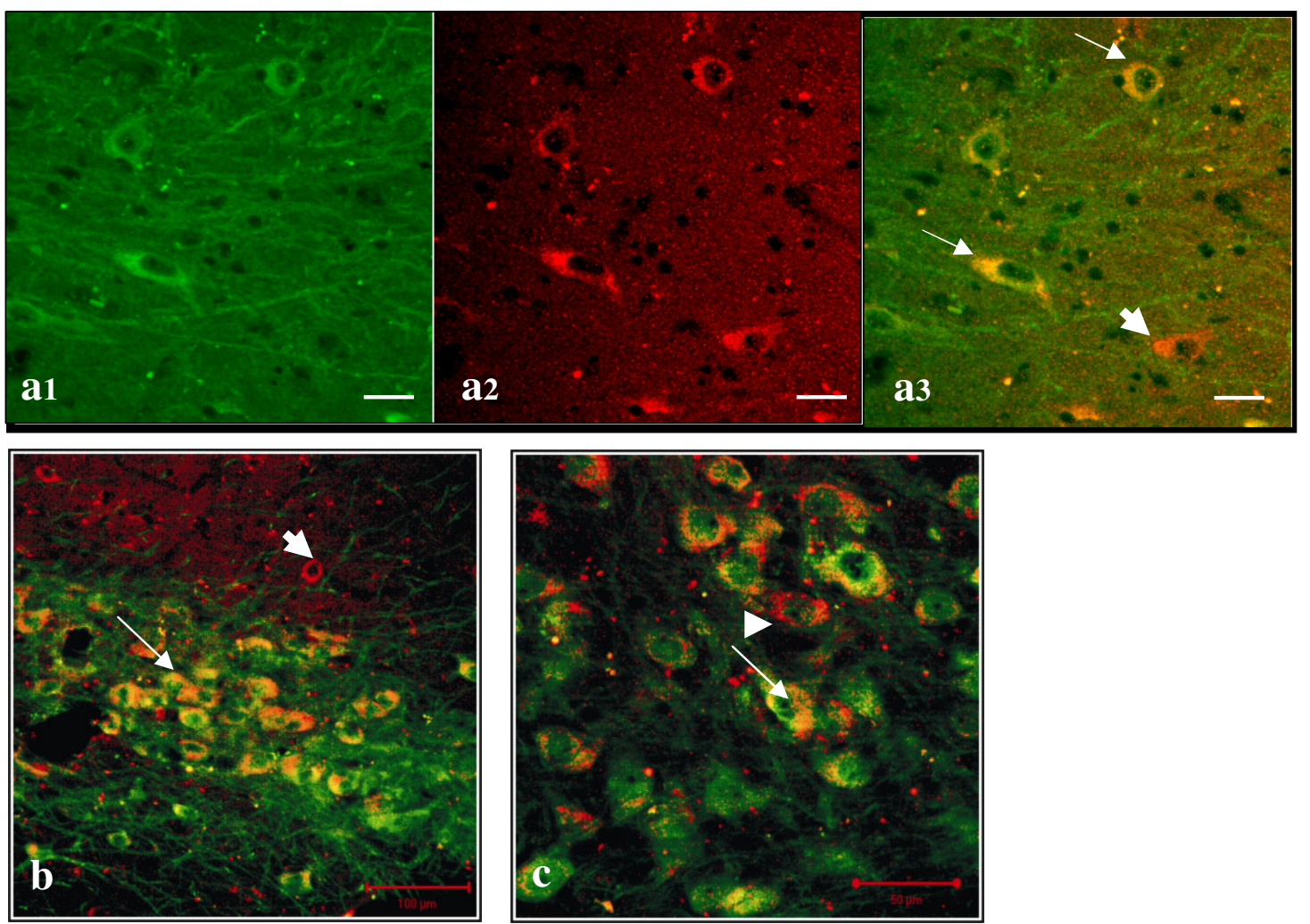

Abb. 4.35: Doppelmarkierung mit fluoreszierenden Antikörpern in der Substantia nigra. Co-Expression von MHC-Klasse-I (rot, Ox-18-Antikörper) and Tyrosinhydroxylase (grün, TH-Antikörper) in Neuronen der Substantia nigra (a1: nur TH-Färbung (grün); a2: nur Ox-18-Färbung (rot), a3, b, c: TH- und Ox-18-Färbung übereinander gelegt (gelb)). Doppelmarkierte Neuronen in der Substantia nigra (weiße Pfeile) zeigen, dass dopaminerge Neuronen MHC-Klasse-I exprimieren $(\mathbf{a 3}, \mathbf{b}, \mathbf{c})$. Einzelne Neuronen exprimieren nur MHC-Klasse-I-Moleküle (a3, b, c, weiße Pfeilspitze). Coronale Schnitte des Gehirns von C. jacchus (E). Skala: $100 \mu \mathrm{m}(\mathbf{b}), 50$ $\mu \mathrm{m}(\mathbf{c}), 20 \mu \mathrm{m}(\mathbf{a 1 - 3})$.

In Abb. 4.35 b, c wurde weiterhin anhand der grünen, roten und gelben Färbungen über den Neuronen erkannt, dass TH-Protein und MHC-Klasse-I-Protein in Neuronen gleichzeitig exprimiert werden. Anhand Abb. 4.35 c konnte deutlich gezeigt werden, dass TH eher im Zytoplasma (grün) der Neuronen lokalisiert war, und MHC-Klasse-I-Protein eher in der Peripherie der Somata (rot). 
4.2.8 Immunhistologie an immunsupprimierten C. jacchus

\subsubsection{Antikörper Ox-18}

Zwei immunsupprimierte Tiere $(\mathrm{G}, \mathrm{H})$ wurden auf MHC-Klasse-I-Proteinexpression mit dem Antikörper Ox-18 untersucht (Abb. 4.36), der bei unbehandelten Tieren starke Färbungen auf Neuronen verschiedener Gehirnareale zeigte (Abb. 4.28-4.32). In den gleichen Bereichen der immunsupprimierten Tiere fielen die Färbungen der Neuronen mit Ox-18 allerdings deutlich schwächer aus (Nucleus ruber (Abb. 4.36 c), Substantia nigra (Abb. $4.36 \mathrm{e}$ ) und Nucleus oculomotorius communis (Abb. $4.36 \mathrm{f}$ )) bis zu gar keinen gefärbten Neuronen (Cortex (Abb. 4.36 a), Hippocampus (Abb. 4.36 b, d)). Blutgefäße waren nicht gefärbt. Dies deutet darauf hin, dass die Immunsuppression durch Tacrolimus die Expression von MHC-Klasse-I unterdrückt. 



Abb. 4.36: Immunhistologie mit $\mathbf{O x}-18$ mit coronalen Gehirnschnitten von immunsupprimierten $C$. jacchus (H) (a - f), Cortex (a), CA4, Gyrus dentatus (Körnerzellen: KöZ) (b), Nucleus ruber (c), CA1 (d), Substantia nigra (e), Nucleus oculomotorius communis (f). Es sind keine bis sehr schwache Färbungen im Cortex und Hippocampus zu erkennen (a, b, d). In Nucleus ruber, Substantia nigra und Nucleus oculomotorius communis sind die Neuronen im Vergleich zu den Neuronen von nicht immunsupprimierten Tieren ebenfalls deutlich schwächer gefärbt $(\mathbf{c}, \mathbf{e}, \mathbf{f})$. Skala: $50 \mu \mathrm{m}(\mathbf{a}-\mathbf{f})$. 


\subsubsection{Antikörper HB115}

Durch Immunhistologie mit dem Antikörper HB115, der bei unbehandelten $C$. jacchus keine Neuronen, dafür aber Blutgefäße und Kapillare im Gehirn färbte (Abb. 4.34), ergab in den immunsupprimierten Tieren die gleiche Färbung von Blutgefäßen und Kapillaren (Abb. 4.37 a-d) wie in den unbehandelten Tieren. Dabei war die Färbung genauso intensiv und nicht herunterreguliert wie es mit dem Ox-18-Antikörper auf Ebene der neuronalen Färbung aussah.
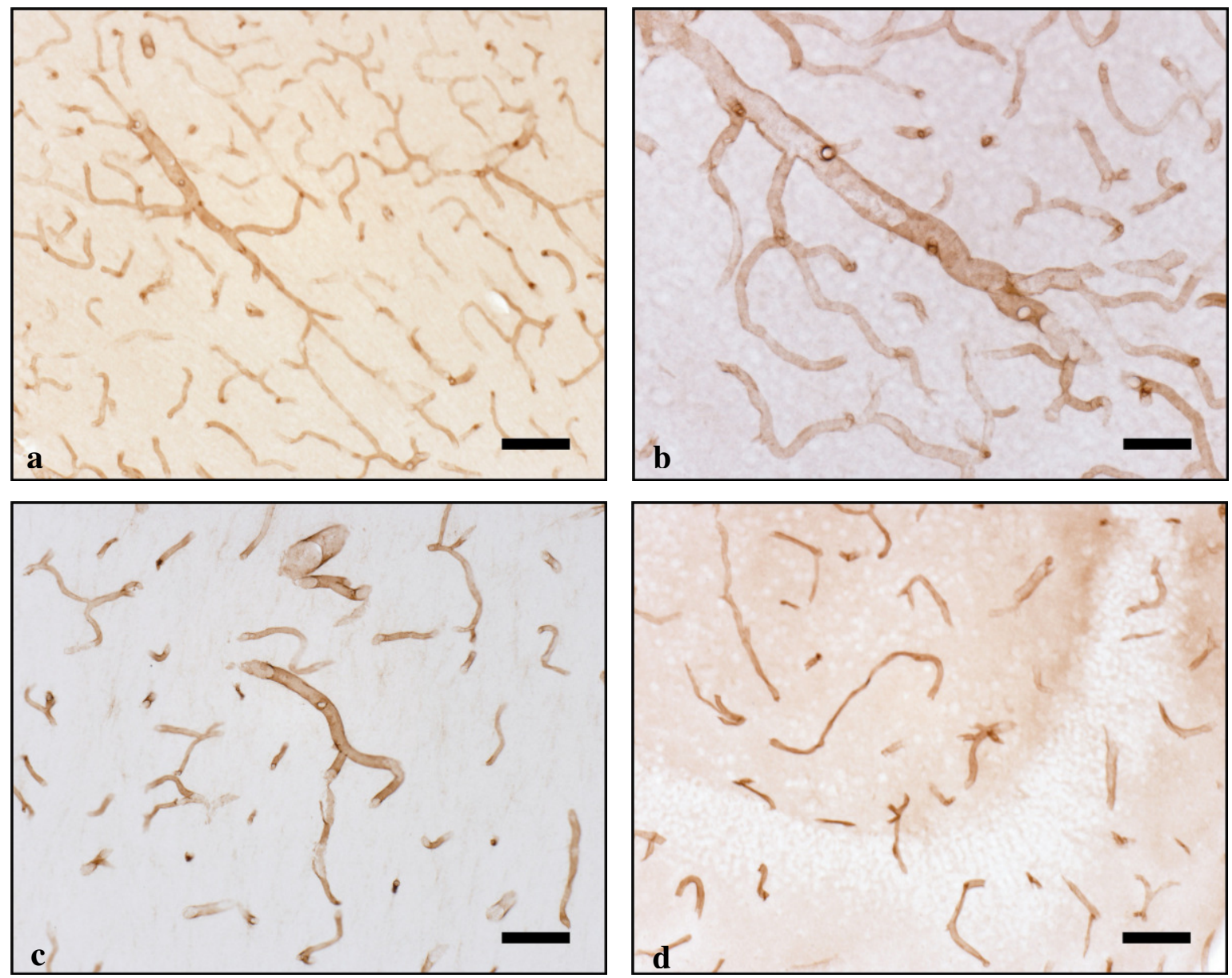

Abb. 4.37: Immunhistologie mit HB115 mit coronalen Gehirnschnitten von immunsupprimierten $C$. jacchus (G). Der Antikörper HB115 färbt in den immunsupprimierten Tieren Blutgefäße und Kapillare im gesamten Gehirn (Cortex (a, b), Corpus callosum (c), CA4 und Gyrus dentatus (d)). Die Intensität der Färbung ist gleich zu der im nicht immunsupprimierten $C$. jacchus. Skala: 50 $\mu \mathrm{m}(\mathbf{b}), 100 \mu \mathrm{m}(\mathbf{a}, \mathbf{b}, \mathbf{c})$. 


\section{Diskussion}

\subsection{MHC-Klasse-I-Expression im Gehirn von Tupaia belangeri und Callithrix jacchus}

Es konnte kürzlich gezeigt werden, dass MHC-Klasse-I-Moleküle neurobiologische Funktionen haben (Übersichtsartikel Boulanger und Shatz, 2004). Obwohl lange Zeit angenommen wurde, dass aufgrund des „Immunprivilegs“ des Gehirns Neuronen keine MHC-Klasse-I-Gene exprimieren, sind nunmehr klare Beweise gefunden für (i) eine hoch geordnete neuronale Expression von MHC-Klasse-I-Genen im Gehirn, (ii) eine wichtige Rolle von bestimmten MHC-Klasse-I-Molekülen bei der neuronalen Plastizität und Gehirnentwicklung, sowie für einen Einfluss von MHC-Klasse-I-Molekülen auf das Verhalten (Corriveau et al., 1998; Lidman et al., 1999; Linda et al., 1999; Huh et al., 2000; Loconto et al., 2003; Ishii et al., 2003; Oliveira et al., 2004).

Damit scheinen MHC-Klasse-I-Moleküle neben einer immunologischen auch eine neurobiologische Funktion auszuüben. Dies konnte bisher an Mäusen, Ratten und Katzen gezeigt werden. Damit stellte sich in der vorliegenden Arbeit die Frage, ob diese Doppelfunktion der MHC-Klasse-I-Moleküle auch in Spezies wiederzufinden ist, die sowohl in der Struktur als auch in der Funktion des Gehirns komplexere Eigenschaften aufweisen als die zuvor untersuchten Mäuse und Ratten. Aus diesem Grund wurde die MHC-Klasse-I-Expression im Gehirn des nicht-humanen Primaten Callithrix jacchus (Weißbüschelaffe) untersucht. Da diese Spezies häufig als nicht-humanes Tiermodell in Studien zu Infektionen oder Autoimmunkrankheiten eingesetzt wird (Genain und Hauser, 2001; 't Hart et al., 2004), kann die Untersuchung der MHC-Klasse-I-Expression im Gehirn vom $C$. jacchus auf wichtige Parallelen zum Primatengehirn oder sogar zum Menschen hinweisen. Weiterhin wurde die MHC-Klasse-I-Expression im Gehirn von Tupaia belangeri (Spitzhörnchen) untersucht. T. belangeri ist ein in der Stressforschung (Fuchs et al., 2001) häufig eingesetztes Versuchstier, dessen Gehirnstrukturen sehr gut bekannt sind. Dadurch konnten MHC-Klasse-I-Expressionsmuster beider Spezies gut verglichen und Parallelen gefunden werden.

Die vorliegende Studie zeigt, dass bei C. jacchus und T. belangeri - wie bei Ratten und Mäusen - MHC-Klasse-I-mRNA und -Moleküle im Gehirn exprimiert werden. Darüber hinaus konnte auch in diesen beiden Tierarten ein räumliches Muster der MHC-Klasse-IExpression festgestellt werden. Regionen positiver MHC-Klasse-I-Expression in beiden 
Spezies waren: Substantia nigra, Hippocampus-Formation, Cortex, Nucleus oculomotorius communis, Plexus choroideus und Ventrikelbereiche. Im Nucleus ruber konnte MHCKlasse-I-Expression nur bei $C$. jacchus und im Corpus geniculatum dorsale nur bei $T$. belangeri nachgewiesen werden. Mit Hilfe der Emulsionsautoradiographie konnten vor allem Neuronen in den einzelnen Regionen (außer Plexus choroideus und Ventikelbereiche) als MHC-Klasse-I-exprimierend identifiziert werden.

Die Expression des Beta-2-Mikroglobulin-Gens, dessen Genprodukt nicht-kovalent an MHC-Klasse-I-Moleküle bindet, wurde mittels In-situ-Hybridisierung ebenfalls anhand der Autoradiogramme im Cortex, Substantia nigra, und Ventrikelbereiche nachgewiesen. In den folgenden Abschnitten werden zunächst die einzelnen Regionen, in denen MHCKlasse-I-Expression nachgewiesen wurde, in Zusammenhang mit anderen Studien gestellt. Anschließend werden funktionelle Aspekte, mögliche Interaktionspartner für MHCKlasse-I-Moleküle und der Einfluss von FK506 auf die MHC-Klasse-I-Expression diskutiert.

\section{Substantia nigra}

Die Substantia nigra ist ein Kernkomplex im Bereich des Mittelhirns. Die dopaminergen Neuronen der Substantia nigra, pars compacta $(\mathrm{SNc})$, deren Morphologie durch dicht gelagerte, melaninhaltige Neuronen gekennzeichnet ist, projizieren in den Nucleus caudatus und ins Putamen. Dabei werden Signale vermittelt, die motorische Wirkungen haben. Bei Verlust der dopaminergen Neuronen in der SNc durch Degeneration kommt es zu motorischen Defiziten wie sie bei Morbus Parkinson zu beobachten sind. Neuronen der pars reticularis sind weniger dicht gelagert und kleiner als die dopaminergen Neuronen der pars compacta (Zilles und Rehkämper, 1993).

Sowohl bei $C$. jacchus als auch bei T. belangeri konnten vor allem in der SNc MHCKlasse-I-mRNA und -Protein in Neuronen nachgewiesen werden. Da es sich nicht ausschließlich um dopaminerge Neuronen in der SNc handelt, wurde durch eine Doppelmarkierung untersucht, ob es sich bei den MHC-Klasse-I-positiven Zellen auch um dopaminproduzierende Zellen handelt. Dabei wurden Doppelmarkierungen beobachtet, bei denen es sich um Neuronen handelt, die sowohl MHC-Klasse-I als auch Tyrosinhydroxylase (Markerenzym für dopaminerge Neuronen) exprimieren. Es wurden aber auch Zellen in der SNc beobachtet, die nur MHC-Klasse-I exprimieren. Da nicht alle Neuronen in der SNc dopaminerg sind, ist es wahrscheinlich, dass die MHC-Klasse-IExpression nicht ausschließlich auf dopaminerge Neuronen begrenzt ist. Lidman et al., 
(1999) fanden ebenfalls sowohl mRNA- als auch Proteinexpression nicht-klassischer MHC-Klasse-I-Gene und von B2M in der SNc von Ratten, wo die Expression im Vergleich zu den anderen positiven Regionen am stärksten war. Die Beobachtung, dass die konstitutive MHC-Klasse-I-Expression in der SNc im Vergleich zu anderen Regionen sehr stark ist, konnte in dieser Arbeit auch im T. belangeri- und C. jacchus-Gehirn gemacht werden. MHC-Klasse-I-Expression in der SN der Ratte sind auch von Linda et al. (1999) und in der Maus von Huh et al. (2000) gezeigt worden.

Da MHC-Klasse-I-Moleküle in den dopaminergen Neuronen der SNc nachweisbar sind, erscheint eine Rolle in der Entstehung neurodegenerativer Krankheiten wie Morbus Parkinson denkbar. Eine Beteiligung der MHC-Klasse-I-Moleküle an der Entstehung/Promotion neurodegenerativer Erkrankungen könnte z. B. in Form einer gestörten Expressionsregulation dieser Gene bestehen, die dann zu Störungen in synaptischen Verbindungen und schließlich im Absterben von diesen Neuronen resultieren könnte. Zwar konnte auch in anderen Kerngebieten MHC-Klasse-I-Expression nachgewiesen werden, allerdings ist ein deutlicher Unterschied in der Stärke der Expression festzustellen. Teilweise extrem starke Anhäufungen von Silberkörnern waren um Neuronen der SNc bei T. belangeri und bei C. jacchus zu beobachten. In diesem Zusammenhang könnte die individuelle MHC-Klasse-I-Genausstattung von Bedeutung sein (siehe Kapitel 5.3.2).

\section{Hippocampus-Formation}

Die Hippocampus-Formation besteht aus dem Ammonshorn mit den Subregionen CA1CA4, dem Gyrus dentatus und Subiculum. Der Gyrus dentatus besteht aus drei Schichten, wobei die dicht gepackten Körnerzellen die Körnerzellschicht bilden. Die Axone der Körnerzellen projizieren vor allem zu den Pyramidenzellen in der CA3-Region. Die Dendriten der Körnerzellen erhalten Signale aus dem entorhinalen Cortex (Amaral und Witter, 1989). Die Hippocampus-Formation ist eine wichtige Struktur für Gedächtnisfunktionen (Morris und Frey, 1997; Morris et al., 2003). Durch wiederholte Reizung von Neuronen des Hippocampus tritt eine Langzeitpotenzierung auf, wobei es bei erneuter Reizung trotz gleicher Intensität zu einer Vergrößerung der Reizantwort kommt (Bliss und Lømo, 1973). Dies ist ein Zeichen synaptischer Plastizität im Hippocampus.

In der vorliegenden Arbeit konnte sowohl bei C. jacchus als auch bei T. belangeri MHCKlasse-I-Expression in Neuronen der Hippocampus-Formation nachgewiesen werden. Bei T. belangeri konnte MHC-Klasse-I-mRNA in einzelnen Neuronen der CA1-, CA3-, CA4- 
Region und in den Körnerzellen des Gyrus dentatus festgestellt werden. Bei C. jacchus wurde MHC-Klasse-I-mRNA in Neuronen der CA3- und CA4-Region, in den Körnerzellen des Gyrus dentatus und im Subiculum nachgewiesen. Im Unterschied zum $T$. belangeri konnten bei C. jacchus in der CA4-und CA3-Region deutlich mehr stark MHCKlasse-I-positive Neuronen gefunden werden, wohingegen bei T. belangeri nur wenige Neuronen MHC-Klasse-I-positiv waren. Auf Proteinebene ist bei T. belangeri und bei $C$. jacchus die Quantität der MHC-Klasse-I-Expression ähnlich. In der CA4-Region waren in beiden Spezies ein großer Teil der Neuronen (morphologisch Pyramidenneuronen) MHCKlasse-I-positiv. In der Körnerzellschicht sind dagegen nur sehr wenige einzelne Zellen MHC-Klasse-I-positiv. Diese Ergebnisse fügen sich in eine Reihe von Daten ein, die MHC-Klasse-I-positive Neuronen in der Hippocampus-Formation von Ratten und Katzen zeigen (Neumann et al., 1995; Corriveau et al., 1998; Huh et al., 2000). Eine kongruente MHC-Klasse-I-Expression in der CA3-Region im Hippocampus konnte außer bei der Katze (Corriveau et al., 1998) auch bei C. jacchus nachgewiesen werden. Damit zeigen sich klare Parallelen der MHC-Klasse-I-Expression im Hippocampus verschiedener Säugetiere (Maus, Ratte, Katze, C. jacchus), was auf eine konservierte neurobiologische Funktion (z.B. Beteiligung an synaptischer Plastizität) dieser Gene in den Hippocampi der verschiedenen Spezies hindeutet.

\section{Cortex}

Der Cortex cerebri bildet sich aus funktionell und strukturell verschiedenen Nervenzellen, die in einer sechsschichtigen Struktur angeordnet sind. Räumliche Einheiten des Cortex bilden funktionelle Zentren, die die sensorischen und motorischen Sinnesbereiche oder Assoziationsgebiete bilden (Zilles und Rehkämper, 1993).

In dieser Arbeit konnte sowohl bei $C$. jacchus als auch bei T. belangeri MHC-Klasse-IExpression in cortikalen Neuronen nachgewiesen werden. Bei T. belangeri konnten viele MHC-Klasse-I-positive Neuronen durch mehrere Schichten hindurch gezeigt werden, wohingegen bei $C$. jacchus vor allem in der Schicht 5, aber auch in anderen Schichten, einzelne Pyramidenneuronen als MHC-Klasse-I-exprimierend gefunden wurden. Immunfärbungen mit dem MHC-Klasse-I-Antikörper Ox18 wiesen bei $C$. jacchus starke MHC-Klasse-I-Proteinmengen vor allem in den Pyramidenneuronen aus. Interneuronen zeigten ebenfalls Färbungen, die allerdings sehr schwach waren. Weiterhin war MHCKlasse-I-Protein an Fortsätzen der Pyramidenzellen bei C. jacchus nachzuweisen, wonach das MHC-Klasse-I-Protein wahrscheinlich vom Perikaryon auch in die Axone oder 
Dendriten transportiert wird. Eine eventuelle Beteiligung der Fortsätze mit den MHCKlasse-I-Proteinen an Interaktionen mit Rezeptoren anderer Zellen ist daher wahrscheinlich. MHC-Klasse-I-mRNA und -Protein in Neuronen des Cortex von Ratten wurde zuvor auch von Corriveau et al. (1998) gezeigt. Dabei wurde ebenfalls MHCKlasse-I-Protein an den apikalen und basalen Dendriten der Neuronen nachgewiesen. Insitu-Hybridisierung mit einer nicht-klassischen MHC-Klasse-I-Sonde an Mausgehirnen ergab wie bei $C$. jacchus positive Signale in Neuronen der Schicht 5 und 6 des somatosensorischen Cortex (Huh et al., 2000). Im Zusammenhang mit MHC-Klasse-IMolekülen und synaptischer Plastizität im Cortex ist die Studie von Trachtenberg et al. (2002) sehr interessant. Die Autoren konnten zeigen, dass erfahrungsabhängige Plastizität im adulten Cortex der Maus mit erhöhter Synapsenbildung und -abbau einhergeht. Ebenfalls postulieren Intrator et al. (1993), dass im adulten Gehirn nicht nur im Hippocampus Prozesse erfahrungsabhängiger synaptischer Plastizität stattfinden, sondern auch im Cortex gleiche Mechanismen zu finden seien. Es wäre denkbar, dass in diese Prozesse aufgrund ihrer neurobiologischen Funktion auch MHC-Klasse-I-Moleküle involviert sind. Diese Moleküle könnten für die Retraktion synaptischer Verbindungen mit verantwortlich sein (Boulanger und Shatz, 2004). Da im Cortex eine Expression von MHC-Klasse-I-Genen bei verschiedenen Spezies nachgewiesen wurde, deutet sich auch in diesen Hirnareal eine konservierte Funktion dieser Gene an.

\section{Nucleus oculomotorius communis und Nucleus ruber}

Der Nucleus oculomotorius communis (NOD) ist das Kerngebiet des Hirnnerves, der mit zwei weiteren Nerven die äußeren Augenmuskeln aktiviert. Sowohl bei T. belangeri als auch bei C. jacchus konnten in diesem Kerngebiet MHC-Klasse-I-positive Neuronen nachgewiesen werden. Diese Ergebnisse stimmen mit Daten aus Ratten überein. Sowohl Lidman et al. (1999) als auch Linda et al. (1999) zeigen eine moderate MHC-Klasse-IExpression im NOD von Ratten.

Der Nucleus ruber (NR) ist ein Kernbereich, der dorsal zur Substantia nigra liegt. Er ist unterteilt in den Pars parvocellularis (kleinzellig), der über Zwischenstationen in das Cerebellum projiziert, und Pars magnocellularis (großzellig), der über den Tractus rubrospinalis in das Rückenmark projiziert und damit eine wichtige Funktion im motorischen System speziell der Feinmotorik erfüllt. MHC-Klasse-I-Expression auf mRNA- und Protein-Ebene konnte in dieser Arbeit bei C. jacchus nachgewiesen werden (von T. belangeri lagen keine Gehirnschnitten dieses Kernbereiches vor). Aufgrund der 
Morphologie der mit Ox-18 immungefärbten Zellen und auch des von Silberkörnern überlagerten Zytoplasmas handelt es sich wahrscheinlich um sehr große Zellen und damit um Neuronen im NR pars magnocellularis. Ebenfalls positive MHC-Klasse-I-Expression im NR der Ratte wurden in Arbeiten von Lidman et al. (1999) und Linda et al. (1999) beschrieben. Lidman et al. (1999) konnten eine moderate Markierung im NR nachweisen, wohingegen bei Linda et al. (1999) und in der vorliegenden Arbeit starke Anhäufungen von Silberkörnern in der In-situ-Hybridisierung im NR gezeigt werden konnten, was auf eine starke MHC-Klasse-I-Expression hinweist. Mit dem Antikörper gegen MHC-Klasse-I (Ox-18) konnte ebenfalls starke MHC-Klasse-I-Proteinexpression beobachtet werden. Damit zeigten sich für die MHC-Klasse-I-Expression im NR und NOD ebenfalls klare Parallelen zwischen Nagetieren und dem nicht-humanen Primaten C. jacchus. Diese Ergebnisse lassen vermuten, dass die MHC-Klasse-I-Moleküle in diesen beiden Kernen ebenfalls spezifische neurobiologische Funktionen wahrnehmen. Dabei könnten sie an synaptischen Änderungen in diesen Kernen beteiligt sein.

\section{Corpus geniculatum laterale}

Das Corpus geniculatum laterale (CGL) ist Teil des Thalamus und stellt eine wichtige Relaisstation für die visuelle Sinneswahrnehmung dar. Informationen der optischen Nerven werden über den CGL in den visuellen Cortex geleitet (Zilles und Rehkämper, 1993). In dieser Arbeit konnten in Neuronen des CGL bei T. belangeri MHC-Klasse-I-mRNAExpression nachgewiesen werden. Bei $C$. jacchus erscheint in den Autoradiogrammen der Kern etwas dunkler, allerdings konnten nur sehr wenige positive Neuronen gefunden werden. MHC-Klasse-I-mRNA-Expression im CGL wurde zuvor von Corriveau et al. (1998) beschrieben. Dabei wurde die Entwicklung des visuellen Systems im embryonalen und postnatalen Katzengehirn untersucht. Die Autoren konnten deutlich zeigen, dass die MHC-Klasse-I-mRNA-Expression während der Entwicklung des visuellen Systems dynamisch reguliert wird und die Expression dabei mit Entwicklungsstufen und Regionen korreliert, in denen synaptische Verbindungen neu geknüpft oder gefestigt werden. $\mathrm{Zu}$ Beginn der augenspezifischen Schichtenbildung im embryonalen Gehirn stellten Corriveau et al. (1998) eine mäßige MHC-Klasse-I-mRNA-Expression fest, die während der Schichtenbildung weiter anstieg und am Tag 10 postnatal das Maximum erreichte. Danach sank die mRNA-Expression wieder auf ein niedriges aber detektierbares Niveau. Ähnliches wurde von Huh et al. (2000) im sich entwickelnden Mausgehirn beschrieben. MHC-Klasse-I-Expression im CGL konnte während der ersten zwei Wochen detektiert 
werden, wenn sich die augenspezifischen Schichten bilden und sich damit in einer Phase aktivitätsabhängiger Synapsenänderung befinden. Diese Beobachtungen stimmen mit denen am C. jacchus überein. Ebenfalls nur schwache Signale positiver MHC-Klasse-IExpression konnten im adulten Tier beobachtet werden. Dagegen widersprechen dieser entwicklungsabhängigen MHC-Klasse-I-Expression die Ergebnisse vom T. belangeri. Auch bei diesen Tieren handelte es sich um adulte, deren MHC-Klasse-I-Expression im CGL sehr stark war. Es erscheint unwahrscheinlich, dass im adulten T. belangeri die Schichtenbildung im visuellen System noch nicht abgeschlossen ist. Möglicherweise sind MHC-Klasse-I-Moleküle in diesem Kern an anderen Prozessen beteiligt, die bisher unbekannt sind. Es könnte aber auch möglich sein, dass bei T. belangeri auch im adulten ZNS ein hohes Potenzial synaptischer Plastizität im CGL vorliegt, dessen Funktion unbekannt ist.

\section{Ventrikelbereiche, Plexus choroideus und Blutgefäße}

Das Gehirn ist eingebettet in Liquorflüssigkeit. Neben dem äußeren liquorgefüllten Raum (Subarachnoidalraum) besitzt das Gehirn auch einen inneren Liquorraum, der das Ventrikelsystem darstellt. Dieser setzt sich aus Seitenventrikeln, 3. und 4. Ventrikel zusammen. Die Ventrikel sind mit Ependymzellen ausgekleidet. In die Ventrikel hinein reichen die Plexus choroidei, die eine Art Adergeflecht darstellen und die Liquorflüssigkeit durch Filtration aus dem Blut produzieren. Die Oberfläche der Plexus choroidei besteht aus speziellen Ependymzellen die an der dem Ventrikelraum zugewandten Seite durch ,tight junctions" verbunden sind und somit eine Liquor-Blut-Schranke (Zilles und Rehkämper, 1993) bilden.

Die Versorgung des Gehirns mit Nährstoffen geschieht über Blutgefäße. Die Eintrittsstellen der Blutgefäße in das Nervengewebe sind von der Pia mater ausgekleidet, die wiederum durch eine Basallamina (Gliazellfortsätze) vom Nervengewebe und den Blutgefäßen getrennt ist. Damit bildet sie um die Blutgefäße herum einen perivaskulären Spalt. Nach Aufspaltung der Blutgefäße in feine Kapillare endet die Pia mater, allerdings setzt sich die Basallamina auf den Kapillaren fort. Zwischen Nervengewebe und Blut bildet sich somit mit den Endothelzellen der Kapillare, die durch „tight junctions“ verbunden sind, und der Basalmembran die Blut-Hirn-Schranke (Zilles und Rehkämper, 1993).

In der vorliegenden Arbeit wurde sowohl bei T. belangeri als auch bei C. jacchus starke MHC-Klasse-I-mRNA-Expression im Plexus choroideus nachgewiesen. Weiterhin konnte 
MHC-Klasse-I-mRNA-Expression in Ventrikelbereichen bei $C$. jacchus und in Blutgefäßen bei $T$. belangeri beobachtet werden. Positive MHC-Klasse-I- und B2MmRNA-Expression in Endothel- und Ependymzellen und Zellen der Hirnhäute wurde zuvor im Gehirn von Ratten von Linda et al. $(1998,1999)$ beschrieben. Lidman et al. (1999) konnten im Rattengehirn MHC-Klasse-I-Protein in Endothel- und Ependymzellen nachweisen.

Interessanterweise beschreiben Engelhardt et al. (2001), dass unstimulierte MausEpithelzellen des Plexus choroideus in vitro keine MHC-Klasse-I-Antigene exprimieren. Erst die Stimulation mit Interferon-gamma führt zu einer Induktion von MHC-Klasse-IMolekülen und in einigen Zellen von MHC-Klasse-II-Molekülen. Die Autoren vermuten, dass die Epithelzellen der Plexus choroidei mit Hilfe von Adhäsionsmolekülen intraventrikuläre Leukozyten binden und damit den Eintritt in das ZNS ermöglichen. Damit wären nicht nur die Endothelzellen der cerebralen Gefäße bei der Migration von Immunzellen beteiligt, sondern auch der Plexus choroideus. Im Gegensatz zu diesen Beobachtungen wurden in dieser Arbeit sowohl bei $C$. jacchus als auch bei T. belangeri im Plexus choroideus starke MHC-Klasse-I-mRNA-Expression nachgewiesen. Da es sich dabei um unbehandelte Tiere handelte, scheint die Expression von MHC-Klasse-I-mRNA nicht induziert worden zu sein, sondern konstitutiv zu erfolgen. Interessanterweise ist die MHC-Klasse-I-Protein-Expression sehr wahrscheinlich genspezifisch. Mit dem Ox-18Antikörper sind kaum Proteinfärbungen zu erkennen (Daten nicht gezeigt), abgesehen von DAB-Präzipitaten, die sich an Geweberändern ablagern. Dagegen sind mit dem HB-115Antikörper deutliche Farbumrandungen an Zellen des Plexus choroideus zu erkennen, die damit auf eine MHC-Klasse-I-Protein-Expression hinweisen. Diese Unterschiede zwischen beiden Antikörpern werden im Kapitel 4.4 (Caja-G und Caja-E Spezifität) näher diskutiert.

Die MHC-Klasse-I-Protein-Expression im Plexus choroideus steht damit im Gegensatz zu den von Engelhardt et al. (2001) beschriebenen Beobachtungen. Da es sich bei diesen Daten nur um die MHC-Klasse-I-Protein-Expression handelt, wäre die genspezifische MHC-Klasse-I-Expression auch in der Maus eine mögliche Erklärung. Es wäre möglich, dass die Autoren mit dem verwendeten Antikörper nur bestimmte MHC-Klasse-I-Proteine detektierten, die gerade nicht auf Zellen des Plexus choroideus exprimiert sind. Damit wären unterschiedliche Funktionen für verschiedene MHC-Klasse-I-Moleküle auch im Plexus choroideus wahrscheinlich. 


\subsection{B2M-Expression im Gehirn von Callithrix jacchus}

Das funktionell vollständige MHC-Klasse-I-Protein besteht aus einer schweren Kette, die in der MHC-Klasse-I-Genregion codiert ist, und einer nicht-kovalent gebundenen leichten Kette, dem Beta-2-Mikroglobulin (B2M), das außerhalb des MHC-Klasse-I-Komplexes codiert ist. Eine Ausnahme dabei bilden die MIC-Gene, die ohne die Bindung von B2M an der Zelloberfläche exprimiert werden (Groh et al., 1996). In dieser Arbeit wurde die B2MExpression beim nicht-humanen Primaten $C$. jacchus in verschiedenen Regionen im Gehirn durch Autoradiographie nachgewiesen. Dazu gehören die Substantia nigra, Hippocampus, Cortex cerebri, Plexus choroideus und Ventrikelbereiche, die somit annähernd das gleiche Muster wie die nachgewiesene MHC-Klasse-I-Expression zeigen. Damit ist davon auszugehen, dass in den Neuronen dieser Regionen die vollständige Expression des MHC-Klasse-I-Proteins sehr wahrscheinlich ist, was mit Hilfe der Immunfärbung auch gezeigt werden konnte. Die Co-Expression von MHC-Klasse-I und $B 2 M$ in Neuronen konnte zuvor auch schon in Ratten und Katzen gezeigt werden (Neumann et al., 1997; Linda et al., 1998, 1999; Corriveau et al., 1998; Huh et al., 2000; Edström et al., 2004).

Linda et al. (1998) zeigten in normalen spinalen Neuronen der Ratte eine starke konstitutive MHC-Klasse-I-Expression, wohingegen $B 2 M$ nicht in allen Neuronen exprimiert war, sondern auf spezifische Motoneuronen beschränkt war. Es konnte gezeigt werden, dass die Regulation von MHC-Klasse-I-Molekülen auf Neuronen hauptsächlich durch Änderungen der Expression von B2M hervorgerufen wird (Linda et al., 1998). Corriveau et al. (1998) wiesen B2M-Expression in Neuronen des LGN, des primären visuellen Cortex (Schicht 4) und in Pyramidenneuronen des Hippocampus nach.

Linda et al. (1999) fanden in der Ratte MHC-Klasse-I-mRNA-Expression in Neuronen des Hirnstamms, der Substantia nigra, des Nucleus ruber und Nucleus oculomotorius communis, wohingegen $B 2 M$-mRNA-Expression nur in dopaminergen Substantia nigraNeuronen, in großen Motoneuronen im Hirnstamm und in Endothel-, Ependymzellen, Zellen der Hirnhaut und in einigen Gliazellen zu finden war. Die Autoren vermuten, dass nur die Neurone MHC-Klasse-I-Protein synthetisieren, die auch ausreichende Mengen an MHC-Klasse-I- und B2M-mRNA exprimieren. Allerdings konnte in der vorliegenden Arbeit positive MHC-Klasse-I-Proteinexpression nicht nur in der Substantia nigra sondern auch im Nucleus ruber und Nucleus oculomotorius communis nachgewiesen werden. Das deutet daraufhin, dass auch in diesen Kernen MHC-Klasse-I und B2M co-exprimiert 
werden. Diese Vermutung, dass auch im Nucleus oculomotorius communis MHC-Klasse-I und B2M co-exprimiert werden, wird durch die Arbeit von Lidman et al. (1999) bestätigt. Die Autoren konnten in der Ratte die Co-Expression von MHC-Klasse-I und B2M in der Substantia nigra, Nucleus oculomotorius communis, Hippocampus und in Motoneuronen des Rückenmarks zeigen. Huh et al. (2000) zeigten in der Maus, dass das Fehlen der B2MExpression in Neuronen für Abweichungen in der Ausbildung präziser visueller Regionen im LGN verantwortlich ist und damit die Expression des vollständigen MHC-Klasse-IProteins essentiell für die synaptische Organisation ist. Edström et al. (2004) zeigten ebenfalls MHC-Klasse-I- und B2M-Expression in seneszenten Motoneuronen des Rückenmarks. Die vorliegenden Ergebnisse unterstützen die bereits beschriebenen Vermutungen, dass MHC-Klasse-I-Moleküle im Gehirn mit B2M co-exprimiert werden und nur so ein vollständiger, funktionsfähiger Proteinkomplex vorliegt. Die neuronale CoExpression von MHC-Klasse-I und B2M scheint damit sowohl in Nagetieren als auch im nicht-humanen Primaten $C$. jacchus eine notwendige Vorraussetzung der funktionellen Vollständigkeit der MHC-Klasse-I-Proteine im Gehirn zu sein.

\subsection{MHC-Klasse-I-Moleküle und deren mögliche Funktion im Gehirn}

5.3.1. Mögliche Rolle von MHC-Klasse-I bei der Neuroplastizität, bei der Entwicklung und im adulten Organismus

Das MHC-Klasse-I-Expressionsmuster im Gehirn von T. belangeri und bei nicht-humanen Primaten ähnelt dem Expressionsmuster von Nagetieren. Dies deutet darauf hin, dass die Funktionen der MHC-Klasse-I-Proteine im Gehirn von T. belangeri und nicht-humanen Primaten vergleichbar sind mit denen, die für Nagetiere beschrieben wurden.

In einem Übersichtsartikel beschreibt Corriveau (1999), dass die elektrische Aktivität von Neuronen die Genexpression beeinflusst und dadurch die aktivitätsabhängige synaptische Plastizität während der Entwicklung ermöglicht. Daraus resultiert letztlich die Ausbildung neuronaler Vernetzungen im Gehirn. Weiterhin schreibt Corriveau (1999), dass das Ausmaß der synaptischen Plastizität - im engeren Sinne das Modulieren der Festigung synaptischer Verbindungen - sehr unterschiedlich sein kann und dass diesen Veränderungen molekulare Mechanismen zugrunde liegen. Diese Mechanismen sind allerdings nicht nur auf die Entwicklung beschränkt, sondern auch im adulten Gehirn zu finden (Malenka und Nicoll, 1993). 
Bezüglich molekularer Mechanismen postulieren Corriveau et al. (1998) für MHC-KlasseI-Moleküle eine Funktion in neuronaler Signalgebung und aktivitätsabhängiger synaptischer Plastizität im Gehirn von Katzen. Sie zeigten für retinogeniculocortikale Pfade, dass MHC-Klasse-I-Gene stark postsynaptisch in Neuronen exprimiert werden, die sich in der Endphase aktivitätsabhängiger synaptischer Umstrukturierung befinden und ihre Axonterminale stabilisieren. Weiterhin konnten sie zeigen, dass MHC-Klasse-I-Gene im pränatalen Hippocampus gering exprimiert werden, aber reife Hippocampusneurone eine starke Expression zeigen. Interessanterweise sind im Hippocampus adulter Organismen ebenfalls Formen der aktivitätsabhängigen Plastizität, wie Langzeitpotenzierung zu finden (Bliss und Lømo, 1973). Übereinstimmend mit diesen Beobachtungen konnte in der vorliegenden Arbeit sowohl bei T. belangeri als auch bei $C$. jacchus in reifen Pyramidenneuronen des Hippocampus MHC-Klasse-I-Expression nachgewiesen werden. Dieses deutet darauf hin, dass die Beteiligung von MHC-Klasse-I an oben beschriebenen Mechanismen zur aktivitätsabhängigen Plastizität sehr wahrscheinlich auch im nicht-humanen Primaten zu finden ist.

Ähnliche Hinweise bezüglich der Funktion von MHC-Klasse-I im Gehirn liefern Huh et al. (2000). Sie konnten in ihrer Arbeit zeigen, dass MHC-Klasse-I und die Rezeptorkomponente CD3 $\xi$ im sich entwickelnden Mäusegehirn exprimiert werden und dabei ein räumliches und zeitliches Expressionsmuster zeigen, das auf eine Rolle bei aktivitätsabhängiger Strukturänderung und synaptischer Plastizität hinweist. So postulieren die Autoren, dass MHC-Klasse-I-Moleküle im Gehirn über CD3 $\xi$-bindende Rezeptoren Signale senden, die für Änderungen der synaptischen Stabilität verantwortlich sind und dadurch zur Etablierung effektiver funktionsfähiger Synapsen führen. Im Detail können sich die Autoren vorstellen, dass MHC-Klasse-I-Moleküle möglicherweise direkt an der Synapse aktiv sind und dabei die Eliminierung nichteffektiver, nicht funktionsfähiger synaptischer Verbindungen fördern. Damit beschreiben Huh et al. (2000), dass MHCKlasse-I auch für normale regressive Vorgänge wie aktivitätsabhängige synaptische Lockerung und strukturelle Verfeinerung im sich entwickelnden und adulten ZNS benötigt wird. Weitere Beweise für eine Beteiligung von MHC-Klasse-I-Molekülen an synaptischer Umstrukturierung liefern Edström et al. (2004). Diese Autoren konnten in alternden Motorneuronen eine erhöhte MHC-Klasse-I-Expression feststellen und vermuten eine Beteiligung von MHC-Klasse-I-Molekülen bei der Signalübermittelung in alternden Motorneuronen, bei denen der Verlust von Boutons (Axonterminalien) zu beobachten ist. Oliveira et al. (2004) postulieren, dass MHC-Klasse-I-Moleküle eine wichtige Rolle in der 
Stabilisierung spezifischer synaptischer Kontakte nach Läsionen im adulten Nervensystem spielen. Damit stehen diese Ergebnisse allerdings im Kontrast zu denen von Huh et al. (2000), die MHC-Klasse-I-Moleküle für regressive Vorgänge wie aktivitätsabhängiger synaptischer Lockerung verantwortlich sehen. Allerdings betonen Oliveira et al. (2004) auch, dass MHC-Klasse-I-Moleküle im Immunsystem ebenfalls unterschiedliche Effekte vermitteln, die einerseits aktivierend oder inhibierend sein können. Diese Effekte werden im Immunsystem durch Interaktionen mit MHC-Klasse-I-Molekülen und aktivierenden bzw. inhibierenden Rezeptoren vermittelt.

Insgesamt tauchen in den Ergebnissen der verschiedenen Studien starke Gegensätze auf. So gehen Neumann et al. (2002) davon aus, dass MHC-Klasse-I-Moleküle nicht konstitutiv auf Neuronen exprimiert werden, sondern nur durch inflammatorische und degenerative ZNS-Krankheiten induziert werden. Damit nehmen die Autoren an, dass eindringende zytotoxische T-Zellen in das gesunde Gehirn auf den Neuronen keine Ziele finden. Diese Ansicht steht deutlich im Kontrast zu den Ergebnissen dieser Arbeit und anderen (Corriveau et al., 1998; Lidman et al., 1999; Linda et al., 1999; Huh et al., 2000; Loconto et al., 2003; Ishii et al., 2003; Oliveira et al., 2004), in denen konstitutive MHC-Klasse-IExpression auf Neuronen ohne inflammatorische Bedingungen nachgewiesen wurde. Mögliche Erklärungen der Diskrepanz der Ergebnisse werden von Boulanger und Shatz (2004) diskutiert. Die Autoren vermuten methodische Probleme beim Nachweis von MHC-Klasse-I-Molekülen in Gewebeschnitten. Aufgrund von Überfixierung und damit Epitopveränderungen könnten viele Antikörper nicht mehr an MHC-Klasse-I-Moleküle binden. Weiterhin vermuten die Autoren, dass die Etablierung sensitiverer Methoden, die geringe mRNA-Mengen detektieren, ebenfalls dafür verantwortlich ist.

Zusammenfassend zeigen die Ergebnisse der verschiedenen Studien, dass MHC-Klasse-IMoleküle sehr wahrscheinlich an der synaptischen Plastizität beteiligt sind. Darüber hinaus wurde deutlich, dass diese Beteiligung nicht nur während der Entwicklungsphase, in der eine hohe Bereitschaft neuronale Vernetzungen zu bilden, vorliegt, sondern auch in adulten Organismen, in denen die synaptische Plastizität ein geringeres Potential aufweist.

\subsubsection{Pathologie - Einfluß von MHC-Klasse-I auf die Entstehung von} Krankheiten

MHC-Klasse-I-Moleküle könnten neben der Beteiligung bei Prozessen zur Verbindung von Synapsen auch an pathologischen Prozessen des ZNS beteiligt sein. Eine konstitutive MHC-Klasse-I-Expression in diversen Neuronengruppen der Ratte wurde von Linda et al. 
(1998, 1999) und Lidman et al. (1999) nachgewiesen. Linda et al. (1998) vermuten, dass die MHC-Klasse-I-Moleküle auf Motoneuronen der Ratte Peptidantigene an CD8 ${ }^{+}-\mathrm{T}$ Zellen präsentieren und dadurch für die resultierende Schädigung der Neuronen bei neurodegenerativen Krankheiten wie Amyotrophe Lateralsklerose (ALS) verantwortlich sein könnten. Weiterhin wird ein Einfluss der allelischen Diversität der MHC-Klasse-IMoleküle in diesem Zusammenhang nicht ausgeschlossen. Interessanterweise werden MHC-Klasse-I-Moleküle in Motoneuronen nicht nur konstitutiv exprimiert, sondern können auch durch Axotomie induziert werden (Linda et al., 1998). Einen Zusammenhang zwischen der MHC-Klasse-I-Expression einiger Neuronengruppen und dem Verstehen der Pathogenese von Infektionen, Autoimmunkrankheiten und Neurodegenerationen im ZNS sehen auch Lidman et al. (1999). In normalen adulten Ratten wiesen Linda et al. (1999) die gleichzeitige Expression von MHC-Klasse-I- und B2M-Genen nur in dopaminergen Neuronen und in Motoneuronen nach. In anderen Neuronengruppen konnten die Autoren dagegen nur MHC-Klasse-I-Expression feststellen. Damit gehen sie davon aus, dass nur in den dopaminergen Neuronen und Motoneuronen auch das vollständige MHC-Klasse-IMolekül exprimiert wird. Aus diesem Grund wird für die Funktion von MHC-Klasse-IMolekülen ebenfalls ein Zusammenhang zu neurodegenerativen Erkrankungen wie M. Parkinson und ALS, bei denen diese Neuronengruppen betroffen sind, postuliert (Linda et al., 1999). Im Einklang mit diesem Postulat wurden in der vorliegenden Arbeit ebenfalls starke MHC-Klasse-I- und B2M-Expressionen in der SNc nachgewiesen, dort wo sich die meisten dopaminergen Neuronen befinden. Allerdings sind auf Proteinebene auch in anderen Neuronengruppen MHC-Klasse-I-Moleküle zu finden, die mit diesen Krankheiten nicht im Zusammenhang stehen. Es ist aber hervorzuheben, dass die MHC-Klasse-ImRNA-Expression in der SNc sowohl bei T. belangeri als auch bei C. jacchus mit Abstand am stärksten war. Einen Zusammenhang zwischen der Überexpression bestimmter MHCKlasse-I-Allele und einer erhöhte Anfälligkeit für neurodegenerative Krankheiten zu untersuchen, wäre Aufgabe weiterer Forschungen. Hinweise auf Assoziationen zwischen polymorphen Gen-Loci und Erkrankungen des ZNS sind dazu bereits beschrieben (Lidman et al., 2003; Olsson et al., 2005).

In Mäusen wurde unter pathologischen Bedingungen interessanterweise beobachtet, dass zwar alle Komponenten des vollständigen MHC-Klasse-I-Moleküls in Neuronen auf mRNA-Ebene exprimiert wurden, aber kein MHC-Klasse-I-Protein nachgewiesen werden konnte (Kimura und Griffin, 2000). Auch Foster et al. (2002) konnten die Induktion von MHC-Klasse-I-mRNA-Expression als Antwort auf eine chronische Entzündung zeigen. 
Daraus geht hervor, dass MHC-Klasse-I-Moleküle unter pathologischen Bedingungen im ZNS immunologische Funktionen wahrnehmen. Die beschriebenen Induktionen und Steigerungen der MHC-Klasse-I-Expression im ZNS weisen daraufhin, dass sehr wahrscheinlich verschiedene MHC-Klasse-I-Gene an den unterschiedlichen Funktionen im ZNS teilnehmen. Wie im nachfolgenden Kapitel ebenfalls beschrieben wird, gibt es Hinweise, dass die MHC-Klasse-I-Expression auf Neuronen in verschiedenen Regionen im Gehirn vor allem eine nicht-klassische MHC-Klasse-I-Expression ist (Lidman et al., 1999). Bei der durch Entzündungsreaktionen induzierten MHC-Klasse-I-Expression könnte es sich daher wahrscheinlich eher um eine klassische MHC-Klasse-I-Expression handeln das hieße MHC-Klasse-I-Gene, die auch im Immunsystem eine klassische Antigenpräsentierende Funktion ausüben.

Zusammenfassend machen die Ergebnisse sowohl unter gesunden als auch pathologischen Bedingungen des ZNS deutlich, dass MHC-Klasse-I-Moleküle auch im ZNS bei verschiedenen Funktionen (synaptische Plastizität und Antigenpräsentation) beteiligt sind. Diese Multifunktionalität derselben Molekülklasse ist aus dem Immunsystem nicht unbekannt. MHC-Klasse-I-Moleküle oder MHC-Klasse-Ib-Moleküle sind neben der Antigenpräsentation im Immunsystem unter anderem auch am Fettstoffwechsel (Sanchez et al., 1999), am Eisenmetabolismus (Feder et al., 1996; Cardoso und de Sousa, 2003), der Blutgerinnung (Fukudome und Esmon, 1994) oder der Aufnahme von mütterlichen Immunglobulinen aus der Milch (Simister und Mostov, 1989) beteiligt.

\subsection{Caja-G- und Caja-E-Spezifität}

Die oben besprochenen Ergebnisse zu C. jacchus wurden mit der Caja-G Exon2-4-Sonde erhalten. Die Sequenz der Sonde umfasst das Exon 2, Exon 3 und Exon 4 der Caja-G cDNA. Damit beinhaltet die Sonde das konservierte Exon 4. Das bedeutet aber auch, dass mit dieser Sonde sehr wahrscheinlich alle exprimierten MHC-Klasse-I-Gene in der In-situHybridisierung detektiert wurden. Um mögliche genspezifische Expressionsmuster zu finden, wurden Gehirnschnitte von $C$. jacchus mit den spezifischeren Sonden Caja-G Exon2-3 und Caja-E Exon2-3 hybridisiert. Dabei konnten zwar gleiche Expressionsmuster aber sehr unterschiedliche Expressionsintensitäten zwischen den beiden Sonden beobachtet werden. Die Caja-G Exon2-3-Sonde ergab eine deutlich stärkere MHC-Klasse-IExpression in den Regionen Substantia nigra, Hippocampus-Formation und Cortex als dies mit der Sonde Caja-E Exon2-3 zu sehen war. Durch RT-PCR wurde ebenfalls die 
Expression von Caja-G und Caja-E untersucht und im Cerebellum beide Transkripte nachgewiesen. Diese Ergebnisse weisen daraufhin, dass nicht alle MHC-Klasse-I-Loci in Neuronen des nicht-humanen Primaten gleich exprimiert sind und dass wahrscheinlich verschiedene MHC-Klasse-I-Loci unterschiedlich zur gesamten MHC-Klasse-I-Expression im Gehirn beitragen.

Diese Beobachtung wird durch die unterschiedliche Reaktivität mit den MHC-Klasse-IAntikörpern Ox-18 und HB115 unterstützt. Der Ox-18-Antikörper reagiert mit MHCKlasse-I-Molekülen, die auf Neuronen, aber nicht auf Leukozyten oder Endothelzellen exprimiert werden, während der HB115-Antikörper vice versa reagiert. Somit werden von diesen Antikörpern auch unterschiedliche MHC-Klasse-I-Moleküle, bzw. ein unterschiedliches Expressionsmuster dieser unterschiedlichen Moleküle nachgewiesen. Genspezifische MHC-Klasse-I-Expression wurde zuvor auch im Gehirn von Ratte und Maus festgestellt (Lidman et al., 1999; Huh et al., 2000). Lidman et al. (1999) zeigten, dass die MHC-Klasse-I-Expression in verschiedenen Regionen im Gehirn der Ratte vor allem eine nicht-klassische MHC-Klasse-I-Expression ist. Huh et al. (2000) dagegen konnten zeigen, dass sowohl klassische als auch nicht-klassische MHC-Klasse-I-Expression sehr unterschiedlich in einzelnen Bereichen des Gehirns der Maus verteilt ist.

Im $C$. jacchus wurden bisher drei Typen von MHC-Klasse-I-Genen identifiziert (Cadavid et al., 1997). Es werden Caja-E, Caja-G und Caja-F unterschieden. Dabei können Caja-E und Caja-F eindeutig als orthologe Gene zu HLA-E und HLA-F und damit der nichtklassischen MHC-Klasse-I-Gene zugeordnet werden, während eine orthologe Beziehung zwischen Caja-G und HLA-G nicht besteht (Adams und Parham, 2001). MHC-G-Gene von Neuweltaffen werden als MHC-Klasse-Ia-Gene und $M H C-E$ und $M H C-F$ als nichtklassische MHC-Klasse-Ib-Gene betrachtet (Watkins et al., 1990a, b; Watkins, 1995). Es muss angemerkt werden, dass im Genom vom C. jacchus noch weitere MHC-Klasse-IGene vorkommen können, deren mRNA durch die Caja-G-Sonde detektiert würde. Damit zeigen die Ergebnisse dieser Arbeit zunächst, dass verschiedene MHC-Klasse-I-Loci auf Neuronen im Gehirn des $C$. jacchus unterschiedlich exprimiert werden. Es stellt sich damit die Frage, ob es eventuell unterschiedliche Funktionen für unterschiedliche MHC-Klasse-IGene im Gehirn gibt. In diesem Zusammenhang ist zu erwähnen, dass unterschiedliche Spezies sich hinsichtlich ihrer genetischen Ausstattung mit MHC-Klasse-I-Genen zum Teil recht stark unterscheiden können (Kelley et al., 2005b). Daher könnten Funktionen, die von MHC-Klasse-I-Molekülen in einer Spezies vermittelt werden, in anderen Spezies wiederum anders reguliert sein oder abwesend sein. Daraus könnten unterschiedliche 
Reaktionen wie zum Beispiel Resistenzen auf Pathogene entstehen, es ist aber auch denkbar, dass sich daraus Unterschiede in den neurobiologischen Funktionen (neuronale Plastizität) bzw. neurodegenerativer Krankheiten ergeben.

\subsection{Interaktionspartner von MHC-Klasse-I}

Die Beteiligung von MHC-Klasse-I-Molekülen bei Prozessen, die die synaptische Plastizität im ZNS beeinflussen, ist in Studien nachgewiesen (Corriveau et al., 1998; Huh et al., 2000). Neben der Frage wie MHC-Klasse-I-Moleküle in diese Mechanismen eingreifen, ist auch die Frage nach dem Interaktionspartner von großer Bedeutung. Neben der Präsentation von antigenen Peptiden an T-Zellen über den T-Zell-Rezeptor (TCR), interagieren die MHC-Klasse-I-Moleküle mit einer Reihe sehr unterschiedlicher Rezeptoren der Natürlichen Killerzellen und anderen Immunzellen, wie NKG2/CD94, KIR, LIR und Ly49 (Boulanger und Shatz, 2004). Diese Rezeptoren können inhibitorische oder aktivierende Signale nach Bindung des MHC-Klasse-I-Moleküls vermitteln (Lanier, 2005).

Es ist möglich, dass im ZNS die gleichen Interaktionsmechanismen angewandt werden, aber auch unbekannte Mechanismen mit anderen Molekülen sind nicht auszuschließen. Syken et al. (2006) vermuten, dass Interaktionen zwischen MHC-Klasse-I-Molekülen und Rezeptoren auf anderen Neuronen intrazelluläre Signale generieren, die darüber synaptische Bindungen, die Morphologie von Neuronen und neuronale Schaltkreise ändern könnten. Sowohl Corriveau et al. (1998) als auch Huh et al. (2000) wiesen neben der MHC-Klasse-I-Expression auch die Expression der CD3 $\xi$-Rezeptorkomponente auf Neuronen nach. Corriveau et al. (1998) postulieren, dass MHC-Klasse-I-Moleküle und B2M postsynaptisch in cortikalen Dendriten lokalisiert sind und Signale zu einem CD3 $\xi$ bindenden präsynaptischen Rezeptor senden. Ebenfalls Huh et al. (2000) sehen anhand der Expressionsmuster eine Beteiligung eines CD3 $\xi$-bindenden Rezeptors bei der

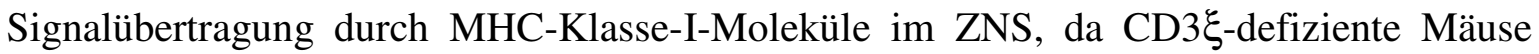
identische neurobiologische Veränderungen zeigen wie MHC-Klasse-I-defiziente Mäuse (Veränderungen in der Langzeitpotenzierung, Langzeitdepression, Projektion, u. a.). Hinweise auf eine Interaktion mit einem anderen Rezeptor liefern Bryceson et al. (2005). Sie konnten die Expression eines Gens, das signifikant homolog zum humanen „killer cell immunoglobulin-like receptor" (KIR) ist, in bestimmten Bereichen (z. B. in Gyrus dentatus) im Mausgehirn detektieren. Allerdings ist auch in diesem Fall nicht geklärt, ob es 
sich dabei um einen Rezeptor für MHC-Klasse-I-Moleküle handelt. Beweise für einen anderen Rezeptor, der auf Neuronen mit MHC-Klasse-I-Molekülen interagieren könnte, beschreiben Syken et al. (2006). Die Autoren zeigten die Expression von PirB (Pairedimmunoglobulibn like receptor-B) im gesamten Mausgehirn, mit starker Expression im Cortex cerebri, Hippocampus, Cerebellum und Bulbus olfactorius. Dies sind genau die Regionen, die auch MHC-Klasse-I-mRNA und -Protein exprimieren (Corriveau et al., 1998; Huh et al., 2000). Interessanterweise zeigten Syken et al. (2006) durch Experimente mit einem PirB-Fusionsprotein, dass PirB in Abhängigkeit von MHC-Klasse-I-Molekülen an Neuronen binden kann. Im Cortex cerebri bindet das PirB-Fusionsprotein an Zellkörper und Dendriten von cortikalen Pyramidenneuronen. Die Autoren zeigten, dass PirB die synaptische Plastizität im ZNS limitiert. Dadurch ist eine selektive Festigung und Stabilisierung synaptischer Verbindungen möglich.

\subsection{Tacrolimus und der Einfluss auf die MHC-Klasse-I-Expression}

Bei Organ- oder Gewebetransplantationen ist es notwendig die Abwehrreaktion des Körpers auf körperfremde Antigene zu unterdrücken. Die Antigenerkennung erfolgt durch T-Zell-Rezeptoren, die den Calcineurin/Calmodulin-Signaltransduktionsweg stimulieren, darüber die Synthese T-Zell-stimulatorischer Zytokine bewirken und letztlich zur Aktivierung zytotoxischer Zellen führt, welche die Abstoßung des Transplantats herbeiführen. Um diese Abstoßung zu vermeiden, muss die Aktivierung der T-Zellen unterdrückt werden, das heißt eine Immunsuppression durchgeführt werden. Eine Möglichkeit ist, die Aktivierung der T-Zellen über die Inhibition der Phosphatase Calcineurin $\mathrm{zu}$ unterbinden. $\mathrm{Zu}$ den Calcineurininhibitoren gehören Cyclosporin und Tacrolimus (FK506), die frühzeitig in den Signalweg der zu aktivierenden T-Zelle eingreifen. Neben einer erhöhten Anfälligkeit für Infektionskrankheiten sind in einigen Fällen auch neurotoxische Erscheinungen Nebenwirkungen bei Immunsuppression mit Calcineurininhibitoren. So sind für Patienten Tremor (Wijdicks, 2001), Sensibilitäts-, Koordinations- und Wortfindungsstörungen, Anfälle, Verwirrtheit und Koma berichtet (Eidelman et al., 1991). Ebenfalls sind Tacrolimus-assoziierte Enzephalopathien (Wong et al., 2003; Grimbert et al., 1999) und Verhaltensänderungen bei FK506-behandelten Patienten beschrieben worden (Kemper et al., 2003). Interessanterweise sind für die Immunsuppressiva Cyclosporin A und FK506 aber auch neuroprotektive Wirkungen bei Schlaganfällen bekannt (Kaminska et al., 2004). Winter et al. (2000) beschreiben durch 
Behandlung mit FK506 ein verzögertes und reduziertes Absterben von Neuronen in der Substantia nigra nach der Durchtrennung der medialen Vorderhirnbündel. Weiterhin konnte in Körnerzellen im Cerebellum gezeigt werden, dass die Phosphatase Calcineurin regulatorisch auf Entwicklungs- und Reifungsprozesse in Neuronen wirkt (Sato et al., 2005), sowie auf Prozesse, die Teil des synaptischen Vesikelrecyclings sind (Kumashiro et al., 2005). Sato et al. (2005) fanden ebenfalls eine große Anzahl an funktionell vielfältigen Genen, deren Expression durch FK506 herunter- oder hochreguliert wurde. In diesem Zusammenhang ist es sehr interessant, dass in der vorliegenden Arbeit ebenfalls eine Regulation der Genexpression festgestellt werden konnte. Durch die Behandlung mit FK506 war bei $C$. jacchus die MHC-Klasse-I-Expression in Neuronen unterdrückt, allerdings blieb die MHC-Klasse-I-Expression in Endothelzellen der Blutgefäße unbeeinflusst. Es ist daher nicht unwahrscheinlich, dass die FK506-Behandlung nur bestimmte MHC-Klasse-I-Moleküle betrifft. Ähnliche Beobachtungen wurden von Ito et al. (2004) beschrieben, die ebenfalls die Abnahme der MHC-Klasse-I-Expression in humanen Haarfollikeln durch FK506 beobachteten. Zusammmenfassend sind diese Beobachtungen sehr interessant im Hinblick auf die oben beschriebenen Nebenwirkungen von FK506 aber auch auf die beschriebene neuroprotektive Wirkung und damit zusammenhängende zumeist noch unbekannte Mechanismen.

\subsection{Schlussfolgerungen}

Die Ergebnisse der vorliegenden Arbeit zeigen erstmals die MHC-Klasse-I-Expression in bestimmten Neuronengruppen im Gehirn von nicht-humanen Primaten. Damit wurde gezeigt, dass das zuvor beschriebene MHC-Klasse-I-Expressionsmuster bei Katzen, Mäusen und Ratten auch bei Primaten zu finden ist. Die zuvor beschriebenen neuen Funktionen von MHC-Klasse-I-Molekülen im Zusammenhang mit synaptischer Plastizität im Gehirn, sind daher auch sehr wahrscheinlich auf das nicht-humane Primatengehirn zu übertragen. Damit wird die Vermutung untermauert, dass MHC-Klasse-I-Moleküle neben einer immunologischen Funktion im Körper auch im ZNS Funktionen wahrnehmen. Möglicherweise ähnliche Funktionen von MHC-Klasse-I-Molekülen im humanen Gehirn sind aufgrund dieser Ergebnisse nicht unwahrscheinlich und es könnte ein Zusammenhang zwischen MHC-Klasse-I-Molekülen und neurodegenerativen Krankheiten bestehen. In diesem Kontext sind der Polymorphismus und die Polygenie des MHCs innerhalb einer Spezies und über Speziesgrenzen hinaus von großer Bedeutung. Höhere Anfälligkeiten für 
bestimmte Krankheiten aufgrund der individuellen MHC-Klasse-I-Gene sind aus dem Immunsystem nicht unbekannt (Parham, 2005) und werden zum Teil auch im ZNS vermutet (Linda et al., 1999). Allerdings bedürfen eventuelle Zusammenhänge noch weiterer Untersuchungen.

Neben dem Polymorphismus innerhalb einer Spezies sind auch genetische Unterschiede in MHC-Klasse-I-Rezeptorsystemen von Bedeutung. So kann die An- oder Abwesenheit von Genen zu unterschiedlichen Rezeptorbindungen führen. Die Bindung oder Nicht-Bindung von MHC-Klasse-I-Molekülen an Rezeptoren (z. B. KIR) kann die Erkennung von Tumoren, Autoimmunreaktionen und Resistenzen gegen Pathogene beeinflussen (Rajagopalan und Long, 2005). Ob diese An- oder Abwesenheit von Genen auch im ZNS relevant ist und Ursache für erhöhte Anfälligkeiten neurodegenerativer Krankheiten ist, wird sich zeigen müssen.

Über den Beitrag zu Krankheitsanfälligkeiten hinaus, ist es sehr wahrscheinlich, dass MHC-Klasse-I-Moleküle im ZNS an der synaptischen Plastizität beteiligt sind (Corriveau et al., 1998; Huh et al., 2000). In dieser Hinsicht sind ebenfalls der Polymorphismus und die Polygenie des MHC und seiner Rezeptoren vor allem zwischen verschiedenen Spezies von großer Bedeutung. Möglicherweise könnten MHC-Klasse-I-Moleküle in höheren Primaten für Bedingungen bei der synaptischen Plastizität beitragen, die es ermöglichen, synaptische Verbindungen hocheffizient $\mathrm{zu}$ gestalten und damit höhere kognitive Fähigkeiten zu erlangen. Allerdings bleiben Fragen bezüglich MHC-Klasse-I-Molekülen und Interaktionspartner, zugrunde liegende Mechanismen des Einflusses von MHCKlasse-I auf die synaptische Plastizität und eventuelle erhöhte Anfälligkeitsrisiken für neurodegenerative Krankheiten aufgrund bestimmter MHC-Klasse-I-Gene noch zu beantworten. 


\section{Zusammenfassung}

MHC-Klasse-I-Gene und deren Produkte sind essentielle Komponenten der adaptiven Immunantwort. Lange Zeit wurde aufgrund zahlreicher Studien davon ausgegangen, dass Neuronen als Teil des „Immunprivileg-Status“ des ZNS keine MHC-Klasse-I-Gene exprimieren. Diese Befunde wurden jedoch durch neuere und sensitivere Methoden widerlegt. Es konnte von unterschiedlichen Arbeitsgruppen in verschiedenen Säugetieren (Katze, Maus, Ratte) gezeigt werden, dass Neuronen MHC-Klasse-I-Gene und -Moleküle exprimieren. Darüber hinaus wurde in Katze und Maus gezeigt, dass MHC-Klasse-IMoleküle in Neuronen sehr wahrscheinlich an der synaptischen Plastizität beteiligt sind und damit neben der Antigenpräsentation eine neurobiologische Funktion erfüllen.

In Hinblick auf diesen Forschungsstand war Ziel dieser Arbeit die MHC-Klasse-I-Gene von Weißbüschelaffen (Callithrix jacchus) und deren Expression im Gehirn zu untersuchen. Mittels In-situ-Hybridisierung konnte in Neuronen dieses nicht-humanen Primaten MHC-Klasse-I- und B2M-mRNA-Expression im Cortex, in der Substantia nigra, in der Hippocampus-Formation, im Nucleus oculomotorius communis, im Nucleus ruber und in Epithel- und Endothelzellen des Plexus choroideus und der Ventrikelbereiche nachgewiesen werden. In den gleichen Bereichen konnte mittels Immunhistologie auch die Expression von MHC-Klasse-I-Molekülen festgestellt werden. Damit zeigte sich ein ähnliches MHC-Klasse-I-Expressionsmuster wie es zuvor in der Maus und Ratte beschrieben wurde. Ein nahezu identisches Expressionsmuster konnte auch für das Spitzhörnchen (Tupaia belangeri) nachgewiesen werden. Weiterhin wurde in immunsupprimierten Weißbüschelaffen eine Reduktion der MHC-Klasse-I-MolekülExpression auf Neuronen aber nicht auf Endothelzellen der cerebralen Blutgefäße beobachtet. Damit scheinen jeweils unterschiedliche MHC-Klasse-I-Moleküle exprimiert zu werden und dabei unterschiedliche Aufgaben wahrzunehmen.

Insgesamt lassen diese Ergebnisse vermuten, dass MHC-Klasse-I-Moleküle bei $T$. belangeri und dem nicht-humanen Primaten $C$. jacchus eine Rolle in der synaptischen Plastizität spielen könnten. Aufgrund der nahen Verwandtschaft könnte dies damit auch im Menschen wahrscheinlich sein. Zusammenhänge zwischen einer erhöhten Suszeptibilität neurodegenerativer Krankheiten und des individuellen MHC-Klasse-I-Genotyps sind aufgrund Beispielen aus dem Immunsystem ebenfalls nicht auszuschließen. 


\section{Summary}

MHC class I genes and their products are essential components of the adaptive immune response. According to numerous studies it was assumed that neurons do not express MHC class I genes as a part of the "immune privilege state" of the CNS. However, this view was disproved by more recent and sensitive methods. From different groups it was shown in different mammals (cat, mice, rat) that neurons express MHC class I genes and molecules. Moreover, studies on cats and mice revealed that MHC class I molecules in neurons are probably involved in synaptic plasticity and therefore fulfill a neurobiological role beside antigen presentation. With regard to this state of research the aim of this study was to investigate the MHC class I genes of the common marmoset monkey (Callithrix jacchus) and their expression in the brain. Using in-situ hybridisation neuronal MHC class I and $B 2 M$ mRNA expression was found in this non-human primate in cortex, substantia nigra, hippocampus formation, nucleus oculomotorius communis, nucleus ruber and on epithelial- and endothelial cells of the plexus choroideus and ventricles. In the same regions MHC class I protein expression was found using immunohistology. This MHC class I expression pattern in the brain of a non-human primate is similar to that described earlier for rodents and cats. A nearly identical expression pattern was also found in tree shrews (Tupaia belangeri). Analysis of the brain of immunsuppressed marmosets revealed a reduction of MHC class I expression in neurons but not in endothelial cells of cerebral blood vessels. It appears that in each case different MHC class I molecules are expressed and that they function differently.

In conclusion, these results suggest that MHC class I molecules might play a role in synaptic plasticity in $T$. belangeri and the non-human primate $C$. jacchus. Because of the closed genetic relationship a similar role of these molecules in the human brain could be possible. Taking into account examples from the immune system correlations between higher susceptibility of neurodegenerative disorders and the individual MHC class I genotype are not be excluded. 


\section{Veröffentlichungen}

Teile dieser Dissertation wurden bereits vorab veröffentlicht in

Rölleke,U., Flügge,G., Plehm,S., Schlumbohm,C., Armstrong,V.W., Dressel,R., UchanskaZiegler,B., Ziegler,A., Fuchs,E., Czeh,B. \& Walter,L. 2006. Differential expression of major histocompatibility complex class I molecules in the brain of a New World monkey, the common marmoset (Callithrix jacchus). J. Neuroimmunol. 176, 39-50. 


\section{Literaturverzeichnis}

Aarli,J.A. 1983. The immune system and the nervous system. J. Neurol. 229, 137-154.

Abbott,D.H., Barnett,D.K., Colman,R.J., Yamamoto,M.E. \& Schultz-Darken,N.J. 2003. Aspects of common marmoset basic biology and life history important for biomedical research. Comp Med. 53, 339-350.

Abraham,W.C. \& Tate,W.P. 1997. Metaplasticity: a new vista across the field of synaptic plasticity. Prog. Neurobiol. 52, 303-323.

Adams,E.J. \& Parham,P. 2001. Species-specific evolution of MHC class I genes in the higher primates. Immunol. Rev. 183, 41-64.

Amaral,D.G. \& Witter,M.P. 1989. The three-dimensional organization of the hippocampal formation: a review of anatomical data. Neuroscience 31, 571-591.

Araki,T., Gejyo,F., Takagaki,K., Haupt,H., Schwick,H.G., Burgi,W., Marti,T., Schaller,J., Rickli,E., Brossmer,R. \& . 1988. Complete amino acid sequence of human plasma Zn-alpha 2-glycoprotein and its homology to histocompatibility antigens. Proc. Natl. Acad. Sci. U. S. A. 85, 679-683.

Armstrong,V.W. \& Oellerich,M. 2001. New developments in the immunosuppressive drug monitoring of cyclosporine, tacrolimus, and azathioprine. Clin. Biochem. 34, 9-16.

Azuma,T., Dijkstra,J.M., Kiryu,I., Sekiguchi,T., Terada,Y., Asahina,K., Fischer,U. \& Ototake,M. 2005. Growth and behavioral traits in Donaldson rainbow trout (Oncorhynchus mykiss) cosegregate with classical major histocompatibility complex (MHC) class I genotype. Behav. Genet. 35, 463-478.

Barker,C.F. \& Billingham,R.E. 1977. Immunologically privileged sites. Adv. Immunol. 25, 1-54.

Bliss,T.V. \& Lømo,T. 1973. Long-lasting potentiation of synaptic transmission in the dentate area of the anaesthetized rabbit following stimulation of the perforant path. J. Physiol 232, 331-356.

Boulanger,L.M. \& Shatz,C.J. 2004. Immune signalling in neural development, synaptic plasticity and disease. Nat. Rev. Neurosci. 5, 521-531.

Braud,V.M., Allan,D.S., O'Callaghan,C.A., Soderstrom,K., D'Andrea,A., Ogg,G.S., Lazetic,S., Young,N.T., Bell,J.I., Phillips,J.H., Lanier,L.L. \& McMichael,A.J. 1998. HLA-E binds to natural killer cell receptors CD94/NKG2A, B and C. Nature 391, 795-799.

Brown,D., Trowsdale,J. \& Allen,R. 2004. The LILR family: modulators of innate and adaptive immune pathways in health and disease. Tissue Antigens 64, 215-225. 
Bryceson,Y.T., Foster,J.A., Kuppusamy,S.P., Herkenham,M. \& Long,E.O. 2005. Expression of a killer cell receptor-like gene in plastic regions of the central nervous system. J. Neuroimmunol. 161, 177-182.

Cadavid,L.F., Shufflebotham,C., Ruiz,F.J., Yeager,M., Hughes,A.L. \& Watkins,D.I. 1997. Evolutionary instability of the major histocompatibility complex class I loci in New World primates. Proc. Natl. Acad. Sci. U. S. A. 94, 14536-14541.

Cardoso,C.S. \& de Sousa,M. 2003. HFE, the MHC and hemochromatosis: paradigm for an extended function for MHC class I. Tissue Antigens 61, 263-275.

Carroll,R.C., Lissin,D.V., von Zastrow,M., Nicoll,R.A. \& Malenka,R.C. 1999. Rapid redistribution of glutamate receptors contributes to long-term depression in hippocampal cultures. Nat. Neurosci. 2, 454-460.

Carson,M.J., Doose,J.M., Melchior,B., Schmid,C.D. \& Ploix,C.C. 2006. CNS immune privilege: hiding in plain sight. Immunol. Rev. 213, 48-65.

Castellani,G.C., Quinlan,E.M., Bersani,F., Cooper,L.N. \& Shouval,H.Z. 2005. A model of bidirectional synaptic plasticity: from signaling network to channel conductance. Learn. Mem. 12, 423-432.

Corriveau,R.A., Huh,G.S. \& Shatz,C.J. 1998. Regulation of class I MHC gene expression in the developing and mature CNS by neural activity. Neuron 21, 505-520.

Corriveau,R.A. 1999. Electrical activity and gene expression in the development of vertebrate neural circuits. J. Neurobiol. 41, 148-157.

Dash,P.K., Hochner,B. \& Kandel,E.R. 1990. Injection of the cAMP-responsive element into the nucleus of Aplysia sensory neurons blocks long-term facilitation. Nature 345, 718-721.

Davis,H.P. \& Squire,L.R. 1984. Protein synthesis and memory: a review. Psychol. Bull. 96, 518559.

Davis,M.M. \& Bjorkman,P.J. 1988. T-cell antigen receptor genes and T-cell recognition. Nature 334, 395-402.

Dermietzel,R. 1975. Junctions in the central nervous system of the cat. IV. Interendothelial junctions of cerebral blood vessels from selected areas of the brain. Cell Tissue Res. 164, 45-62.

Drew,P.D., Lonergan,M., Goldstein,M.E., Lampson,L.A., Ozato,K. \& McFarlin,D.E. 1993. Regulation of MHC class I and beta 2-microglobulin gene expression in human neuronal cells. Factor binding to conserved cis-acting regulatory sequences correlates with expression of the genes. J. Immunol. 150, 3300-3310. 
Edström,E., Kullberg,S., Ming,Y., Zheng,H. \& Ulfhake,B. 2004. MHC class I, beta2 microglobulin, and the INF-gamma receptor are upregulated in aged motoneurons. J. Neurosci. Res. 78, 892-900.

Eidelman,B.H., Abu-Elmagd,K., Wilson,J., Fung,J.J., Alessiani,M., Jain,A., Takaya,S., Todo,S.N., Tzakis,A., Van Thiel,D. \& . 1991. Neurologic complications of FK 506. Transplant. Proc. 23, 31753178.

Engelhardt,B., Wolburg-Buchholz,K. \& Wolburg,H. 2001. Involvement of the choroid plexus in central nervous system inflammation. Microsc. Res. Tech. 52, 112-129.

Engert,F. \& Bonhoeffer,T. 1999. Dendritic spine changes associated with hippocampal long-term synaptic plasticity. Nature $399,66-70$.

Falk,K., Rotzschke,O. \& Rammensee,H.G. 1990. Cellular peptide composition governed by major histocompatibility complex class I molecules. Nature 348, 248-251.

Falk,K., Rotzschke,O., Stevanovic,S., Jung,G. \& Rammensee,H.G. 1991. Allele-specific motifs revealed by sequencing of self-peptides eluted from MHC molecules. Nature 351, 290-296.

Feder,J.N., Gnirke,A., Thomas,W., Tsuchihashi,Z., Ruddy,D.A., Basava,A., Dormishian,F., Domingo,R., Jr., Ellis,M.C., Fullan,A., Hinton,L.M., Jones,N.L., Kimmel,B.E., Kronmal,G.S., Lauer,P., Lee,V.K., Loeb,D.B., Mapa,F.A., McClelland,E., Meyer,N.C., Mintier,G.A., Moeller,N., Moore,T., Morikang,E., Prass,C.E., Quintana,L., Starnes,S.M., Schatzman,R.C., Brunke,K.J., Drayna,D.T., Risch,N.J., Bacon,B.R. \& Wolff,R.K. 1996. A novel MHC class I-like gene is mutated in patients with hereditary haemochromatosis. Nat. Genet. 13, 399-408.

Ferguson,T.A. \& Griffith,T.S. 1997. A vision of cell death: insights into immune privilege. Immunol. Rev. 156, 167-184.

Finsen,B.R., Jorgensen,M.B., Diemer,N.H. \& Zimmer,J. 1993. Microglial MHC antigen expression after ischemic and kainic acid lesions of the adult rat hippocampus. Glia 7, 41-49.

Fishman,D., Elhyany,S. \& Segal,S. 2004. Non-immune functions of MHC class I glycoproteins in normal and malignant cells. Folia Biol. (Praha) 50, 35-42.

Flügge,P., Fuchs,E., Günther,E. \& Walter,L. 2002. MHC class I genes of the tree shrew Tupaia belangeri. Immunogenetics 53, 984-988.

Foster,J.A., Quan,N., Stern,E.L., Kristensson,K. \& Herkenham,M. 2002. Induced neuronal expression of class I major histocompatibility complex mRNA in acute and chronic inflammation models. J. Neuroimmunol. 131, 83-91.

Fuchs,E. \& Flügge,G. 2001. [Psychosocial stress induces molecular and structural alterations in the brain - How animal experiments help to understand pathomechanisms of depressive illnesses]. Z. Psychosom. Med. Psychother. 47, 80-97. 
Fuchs,E., Flügge,G., Ohl,F., Lucassen,P., Vollmann-Honsdorf,G.K. \& Michaelis,T. 2001. Psychosocial stress, glucocorticoids, and structural alterations in the tree shrew hippocampus. Physiol Behav. 73, 285-291.

Fujimaki,H., Hikawa,N., Nagoya,M., Nagata,T. \& Minami,M. 1996. IFN-gamma induces expression of MHC class I molecules in adult mouse dorsal root ganglion neurones. Neuroreport 7, 2951-2955.

Fukudome,K. \& Esmon,C.T. 1994. Identification, cloning, and regulation of a novel endothelial cell protein C/activated protein C receptor. J. Biol. Chem. 269, 26486-26491.

Fukumoto,T., McMaster,W.R. \& Williams,A.F. 1982. Mouse monoclonal antibodies against rat major histocompatibility antigens. Two la antigens and expression of la and class I antigens in rat thymus. Eur. J. Immunol. 12, 237-243.

Garcia,P., Llano,M., de Heredia,A.B., Willberg,C.B., Caparros,E., Aparicio,P., Braud,V.M. \& LopezBotet,M. 2002. Human T cell receptor-mediated recognition of HLA-E. Eur. J. Immunol. 32, 936944.

Genain,C.P. \& Hauser,S.L. 2001. Experimental allergic encephalomyelitis in the New World monkey Callithrix jacchus. Immunol. Rev. 183, 159-172.

Gleimer,M. \& Parham,P. 2003. Stress management: MHC class I and class I-like molecules as reporters of cellular stress. Immunity. 19, 469-477.

Goddard,C.A., Butts,D.A. \& Shatz,C.J. 2007. Regulation of CNS synapses by neuronal MHC class I. Proc. Natl. Acad. Sci. U. S. A. 104, 6828-6833.

Goodman,C.S. \& Shatz,C.J. 1993. Developmental mechanisms that generate precise patterns of neuronal connectivity. Cell 72 Suppl, 77-98.

Gorer,P.A. 1936. The detection of antigenic differences in mouse erythrocytes by the employment of immune sera. Br. J. Exp. Path. : 18, 31-36.

Grimbert,P., Azema,C., Pastural,M., Dhamane,D., Remy,P., Salomon,L., Schortgen,F., Baron,C. \& Lang,P. 1999. Tacrolimus (FK506)-induced severe and late encephalopathy in a renal transplant recipient. Nephrol. Dial. Transplant. 14, 2489-2491.

Groh,V., Bahram,S., Bauer,S., Herman,A., Beauchamp,M. \& Spies,T. 1996. Cell stress-regulated human major histocompatibility complex class I gene expressed in gastrointestinal epithelium. Proc. Natl. Acad. Sci. U. S. A. 93, 12445-12450.

Groh,V., Steinle,A., Bauer,S. \& Spies,T. 1998. Recognition of stress-induced MHC molecules by intestinal epithelial gammadelta T cells. Science 279, 1737-1740. 
't Hart,B.A., Laman,J.D., Bauer,J., Blezer,E., van Kooyk,Y. \& Hintzen,R.Q. 2004. Modelling of multiple sclerosis: lessons learned in a non-human primate. Lancet Neurol. 3, 588-597.

Hayashi,Y., Shi,S.H., Esteban,J.A., Piccini,A., Poncer,J.C. \& Malinow,R. 2000. Driving AMPA receptors into synapses by LTP and CaMKII: requirement for GluR1 and PDZ domain interaction. Science 287, 2262-2267.

Heinzel,A.S., Grotzke,J.E., Lines,R.A., Lewinsohn,D.A., McNabb,A.L., Streblow,D.N., Braud,V.M., Grieser,H.J., Belisle,J.T. \& Lewinsohn,D.M. 2002. HLA-E-dependent presentation of Mtb-derived antigen to human CD8+ T cells. J. Exp. Med. 196, 1473-1481.

Hibino,H., Tani,K., Ikebuchi,K., Wu,M.S., Sugiyama,H., Nakazaki,Y., Tanabe,T., Takahashi,S., Tojo,A., Suzuki,S., Tanioka,Y., Sugimoto,Y., Nakahata,T. \& Asano,S. 1999. The common marmoset as a target preclinical primate model for cytokine and gene therapy studies. Blood $\mathbf{9 3}$, 2839-2848.

Higgins,C.F. 1992. ABC transporters: from microorganisms to man. Annu. Rev. Cell Biol. 8, 67113.

Hubel,D.H. \& Wiesel,T.N. 1970. The period of susceptibility to the physiological effects of unilateral eye closure in kittens. J. Physiol 206, 419-436.

Hubel,D.H., Wiesel,T.N. \& LeVay,S. 1977. Plasticity of ocular dominance columns in monkey striate cortex. Philos. Trans. R. Soc. Lond B Biol. Sci. 278, 377-409.

Huh,G.S., Boulanger,L.M., Du,H., Riquelme,P.A., Brotz,T.M. \& Shatz,C.J. 2000. Functional requirement for class I MHC in CNS development and plasticity. Science 290, 2155-2159.

Intrator,N., Bear,M.F., Cooper,L.N. \& Paradiso,M.A. 1993. Theory of synaptic plasticity in visual cortex. In: Synaptic Plasticity: Molecular, Cellular and Functional Aspects (Ed. by J.D.R.Thomppson.M.Baudry), pp. 147-167. Cambridge, MA, MIT Press.

Ishii,T., Hirota,J. \& Mombaerts,P. 2003. Combinatorial coexpression of neural and immune multigene families in mouse vomeronasal sensory neurons. Curr. Biol. 13, 394-400.

Ito,T., Ito,N., Bettermann,A., Tokura,Y., Takigawa,M. \& Paus,R. 2004. Collapse and restoration of MHC class-I-dependent immune privilege: exploiting the human hair follicle as a model. Am. J. Pathol. 164, 623-634.

Janeway,C.A., Travers,P., Walport,M. \& Shlomchik,M. 2001. Immunobiology: the Immune System in Health and Disease. 5th edn. Garland.

Joly,E., Mucke,L. \& Oldstone,M.B. 1991. Viral persistence in neurons explained by lack of major histocompatibility class I expression. Science 253, 1283-1285. 
Joly,E. \& Oldstone,M.B. 1992. Neuronal cells are deficient in loading peptides onto MHC class I molecules. Neuron 8, 1185-1190.

Kaminska,B., Gaweda-Walerych,K. \& Zawadzka,M. 2004. Molecular mechanisms of neuroprotective action of immunosuppressants--facts and hypotheses. J. Cell Mol. Med. 8, 45-58.

Katz,L.C. \& Shatz,C.J. 1996. Synaptic activity and the construction of cortical circuits. Science 274, 1133-1138.

Kelley,J. \& Trowsdale,J. 2005a. Features of MHC and NK gene clusters. Transpl. Immunol. 14, 129-134.

Kelley,J., Walter,L. \& Trowsdale,J. 2005b. Comparative genomics of major histocompatibility complexes. Immunogenetics 56, 683-695.

Kemper,M.J., Sparta,G., Laube,G.F., Miozzari,M. \& Neuhaus,T.J. 2003. Neuropsychologic sideeffects of tacrolimus in pediatric renal transplantation. Clin. Transplant. 17, 130-134.

Kew,J.N., Koester,A., Moreau,J.L., Jenck,F., Ouagazzal,A.M., Mutel,V., Richards,J.G., Trube,G., Fischer,G., Montkowski,A., Hundt,W., Reinscheid,R.K., Pauly-Evers,M., Kemp,J.A. \& Bluethmann,H. 2000. Functional consequences of reduction in NMDA receptor glycine affinity in mice carrying targeted point mutations in the glycine binding site. J. Neurosci. 20, 4037-4049.

Kida,S., Josselyn,S.A., de Ortiz,S.P., Kogan,J.H., Chevere,I., Masushige,S. \& Silva,A.J. 2002. CREB required for the stability of new and reactivated fear memories. Nat. Neurosci. 5, 348-355.

Kimura,T. \& Griffin,D.E. 2000. The role of CD8(+) T cells and major histocompatibility complex class I expression in the central nervous system of mice infected with neurovirulent Sindbis virus. J. Virol. 74, 6117-6125.

Kirkwood,A., Dudek,S.M., Gold,J.T., Aizenman,C.D. \& Bear,M.F. 1993. Common forms of synaptic plasticity in the hippocampus and neocortex in vitro. Science 260, 1518-1521.

Kirkwood,A. \& Bear,M.F. 1995. Elementary forms of synaptic plasticity in the visual cortex. Biol. Res. 28, 73-80.

Kumashiro,S., Lu,Y.F., Tomizawa,K., Matsushita,M., Wei,F.Y. \& Matsui,H. 2005. Regulation of synaptic vesicle recycling by calcineurin in different vesicle pools. Neurosci. Res. 51, 435-443.

Lampson,L.A. \& Fisher,C.A. 1984. Weak HLA and beta 2-microglobulin expression of neuronal cell lines can be modulated by interferon. Proc. Natl. Acad. Sci. U. S. A. 81, 6476-6480.

Lampson,L.A. \& Hickey,W.F. 1986. Monoclonal antibody analysis of MHC expression in human brain biopsies: tissue ranging from "histologically normal" to that showing different levels of glial tumor involvement. J. Immunol. 136, 4054-4062. 
Lampson,L.A. 1988. Biological significance of HLA-A,B,C expression in neuroblastoma and related cell lines. Prog. Clin. Biol. Res. 271, 409-420.

Lampson,L.A. 1995. Interpreting MHC class I expression and class I/class II reciprocity in the CNS: reconciling divergent findings. Microsc. Res. Tech. 32, 267-285.

Lanier,L.L. 2005. NK cell recognition. Annu. Rev. Immunol. 23, 225-274.

Lee,N., Llano,M., Carretero,M., Ishitani,A., Navarro,F., Lopez-Botet,M. \& Geraghty,D.E. 1998. HLA-E is a major ligand for the natural killer inhibitory receptor CD94/NKG2A. Proc. Natl. Acad. Sci. U. S. A. 95, 5199-5204.

Leibson,P.J. 1998. Cytotoxic lymphocyte recognition of HLA-E: utilizing a nonclassical window to peer into classical MHC. Immunity. 9, 289-294.

LeVay,S., Stryker,M.P. \& Shatz,C.J. 1978. Ocular dominance columns and their development in layer IV of the cat's visual cortex: a quantitative study. J. Comp Neurol. 179, 223-244.

LeVay,S., Wiesel,T.N. \& Hubel,D.H. 1980. The development of ocular dominance columns in normal and visually deprived monkeys. J. Comp Neurol. 191, 1-51.

Lidman,O., Olsson,T. \& Piehl,F. 1999. Expression of nonclassical MHC class I (RT1-U) in certain neuronal populations of the central nervous system. Eur. J. Neurosci. 11, 4468-4472.

Lidman,O., Swanberg,M., Horvath,L., Broman,K.W., Olsson,T. \& Piehl,F. 2003. Discrete gene loci regulate neurodegeneration, lymphocyte infiltration, and major histocompatibility complex class II expression in the CNS. J. Neurosci. 23, 9817-9823.

Linda,H., Hammarberg,H., Cullheim,S., Levinovitz,A., Khademi,M. \& Olsson,T. 1998. Expression of MHC class I and beta2-microglobulin in rat spinal motoneurons: regulatory influences by IFNgamma and axotomy. Exp. Neurol. 150, 282-295.

Linda,H., Hammarberg,H., Piehl,F., Khademi,M. \& Olsson,T. 1999. Expression of MHC class I heavy chain and beta2-microglobulin in rat brainstem motoneurons and nigral dopaminergic neurons. J. Neuroimmunol. 101, 76-86.

Linden,D.J. 1994. Long-term synaptic depression in the mammalian brain. Neuron 12, 457-472.

Loconto,J., Papes,F., Chang,E., Stowers,L., Jones,E.P., Takada,T., Kumanovics,A., Fischer,L.K. \& Dulac,C. 2003. Functional expression of murine V2R pheromone receptors involves selective association with the M10 and M1 families of MHC class lb molecules. Cell 112, 607-618.

Maehlen,J., Schroder,H.D., Klareskog,L., Olsson,T. \& Kristensson,K. 1988. Axotomy induces MHC class I antigen expression on rat nerve cells. Neurosci. Lett. 92, 8-13. 
Malenka,R.C. \& Nicoll,R.A. 1993. NMDA-receptor-dependent synaptic plasticity: multiple forms and mechanisms. Trends Neurosci. 16, 521-527.

Malenka,R.C. \& Nicoll,R.A. 1999. Long-term potentiation--a decade of progress? Science 285, 1870-1874.

Malinow,R. \& Malenka,R.C. 2002. AMPA receptor trafficking and synaptic plasticity. Annu. Rev. Neurosci. 25, 103-126.

Martin,K.C. \& Kandel,E.R. 1996. Cell adhesion molecules, CREB, and the formation of new synaptic connections. Neuron $17,567-570$.

Martin,S.J. \& Morris,R.G. 2002. New life in an old idea: the synaptic plasticity and memory hypothesis revisited. Hippocampus 12, 609-636.

Medawar,P.B. 1948. Immunity to homologous grafted skin. III. The fate of skin homografts transplanted to the brain, to subcutaneous tissue, and to the anterior chamber of the eye. British J. Exp. Pathol. 29, 58-69.

Meyer,H., Palchaudhuri,M., Scheinin,M. \& Flügge,G. 2000. Regulation of alpha(2A)-adrenoceptor expression by chronic stress in neurons of the brain stem. Brain Res. 880, 147-158.

Michaelsson,J., Teixeira,d.M., Achour,A., Lanier,L.L., Karre,K. \& Soderstrom,K. 2002. A signal peptide derived from hsp60 binds HLA-E and interferes with CD94/NKG2A recognition. J. Exp. Med. 196, 1403-1414.

Mo,X.Y., Cascio,P., Lemerise,K., Goldberg,A.L. \& Rock,K. 1999. Distinct proteolytic processes generate the $\mathrm{C}$ and $\mathrm{N}$ termini of MHC class I-binding peptides. J. Immunol. 163, 5851-5859.

Moretta,L. \& Moretta,A. 2004a. Unravelling natural killer cell function: triggering and inhibitory human NK receptors. EMBO J. 23, 255-259.

Moretta,L. \& Moretta,A. 2004b. Killer immunoglobulin-like receptors. Curr. Opin. Immunol. 16, 626633.

Morris,R.G. \& Frey,U. 1997. Hippocampal synaptic plasticity: role in spatial learning or the automatic recording of attended experience? Philos. Trans. R. Soc. Lond B Biol. Sci. 352, 14891503.

Morris,R.G., Moser,E.I., Riedel,G., Martin,S.J., Sandin,J., Day,M. \& O'Carroll,C. 2003. Elements of a neurobiological theory of the hippocampus: the role of activity-dependent synaptic plasticity in memory. Philos. Trans. R. Soc. Lond B Biol. Sci. 358, 773-786. 
Mucke,L. \& Oldstone,M.B. 1992. The expression of major histocompatibility complex (MHC) class I antigens in the brain differs markedly in acute and persistent infections with lymphocytic choriomeningitis virus (LCMV). J. Neuroimmunol. 36, 193-198.

Nakazawa,K., Quirk,M.C., Chitwood,R.A., Watanabe,M., Yeckel,M.F., Sun,L.D., Kato,A., Carr,C.A., Johnston,D., Wilson,M.A. \& Tonegawa,S. 2002. Requirement for hippocampal CA3 NMDA receptors in associative memory recall. Science 297, 211-218.

Nägerl,U.V., Eberhorn,N., Cambridge,S.B. \& Bonhoeffer,T. 2004. Bidirectional activity-dependent morphological plasticity in hippocampal neurons. Neuron 44, 759-767.

Neumann,H., Cavalie,A., Jenne,D.E. \& Wekerle,H. 1995. Induction of MHC class I genes in neurons. Science 269, 549-552.

Neumann,H., Schmidt,H., Cavalie,A., Jenne,D. \& Wekerle,H. 1997. Major histocompatibility complex (MHC) class I gene expression in single neurons of the central nervous system: differential regulation by interferon (IFN)-gamma and tumor necrosis factor (TNF)-alpha. J. Exp. Med. 185, 305-316.

Oliveira,A.L., Thams,S., Lidman,O., Piehl,F., Hokfelt,T., Karre,K., Linda,H. \& Cullheim,S. 2004. A role for MHC class I molecules in synaptic plasticity and regeneration of neurons after axotomy. Proc. Natl. Acad. Sci. U. S. A. 101, 17843-17848.

Olsson,T., Maehlen,J., Love,A., Klareskog,L., Norrby,E. \& Kristensson,K. 1987. Induction of class I and class II transplantation antigens in rat brain during fatal and non-fatal measles virus infection. J. Neuroimmunol. 16, 215-224.

Olsson,T., Kristensson,K., Ljungdahl,A., Maehlen,J., Holmdahl,R. \& Klareskog,L. 1989. Gammainterferon-like immunoreactivity in axotomized rat motor neurons. J. Neurosci. 9, 3870-3875.

Olsson,T., Piehl,F., Swanberg,M. \& Lidman,O. 2005. Genetic dissection of neurodegeneration and CNS inflammation. J. Neurol. Sci. 233, 99-108.

Parham,P. 2005. MHC class I molecules and KIRs in human history, health and survival. Nat. Rev. Immunol. 5, 201-214.

Peng,Z.C., Kristensson,K. \& Bentivoglio,M. 1998. Distribution and temporal regulation of the immune response in the rat brain to intracerebroventricular injection of interferon-gamma. Exp. Neurol. 154, 403-417.

Pike,F.G., Meredith,R.M., Olding,A.W. \& Paulsen,O. 1999. Rapid report: postsynaptic bursting is essential for 'Hebbian' induction of associative long-term potentiation at excitatory synapses in rat hippocampus. J. Physio/ 518 ( Pt 2), 571-576. 
Plehm,S.J.C. 2006. Molekulare Analyse Von MHC-Klasse-I-Proteinen in Neuronen Nicht-Humaner Primaten. Diplomarbeit an der Universität Göttingen.

Purves D., Augustine G.J., Fitzpatrick D., Katz L.C., LaMantia A.-S., McNamara J.O. \& Williams S.M. 2001. Neuroscience. 2. edn. Sunderland: Sinauer Associates, Inc.

Rajagopalan,S. \& Long,E.O. 2005. Understanding how combinations of HLA and KIR genes influence disease. J. Exp. Med. 201, 1025-1029.

Rall,G.F., Mucke,L. \& Oldstone,M.B. 1995. Consequences of cytotoxic T lymphocyte interaction with major histocompatibility complex class I-expressing neurons in vivo. J. Exp. Med. 182, 12011212.

Ransohoff,R.M., Kivisakk,P. \& Kidd,G. 2003. Three or more routes for leukocyte migration into the central nervous system. Nat. Rev. Immunol. 3, 569-581.

Risau,W. \& Wolburg,H. 1990. Development of the blood-brain barrier. Trends Neurosci. 13, 174178.

Rock,K.L. \& Goldberg,A.L. 1999. Degradation of cell proteins and the generation of MHC class Ipresented peptides. Annu. Rev. Immunol. 17, 739-779.

Sakimura,K., Kutsuwada,T., Ito,I., Manabe,T., Takayama,C., Kushiya,E., Yagi,T., Aizawa,S., Inoue,Y., Sugiyama,H. \& . 1995. Reduced hippocampal LTP and spatial learning in mice lacking NMDA receptor epsilon 1 subunit. Nature $373,151-155$.

Sanchez,L.M., Chirino,A.J. \& Bjorkman,P. 1999. Crystal structure of human ZAG, a fat-depleting factor related to MHC molecules. Science 283, 1914-1919.

Sanger,F., Nicklen,S. \& Coulson,A.R. 1977. DNA sequencing with chain-terminating inhibitors. Proc. Natl. Acad. Sci. U. S. A. 74, 5463-5467.

Sato,M., Suzuki,K., Yamazaki,H. \& Nakanishi,S. 2005. A pivotal role of calcineurin signaling in development and maturation of postnatal cerebellar granule cells. Proc. Natl. Acad. Sci. U. S. A. 102, 5874-5879.

Schmidt-Hieber,C., Jonas,P. \& Bischofberger,J. 2004. Enhanced synaptic plasticity in newly generated granule cells of the adult hippocampus. Nature 429, 184-187.

Shapiro,M. 2001. Plasticity, hippocampal place cells, and cognitive maps. Arch. Neurol. 58, 874881.

Shawar,S.M., Vyas,J.M., Rodgers,J.R. \& Rich,R.R. 1994. Antigen presentation by major histocompatibility complex class I-B molecules. Annu. Rev. Immunol. 12, 839-880. 
Shi,S.H., Hayashi,Y., Petralia,R.S., Zaman,S.H., Wenthold,R.J., Svoboda,K. \& Malinow,R. 1999. Rapid spine delivery and redistribution of AMPA receptors after synaptic NMDA receptor activation. Science 284, 1811-1816.

Simister,N.E. \& Mostov,K.E. 1989. An Fc receptor structurally related to MHC class I antigens. Nature 337, 184-187.

Snell,G.D. 1948. Methods for the study of histocompatibility genes. J. Genet. 49, 87-108.

Squire,L.R., Clark,R.E. \& Knowlton,B.J. 2001. Retrograde amnesia. Hippocampus 11, 50-55.

Stam,N.J., Spits,H. \& Ploegh,H.L. 1986. Monoclonal antibodies raised against denatured HLA-B locus heavy chains permit biochemical characterization of certain HLA-C locus products. J. Immunol. 137, 2299-2306.

Stephan,H., Baron,G. \& Schwerdtfeger,W.K. 1980. The Brain of the Common Marmoset (Callithrix Jacchus) a Stereotaxic Atlas. Berlin, Heidelberg, New York: Springer.

Streilein,J.W. 1993. Tissue barriers, immunosuppressive microenvironments, and privileged sites: the eye's point of view. Reg Immunol. 5, 253-268.

Streilein,J.W. \& Stein-Streilein,J. 2000. Does innate immune privilege exist? J. Leukoc. Biol. 67, 479-487.

Streit,F., Armstrong,V.W. \& Oellerich,M. 2002. Rapid liquid chromatography-tandem mass spectrometry routine method for simultaneous determination of sirolimus, everolimus, tacrolimus, and cyclosporin A in whole blood. Clin. Chem. 48, 955-958.

Sullivan,L.C., Hoare,H.L., McCluskey,J., Rossjohn,J. \& Brooks,A.G. 2006. A structural perspective on MHC class Ib molecules in adaptive immunity. Trends Immunol. 27, 413-420.

Syken,J. \& Shatz,C.J. 2003. Expression of T cell receptor beta locus in central nervous system neurons. Proc. Natl. Acad. Sci. U. S. A. 100, 13048-13053.

Syken,J., Grandpre,T., Kanold,P.O. \& Shatz,C.J. 2006. PirB restricts ocular-dominance plasticity in visual cortex. Science 313, 1795-1800.

Thompson,J.D., Higgins,D.G. \& Gibson,T.J. 1994. CLUSTAL W: improving the sensitivity of progressive multiple sequence alignment through sequence weighting, positions-specific gap penalties and weight matrix choice. Nucleic Acids Research 22, 4673-4680.

Thompson,S.M. 2000. Synaptic plasticity: Building memories to last. Curr. Biol. 10, R218-R221.

Tigges J. \& Shantha T.R. 1969. A Stereotaxic Brain Atlas of the Tree Shrew (Tupaia Glis). Baltimore: Williams \& Wilkins. 
Trachtenberg,J.T., Chen,B.E., Knott,G.W., Feng,G., Sanes,J.R., Welker,E. \& Svoboda,K. 2002. Long-term in vivo imaging of experience-dependent synaptic plasticity in adult cortex. Nature 420, 788-794.

Trowsdale,J. 2001. Genetic and functional relationships between MHC and NK receptor genes. Immunity. 15, 363-374.

Van Kaer,L. 2002. Major histocompatibility complex class I-restricted antigen processing and presentation. Tissue Antigens 60, 1-9.

Vass,K. \& Lassmann,H. 1990. Intrathecal application of interferon gamma. Progressive appearance of MHC antigens within the rat nervous system. Am. J. Pathol. 137, 789-800.

Vinitsky,A., Anton,L.C., Snyder,H.L., Orlowski,M., Bennink,J.R. \& Yewdell,J.W. 1997. The generation of $\mathrm{MHC}$ class I-associated peptides is only partially inhibited by proteasome inhibitors: involvement of nonproteasomal cytosolic proteases in antigen processing? J. Immunol. 159, 554564.

Walaas,S.I. \& Greengard,P. 1991. Protein phosphorylation and neuronal function. Pharmacol. Rev. 43, 299-349.

Watkins,D.I., Chen,Z.W., Hughes,A.L., Hodi,F.S. \& Letvin,N.L. 1990a. Genetically distinct cell populations in naturally occurring bone marrow-chimeric primates express similar MHC class I gene products. J. Immunol. 144, 3726-3735.

Watkins,D.I., Chen,Z.W., Hughes,A.L., Evans,M.G., Tedder,T.F. \& Letvin,N.L. 1990b. Evolution of the MHC class I genes of a New World primate from ancestral homologues of human non-classical genes. Nature 346, 60-63.

Watkins,D.I. 1995. The evolution of major histocompatibility class I genes in primates. Crit Rev. Immunol. 15, 1-29.

White,L.A., Keane,R.W. \& Whittemore,S.R. 1994. Differentiation of an immortalized CNS neuronal cell line decreases their susceptibility to cytotoxic T cell lysis in vitro. J. Neuroimmunol. 49, 135143.

Wijdicks,E.F. 2001. Neurotoxicity of immunosuppressive drugs. Liver Transpl. 7, 937-942.

Williams,A., Peh,C.A. \& Elliott,T. 2002. The cell biology of MHC class I antigen presentation. Tissue Antigens 59, 3-17.

Winter,C., Schenkel,J., Burger,E., Eickmeier,C., Zimmermann,M. \& Herdegen,T. 2000. The immunophilin ligand FK506, but not GPI-1046, protects against neuronal death and inhibits C-Jun expression in the substantia nigra pars compacta following transection of the rat medial forebrain bundle. Neuroscience $95,753-762$. 
Wong,G.H., Bartlett,P.F., Clark-Lewis,I., Battye,F. \& Schrader,J.W. 1984. Inducible expression of $\mathrm{H}-2$ and la antigens on brain cells. Nature 310, 688-691.

Wong,G.H., Bartlett,P.F., Clark-Lewis,I., McKimm-Breschkin,J.L. \& Schrader,J.W. 1985. Interferongamma induces the expression of $\mathrm{H}-2$ and la antigens on brain cells. J. Neuroimmunol. 7, 255-278.

Wong,R., Beguelin,G.Z., de Lima,M., Giralt,S.A., Hosing,C., Ippoliti,C., Forman,A.D., Kumar,A.J., Champlin,R. \& Couriel,D. 2003. Tacrolimus-associated posterior reversible encephalopathy syndrome after allogeneic haematopoietic stem cell transplantation. Br. J. Haematol. 122, 128-134.

York,I.A., Goldberg,A.L., Mo,X.Y. \& Rock,K.L. 1999. Proteolysis and class I major histocompatibility complex antigen presentation. Immunol. Rev. 172, 49-66.

Zilles,K. \& Rehkämper,G. 1993. Funktionelle Neuroanatomie. Berlin ; Heidelberg ; New York ; London ; Paris ; Tokyo ; Hong Kong ; Barcelona ; Budapest: Springer.

Zinkernagel,R.M. \& Doherty,P.C. 1974a. Immunological surveillance against altered self components by sensitised T lymphocytes in lymphocytic choriomeningitis. Nature 251, 547-548.

Zinkernagel,R.M. \& Doherty,P.C. 1974b. Restriction of in vitro T cell-mediated cytotoxicity in lymphocytic choriomeningitis within a syngeneic or semiallogeneic system. Nature 248, 701-702.

Zwirner,N.W., Fernandez-Vina,M.A. \& Stastny,P. 1998. MICA, a new polymorphic HLA-related antigen, is expressed mainly by keratinocytes, endothelial cells, and monocytes. Immunogenetics 47, 139-148. 


\section{Anhang}

\subsection{Sequenzvergleiche}

\begin{tabular}{|c|c|}
\hline $\begin{array}{l}\text { CajaE-G } \\
\text { CjELeb }\end{array}$ &  \\
\hline \multirow[t]{2}{*}{ CajaE-A } & $\begin{array}{r}\text { CTCCTCTTGCTGCTCTCGGGAGCCCTAGCCCTGACCGACACCTGGGCGAGCTCCCACTCCTTGAGGTATTTCCACACCTCCG } \\
* * * * * * * * * * * * * * * * * * * * * * * * * * *\end{array}$ \\
\hline & \\
\hline ajaE-G & TGTCCCGGCCCGGCCGCGGGGAGCCTCACTTCATCTCCGTGGGATACGTGGACGACACGCAGTTCGTACGGTTCGACAGCGA \\
\hline CjELeb & TGTCCCGGCCCGGCCGCGGGGAGCCTCACTTCATCTCCGTGGGATACGTGGACGACACGCAGTTCGTACGGTTCGACAGCGA \\
\hline \multirow[t]{2}{*}{ CajaE-A } & TGTCCCGGCCCGGCCGCGGGGAGCCTCACTTCATCTCCGTGGGATACGTGGACGACACGCAGTTCGTACGGTTCGACAGCGA \\
\hline &  \\
\hline CajaE-G & CGCCGCGATTCCCAGGATGGAGCCGCGGGCGCCGTGGATGGAGCAGCAGGGACAGGAGTATTGGGACCGGGAGACACGGAGC \\
\hline CjELeb & CGCCGCGATTCCCAGGATGGAGCCGCGGGCGCCGTGGATGGAGCAGCAGGGACAGGAGTATTGGGACCGGGAGACACGGAGC \\
\hline \multirow[t]{2}{*}{ CajaE-A } & CGCCGCGATTCCCAGGATGGAGCCGCGGGCGCCGTGGATGGAGCAGCAGGGACAGGAGTATTGGGACCGGGAGACACGGAGC \\
\hline & \\
\hline JaE-G & GCCAGGGACACCGCACAGAGTTTCCGAGTGAACCTGCGGACCCTGCTCCGCTACTACAACCAGAGCGAGGCCGGGTCTCACA \\
\hline CjELeb & GCCAGGGACACCGCACAGAGTTTCCGAGTGAACCTGCGGACCCTGCTCCGCTACTACAACCAGAGCGAGGCCGGGTCTCACA \\
\hline \multirow[t]{2}{*}{ CajaE-A } & GCCAGGGACACCGCACAGAGTTTCCGAGTGAACCTGCGGACCCTGCTCCGCTACTACAACCAGAGCGAGGCCGGGTCTCACA \\
\hline &  \\
\hline CajaE-G & СССTCCAGTGGCTGCATGGCTGCGACTTGGGGCCAGACGGGCGCTTCCTCCGCGGGTATGAACAGTTCGCCTACGATGGCAA \\
\hline CjELeb & 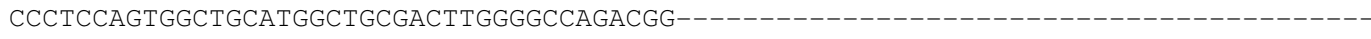 \\
\hline \multirow[t]{2}{*}{ CajaE-A } & CCCTCCAGTGGCTGCATGGCTGCGACTTGGGGCCAGACGGGCGCTTCCTCCGCGGGTATGAACAGTTCGCCTACGATGGCAA \\
\hline & 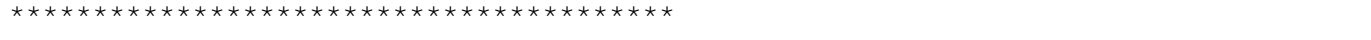 \\
\hline -G & GGATTACCTCACCTTGAACGAGGACCTGCGCTCCTGGACCGCAGCGGACACCGCGGCTCAGATCTCCCAGCGCAAGTCAGAG \\
\hline CjELeb &  \\
\hline ajaE-A & GGATTACCTCACCTTGAACGAGGACCTGCGCTCCTGGACCGCAGCGGACACCGCGGCTCAGATCTCCCAGCGCAAGTCAGAG \\
\hline ajaE-G & GAGGCCTGTGAGGCGGAGCACCAAAGGGCCTACCTGGAGGACACGTGCGTGGAGTGGCTCCGCAGATACCTGGAGAACGGGA \\
\hline CJEI & 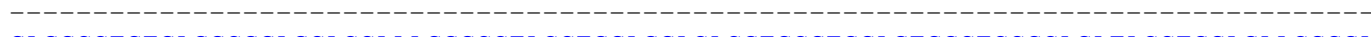 \\
\hline CajaE-A & GAGGCCTGTGAGGCGGAGCACCAAAGGGCCTACCTGGAGGACACGTGCGTGGAGTGGCTCCGCAGATACCTGGAGAACGGGA \\
\hline CajaE-G & AGGAGACGCTGCAGCGTGCGGAACCCCCAAAGACACATGTGACCCACCACCCTGTCTCTGACCATGAGGCCACCCTGAGATG \\
\hline CjE. & 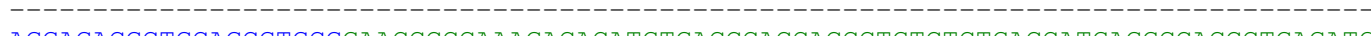 \\
\hline -A & AGGAGACGCTGCAGCGTGCGGAACCCCCAAAGACACATGTGACCCACCACCCTGTCTCTGACCATGAGGCCACCCTGAGATG \\
\hline Caj & CTGGGCCCTGGGTTTCTACCCTGCGGAGATCACACT GACCTGGCAGTGGGATGGGGAGGACCAGACCCAGGACATGGAGCT T \\
\hline ajaE-A & CTGGGCCCTGGGTTTCTACCCTGCGGAGATCACACTGACCTGGCAGTGGGATGGGGAGGACCAGACCCAGGACATGGAGCTI \\
\hline G & GTGGAGACCAGGCCAGCAGGGGATGGAACCTTCCAGAAGTGGGCGGCTGTGGTGGTGCCTTCTGGAGAGGAGCAAAGATACA \\
\hline CjE & \\
\hline CajaE-A & GTGGAGACCAGGCCAGCAGGGGATGGAACCTTCCAGAAGTGGGCGGCTGTGGTGGTGCCTTCTGGAGAGGAGCAAAGATACA \\
\hline & CCTGCCATGTGCAGCATGAGGGGCTGCG_GAGCCCCTCACCCTGAGATGGGAGCCATCTTCCCAGCCCACCATCCCCATCGI \\
\hline jELeb & AGCCCCTCACCCTGAGATGGGAGCCATCTTCCCAGCCCACCATCCCCATCGI \\
\hline
\end{tabular}

Abb. A.1: Vergleich Caja-E Genotyp A (CajaE-A) (EF014284); Caja-E Genotyp G (CajaE-G) (EF014285) und Caja-E-Klon aus Leber (A) (CjELeb). CjELeb ist zu 100\% identisch mit CajaE-A und CajaE-G. rot: Exon 2; blau: Exon3; grün: Exon 4; lila: Exon 5. (*) bedeutet Sequenzübereinstimmung. 


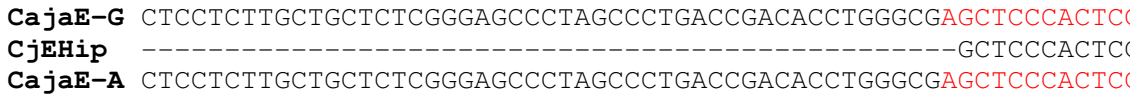

Cajat-G TGTCCCGGCCCGGCCGCGGGGAGCCTCACTTCATCTCCGTGGGATACGTGGACGACACGCAGTTCGTACGGTTCGACAGCGA CjEHip TGTCCCGGCCCGGCCGCGGGGAGCCTCACTTCATCTCCGTGGGATACGTGGACGACACGCAGTTCGTACGGTTCGACAGCGA CajaE-A TGTCCCGGCCCGGCCGCGGGGAGCCTCACTTCATCTCCGTGGGATACGTGGACGACACGCAGTTCGTACGGTTCGACAGCGA

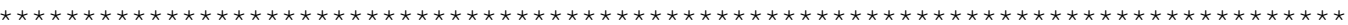

CajaE-G CGCCGCGATTCCCAGGATGGAGCCGCGGGCGCCGTGGATGGAGCAGCAGGGACAGGAGTATTGGGACCGGGAGACACGGAGC CjEHip CGCCGCGATTCCCAGGATGGAGCCGCGGGCGCCGTGGATGGAGCAGCAGGGACAGGAGTATTGGGACCGGGAGACACGGAGC CajaE-A CGCCGCGATTCCCAGGATGGAGCCGCGGGCGCCGTGGATGGAGCAGCAGGGACAGGAGTATTGGGACCGGGAGACACGGAGC $* * * * * * * * * * * * * * * * * * * * * * * * * * * * * * * * * * * * * * * * * * * * * * * * * * * * * * * * * * * * * * * * * * * * * * * * * * * * * * * * * *$

CajaE-G GCCAGGGACACCGCACAGAGTTTCCGAGTGAACCTGCGGACCCTGCTCCGCTACTACAACCAGAGCGAGGCCGGGTCTCACA CjeHip GCCAGGGACACCGCACAGAGTTTCCGAGTGAACCTGCGGACCCTGCTCCGCTACTACAACCAGAGCGAGGCCGGGTCTCACA CajaE-A GCCAGGGACACCGCACAGAGTTTCCGAGTGAACCTGCGGACCCTGCTCCGCTACTACAACCAGAGCGAGGCCGGGTCTCACA



CajaE-G CCCTCCAGTGGCTGCATGGCTGCGAC CjEHip CCCTCCAGTGGCTGCATGGCTGCGAC CajaE-A CCCTCCAGTGGCTGCATGGCTGCGAC GGGGCCAGACGGGCGCTTCCTCCG GGGGCCAGACGGGCGCTTCCTCCG TGGGGCCAGACGGGCGCTTCCTCCG GGTATGAACAGTTCGCCTACGATGGCAA GGGTATGAACAGTTCGCCTACGATGGCAA

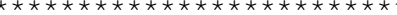
GGGTATGAACAGTTCGCCTACGATGGCAA

CajaE-G GGATTACCTCACCTTGAACGAGGACCTGCGCTCCTGGACCGCAGCGGACACCGCGGCTCAGATCTCCCAG------------



CajaE-A GGATTACCTCACCTTGAACGAGGACCTGCGCTCCTGGACCGCAGCGGACACCGCGGCTCAGATCTCCCAG------------

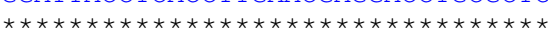

Abb. A.2: Vergleich Caja-E-Genotyp A (CajaE-A) (EF014284); Caja-E-Genotyp G (CajaE-G) (EF014285) und Caja-E-Klon aus Hippocampus (A) (CjEHip). CjEHip ist zu 99,24\% identisch mit CajaE-A und CajaE-G. rot: Exon 2; blau: Exon3. (*) bedeutet Sequenzübereinstimmung.

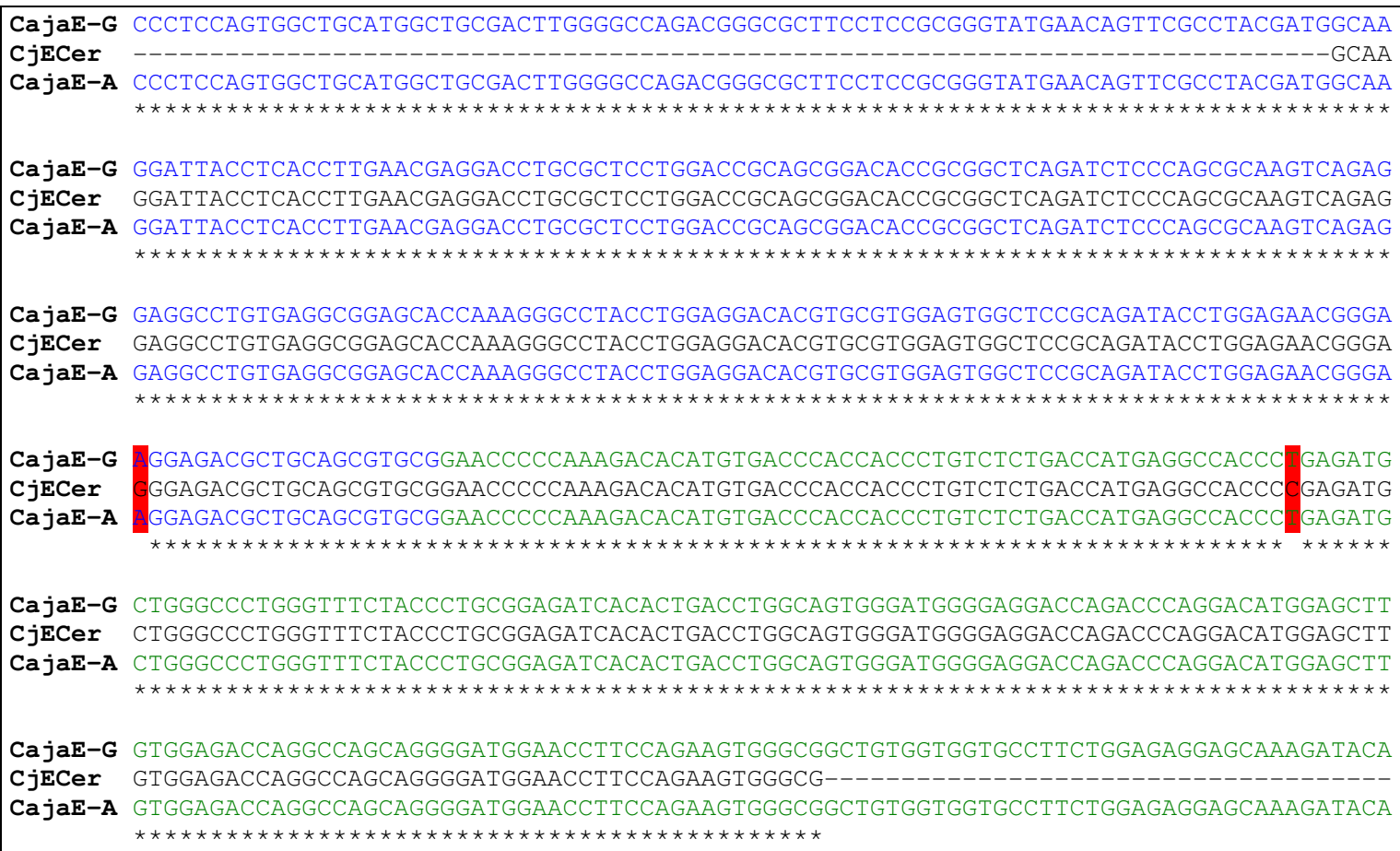

Abb. A.3: Vergleich Caja-E-Genotyp A (CajaE-A) (EF014284); Caja-E-Genotyp G (CajaE-G) (EF014285) und Caja-E-Klon aus Cerebellum (A) (CjECer).CjECer ist zu 99,47\% identisch mit CajaE-A und CajaE-G. blau: Exon3; grün: Exon 4. (*) bedeutet Sequenzübereinstimmung. 


\begin{tabular}{|c|c|}
\hline & ------------------------------------------------ GCTCCCACTCCATGAGGTATTTCAGCACCG \\
\hline U59640 & 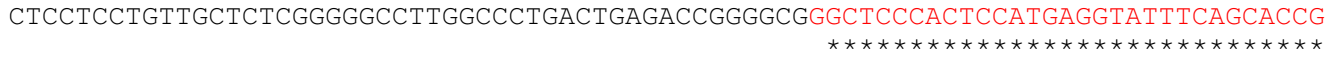 \\
\hline $\begin{array}{l}\text { CjGLeb15 } \\
\text { U59640 }\end{array}$ & 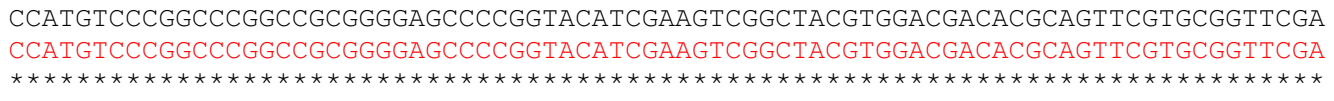 \\
\hline CjGLeb15 & CAGCGACGCCGCGAGTCCGAGGATGGAGCCGCGGGCGCCGTGGGTGGAGCAGGAGGGGCCGGAGTATTGGGACGAGGAG \\
\hline U59640 &  \\
\hline $\begin{array}{l}\text { CjGLeb15 } \\
\text { U59640 }\end{array}$ & 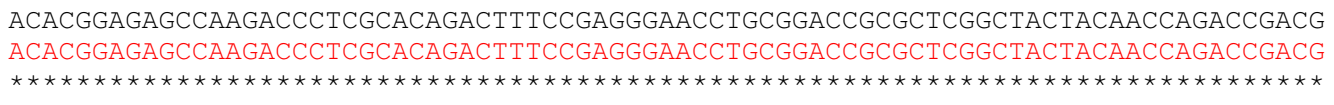 \\
\hline $\begin{array}{l}\text { CjGLeb15 } \\
\text { U59640 }\end{array}$ & 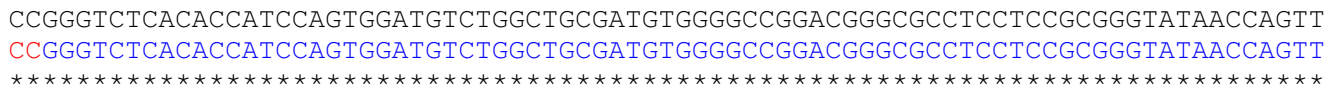 \\
\hline $\begin{array}{l}\text { CjGLeb15 } \\
\text { U59640 }\end{array}$ & 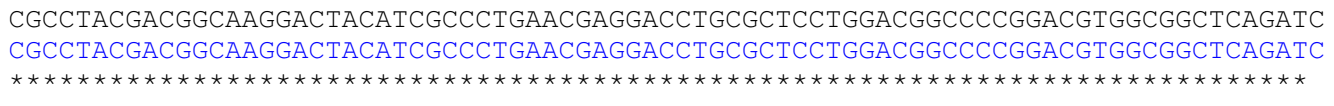 \\
\hline $\begin{array}{l}\text { CjGLeb15 } \\
\text { U59640 }\end{array}$ &  \\
\hline $\begin{array}{l}\text { CjGLeb15 } \\
\text { U59640 }\end{array}$ & 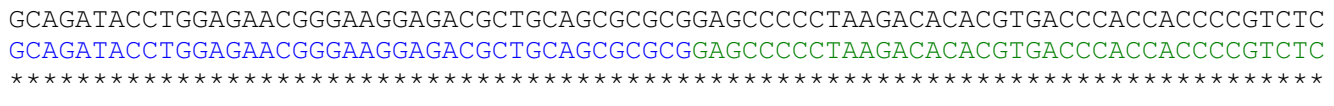 \\
\hline $\begin{array}{l}\text { CjGLeb15 } \\
\text { U59640 }\end{array}$ & 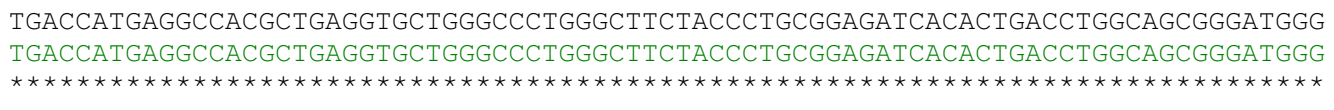 \\
\hline $\begin{array}{l}\text { CjGLeb15 } \\
\text { U59640 }\end{array}$ &  \\
\hline
\end{tabular}

Abb. A.4: Vergleich Caja-G-04 (U59640) und Caja-G-Klon 15 aus Leber (A) (CjGLeb15). CjGLeb15 ist zu $100 \%$ identisch mit Caja-G-04 bei 734 bp im Exon 2-4. rot: Exon 2; blau: Exon3; grün: Exon 4. (*) bedeutet Sequenzübereinstimmung.

\begin{tabular}{|c|c|}
\hline $\begin{array}{l}\text { CjGLeb11 } \\
\text { U59641 }\end{array}$ & 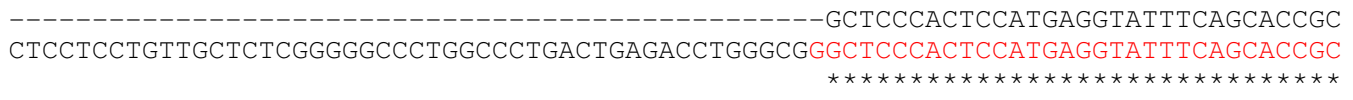 \\
\hline CjG. & CGTGTCCCGGCCCGGCCGCGAGGAGCCCCGCTTCATCTCCGTGGGCTACGTGGACGACACGCAGTTCGTGCGGTTCGACA \\
\hline U59 & 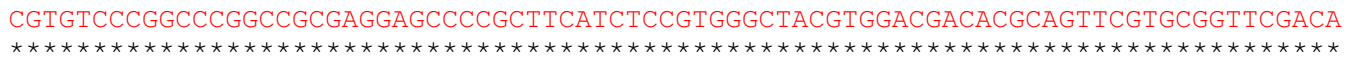 \\
\hline $\begin{array}{l}\text { CjGLeb11 } \\
\text { U59641 }\end{array}$ & $\begin{array}{l}\text { GCGACGCCGCGATTCCGAGAGATGAGCCGCGGGCGCCGTGGGTGGAGCAGGAGGGGCCGGAGTATTGGGAGGAGCAGACA } \\
\text { GCGACGCCGCGATTCCGAGAGATGAGCCGCGGGCGCCGTGGGTGGAGCAGGAGGGGCCGGAGTATTGGGAGGAGCAGACA } \\
\star \star \star \star \star \star \star \star \star \star \star \star ~\end{array}$ \\
\hline $\begin{array}{l}\text { CjGLeb11 } \\
\text { U59641 }\end{array}$ &  \\
\hline $\begin{array}{l}\text { CjGLeb11 } \\
\text { U59641 }\end{array}$ &  \\
\hline $\begin{array}{l}\text { CjGLeb11 } \\
\text { U59641 }\end{array}$ & 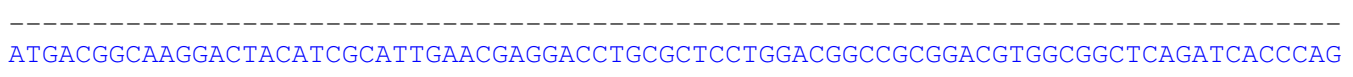 \\
\hline $\begin{array}{l}\text { CjGLeb11 } \\
\text { U59641 }\end{array}$ &  \\
\hline $\begin{array}{l}\text { CjGLeb11 } \\
\text { U59641 }\end{array}$ & 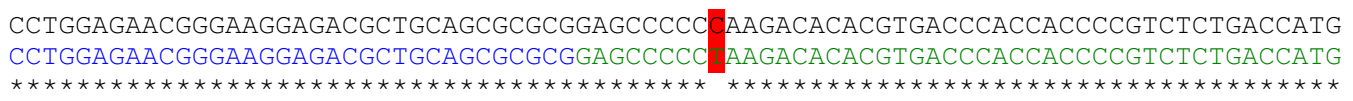 \\
\hline
\end{tabular}


CjGLeb11 AGGCCACCCTGAGGTGCTGGGCCCTGGGCTTCTACCCTGCGGAGATCACACTGACCTGGCAGCGGGATGGGGAGGACCA U59641 AGGCCACCCTGAGGTGCTGGGCCCTGGGCTTCTACCCTGCGGAGATCACACTGACCTGGCAGCGGGATGGGGAGGACCA



CjGLeb11 GACCCAGGACATGGAGCTCGTAGAGACCAGGCCCGCAGGGGATAGAACCTTCCAGAAGTGGGC

U59641 GACCCAGGACATGGAGCTCGTAGAGACCAGGCCCGAGGGGATAGAACCTTCCAGAAGTGGGCTGCTGTGGTGGTACT



Abb. A.5: Vergleich Caja-G-05 (U59641) und Caja-G-Klon 11 aus Leber (A) (CjGLeb11). CjGLeb11 ist zu 99,81\% identisch mit Caja-G-05. rot: Exon 2; blau: Exon3; grün: Exon 4. (*) bedeutet Sequenzübereinstimmung.

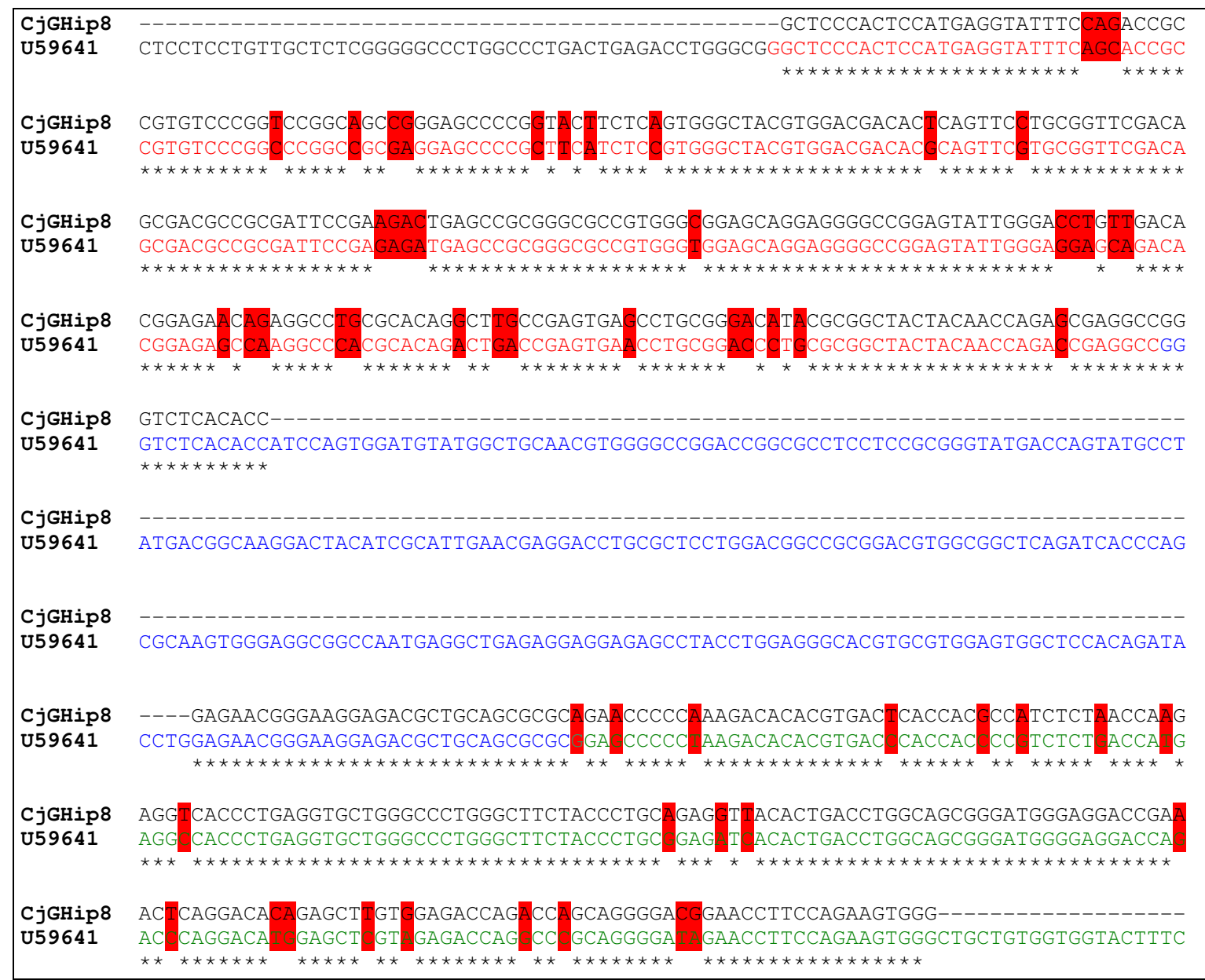

Abb. A.6: Vergleich Caja-G-05 (U59641) und Caja-G-Klon 8 aus Hippocampus (A) (CjGHip8). CjGHip8 ist zu $88,15 \%$ identisch. rot: Exon 2; blau: Exon3; grün: Exon 4. (*) bedeutet Sequenzübereinstimmung. 


\begin{tabular}{|c|c|}
\hline 13 &  \\
\hline U59 & 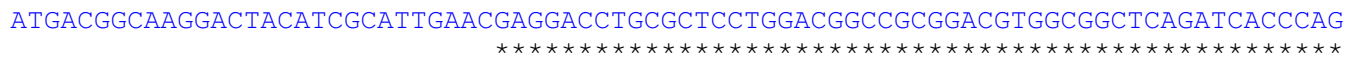 \\
\hline $\begin{array}{l}\text { CjGC } \\
\text { U59 }\end{array}$ & 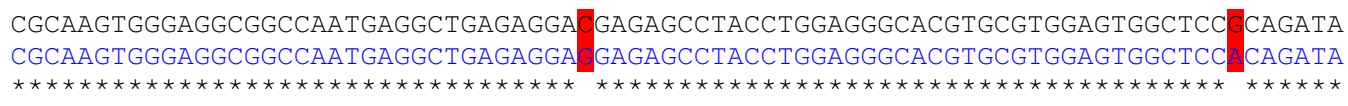 \\
\hline $\begin{array}{l}\text { CjGCer13 } \\
\text { U59641 }\end{array}$ & 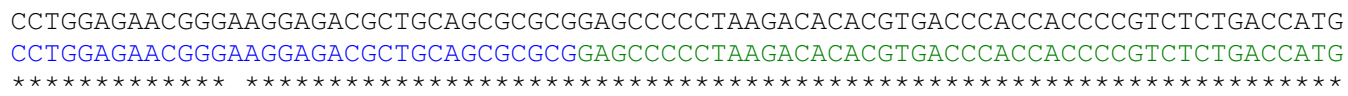 \\
\hline $\begin{array}{l}\text { CjGCer13 } \\
\text { U59641 }\end{array}$ &  \\
\hline $\begin{array}{l}\text { jGCer } 13 \\
59641\end{array}$ & 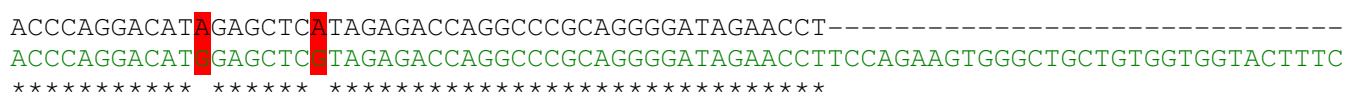 \\
\hline
\end{tabular}

Abb. A.7: Vergleich Caja-G-05 (U59641) und Caja-G-Klon 13 aus Cerebellum (A) (CjGCer13). CjGCer13 ist $\mathrm{zu} 98,82 \%$ identisch mit Caja-G-05. blau: Exon3; grün: Exon 4. (*) bedeutet Sequenzübereinstimmung.

\begin{tabular}{|c|c|}
\hline $\begin{array}{l}\text { CjGCer15 } \\
\text { U59640 }\end{array}$ & 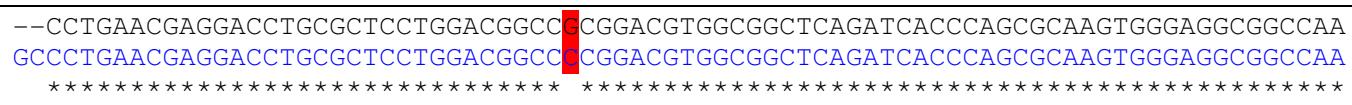 \\
\hline $\begin{array}{l}\text { CjGCer15 } \\
\text { U59640 }\end{array}$ & 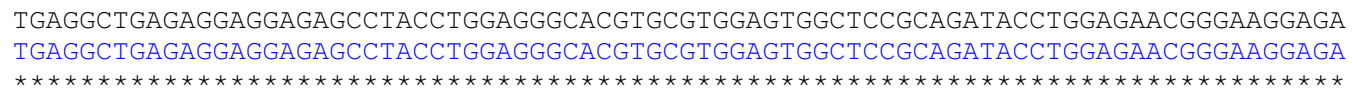 \\
\hline $\begin{array}{l}\text { CjGCer15 } \\
\text { U59640 }\end{array}$ & 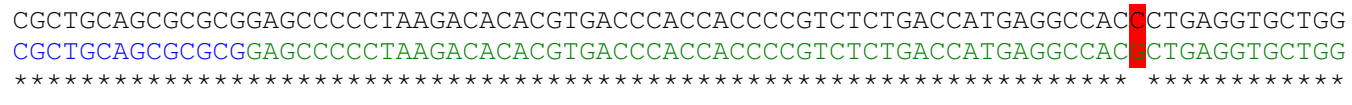 \\
\hline $\begin{array}{l}\text { CjGCer15 } \\
\text { U59640 }\end{array}$ &  \\
\hline $\begin{array}{l}\text { CjGCer15 } \\
\text { U59640 }\end{array}$ & 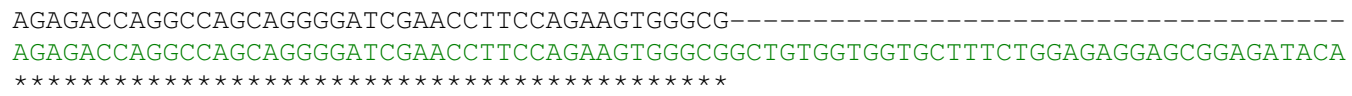 \\
\hline
\end{tabular}

Abb. A.8: Vergleich Caja-G-04 (U59640) und Caja-G-Klon 15 aus Cerebellum (A) (CjGCer15). CjGCer15 ist zu 99,44\% identisch mit Caja-G-05. blau: Exon3; grün: Exon 4. (*) bedeutet Sequenzübereinstimmung. 


\section{Danksagung}

An erster Stelle gilt mein Dank PD Dr. Lutz Walter und Prof. Dr. Eberhard Fuchs, die mir eine wissenschaftliche Ausbildung ermöglicht haben. Durch die Bereitstellung dieses Themas war es mir möglich an einer sehr interessanten und aktuellen Fragestellung zu arbeiten. Prof. Dr. Eberhard Günther, der leider kurz nach Beginn der Arbeit verstorben ist, danke ich für die freundliche Aufnahme in die Abteilung Immungenetik in der Universität Göttingen. Prof. Dr. Schürmann danke ich für die freundliche Übernahme der externen Betreuung dieser Arbeit. Prof. Dr. Gabriele Flügge und PD Dr. Lutz Walter danke ich für die hervorragende direkte wissenschaftliche Betreuung und stete Unterstützung in allen Fragen. Vor allem vielen Dank für die Motivation nach der Geburt meiner Tochter.

Aus der damaligen Abteilung Immungenetik danke ich Petra Kiesel, für ihre sehr hilfsbereite Weise in allen Laborfragen; Leslie Elsner und Ralf Dressel, für ihre Hilfsbereitschaft bei FACS-Messungen und Antikörperfragen.

Aus der Forschergruppe Primatengenetik (DPZ) danke ich besonders Svenja Kosin, Christiane Schwarz und Nico Westphal für ihre Hilfe im Labor und Christian Roos für seine kompetente Hilfe bei wissenschaftlichen Fragen. Weiterhin danke ich Anne Averdam, Immanuel Grützner, Anna Herr, Philip Kruse, Martin Osterholz, Nicole Otto, Beatrix Petersen, Stephanie Plehm, Adema Ribic, Cornelia Rosner, Olivia Sövegjarto, Van Ngoc Thinh und Despina Tilikidou für das sehr nette und freundliche Arbeitsklima.

Aus der Forschergruppe Klinische Neurobiologie (DPZ) danke ich besonders Stefanie Gleisberg, die mir beim Erlernen der In-situ-Hybridisierung stets zur Hilfe war. Besonderer Dank gilt Anna Hoffmann, für wertvolle Unterstützung im Laboralltag; Simone Lüert und Susanne Bauch für Hilfe bei der Immunhistologie. Weiterhin danke ich Nashat Abumaria, Ursula Buchhorn, Ben Cooper, Boldizsár Czéh, Melanie Dörfer, Cornelia Heckmann, Andreas Heutz, Urs Heilbronner, Jeanine Müller-Keuker, Claudia Perez-Cruz, Christina Schlumbohm und Barthel Schmelting für das ebenfalls sehr nette und freundliche Arbeitsklima.

Britta Müller danke ich für die vielen wissenschaftlichen und nicht-wissenschaftlichen Gespräche.

Der Deutschen Forschungsgemeinschaft (DFG) danke ich für die Stipendiumsförderung im Rahmen des Graduiertenkollegs GRK 289/3.

Zum Schluss möchte ich vor allem meinen Eltern danken für ihre stete Unterstützung und ihr Vertrauen. 


\section{Lebenslauf}

Ulrike Rölleke, geb. Geisler

Diplombiologin

geboren am 12.07.1978 in Halberstadt

seit Juli 2003

Anfertigung der vorliegenden Dissertation in den Forschergruppen

„Primatengenetik“ bei PD. Dr. L. Walter und „Klinische

Neurobiologie“" bei Prof. E. Fuchs am Deutschen Primatenzentrum

Göttingen.

Stipendiumsförderung im Rahmen des Graduiertenkollegs

"Perspektiven der Primatologie: Integration genetischer, neurobiologischer und ethologischer Forschungsansätze " GRK 289/3

2003

Abschluss des Studiums als Diplom-Biologin

$1996-2003$

Studium im Fachbereich Biologie an der Georg-August Universität in Göttingen

$1999-2000$

Erasmus-Semester an der Universität von Wales, Bangor

1996

Abitur

$1988-1996$

Oberschule/Gymnasium Osterwieck

$1984-1988$

Grundschule Dedeleben 